ERNŐ MAROSI*

\title{
DIE KATHEDRALE „ESZTERGOM II“ \\ DER BAU DER ST. ADALBERTSKATHEDRALE IM 12. JAHRHUNDERT
}

The cathedral "Esztergom II". The construction of the St. Adalbert's Cathedral in the twelfth century with an Excurse: To the chronology of the Early Gothic in the middle of the Kingdom as witnessed by the Cistercian Abbey of Kerc (Cărța, Kerz, RO), Transylvania. Among at least 4 construction periods of the medieval Cathedral (not counting additional buildings) the second building cannot be dated by written sources and is only witnessed by its High Romanesque and Early Gothic stone sculpture. As in the late seventeenth and in the eighteenth century stone elements from the ruins of the Cistercian Abbey of Pilis were used as building material in Esztergom and later also medieval stone sculptures from the region (mainly from the provostry in Dömös) entered in the collection of the Esztergom Castle. The distinction among these related monuments has in recent times also determined our concept of reconstruction of the Esztergom Cathedral. This reconstruction can be based on a few authentic landscapes, on a series of surveys drawn by military engineers and a description of the ruins before their final demolition. The early book by J. B. Máthes (1827) also contains a detailed ground plan of the St. Adalbert Church - a survey drawing from the early eighteenth century with possible traces of an ideal reconstruction. In recent times more efforts were spent to hypotheses concerning the building I of St. Adalbert's than to the second construction, the ruins of which were still standing by the middle of the eighteenth century. It was a basilical building originally with an apse (rebuilt as a polygonal choir in the fourteenth century) between two towers in the East. The levels of the oriental part of the church are well documented: as the canons' choir in the 3 east bays of the nave was elevated by 2 steps over the aisles, the choir square with the main apse was higher than the chorus minor. As the altar of the Virgin Mary in front of the choir was dedicated in 1156, the eastern parts of the building together with several parts of the nave can be dated about this time. The sculptures belonging to this building are classicizing (Corinthian and composite) capitals, partly with figurative elements, going back to figurative capitals from Dömös and related to classicizing details from the construction of the first half of the twelfth century of the royal priory in Óbuda. It seems that the capitals have belonged to a construction both with composed piers and with columns - perhaps in a form of alternation. The nave was not vaulted until the fourteenth century, but vaulting in choir and also in the aisles seems probable. The western part of the nave was built with cross-shaped piers observed by an eighteenth century witness of the ruins. Capitals with acanthus leaves and also with elements of chapiteaux à crochet appear as typical elements of this style also present in the inferior room of the annex to the donjon of the royal Palace, which was built presumably in the 1180's. The role of North-Italian (magistri campionesi and also Antelami) models in the transmission of stylistic elements of French Early Gothic mixed with Italian traditions has received a strong accent mainly in the art-historical literature of the last decades. The author indicates a very strong analogy of this orientation in Esztergom with the late twelfth century reconstruction of the Salzburg Cathedral of Archbishop Konrad III, the crypt of which was dedicated in 1219. The use of local red marbles - together with the polychromy of different stones - on a series of decorative works following the models of the Salzburg Cathedral in the first half of the thirteenth century is comparable to Esztergom. Recent research - supported both by analysis of sources, technical observations and also geological investigation - have proved that large surfaces of the Esztergom Cathedral were covered with red limestone plates, for obtaining a noble effect. The supposed chronology of Esztergom can be supported by a new chronology of the Transylvanian Cistercian Abbey of Kerc, where the earliest parts of the building seem to correspond to models in Esztergom and Pilisszentkereszt about the hypothetical foundation year 1202. The relationship of this workshop to the central region of the country found its continuation about 1220 as on Kerc monastery appear influences of later works of the same circle (Óbuda, royal palace, cathedral Kalocsa II) and elements of the South German Early Gothic (Magdeburg, Walkenried, Maulbronn) as well. The parish church in Szászsebes (Mühlbach, Sebeş, RO) can be considered as a parallel to Kerc Abbey. Among local followers

* Prof. em. Ernô Marosi, Budapest; e-mail: marosi.erno@btk.mta.hu 
of Kerc, in Brassó (St. Barthelemys' Kronstadt, Braşov, RO), and Halmágy (Holmwegen, Halmăgiu, RO) can be identified decorative and also figurative forms originating from Salzburg, maybe through the intermediary of Kalocsa. It seems, that up to the first third of the thirteenth century the model of Kerc is still valid for provincialized followers as Prázsmár (Tartlau, Prejmer, RO) and Szék (Sic, RO). The latest phase of its influence shows a modernisation following the cathedral of Gyulafehérvár (Weißenburg, Karlsstadt, Alba Iulia, RO).

Keywords: Esztergom, Early Gothic, Emilian Late Romanesque, Modena, Salzburg, polychromy

\section{DIE MITTELALTERLICHEN BAUPERIODEN DER ADALBERTSKATHEDRALE}

An der in mehreren Etappen erbauten und von verschiedenen Anbauten beinahe völlig umgebenen Kathedrale von Esztergom (deutsch Gran, lateinisch Strigonium) wurde seit ihrer Gründung, von 1000 bis zu 1543 fast ständig gebaut. Damals erlitt sie bei der Belagerung der Stadt die ersten schweren Kriegsschäden von den Osmanen, die sich hier auf mehr als ein Jahrhundert eingerichtet haben. Insgesamt kann man vier Bauperioden unterscheiden, wobei allein die Gründungsdaten des Erzbistums für Bau I vorliegen. Über Bau II schweigen die zeitgenössischen Schriftquellen ebenfalls, er ist allein in der kunsthistorischen Forschung identifiziert worden. Man nimmt mit Recht an, dass der von den Ruinen im 18. Jahrhundert aufgenommene Kirchengrundriss und die meisten Fragmente der Bauskulptur von diesem zweiten Bau zeugen, der in Schriftquellen keine direkte Erwähnung fand, sondern nur bereits während seines Bestehens entstandene Urkunden und Berichte auf ihn bezogen werden können. Während Stücke der Bauskulptur aus diesem Bau offensichtlich wie Reliquien aufbewahrt wurden, sind die spätmittelalterlichen baulichen Eingriffe in die Gestalt der Kirche eher schriftlich und allein durch wenige Baureste belegt. Bau II blieb mehr

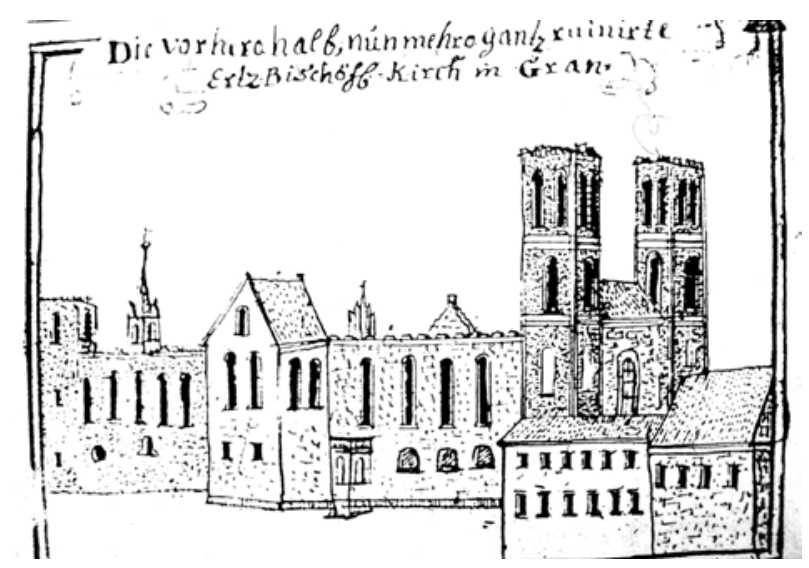

$A b b$. 1. Friedrich Bernhard Werner:

Nordansicht der Ruine der Kathedrale von Esztergom, Federzeichnung (1732),

Peregrinationes oder Christliche Wanderschaft...

(1770, Kraków, Biblioteka Jagiellóńska, ms. 7462. II) oder weniger intakt erhalten, wurde aber im 14. Jahrhundert, während den Bauarbeiten (Bau III) unter Erzbischof Csanád Telegdi (1322-1330), wahrscheinlich gewölbt. ${ }^{1}$ War die Kathedrale (wohl das Mittelschiff) bis dahin nicht gewölbt, wie andere größere Kirchen - zum Beispiel die königliche Stiftskirche zu Székesfehérvár -, die in dieser Zeit ihre Wölbung erhielten? Mit dem Bau IV wurde unter Erzbischof Dénes Szécsi (1440-1465) begonnen. Er wurde 1453 geweiht, der Nachfolger von Szécsi hat sich aber wohl auch noch damit beschäftigt. Da Arbeiten am Dachstuhl unter Erzbischof Johannes Vitéz (1465-1472) belegt werden können, mag die Kathedrale auch eine spätgotische Periode gehabt haben. ${ }^{2}$

Es erscheint seltsam genug, dass der Bau I (Gründungsbau) der erzbischöflichen Kathedrale - zumindest in den letzten 30-40 Jahren - die kunsthistorische Literatur wahrscheinlich mehr beschäftigt hatte, als die darauffolgende Bauphase, von der eine ziemlich einheitliche Gruppe von Fragmenten der Bauskulptur erhalten ist. Esztergom als Sitz der Fürstenfamilie - und der davon stammenden Dynastie der Árpádenkönige - bzw. der im Jahr 1000 gegründeten Erzdiözese erscheint als Macht- und religiöses Zentrum des ungarischen Staats. Der andere, zum Teil konkurrierende, der sakralen Tradition der Dynastie gegenüber eher mit der Tradition des Ständestaats beladene wichtige Ort war Székesfehérvár (Stuhlweißenburg, Alba Regia) gewesen. Lange Zeit, praktisch kontinuierlich seit den Anfängen der ungarischen Kunsthistoriographie, hat man die erhalten gebliebenen Bauskulpturen sowohl in Esztergom als zum Teil auch in Székesfehérvár für Denkmäler aus der Zeit des Heiligen Königs Stephan I. gehalten. In ihnen wollte man eine Art ottonischen Klassizismus, ja sogar ein Nachleben der Formenwelt der pannonischen Römerzeit entdecken, wie die Veröffentlichungen von Tibor Gerevich davon zeugen ${ }^{3}$ und seine Hypothesen von seinem Schüler, Dezsô Dercsényi, herausgearbeitet wurden. ${ }^{4}$ Nach zerstreuten, dieser Datierung widersprechenden Bemerkungen kam es erst in den 1970er Jahren zu einer Wende in der Beurteilung dieser Bau- 


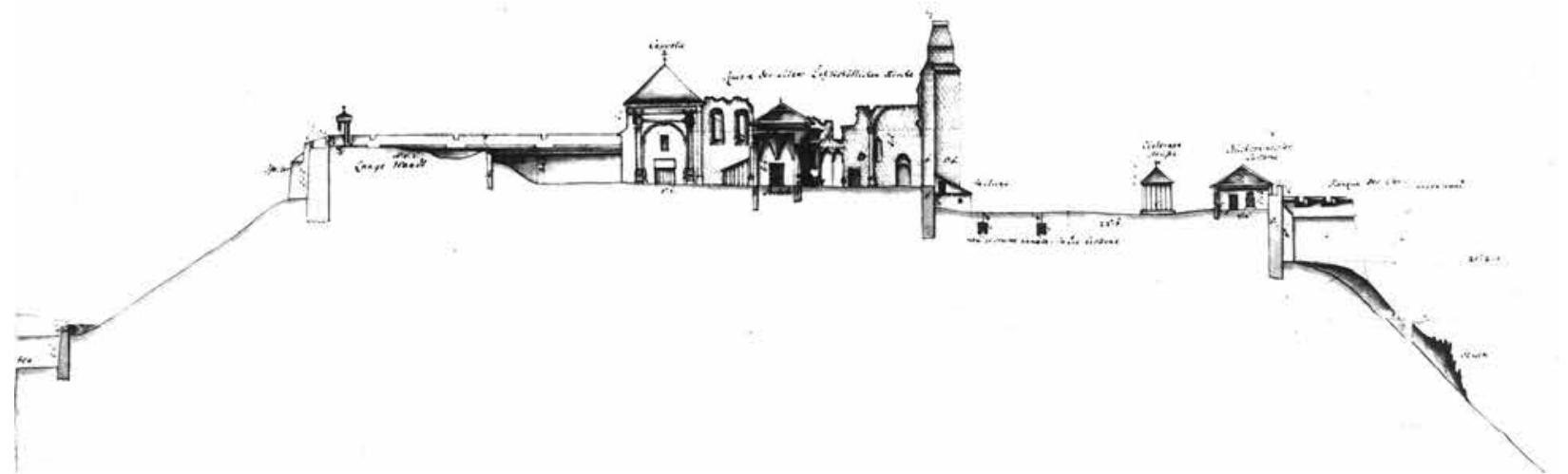

Abb. 2. Andreas Krey: Längsschnitt der Ruinen der Kathedrale von Esztergom, 1756.

Wien, Kriegsarchiv, Inland C V. Gran

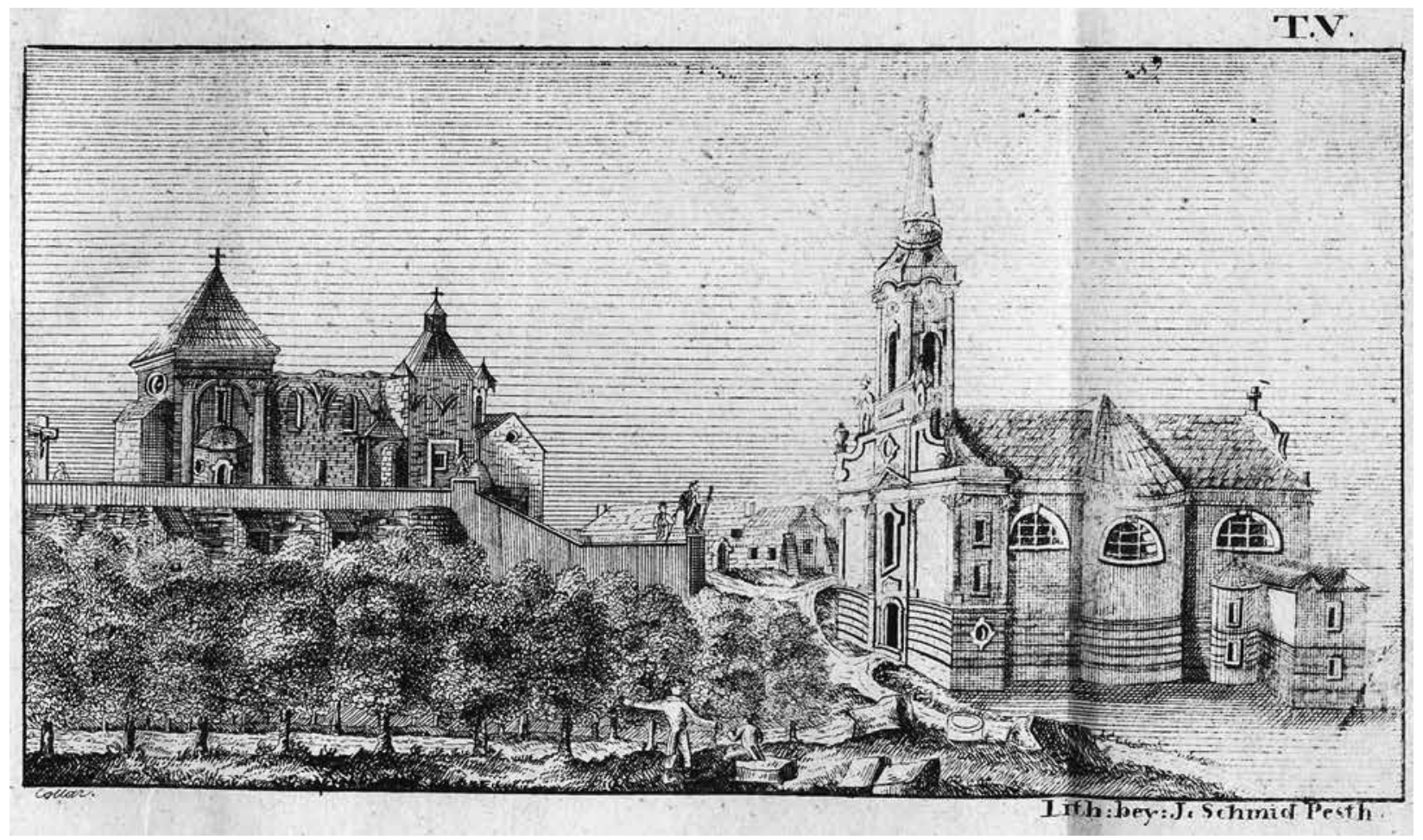

Abb. 3. Ruine der Kathedrale von Esztergom und die provisorische Barockkirche von Norden (MÁTHES 1827, Tab. V)

skulptur, die stilistisch in die Hochromanik eingegliedert wurde. In diesem Sinne wurden sie zuerst 1978 in der der Steinskulptur der Árpádenzeit gewidmeten Ausstellung im Museum von Székesfehérvár und in ihrem Katalog behandelt. ${ }^{5}$ Ferner hat sich die 1984 herausgegebene Monographie des Verfassers grundsätzlich mit dem Bau II befasst, nach der die Bauwerkstatt des zweiten Baus die Voraussetzung für die Anfänge der gotischen Baukunst in Ungarn, die auf die letzten Jahrzehnte des 12. Jahrhunderts datiert wurden, geschafft habe. ${ }^{6}$ In den Veränderungen der Datierung, die freilich als Ausdruck von tiefergehenden Konzeptionen der Geschichte der romanischen Kunst in Ungarn erscheinen, hat die quellenkritische Wende eine große Rolle gespielt.

Obwohl praktisch nichts außer der Tatsache der Gründung des ungarischen Erzbistums und des Auftauchens der Person des Erzbischofs schriftlich belegt ist, schien die Quellenlage über die königliche Stiftskirche in Óbuda (Alt-Ofen) die Datierung der fraglichen Reste der Bauskulptur in Esztergom zu unterstützen. Es handelte sich um die chronikalische Tradition, nach der das St. Peters-Stift von Óbuda vom Heiligen Stephan gegründet worden sei, und andererseits um die Tatsache, dass auch die erhaltenen Fragmente des Stiftes von Óbuda denselben klassizisierenden 


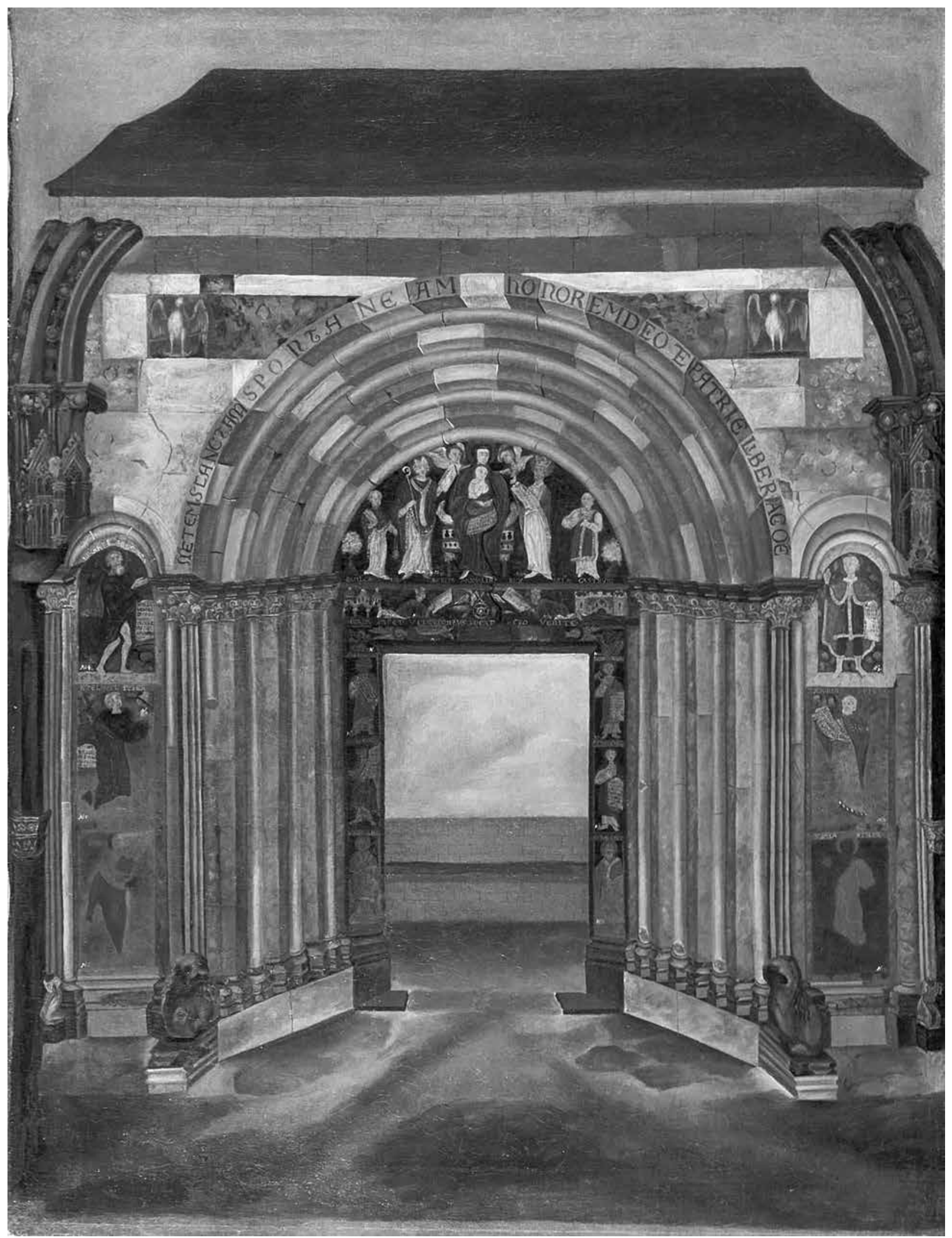

Abb. 4. Unbekannter Maler gegen Mitte des 18. Jahrhunderts: Das Westportal der Adalbertskathedrale von Esztergom, Ölgemälde aus dem Besitz des Bischofs György Klimó von Pécs. Esztergom, Christliches Museum (Foto: Attila Mudrák) 


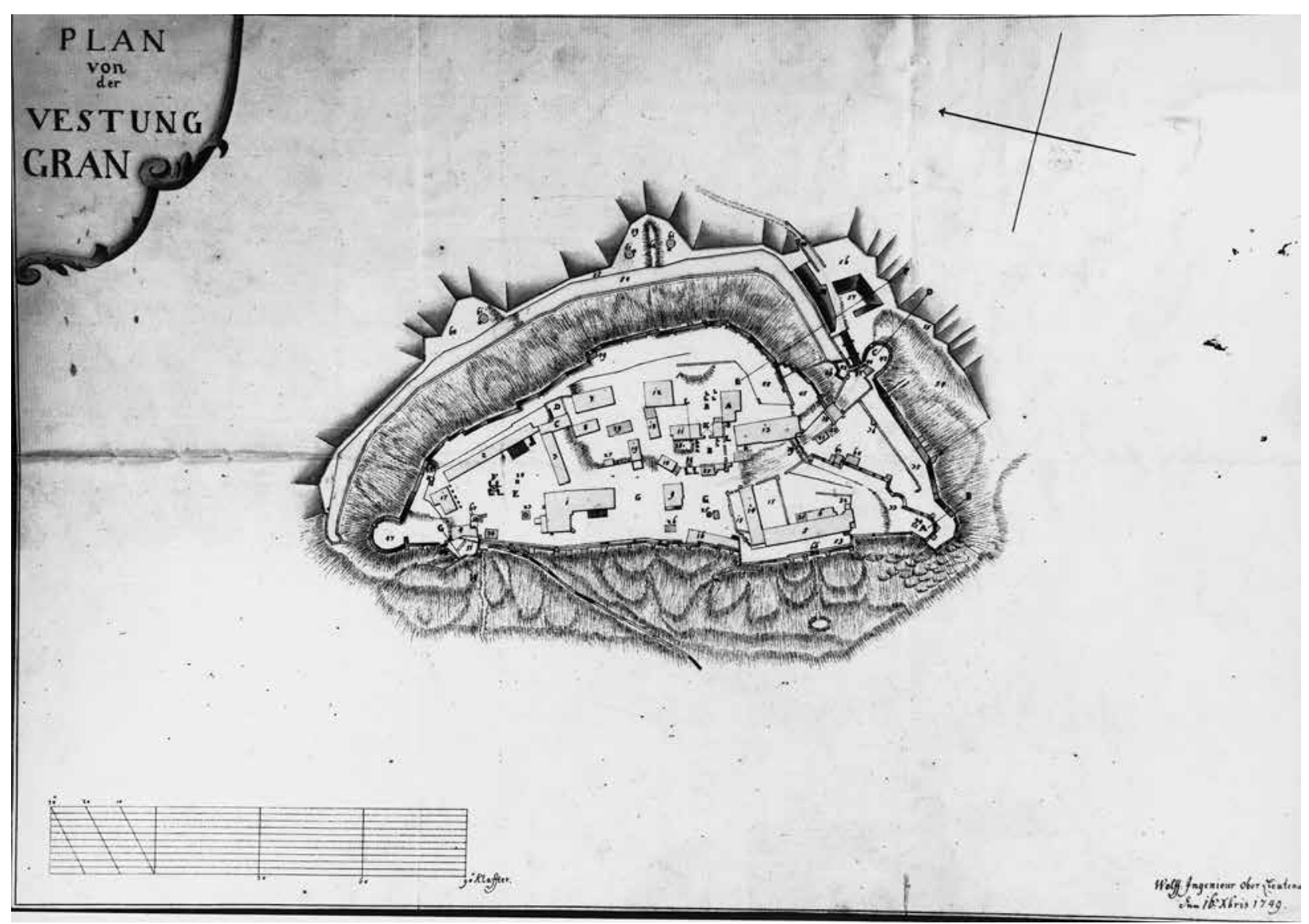

Abb. 5. Wolff: Grundrissaufnahme der Festung Esztergom, 1749, Wien, Kriegsarchiv L Gran 485/3 h (Inland C V. No 4. Gran)

Stil, wie die in Esztergom, aufwiesen. Die Rekonstruktionsvorstellung einer königlichen Bauwerkstatt in Óbuda und Esztergom wurde mit diesen Argumenten von Dezsố Dercsényi herausgearbeitet. ${ }^{7}$ Die historische Quellenkritik hat zuerst das historische Konstrukt, wonach das Stift zu Óbuda vom Heiligen König Stephan gegründet wäre, durch den Nachweis ins Schwanken gebracht, dass diese Tradition erst im 13. Jahrhundert in den Chroniktext interpoliert wurde. Einer späteren Datierung der Fragmente stand dann nichts mehr im Wege.

Heute ist die Datierung der Skulpturenfragmente von Óbuda auf die erste Hälfte - auf Grund des Vergleichs vor allem mit der Bauskulptur des Stifts zu Dömös sogar auf das erste Viertel - des 12. Jahrhunderts ebenso allgemein anerkannt, ${ }^{8}$ wie die Datierung der Stücke von Esztergom. Für die Spätdatierung von Esztergom II konnte eine bis dahin vernachlässigte Schriftquelle, die Urkunde der Donation an den Domklerus herangezogen werden, die der Erzbischof

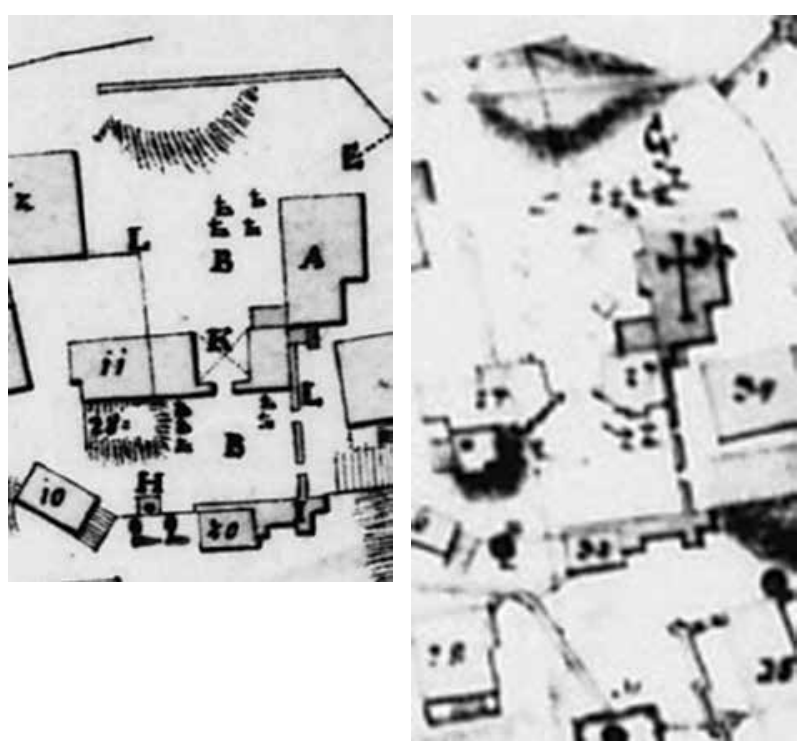

Abb. 6a. Ausschnitt aus Abb. 5: die Ruinen der Kathedrale $A b b$. 6b. Grundrissaufnahme der Festung von Esztergom, 1765, Wien, Kriegsarchiv (Inland C. V.a)

Gran, Nr. 6, Ausschnitt: die Ruinen der Kathedrale 
Martyrius 1156 aus dem Anlass der Weihe des Marienaltars der Kathedrale ausgestellt hatte. Die Weihe des vor dem Chor befindlichen Altars setzt um diese Zeit einen weitgehend brauchbaren Bauzustand des Langhauses voraus. Sonst stehen uns für den Bau der Kathedrale keine anderen Schriftquellen zur Verfügung. In der Literatur lebt aber eine Tradition weiter, deren Quellenbasis sich als zumindest wenig glaubhaft erwies. Es handelt sich um Daten, die die Bedeutung der Regierungszeit vom König Béla III. von Ungarn (1172-1196) unterstützen. Diese Tradition kam auch anders, zum Beispiel auf Grund seines Stifterbildnisses am Westportal (Abb. 4), ${ }^{9}$ der Porta speciosa, zum Ausdruck. Einer Urkunde vom König Emmerich von Ungarn (1196-1204) aus dem Jahr 1198, die als Ersatz für einen früheren, 1188 bei einem Brand vernichteten Donationsbrief entstand, hat man Glaubwürdigkeit zugeschrieben - trotz der Tatsache, dass das angeblich zerstörte "Original“ (in Wahrheit eine Fälschung) ebenfalls erhalten ist. ${ }^{10}$ Der Verdacht einer Manipulation mit den Urkunden wird dadurch kompliziert, dass König Emmerich in der gleichen Zeit wohl nicht völlig auf eigene Initiative, sondern pro discordia vitanda - auf den Palast von Esztergom zugunsten des Erzbischofs verzichtete. ${ }^{11}$

So wird großer Quellenwert einer Grundrissaufnahme der Ruinen der Kathedrale im Zustand gegen Mitte des 18. Jahrhunderts beigemessen. Weder Zeit noch - bestimmt sachkundiger - Autor der Zeichnung ist bekannt, die Joannes Nep. Máthes 1827 veröffentlicht hat (Abb. 10).12 Sie ist die letzte Reserve der Vorstellung von dem Bau der ersten Kathedrale („Esztergom I" - der St. Stephansbau, Anfang des 11. Jahrhunderts). Die Grundrissaufnahme, die eine 1763 auf Befehl des Erzbischofs Ferenc Barkóczy (1761-1765) entstandene Zeichnung ${ }^{13}$ wiedergibt, kann weder der Zeit Máthes' unmittelbar vor dem Abbruch (wie die Ansicht der Südwand von Norden; ${ }^{14} A b b$. 3) noch der Zeit um 1763 entsprechen. In diesem Jahr wurde der Abbruch durch eine Erdbebenkatastrophe auf den ganzen Westteil ausgedehnt. Vielmehr erscheint der Grundriss als eine Art Rekonstruktion ebenso, wie Taf. II als eine ideale Ergänzung und Taf. V, wo Erhaltenes und eine vorläufige Barockkirche (Abb. 3; vgl. Abb. 7, 9) dokumentiert sind. Wie die Ruinen der Kirche Schritt für Schritt seit dem späten 17. Jahrhundert verschwanden, widerspiegeln die Aufnahmen der Kriegsingenieure des 18. Jahrhunderts (Abb. 5-7). In der Dokumentation des Johann Andreas Krey aus dem Jahr 1756 (Abb. 2, 6b) spielen auch Schnittzeichnungen eine Rolle. Ihm verdankt man den einzigen Längs-

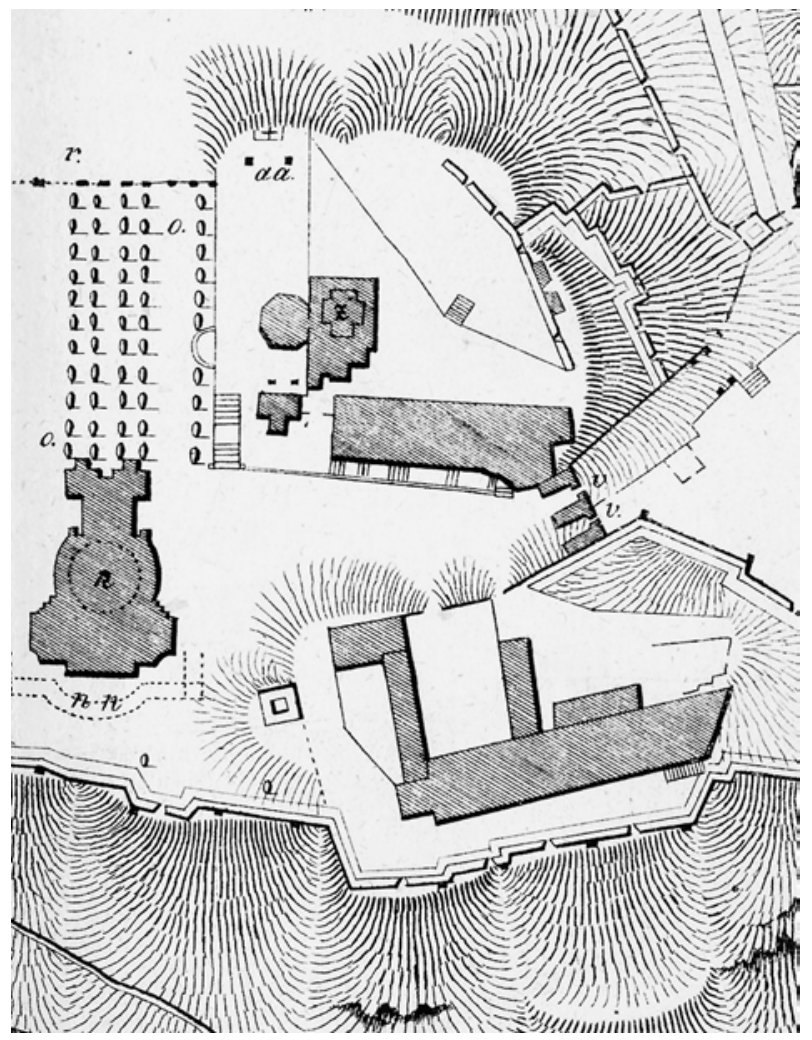

Abb. 7. Grundriss der Burg von Esztergom (MÁthes 1827, Tab. II),

Ausschnitt: die Ruinen der Kathedrale

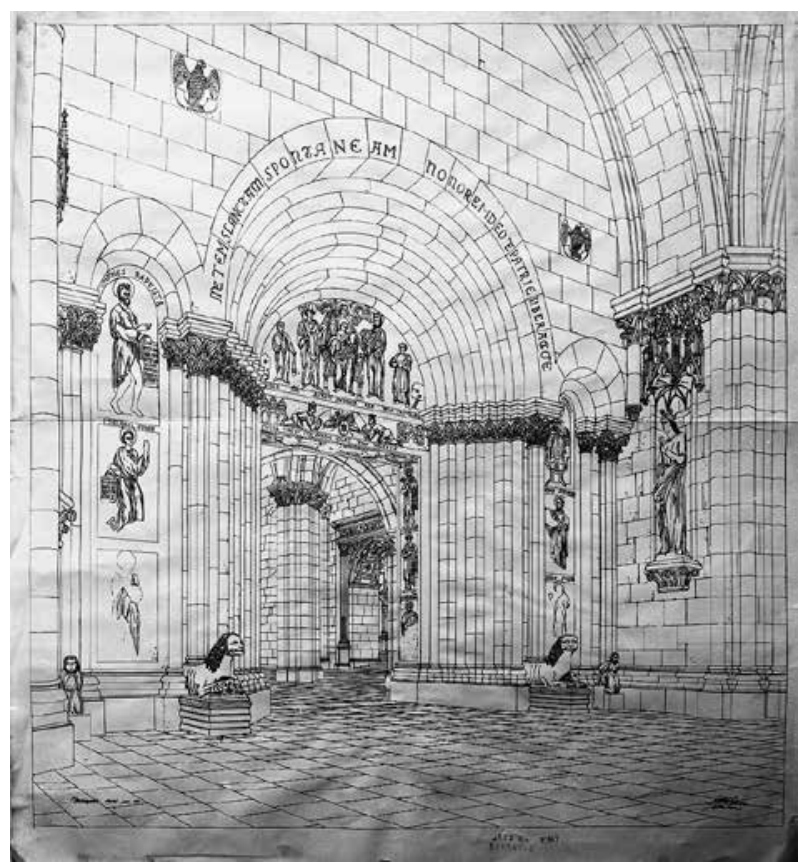

Abb. 8. Kálmán Lux: Rekonstruktionszeichnung der Porta speciosa. Budapest, Planarchiv des ehemaligen Denkmalamtes 


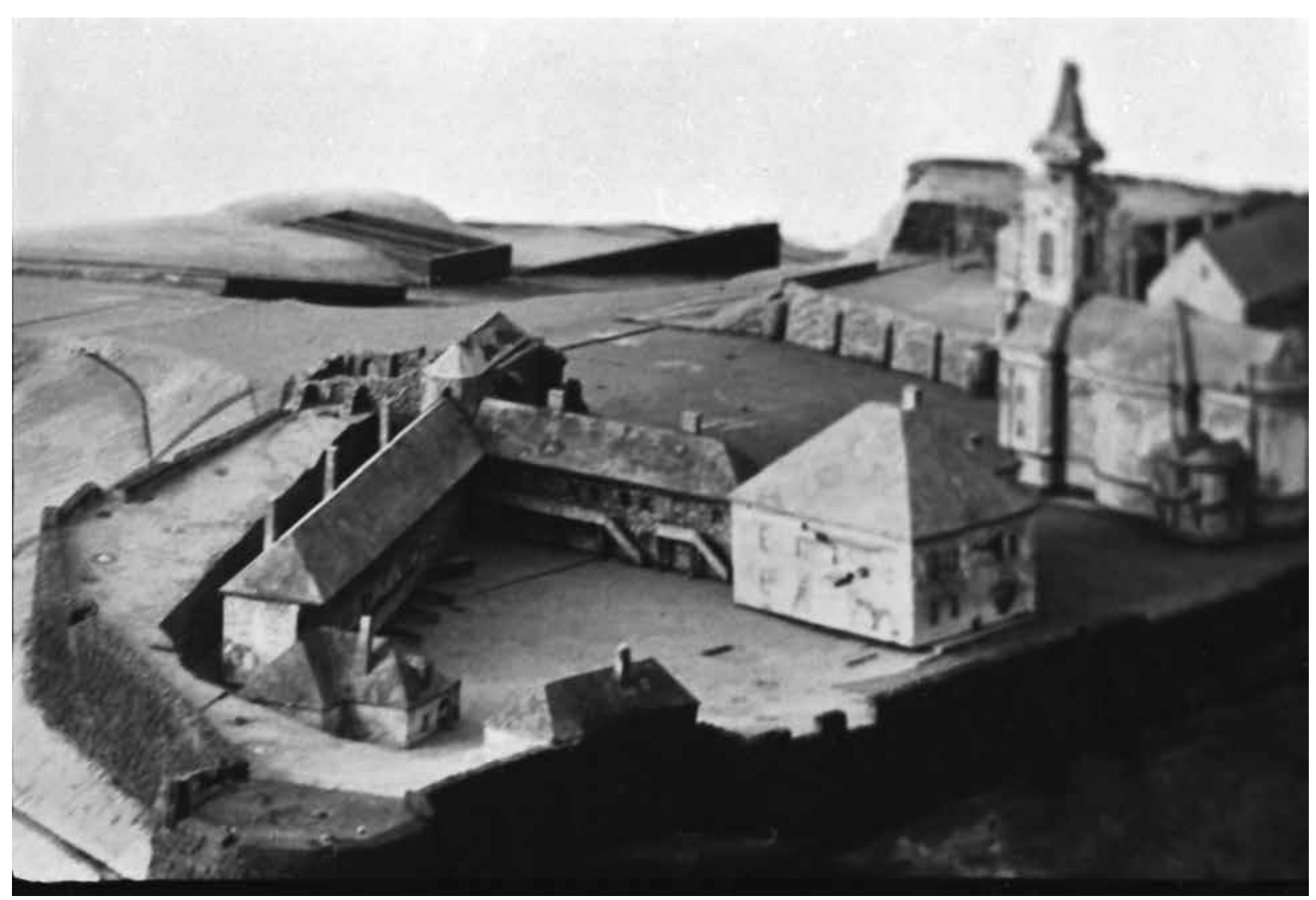

Abb. 9. Modell des Burghügels von Esztergom vor den Nivellierungsarbeiten, Detail von Norden

schnitt mit der südlichen Langhaus- und der Vorhallenwand. ${ }^{15}$

Wie wenig baugeschichtlich Wertvolles man von der Grundrissaufnahme gewinnen kann, zeigt die erst später in den Fragenkreis der Rekonstruktion hineinbezogene Zeichnung der nordwestlichen Ansicht der Kirche aus dem 18. Jahrhundert (Abb. 1). Außer dem westlichen Turmpaar erscheint hier auch ein nordöstlicher Turm. In der Zeichnung wird eine Rekonstruktionsmöglichkeit des Seitenschiffes mit flacher östlicher Abschlusswand und mit einer hochführenden Wendeltreppe konkretisiert. Man kann sich nicht mehr vorstellen, wie viel im 18. Jahrhundert verloren ging. Der fromme Baumeister Friedrich Bernhard Werner, der diese wohl 1732 vor Ort gemachte - aber keineswegs exakte, vielmehr emotionell geladene - Zeichnung in sein Album von Gnadenkirchen aufnahm, konnte 1770 als Bildtitel schreiben: Die vorhero halb, nun mehro gantz ruinirte Ertzbischöfl. Kirch in Gran. ${ }^{16}$ Dass noch beträchtlich hohe Mauern der "halb ruinierten Kirche" trotz aller Zerstörungen im frühen 18. Jahrhundert gestanden haben, zeigen die Reste von Fenstern und die der zum Sakramentshaus gehörenden Fialenspitze des gotischen Chors, die in den 1970er Jahren in einer Zuschüttung in der unmittelbaren Nähe des Kirchenchors gefunden wurden.

Die von Zeit zu Zeit abgehaltenen Tagungen und Festveranstaltungen zeigen, dass unsere tatsächlichen Kenntnisse über die romanischen Denkmäler von Esztergom nicht vermehrt werden können. Es gibt die einzige Möglichkeit der Neuinterpretierung der Quellen - durch eine strenge Quellenkritik und vor allem durch Heranziehung von Parallelen. Der Verfasser erhielt sogar zweimal nacheinander die Gelegenheit, über Fragen der Porta speciosa (Abb. 4, 8) zu berichten: einmal auf der anlässlich des Millenniums der ungarischen Landnahme veranstalteten Tagung 1997 mit dem Titel „Tausend Jahre unter dem Schutz des Heiligen Adalbert"17 und zum zweiten Mal 2000 als Beitrag zur Frage von „Esztergom als eine tausendjährige Metropole der Kultur". ${ }^{18}$ Auf der Tagung von 1997 hat Sándor Tóth die Fragen der Baugeschichte erörtert. Im Unterschied zu meiner Übersicht über die Baugeschichte der Kathedrale, die einen Hintergrund zu ihrer gotischen Architektur bildete, hat er nach einer Möglichkeit gesucht, Züge der frühromanischen Baukunst im uns zugänglichen Material aufzuspüren. Seiner Kritik der einzigen und gemeinsamen Quelle, 


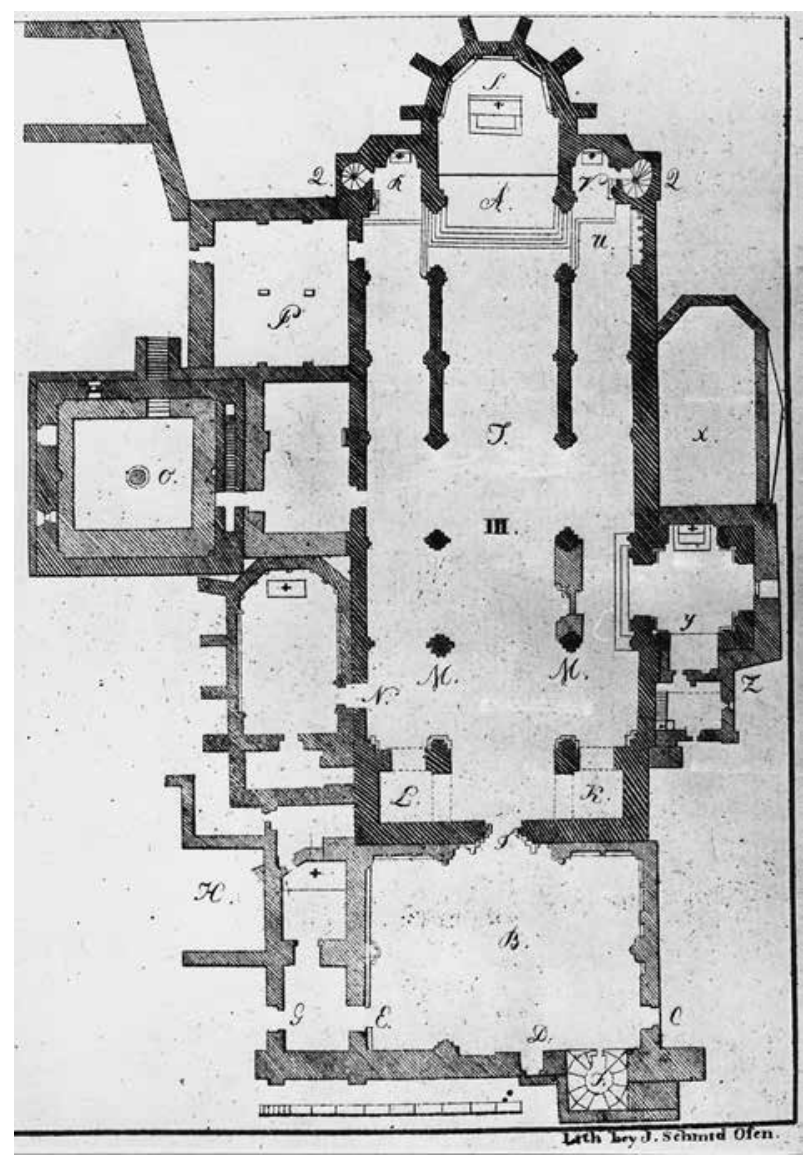

Abb. 10. Grundriss der Kathedrale von Esztergom (MÁthes 1827, Tab. IV)

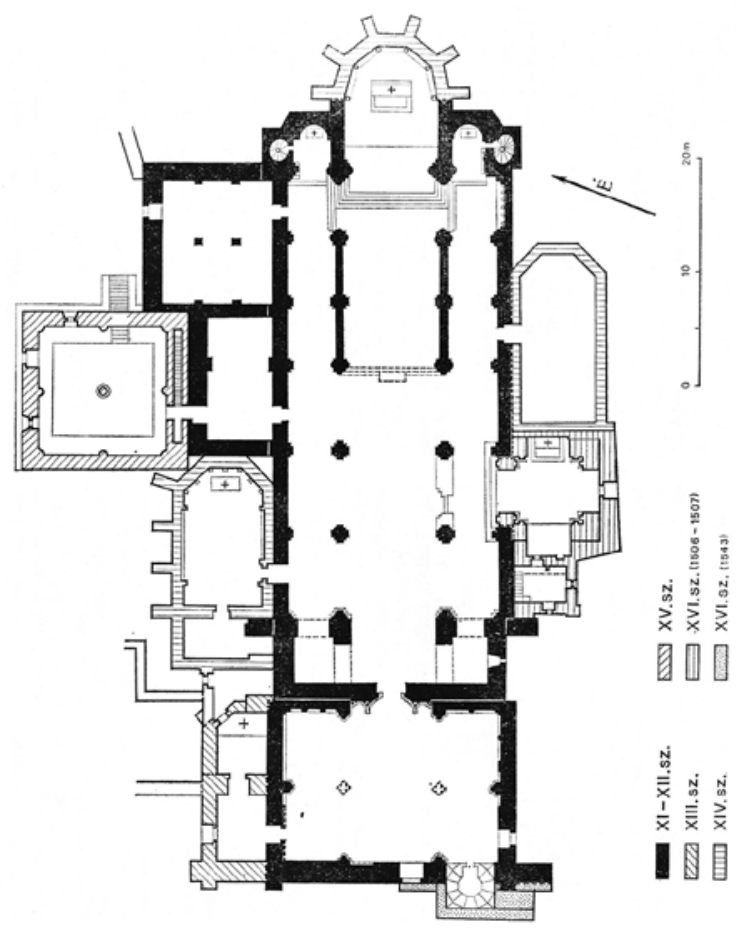

Abb. 11. Grundriss der Kathedrale von Esztergom (István Horváth: MRT 5. 1979) der Máthes'schen Grundrisszeichnung kann man nur zustimmen: „... vor dem Aufmessen wurde der Bau am Beginn der Nivellierung erschlossen. In der gleichen Zeit zeugt die Zeichnung von einer rekonstruktiven Absicht. [...] Auf Máthes mögen - wenigstens zum Teil - die Schraffuren unterschiedlichen Typs auf der Zeichnung [...] zurückgehen.“ Weiterhin „kann sogar die Authentizität [der Zeichnung] in Frage gestellt werden, denn sie ist in zumindest zweimaliger Transposition auf uns gekommen: Außer den Veränderungen von Máthes kann man mit Ungenauigkeiten des Lithographen rechnen. Dazu ist die Korrektheit der Originalzeichnung kaum als sicher anzunehmen, weil ein Großteil seiner Formen mit anderen Quellen gar nicht verglichen werden kann. " ${ }^{19} \mathrm{Da}$ kommt man auf dem Gebiet der unterschiedlichen Überzeugungen und Temperamenten an (Abb. 10-13). Es handelte sich immer um „Esztergom I“, d. h. um die Frage, ob die erste, unter dem Heiligen Stephan erbaute Kathedrale in den Resten noch erkennbar war. Anders formuliert: Es ist fragwürdig, ob Bauperioden - unabhängig von den eingangs erwähnten Problemen der Überlieferung - im Grundriss der Kathedrale zu unterscheiden und durch Farben bzw. Schraffur darzustellen sind. Die vorliegende Arbeit ${ }^{20}$ ist wiederum ein Tagungsbeitrag und wurde als Gegenstück zum Aufsatz Sándor Tóths über den tausendjährigen Gründungsbau Esztergom I geschrieben. Es muss sich um ein Gegenstück handeln, denn es bildet eine alternative Interpretation desselben Quellenmaterials.

Die einfachere Lösung hat Indizien von früheren Bauzuständen im überlieferten Grundriss und in den Niveau-Unterschieden des Fußbodens gesucht (Abb. 14-15). Diesen Hypothesen kann im Allgemeinen das Gegenargument entgegengesetzt werden, dass diese Eigentümlichkeiten funktional bedingt seien, wobei sie baulichen Forderungen im Grundriss und in Raumhöhen zu entsprechen haben. Augenfällige Unregelmäßigkeiten und auch Maßunterschiede haben verschiedenen Vermutungen der Periodisierung zu Grunde gelegen. Bereits Máthes hat sich mit einer Rekonstruktionsvorstellung beschäftigt. Er stellte sich Bau I in der Chorpartie sowie in den Mauern vor, die sowohl im Inneren als auch im Langhaus ein um 8 Stufen (ca. 1,5 m) höheres Bodenniveau bestimmt hatten. ${ }^{21}$ Sándor Tóth ist vor allem von der Beobachtung ausgegangen, dass die Ostpartien eine ähnliche Weite aufgewiesen haben, wie die Westjoche der Kathedrale zusammen mit dem westlichen Turmpaar. Deshalb hat er den ursprünglichen Ostabschluss und den Westbau als Überbleibsel vom Bau I betrachtet, die mit einem 


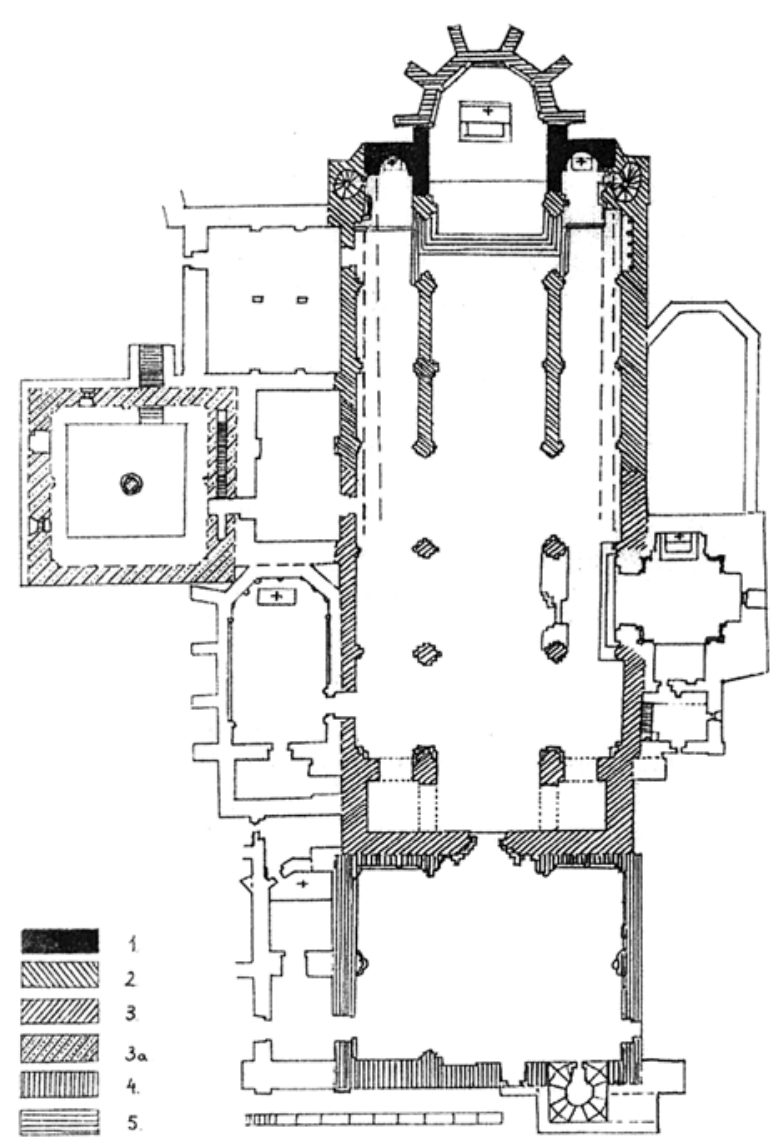

Abb. 12. Grundriss der Kathedrale von Esztergom (Тóth 2000)

breiteren Langhausbau der Periode II verbunden wurden. Als Tóth den Máthes'schen Grundriss interpretiert hat, hat er mit gestrichelter Linie den Umriss einer Kirche mit engeren Seitenschiffen eingezeichnet ( $A b b$. 12). Ein Verhältnis 1:3 der lichten Weite zwischen den Mittel- und den Seitenschiffen - wie etwa an den frühen Kirchenbauten von Szabolcs bzw. in der Kathedrale I von Gyulafehérvár (Weißenburg, Karlsburg, Alba Iulia, RO) - hielt er für eine Eigentümlichkeit der Kirchenbauten des 11. Jahrhunderts. Aus seinen Eintragungen in den Grundriss wird es klar, dass er etwa bis um die Westgrenze des Chors der Domherren mit der ersten Bauperiode des II. Baus rechnete, die durch engere Pfeilerstellungen gekennzeichnet wird (und wesentlich in der Nachfolge von Bau I zu sehen ist). Erst in den drei westlichen Pfeilerstellungen hat er einen Planwechsel angenommen, der zum breiteren, im Mittelschiff beinahe quadratischen Grundriss der Westjoche geführt hat.

Bei der Rekonstruktionsvorstellung der Geschehen mag Sándor Tóth die weit verbreitete Methode beschäftigt haben, wie bei mittelalterlichen Umbauten
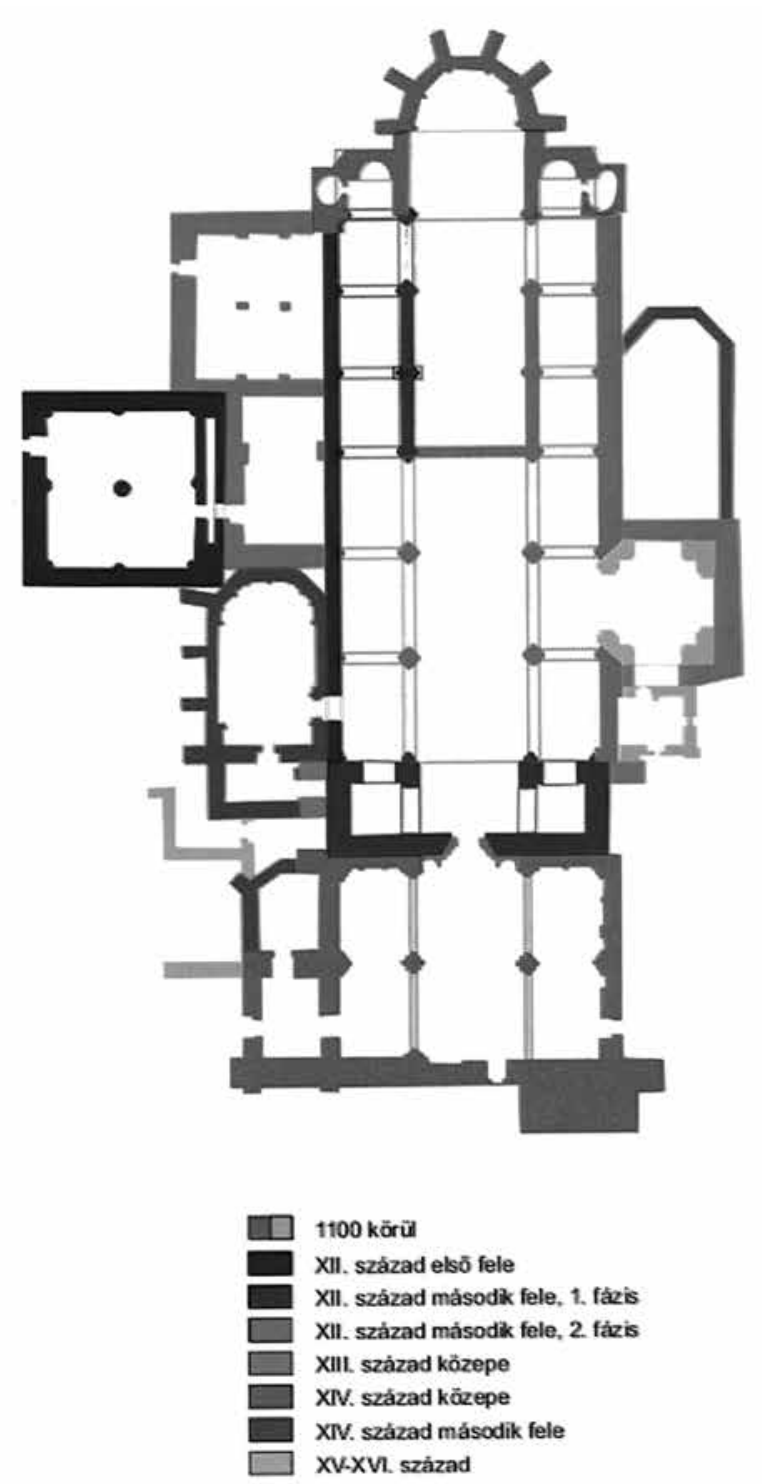

$\underline{0 \quad 10 \mathrm{~m}}$

Abb. 13. Grundriss der Kathedrale von Esztergom (BUZÁs 2004)

ältere Bauteile vor dem Abbruch herumgebaut wurden. Ihr Gebrauch musste auf diese Weise für eine möglichst kurze Zeit gehindert werden. Eine wichtige Studie, die schon posthum herausgegeben wurde, hat er diesen Beobachtungen gewidmet. ${ }^{22}$ Eine jüngst aufgetauchte Hypothese, nach der die Mittelapsis - im 14. Jahrhundert als ein Chorabschluss über einem 5/10 Polygongrundriss erneuert - über einer Kryptaanlage gebaut worden wäre (Abb. 13), ist aber eine durch keinerlei Angaben begründete vage Vermutung. ${ }^{23}$ Man soll nicht vergessen, dass es sich bei diesen Beobachtungen nicht nur um formale Unterschiede, sondern auch um Maße handelt. Der Máthes'sche Grundriss 


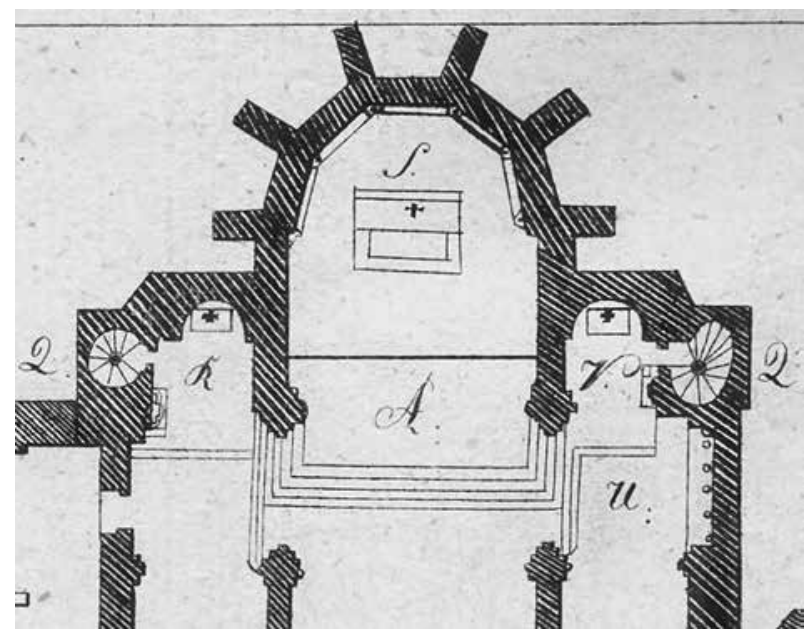

Abb. 14. Detail der Abb. 10

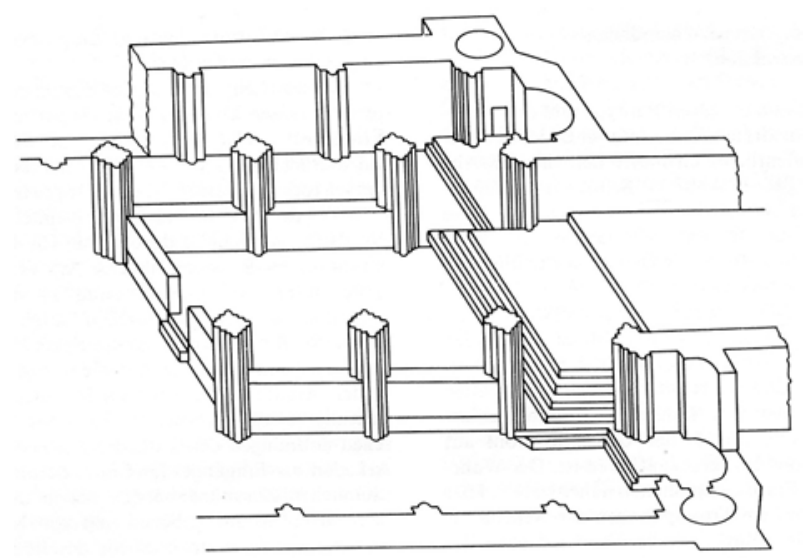

Abb. 15. Niveauverhältnisse von Chor und Apsis, Rekonstruktion auf Grund der Abb. 10 (MARosi 1984, Taf. IV)

(Abb. 10) ist mit einem Maßstab von insgesamt 10 Klaftern - davon der erste in 6 Fuß geteilt - versehen. Bereits die ungleichen Einteilungen der Maßstäbe weisen darauf hin, dass noch mehr Vorsicht bei den auf Maßunterschiede gegründeten Untersuchungen geboten ist, als man es im oben angeführten Zitat von Sándor Tóth findet. Auf dem Grundriss ist die Enge der vor den Seitenapsiden befindlichen rechteckigen Joche gut sichtbar (im Norden etwa 1 Klafter 5 Fuß, dagegen die lichte Weite des zweiten nördlichen Seitenschiffsjochs etwa 2 Klafter 3 Fuß), außer dem Chorbereich findet man jedoch eine so kleine Breite nicht. Für die gleiche Breite von Chorseitenschiff und Westbau findet man keinen Beleg, dagegen zeigt ein Vergleich der Grundrisse der beiden Seitenapsiden (Abb. 14), dass es sich hier um völlig vage Gliederungsformen - zum Beispiel um eine seltsam verzerrte Form der südlichen Wendeltreppe - handelt.

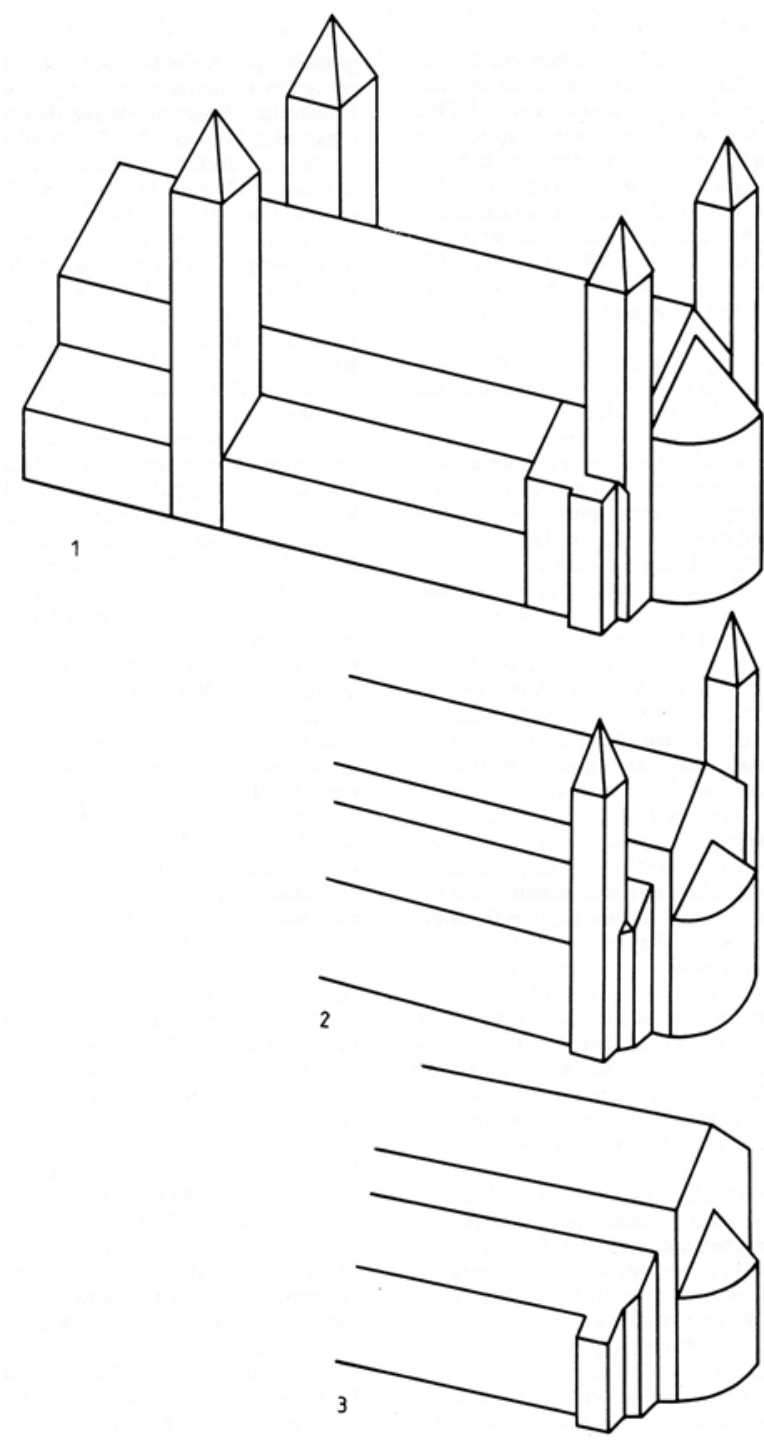

Abb. 16. Rekonstruktionsvarianten der Kathedrale (MAROsi 1984, Taf. VI)

In meiner monographischen Arbeit habe ich nicht weiter zurückzublicken gewagt, als bis zum Bau II, dessen Reste wohl im 18. Jahrhundert noch als Ruinen zu sehen waren. Damals - für den Zweck, die Bautätigkeit des 12. Jahrhunderts (d. h. Bau II) zu untersuchen - hat sich diese Beschränkung als nützlich erwiesen. Die Frage des Verhältnisses vom Bau I zu Bau II ist für die vorliegende Untersuchung auch nicht relevant. Das Ostturmpaar (Abb. 16) beiderseits der Mittelapsis - nicht zuletzt auf Grund der Nordansicht von Werner; Abb. 1 - habe ich im Kontext des zweiten Baus gedeutet, denn eine Trennung der Apsiden von den beiderseits bezeugten Treppentürmen, wie es Sándor Tóth vorgeschlagen und auch dargestellt hatte, ist aus statischen Gründen kaum anzunehmen. 
Die Osttürme und die anschließenden Treppenhäuser in Verbindung mit Apsiden, die sich in den äußeren, flachen östlichen Abschlussmauern befinden, mögen im mittelrheinischen Kontext wurzeln, der für Bau II als maßgebend erscheint. Diese Bauglieder stehen in enger Verbindung mit denen auf den Ostpartien des Doms von Speyer und in seiner Nachfolge. (Beide sind romanische Kirchen: sowohl St. Servatius als auch Unsere Liebe Frau in Maastricht.) Vom Turmpaar und von den Wendeltreppen liest man eine verhältnismäßig ausführliche Beschreibung bei Máthes, für die er wie Friedrich Bernhard Werner, der die Zeit zwischen 1732-1770 als die der Zerstörung bezeichnete - auf Erfahrungen von Augenzeugen spätestens um die Mitte des 18. Jahrhunderts angewiesen war. Máthes bemerkt auch, dass zumindest eine Wendeltreppe aus Rotmarmor bestand (ex porphyrite adstructa). An der gleichen Stelle hat er im Anschluss an die Meinung des Historikers Matthias Bél (1684-1749) die Errichtung dieser Türme auf die Zeit vom König Béla III. und Erzbischof Job datiert. ${ }^{24}$ Man weiß nicht, welche Gründe Bél für seine Datierung hatte, man könnte aber auf Grund der Verwendung des Rotmarmors als Baumaterial oder in nachträglicher Verkleidung früherer Mauerkonstruktionen zu einer ähnlichen Schlussfolgerung kommen.

Die Forschungen über die Bedeutung des als „Rotmarmor" bekannt gewordenen lokalen Kalksteins für verschiedene Epochen der mittelalterlichen Kunst in Ungarn, der im Dombau von Esztergom als Epizentrum und als Musterbeispiel dieser Materialikonologie und repräsentativer Farbenpracht verwendet worden war, lieferten in der letzten Generation zahlreiche wichtige Beiträge über die Eigenart, die künstlerischen Beziehungen, die Technik und die wirtschaftsgeschichtlichen Beziehungen dieses Materials. ${ }^{25}$ Eine in der kunsthistorischen Literatur vernachlässigte Donationsurkunde Königs Ludwig I. von Ungarn aus dem Jahr 1369, in der der Rubinglanz der Kathedrale (praefulget rubinosa) als ein dem Betrachter des 14. Jahrhunderts wichtiger Zug ihrer Erscheinung erwähnt wird, wurde kürzlich auf ihre rotmarmorne Wandverkleidung bezogen. ${ }^{26}$ Dass alle Wandflächen des Inneren mit Rotmarmor bedeckt wurden, hat der Kleriker György Széless in seiner Beschreibung von 1761 nicht nur erwähnt, sondern er hat auch die Technik der Befestigung dieser Verkleidung mit Klammern und Dübeln erklärt. ${ }^{27}$ Dass sogar die Gewölbe mit Rotmarmorplatten bekleidet wurden, hat der Chronist Miklós Istvánffy in seinem Bericht über die türkische Belagerung aus dem Jahr 1543 belegt. Damals wurde das „hohe Ostgewölbe“ wohl des Chors durch Kanonenschüsse zerstört (templi maioris praealta Orientalis fornix, concamerati ac rubri marmoris tabellis incrustati operis, concussa et labefacta repente corruit). ${ }^{28}$ Streng genommen kann man nicht nur mit einer Entstehungszeit gegen oder um 1200 rechnen, sondern auch mit der ersten Hälfte des 14. Jahrhunderts, als der Polygonchor errichtet wurde. Sogar in der oben angeführten Urkunde aus dem Jahr 1369 ist von damals gerade laufenden Bauarbeiten die Rede. ${ }^{29}$

\section{BAU I UND BAU II DER ADALBERTSKATHEDRALE IN DER BAUSKULPTUR}

Da man keine schriftlichen Belege als Stützen der Unterscheidung der Bauperioden besitzt, ist die Periodisierung des Baus wesentlich auf stilistische Bedenken gegründet. Dabei kann man nicht einmal entscheiden, was zu dem Bau I und was dem Zweitbau gehört hat. Das ist nämlich keine reine chronologische Frage, denn man weiß nicht, wann die Arbeit daran begann.

Es gibt ein einziges Stück, das gewiss zum Bau I gehört hat. Es handelt sich um etwa ein Viertel einer Brüstungsplatte aus Kalkstein, die zu einer Chorschranke gehört haben mag (Abb. 17). ${ }^{30}$ Dieses Fragment, auf dem man auch den Anschluss an einen gekehlten Pfeiler entdecken kann, erhielt in der kunsthistorischen Literatur auffallend wenig Aufmerksamkeit. Mit der Behandlung seiner Flechtbandornamen- tik, die in Form von kreisförmigen Medaillen wohl plastische Darstellungen bildete und aus dreiteiligen Bändern mit breiterer Mittelbahn bestand, gehört es gewiss zu einer Gruppe von flechtbandverzierten Steinfragmenten, deren Datierungsfragen kürzlich im Mittelpunkt von Diskussionen standen. Als nächste Parallelen für Stil und Rekonstruktionsvorstellung mögen hier zwei Stücke erwähnt werden, an denen die Problematik und die Methodik der vorromanischen Ornamentik im Ungarn des 11. Jahrhunderts veranschaulicht werden können. Eine ähnlich gegliederte Brüstungsplatte (Abb. 18) aus der dem heiligen Hadrian geweihten Klosterkirche zu Zalavár (an Stelle der karolingischen Mosaburg) mit der Darstellung wahrscheinlich eines Raubvogels mit seiner Beute stammt aus einem vom heiligen König Stephan 


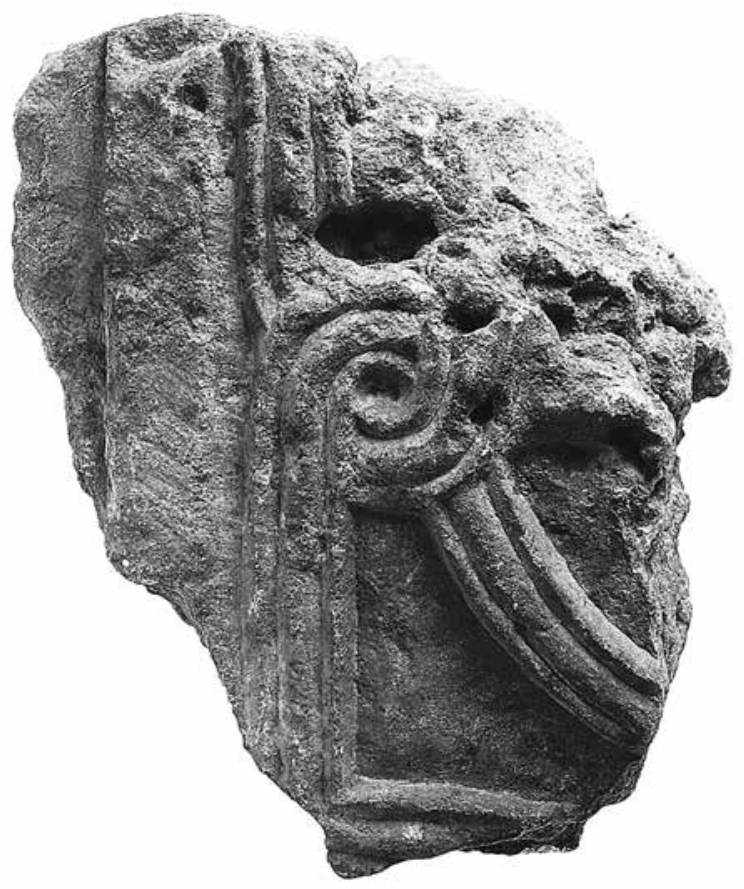

Abb. 17. Fragment einer Flechtbandplatte. Esztergom, Vármúzeum (Burgmuseum)

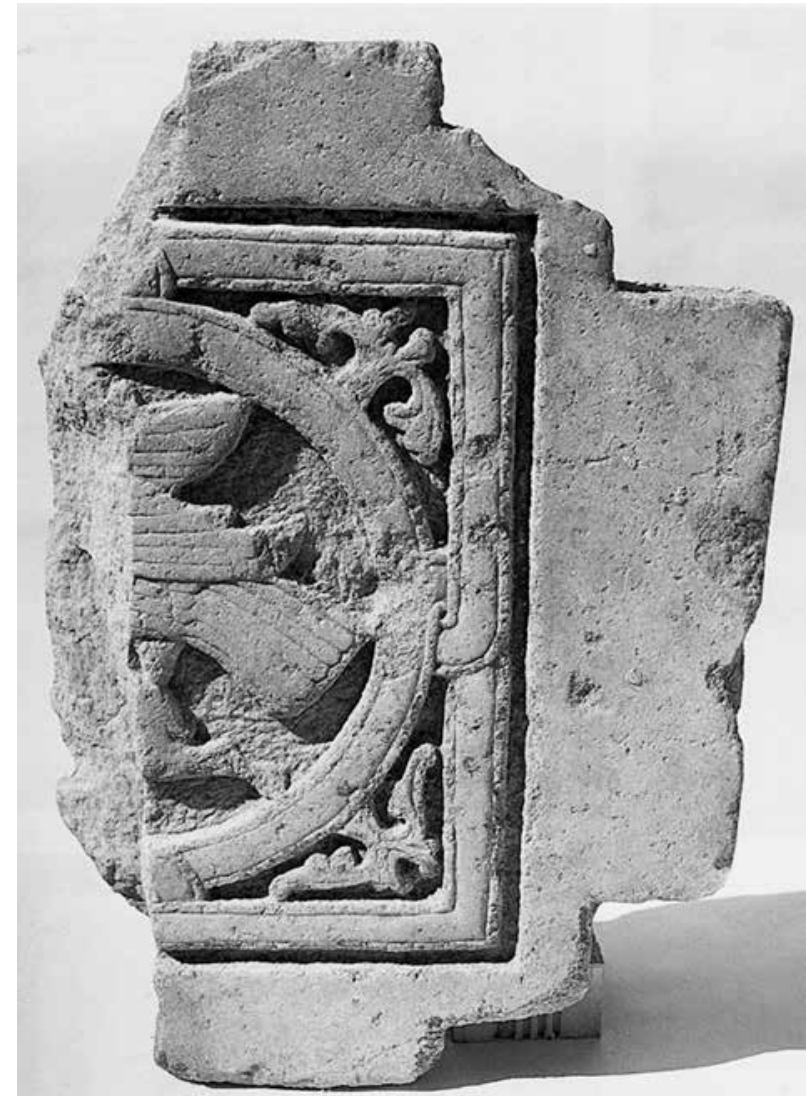

Abb. 18. Fragment einer Brüstungsplatte mit Flechtbandornamentik aus Zalavár

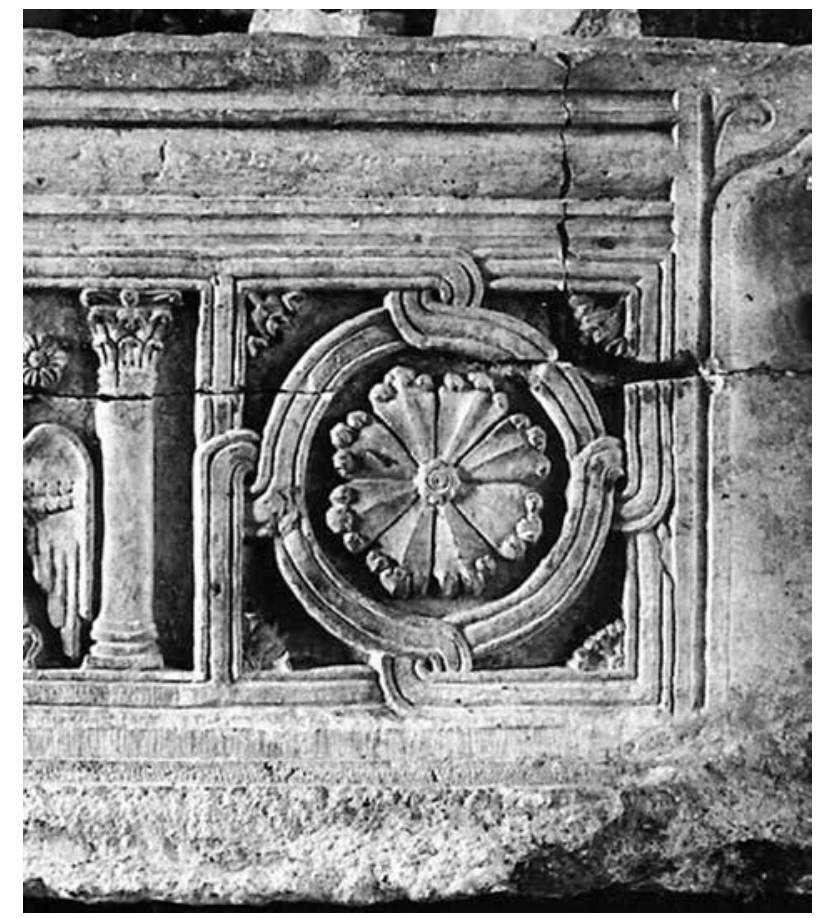

Abb. 19. Sarkophag des Heiligen Stephan, Detail. Székesfehérvár

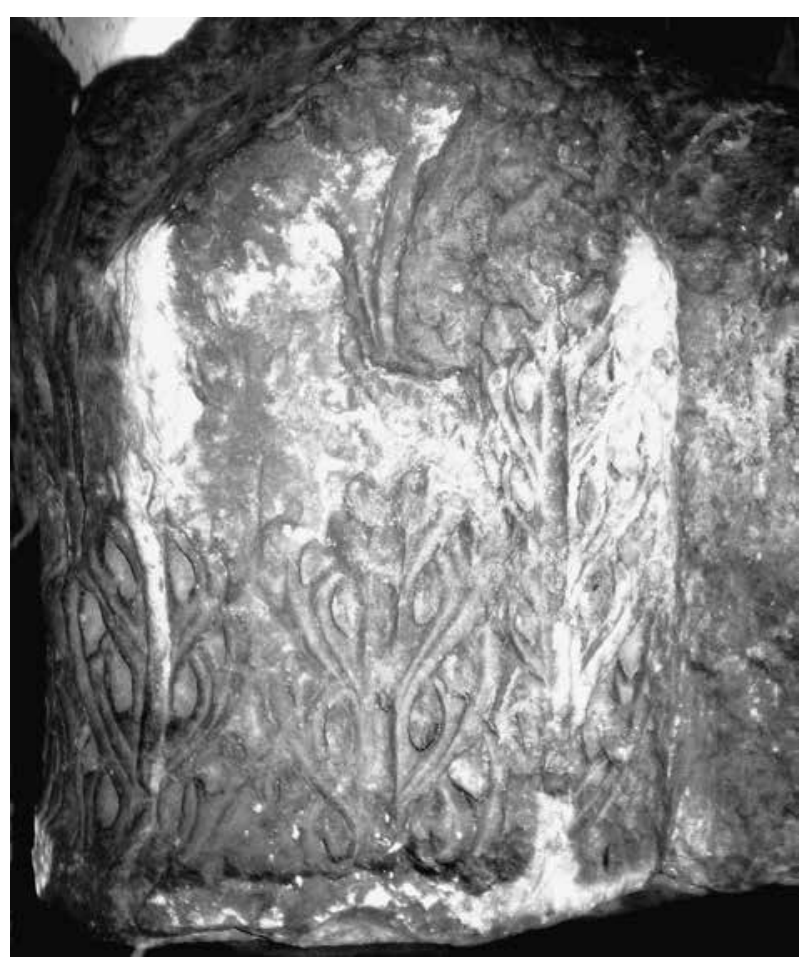

Abb. 20. Pilasterkapitell. Esztergom, Vármúzeum (Burgmuseum) (Marosi 1984, Kat. 10) 


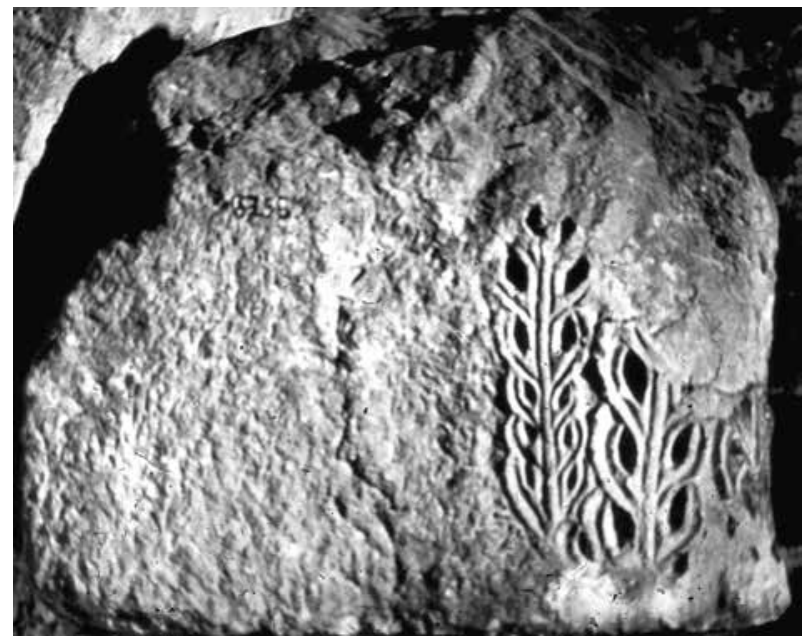

Abb. 21. Pilasterkapitell (Abb. 20), Seitenansicht

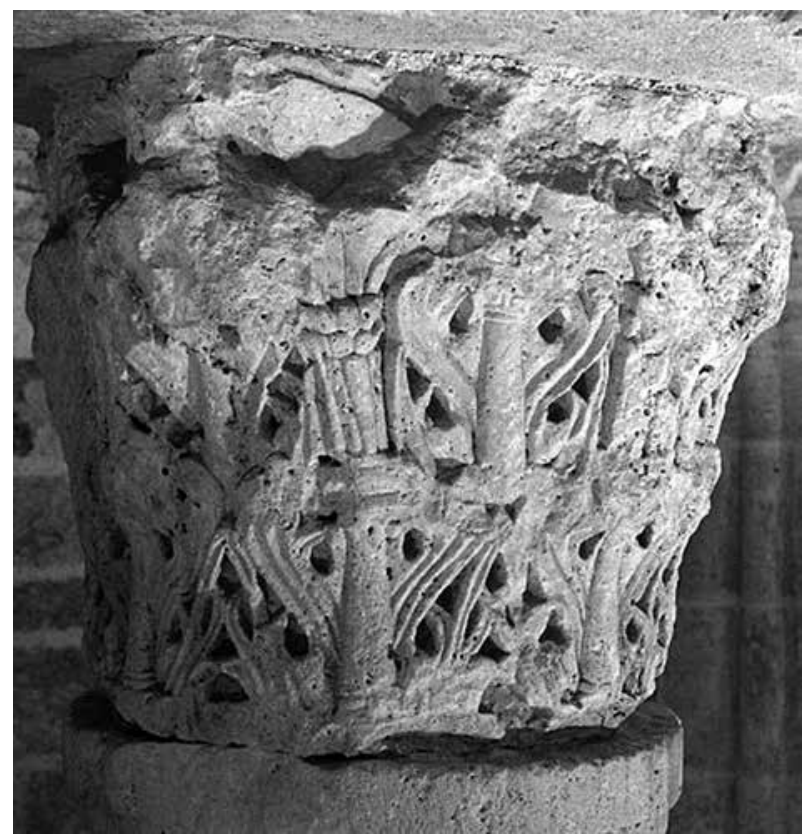

$A b b$. 22. Korinthisierendes Kapitell vor der Apsis, Feldebrô, Krypta

gegründeten Kloster. Da das für Zalavár überlieferte Weihedatum 1019 in einer Fälschung vorkommt, hat Sándor Tóth diese frühe Datierung von der Hand gewiesen und das urkundlich belegte Stiftungsdatum 1061 der Benediktinerabtei Zselicszentjakab als richtungsgebend anerkannt. Als Hauptwerk dieser Richtung hat er den Sarkophag (Reliquiensarkophag) des Heiligen Stefan (Abb. 19) betrachtet, mit einer Datierung statt 1038 (dem Todesjahr des Königs) auf 1083, das Datum seiner Heiligsprechung. ${ }^{31}$ Die Datierung des gewiss aus dem 11. Jahrhundert stammenden Fragments von Esztergom hängt im Wesentlichen davon ab, wie eng man sich den Kontext dieser orna-

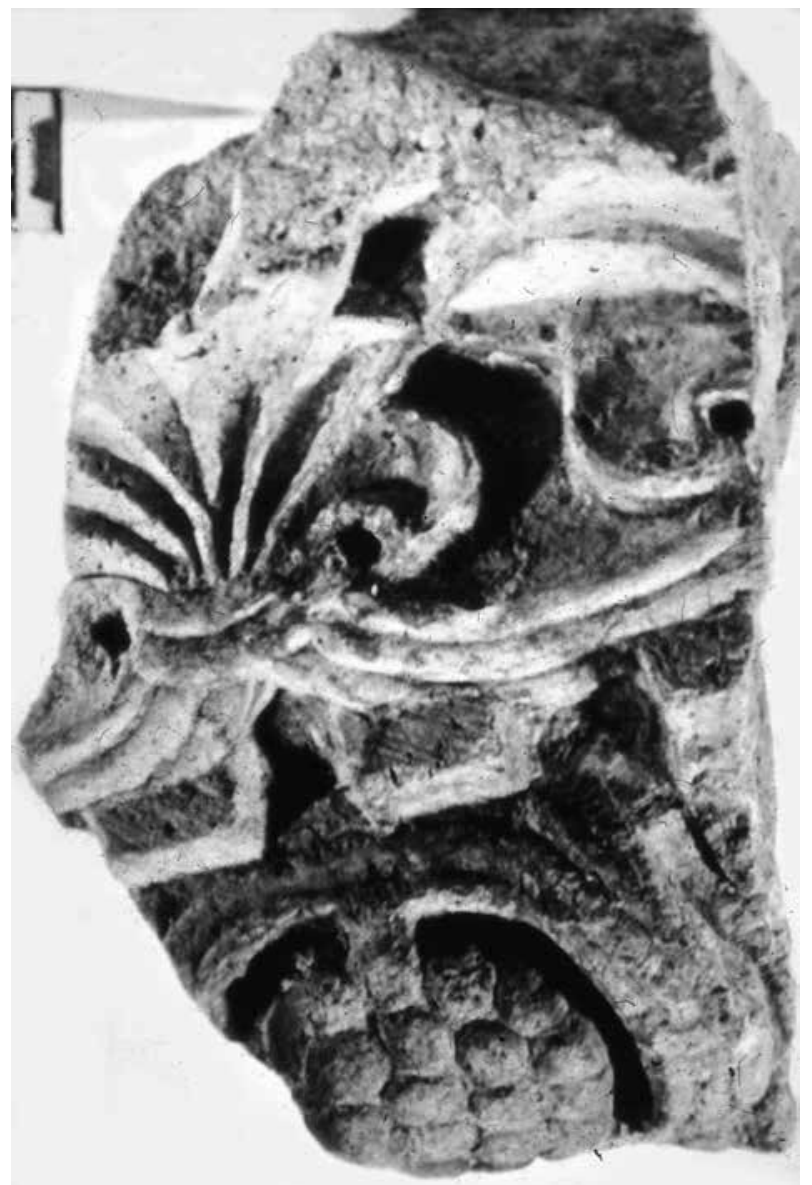

Abb. 23. Gesimsfragment aus Esztergom. Depositum in der Ungarischen Nationalgalerie (Magyar Nemzeti Galéria), Budapest (MAROSI 1984, Kat. 31)

mentalen Skulpturen vorstellt. Die erste Hälfte des 11. Jahrhunderts erscheint als wenig wahrscheinlich.

Der gleiche Kontext kann für ein Pilasterkapitell sehr archaischer Prägung (Abb. 20-21) angenommen werden. Seine Ornamentik weist scharf geschnittene Blätter beiderseits von starken Stängeln auf, die auf den Seitenflächen des Kapitells in eine Stilisierung als Flechtbandreihen übergeht. ${ }^{32}$ Eine ähnliche Behandlung des klassischen Ornaments findet man auf dem Kapitell, das vor der Apsis der Krypta der Kirche von Feldebrô (Abb. 22) Verwendung fand. Chronologisch mag es sich um das Ende des 11. Jahrhunderts handeln. Über die Bauzeit der ersten Kathedrale kann bestimmt nicht mehr die Rede sein, wohl aber über irgendwelche Anbauten. Fraglich muss jedoch bleiben, ob das Fragment bereits zu den ersten Arbeiten des Baus II gehört. Eine ähnliche chronologische und stilistische Einordnung haben wir von einem splitterartig von einem Fries erhaltenen Fragment angenommen (Abb. 23). Die Hypothese, nach der dieses Stück 


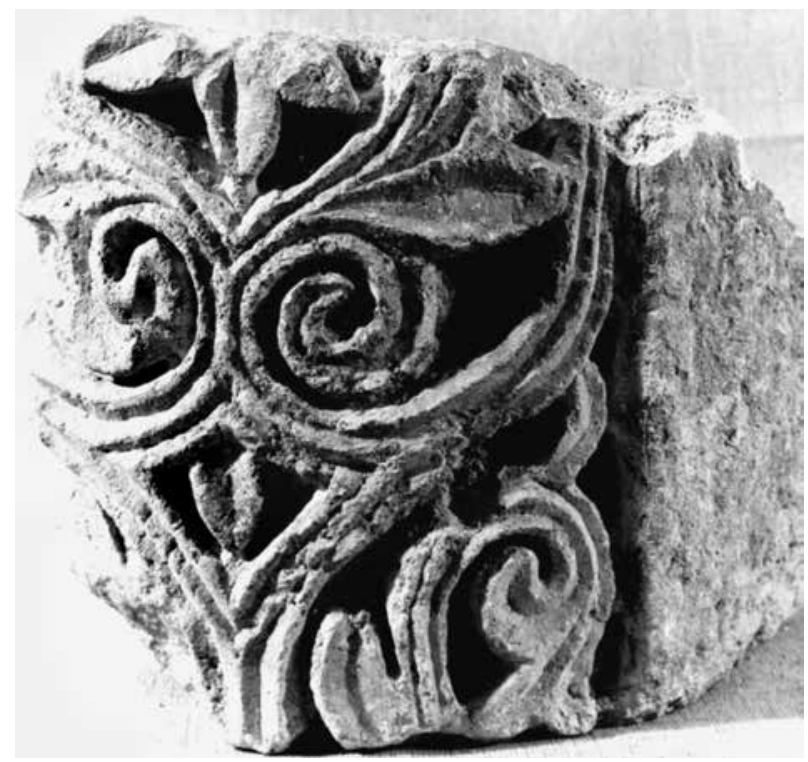

Abb. 24. Pilasterfragment mit Palmettenornamentik aus Esztergom. Depositum in der Ungarischen Nationalgalerie (Magyar Nemzeti Galéria), Budapest (MAROSI 1984, Kat. 41)

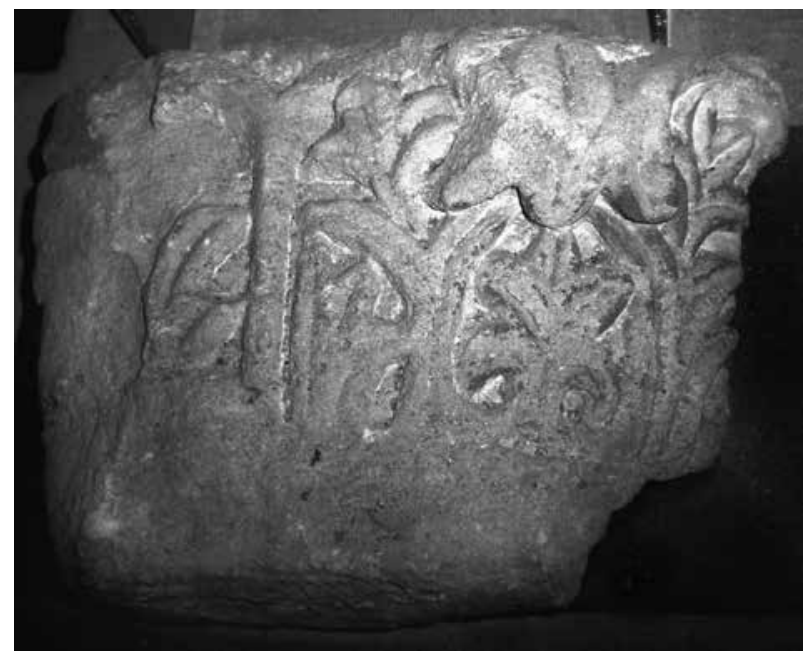

Abb. 25. Pilasterkapitell, Bodenfund im Franziskanerkloster von Esztergom. Esztergom, Balassa Bálint Múzeum

sich mit seinem palmettengeschmückten Sima, Zahnschnitt und Wulst mit Ranken und Trauben reibungslos in die Geschichte der Ornamentik des 11. Jahrhunderts hineinpasse, wurde wesentlich anerkannt. ${ }^{33}$ Diese Datierung hat aber unserem Vorschlag keineswegs entsprochen, denn wir haben ursprünglich das Weiterleben des so genannten Palmettenstils des 11. Jahrhunderts zumindest im ersten Drittel des 12. Jahrhunderts angenommen. ${ }^{34}$ Die Bildhauerarbeit auf diesem Stück und die räumliche Struktur seiner Ornamentik weisen aber auf eine Verwandtschaft mit späteren Fragmenten aus Esztergom hin: mit einem Kapitell und mit dem Fragment eines Pilasters (Abb. 24) sowie

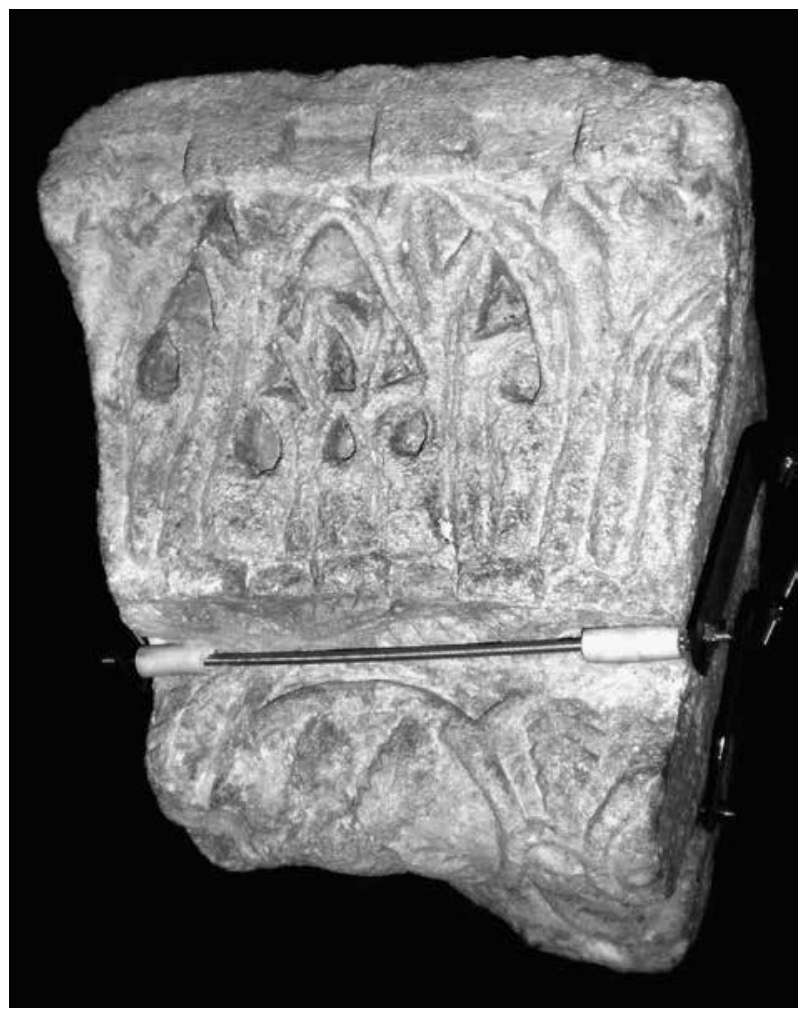

Abb. 26. Gesimsfragment.

Székesfehérvár, Szent István Király Múzeum

mit einem Pilasterkapitell aus dem Franziskanerkloster (Abb. 25), die besonders an Denkmäler des 12. Jahrhunderts von Székesfehérvár (Abb. 26-27) erinnern. ${ }^{35}$ Dort finden sich Parallelen auch für den klassizisierenden Zahnschnitt auf Fragmenten, die eine ähnliche Formbehandlung aufweisen.

Die Frage - Bau I oder Bau II - bezieht sich eigentlich auf die stilgeschichtliche Grenzlinie zwischen Vorromanik und Romanik. In Ungarn ist Esztergom um 1100 nicht der einzige Ort gewesen, wo schwer zu entscheiden ist, wo sich diese Grenze zwischen den Erstbauten aus der Zeit der Gründung (der Kirchenorganisation und auch des Staates) und der zweiten Bauperiode verläuft. Ähnlich ist die Problematik mit der Stiftskirche von Óbuda oder auch mit dem Marienstift von Székesfehérvár. Es ist verhältnismäßig leicht, einen Baubeginn in Esztergom Anfang des 12. Jahrhunderts anzunehmen, denn die Reste aus dem Stiftsbau des Herzogs Álmos in Dömös genaue und offensichtliche Parallelen in Esztergom aufweisen. Wie immer die komplizierten Verhältnisse des dynastischen Konflikts diesen Kirchenbau beeinträchtigt haben, bezeugen sowohl die chronikalische Tradition als auch die Gründungsurkunde, die der Sohn des Gründers, König Béla II. der Blinde (1131-1141), erst 1138 nachträglich herausgegeben hat, ihre Bauzeit am Beginn des 12. 


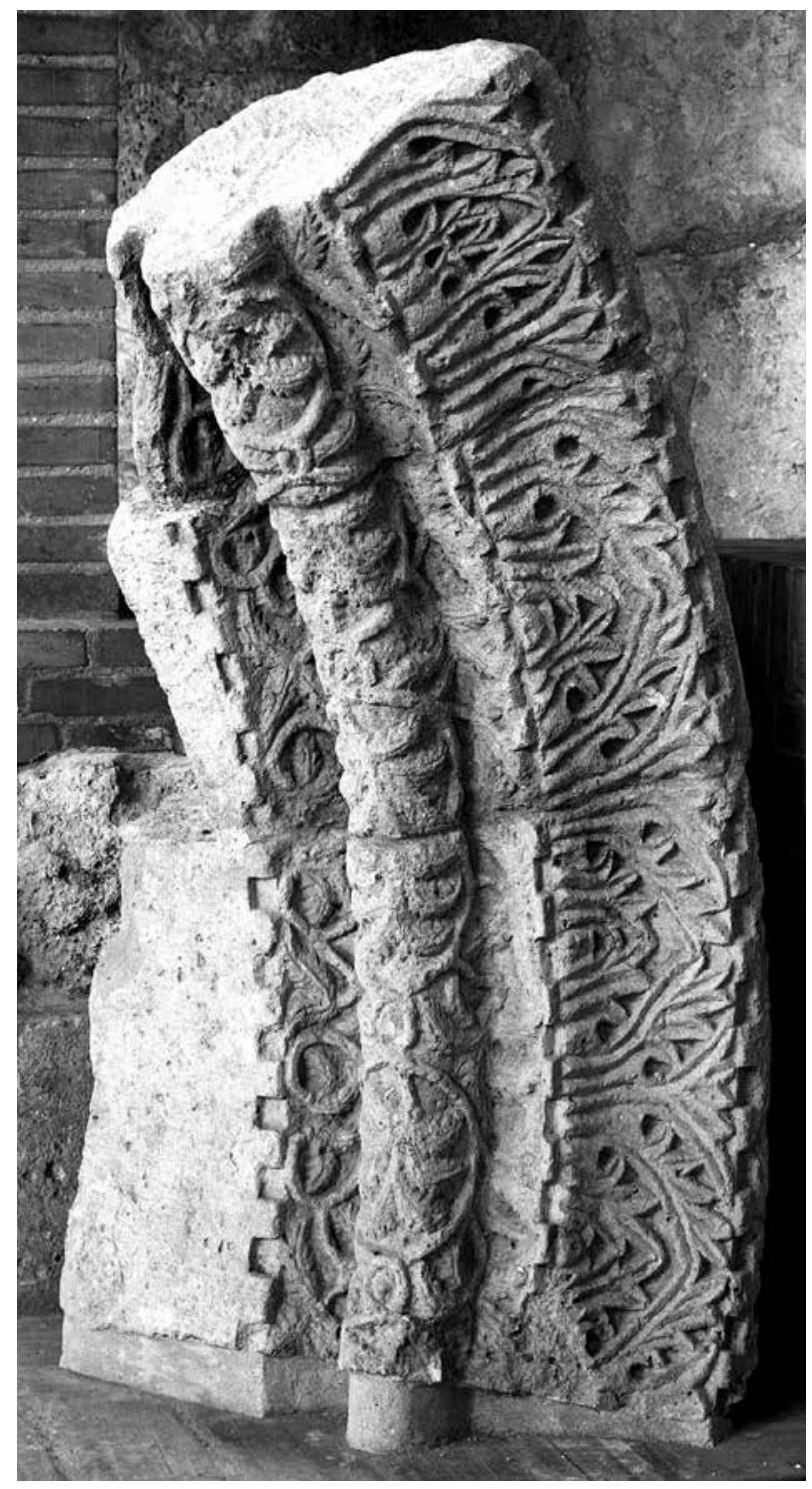

Abb. 27. Archivoltfragmente. Székesfehérvár, Szent István Király Múzeum

Jahrhunderts. Diese setzen die Weihe der Stiftskirche von Dömös ins erste Jahrzehnt des 12. Jahrhunderts. ${ }^{36}$ Es bleibt nur eine Frage offen: Welchem von den beiden, Dömös oder Esztergom, die Priorität gebührt.

Zwischen den beiden bilden allein eine rustikal behandelte Ornamentik und die mit starker Plastizität aufgefassten Figurenkapitelle (Abb. 28) ${ }^{37}$ die Verbindung. Dem Figurenstil nach gehört das halbfertig gehauene, wohl nie versetzte Löwenkapitell in Esztergom (Abb. 28, 33), dessen untere Kranzblätter klassizisierende Akanthusblätter sind, zwischen Dömös und Esztergom. Dadurch erscheint dieses Kapitell als ein Zwischenglied zwischen dem Figurenstil von Dömös und der klassizisierenden Ornamentik, die dort nicht

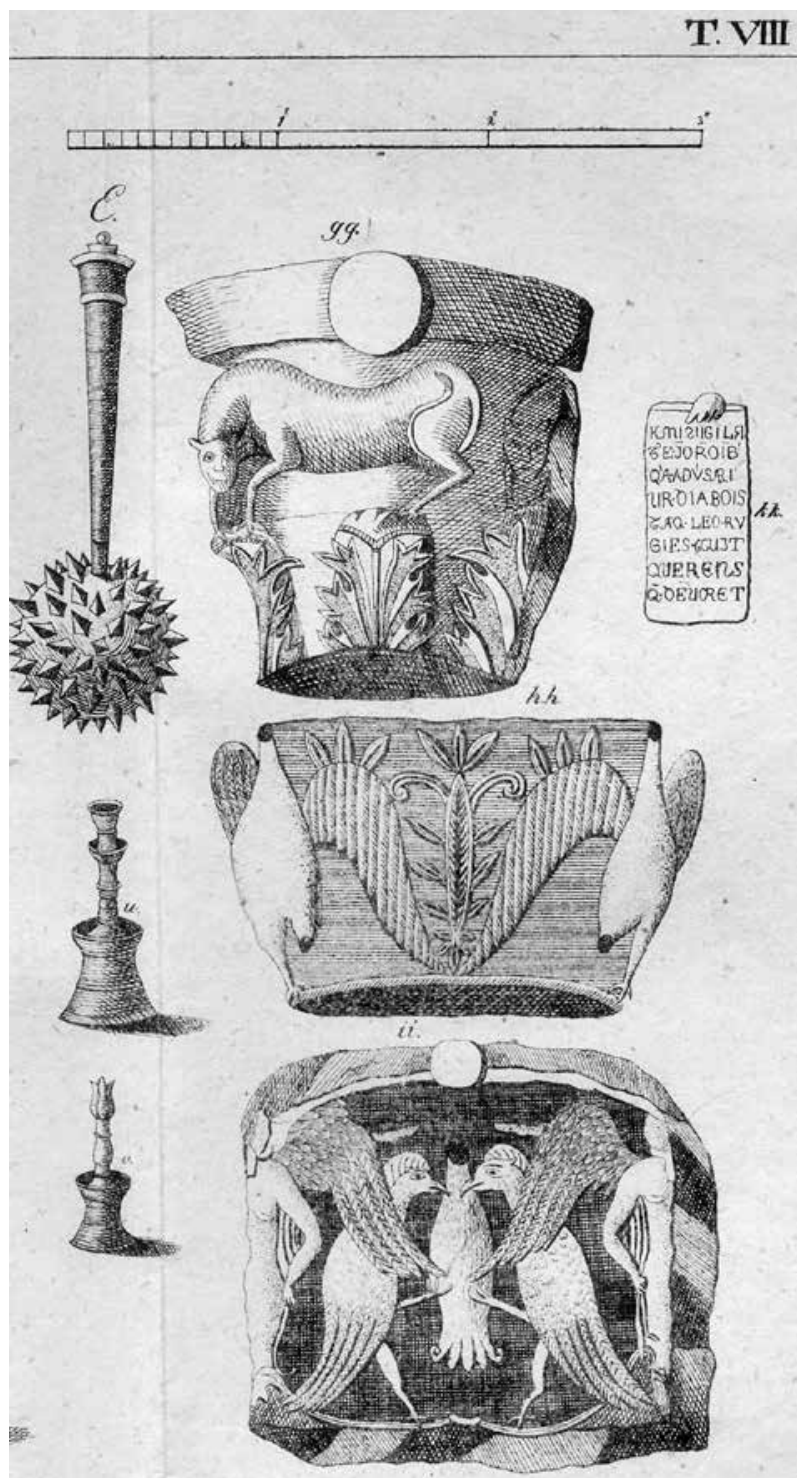

Abb. 28. Kapitelle aus den Grundmauern der St. Stephanskapelle, Esztergom (MÁtHes 1827, Tab. VIII)

vorkommt. Mit Recht wurde gegenüber seiner Einordnung in die Baugeschichte der Kathedrale von Esztergom die Einwand erhoben, dass die bei Máthes reproduzierten drei Kapitelle nicht aus der Kathedrale stammen, sondern sie wurden aus den Grundmauern der im 13. Jahrhundert gebauten Kirche des Heiligen Stephan, des Protomärtyrers, geborgen. ${ }^{38}$ Außer der Tatsache, dass die von Máthes veröffentlichten drei Kapitelle stilistisch keine Verwandtschaft miteinander aufweisen, muss man auch in Betracht ziehen, dass in der Zeit, als die St. Stephanskirche errichtet wurde, man bestimmt noch an der Kathedrale arbeitete. Außerdem passt sich das Löwenkapitell ohne Problem in den Stil der Kapitellskulptur des 12. Jahrhunderts 
der Kathedrale hinein. Dasselbe gilt - aber in einem anderen Kontext - auch für das Adlerkapitell. ${ }^{39}$ Die von Máthes veröffentlichten Abbildungen der drei Kapitelle sind auch in der Hinsicht überaus lehrreich, wie der in den Augen des Graphikers des 19. Jahrhunderts als barbarisch erschienene Stil wiedergegeben oder missverstanden wurde. Jüngst wurde klar, dass Miklós Szeremley 1847 zusammen mit einer Variante der Ansicht der Porta speciosa die drei Kapitelle von Máthes, deren Zeichnungen weitere Missverständnisse zeigen, veröffentlicht hat. ${ }^{40}$
Am interessantesten mag das verschollene dritte Kapitell (Abb. 29) gewesen sein, mit Geniefiguren auf den Ecken, deren nahe Verwandte sich am Sockel des Welfenkreuzes in Berlin befinden (Abb. 30) ${ }^{41}$ Beide finden ihre weder geographisch noch chronologisch entfernten Parallelen in den Geniereliefs von Wiligelmo, die in sekundärer Verwendung auf der Domfassade von Modena erscheinen (Abb. 31). Ikonographisch mag eines der Pfeilerkapitelle aus dem Marienstift von Székesfehérvár (Abb. 32) zu diesem Kontext gehört haben. ${ }^{42}$

\section{DER BAUPLASTISCHE SCHMUCK VON BAU II}

Durch die unerwartet auftauchende ikonographische Parallele mit dem Welfenkreuz und durch sein Verhältnis zur salischen dynastischen Repräsentation erhalten die Beziehungen, in denen der König von Ungarn zwischen dem Papst Gregor VII. und Kaiser Heinrich IV. balancierte, eine scharfe Beleuchtung. Die Entscheidung vom Verzicht auf die Investitur, die eine Wende bedeutete, wurde von den Gesandten König Kolomans von Ungarn 1106 auf der Synode von Guastalla erklärt. Diese Geschehen stehen im Hintergrund derjenigen stilistischen Verwandtschaft, die Esztergom mit der Architektur der mittelrheinischen Kaiserdome verbindet. Offensichtlich hängt das Löwenkapitell von Esztergom (Abb. 33) mit dem Südostportal von Mainz (Abb. 34) zusammen, wobei das Verhältnis der deutschen Denkmäler zu den vermutlichen norditalienischen und lombardischen

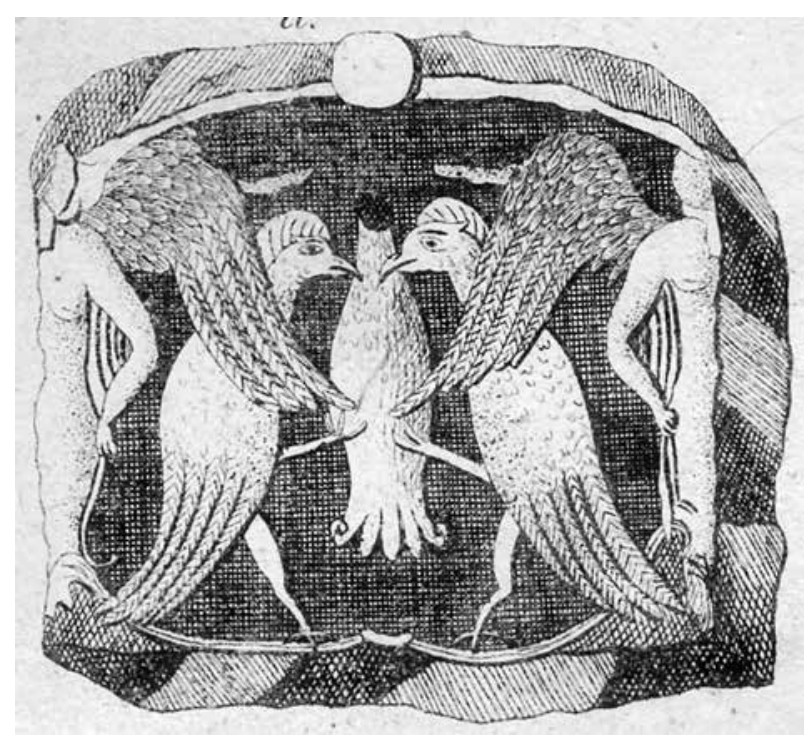

Abb. 29. Kapitell mit Raubvögeln und Engelsfiguren, Esztergom (Detail der Abb. 28)

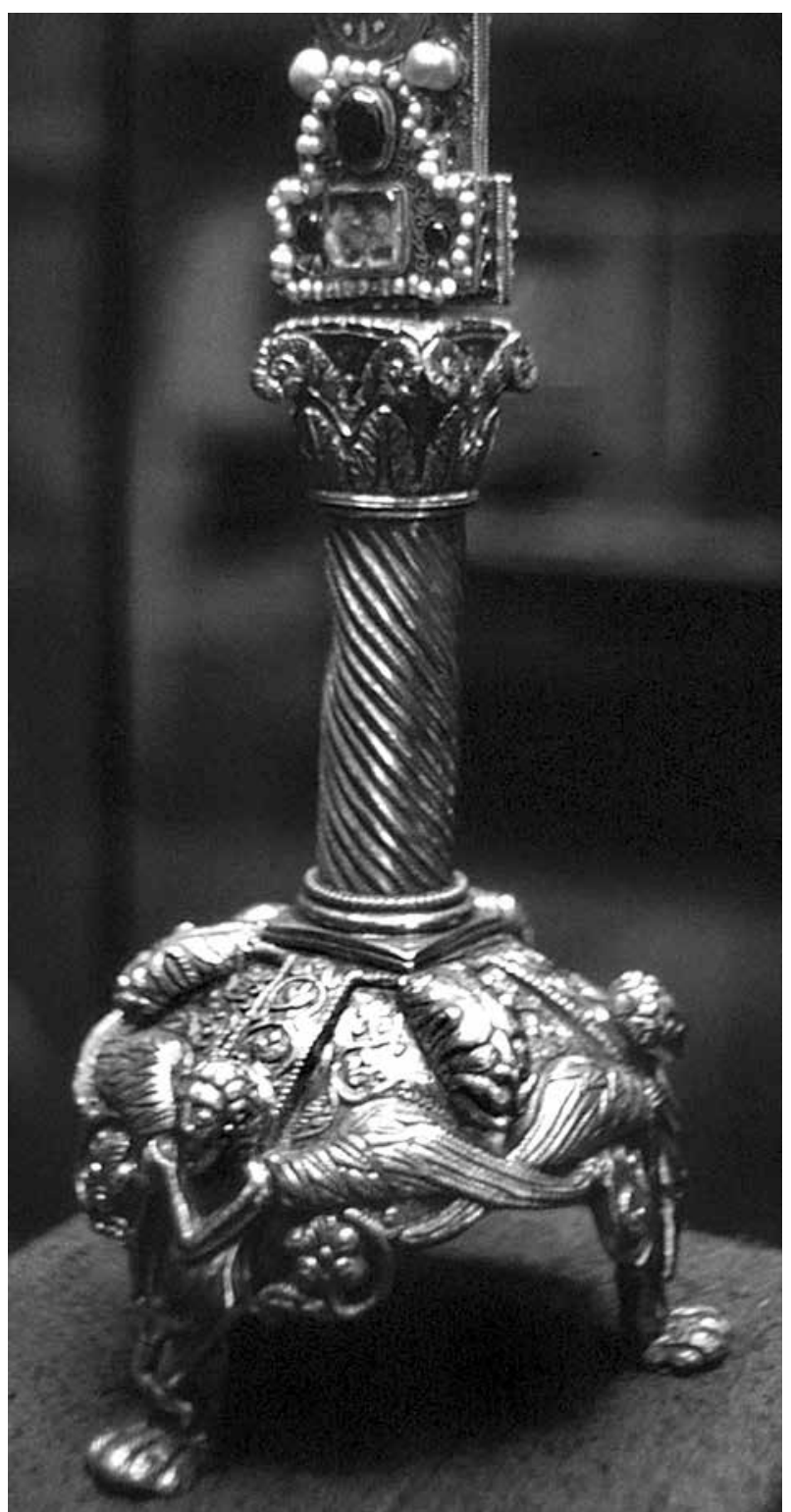

Abb. 30. Fuß des Welfenkreuzes. Berlin, Kunstgewerbemuseum 


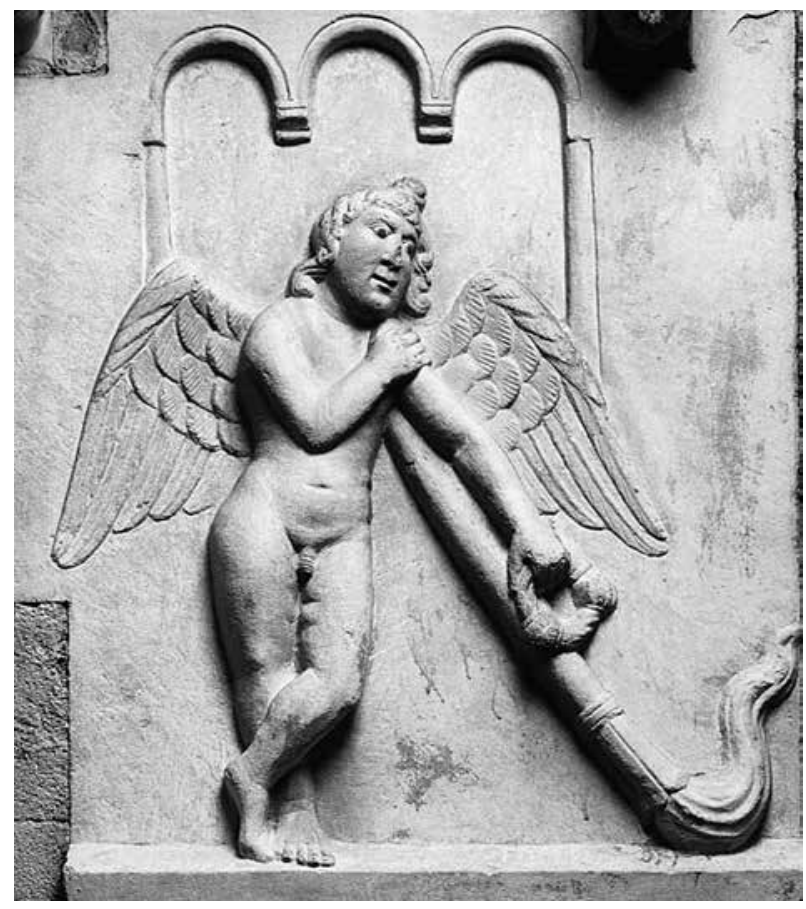

Abb. 31. Relief mit Genius, Modena, Dom, Westfassade (Foto: Imre Takács)

Vorbildern eine bis heute unentschiedene Frage darstellt. Die ältere ungarische Kunsthistoriographie hat das Quellgebiet des Stils in Italien - zum Beispiel in Vercelli, auf dem Kanzel von S. Giulio dell'Orta, in Pavia - gesucht. Die streng klassizisierende Stilvariante fehlt in Dömös. Sie kommt allein auf den beiden königlichen Stiftungen, außer Esztergom noch am Bau des St. Peter-Stifts in Óbuda, vor (Abb. 35; vgl. Abb. 36). In Óbuda handelt es sich aber um reine korinthische Formen, keine Vermischungen von korinthischen Kapitelltypen mit figürlichem Schmuck (Abb. 37). Dadurch wird die chronologische Stelle der Stilvariante auch bestimmt, denn die Beendigung des Baus von Óbuda sowohl mit der Güterschenkung des Königs Géza II. (1141-1162) aus dem Jahr 1148 als auch mit der Tradition zusammenhängt, nach der der Bau 1158 vom Erzbischof Martyrius (1151-1157) ${ }^{43}$ geweiht wurde. Klarer ist die Situation in Esztergom, wo die Urkunde der Donation, die Martyrius für die Gemeinschaft der Domherren 1156 anlässlich der Weihe des als Matutinaltar benutzten Marienaltars getan hatte, erhalten blieb. ${ }^{44}$ Dieser Altar stand vor der westlichen Chorschranke und hat in der öffentlichen Liturgie der Kathedrale eine zentrale Rolle gespielt, wie es aufgrund des spätmittelalterlichen Ordinarius ungefähr genau rekonstruierbar ist. Für die Raumverhältnisse des Chors und der Mittelapsis - wo sich auch der ältere Altar des Heiligen Adalbert befand -

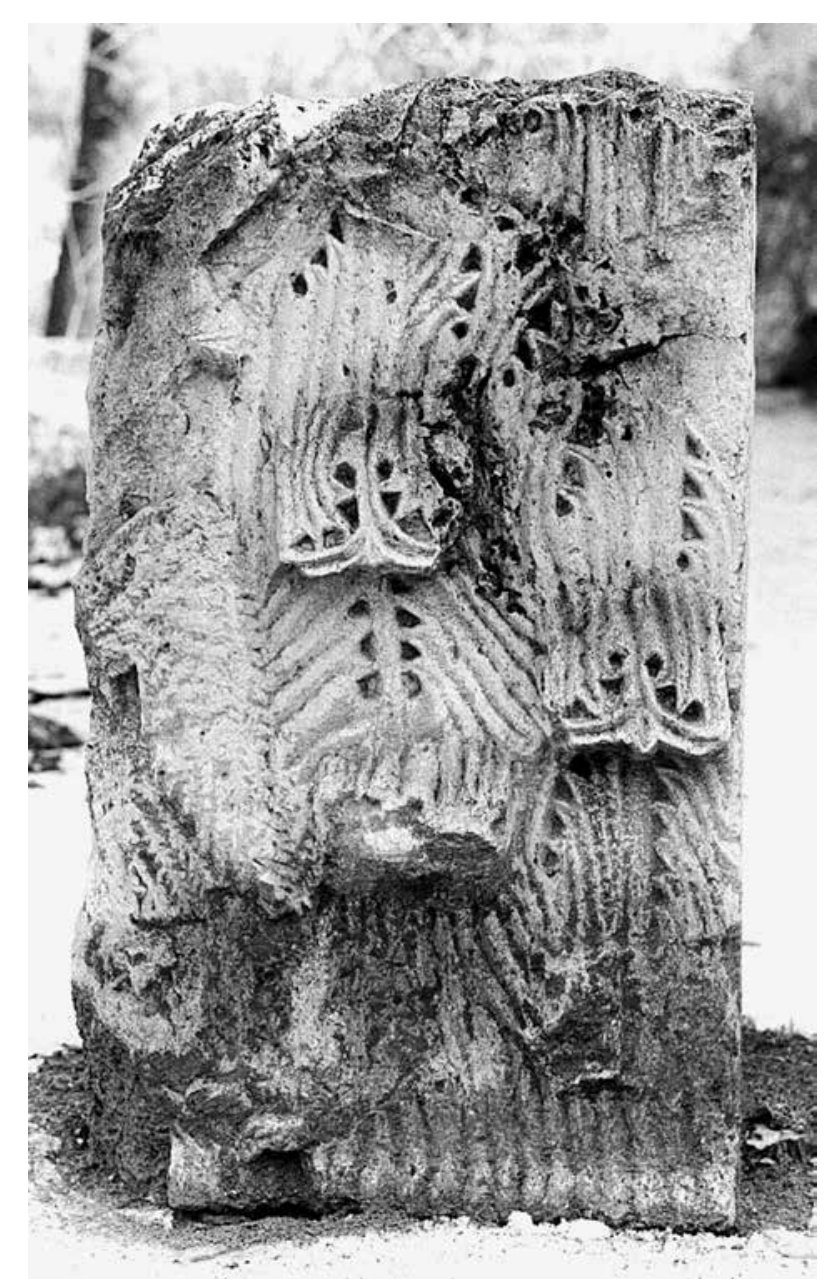

Abb. 32. Pfeilerkapitell mit dem Fragment einer geflügelten Figur. Székesfehérvár, Szent István Király Múzeum

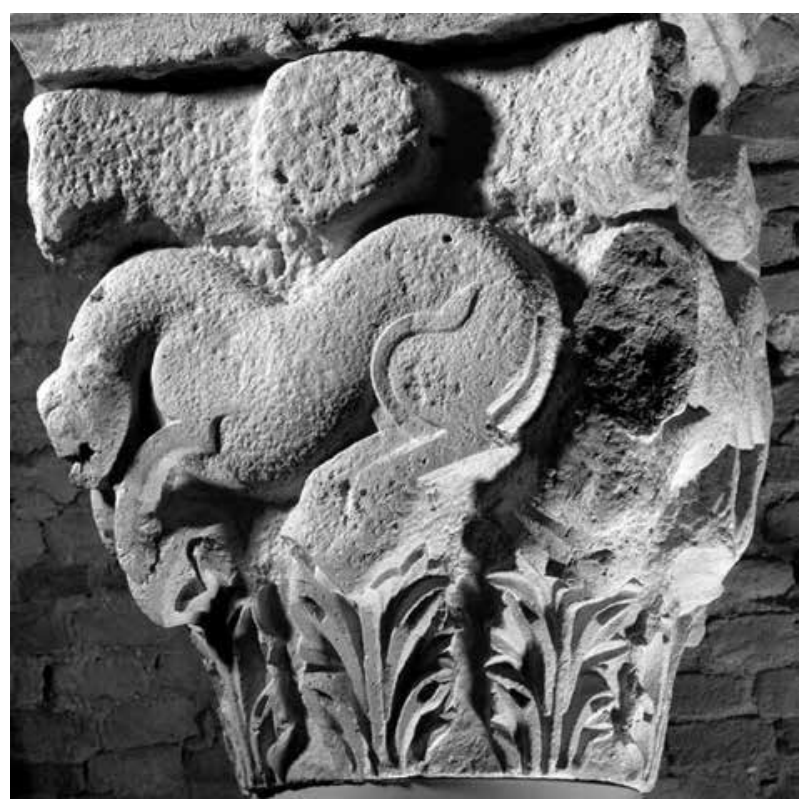

Abb. 33. Halbfertiges Löwenkapitell, Esztergom (vgl. Abb. 28) 


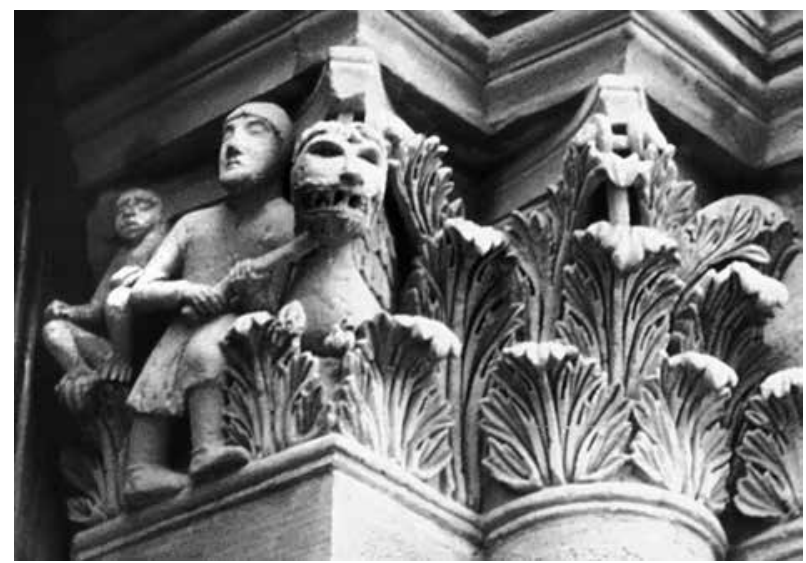

Abb. 34. Mainz, Dom, Südostportal, Gewändekapitelle

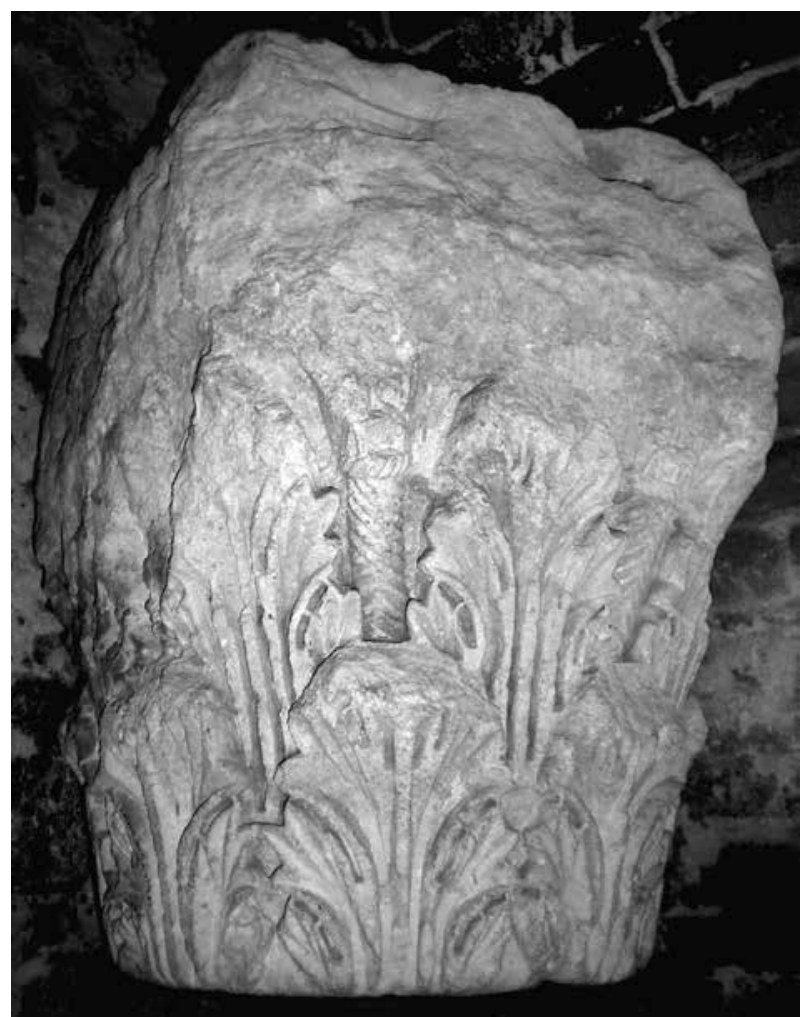

Abb. 35. Pfeilerkapitell aus Óbuda. Budapesti Történeti Múzeum (Historisches Museum Budapest)

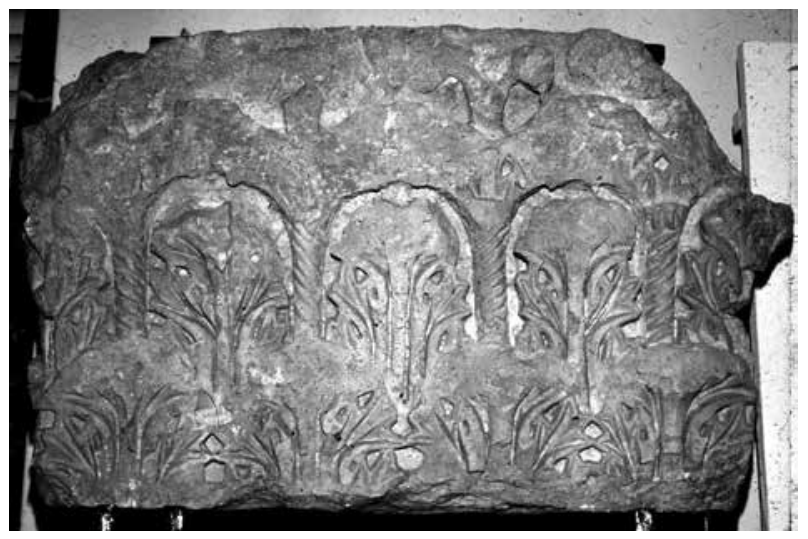

Abb. 36. Korinthisches Pilasterkapitell. Esztergom, Vármúzeum (Burgmuseum) (MARosi 1984, Kat. 8)

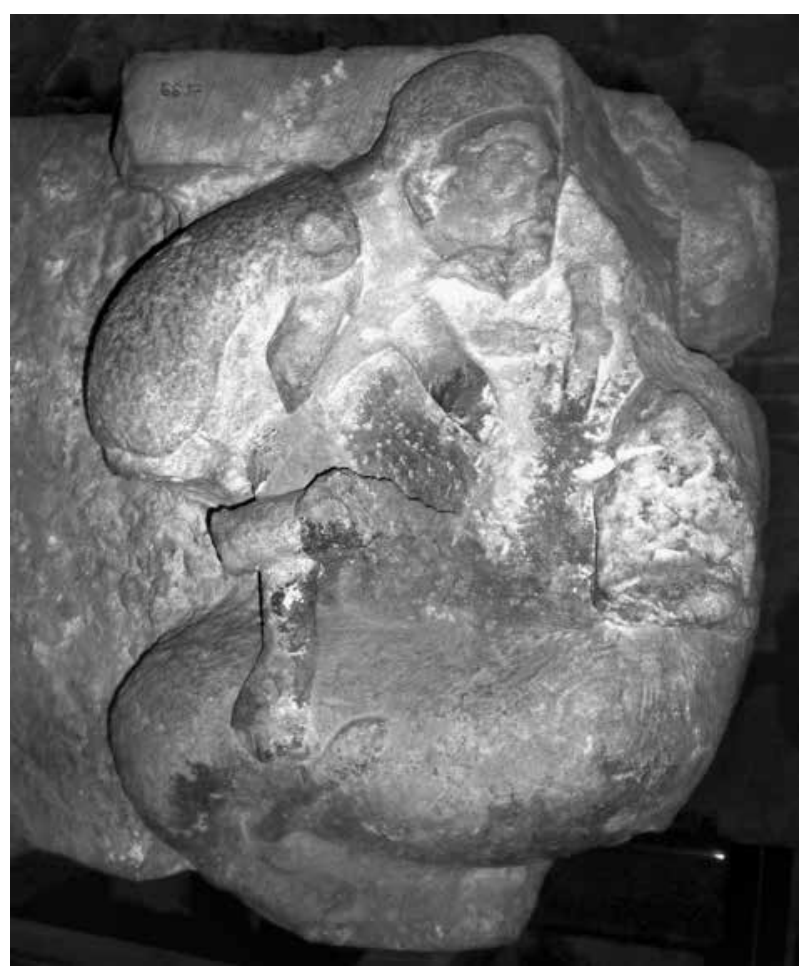

Abb. 37. Kapitell mit Tierkampf. Esztergom, Vármúzeum (Burgmuseum) (MAROSI 1984, Kat. 16)

nur eine Hypothese, denn die Pfeiler in den östlichen Langhauspartien um 1763, als der Máthes'sche Grundriss entstand, seit Langem nicht mehr zu sehen waren. Unmittelbare - wenn auch widerspruchsvolle - Dokumente belegen allein die Form der westlichen Pfeiler des Mittelschiffes. Unter den größten Pilasterkapitellen gibt es ein Paar, die in Scheitelhöhe einheitlich abgeschlossen werden, deren niederen Teile jedoch asymmetrisch - und zwar auf den beiden Stücken in umgekehrter Richtung - ausgebildet sind (Abb. 39-42). Während die Akanthusblätter der unteren 


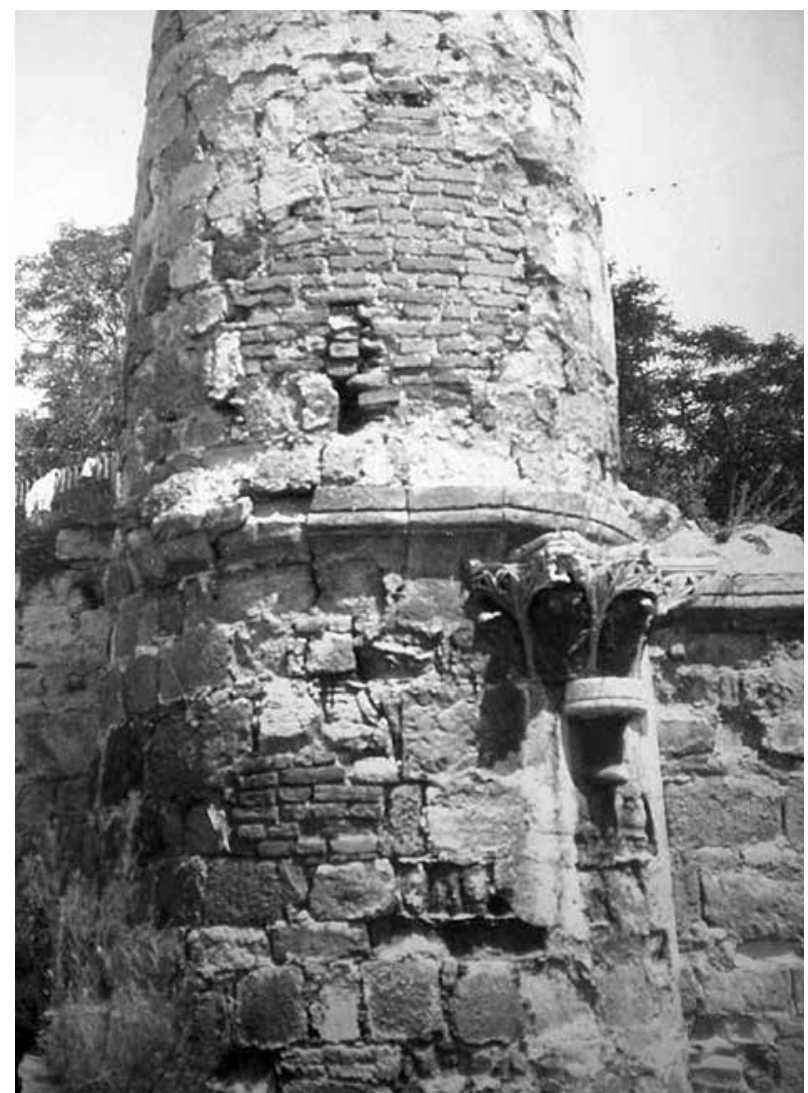

Abb. 38. Esztergom, Detail der Ostfassade der Burg mit korinthischem Kapitell (vgl. Abb. 37)

(Budapest, Fotothek des ehemaligen Denkmalamtes)
Reihe auf einer Seite unten abgeschlossen sind, mögen die Fortsetzung und ein Halsring auf der anderen ein separates Werkstück gewesen sein. ${ }^{47}$ Die nicht vollständig sichtbaren Akanthusblätter haben zu einem stärkeren Dienst gehört, während die vollständigen - und folglich niedrigeren - Akanthusblätter jüngere Vierteldienste gekrönt haben mögen. Der starke Vierteldienst war um $8 \mathrm{~cm}$ bzw. $12 \mathrm{~cm}$ stärker als der jüngere. ${ }^{48}$ Offensichtlich tragen die beiden Kapitelle die Spuren dessen, dass sie ehemals zu zwei unterschiedlichen Teilstrukturen gehört haben. Sie können wohl an einer höher liegenden Stelle angebracht gewesen sein, wo die Basis eines Dienstes tiefer als die des anderen lag. Verschiedene bauliche Situationen kommen in Betracht, zum Beispiel an der Grenze des erhöhten Chores oder eine Emporenöffnung etwa am Obergeschoss eines der Osttürme. Die Frage lässt sich auf Grund unserer Kenntnisse nicht lösen.

Es ist sicher, dass das vollständiger erhaltene Kapitell ( $A b b$. 39; heute im Ungarischen Nationalmuseum, Budapest) in den 1930er Jahren aus der Ostmauer des königlichen Palastes herausgelöst wurde. Es wurde als Kragstein unter einem türkischen Wachtturm angebracht, wohl bei der Ausbesserung der Schäden, die die Belagerungen der Burg zwischen 1595 und 1605 verursacht haben (Abb. 38). Deshalb kann angenommen werden, dass es von den Ostpartien der Kathe-

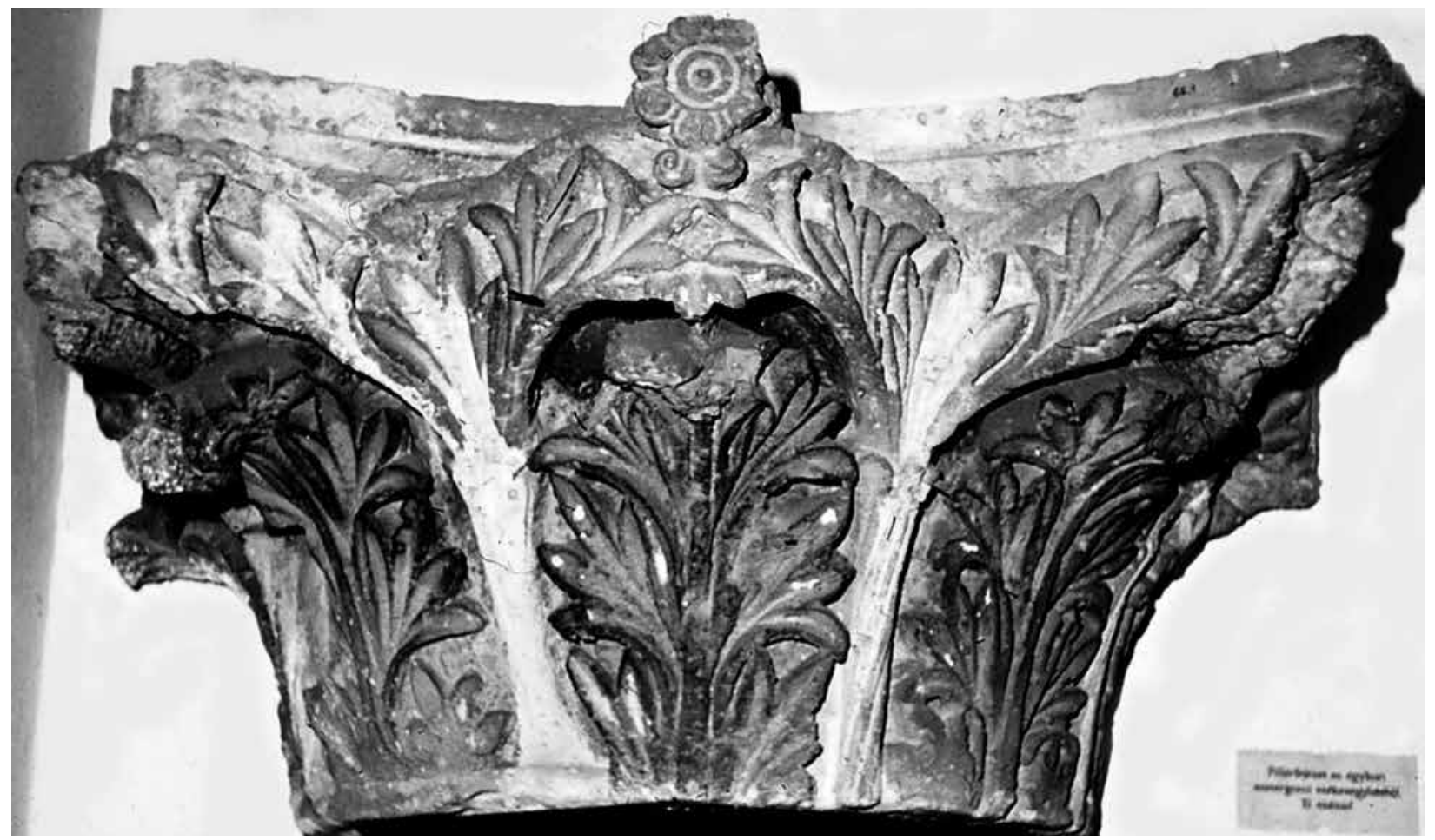

Abb. 39. Pilasterkapitell, Esztergom. Depositum im Ungarischen Nationalmuseum (Magyar Nemzeti Múzeum), Budapest (MAROSI 1984, Kat. 1) 


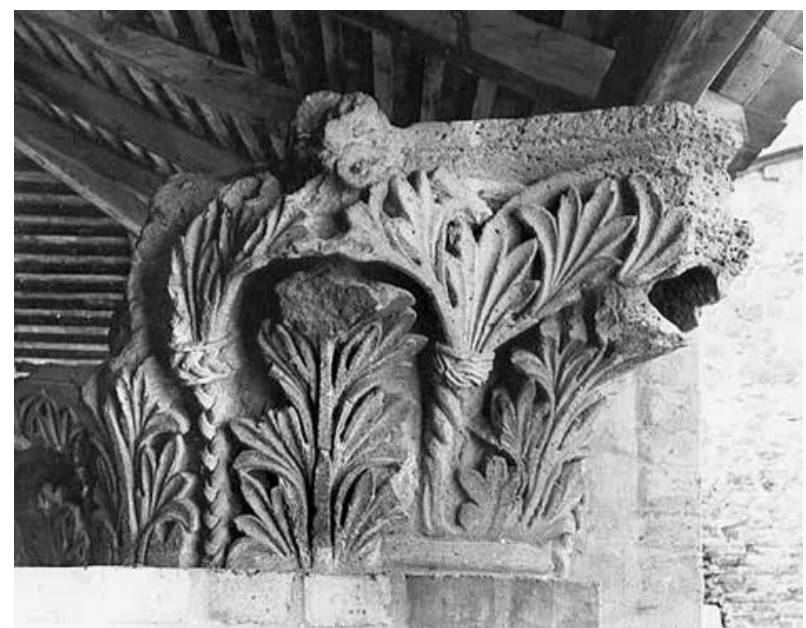

Abb. 40. Pilasterkapitell. Esztergom, Vármúzeum (Burgmuseum) (MAROsi 1984, Kat. 2)

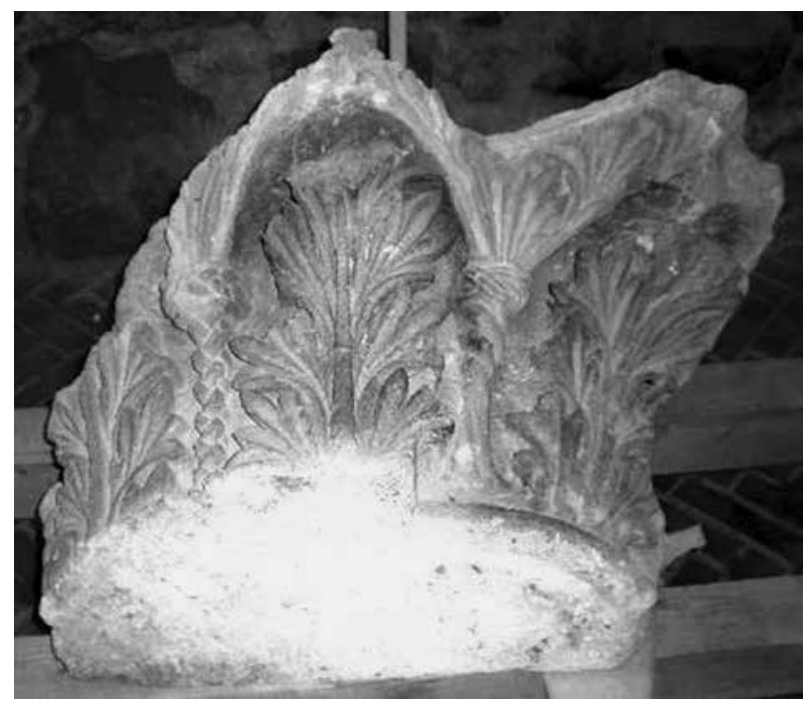

Abb. 41. Pilasterkapitell (vgl. Abb. 40), Untersicht
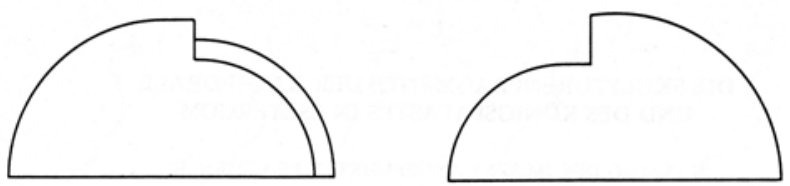

Abb. 42. Pilastergrundrisse (vgl. Abb. 39, 40) (nach MAROSI 1984)

drale stammt, die dem Artilleriefeuer mehr ausgesetzt und im 18. Jahrhundert weniger sichtbar waren. Auf Grund derselben Kriegsschäden, die diese Teile stärker als andere getroffen haben, lässt sich annehmen, dass das Wandgliederungssystem des Chores auf dem Máthes'schen Grundriss (Abb. 10) als eine Art Rekonstruktion aufgefasst werden kann, der die Pfeilerformen, die damals im westlichen Teil des Langhauses noch zu sehen waren, als Vorbilder gedient haben. Unter den Fragmenten, die wohl aus den Ostpartien

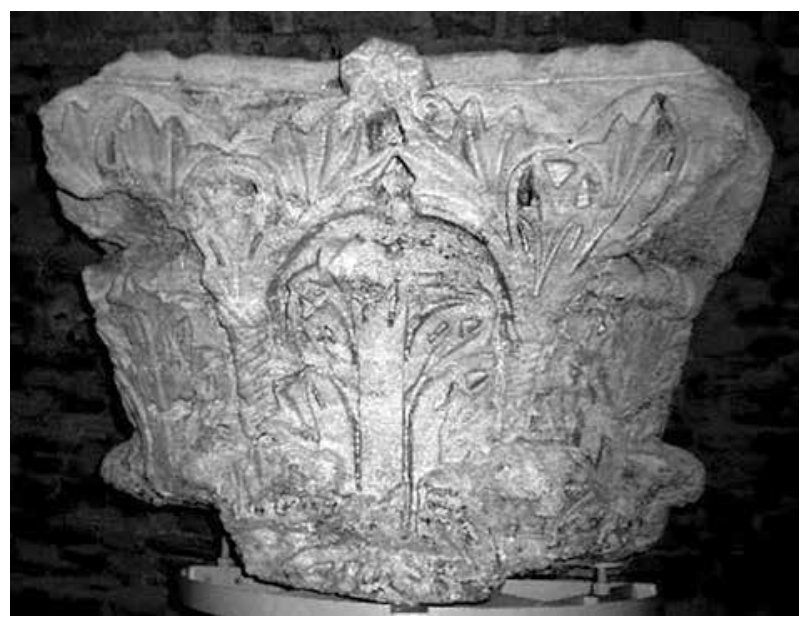

Abb. 43. Säulenkapitell. Esztergom, Vármúzeum (Burgmuseum) (MAROSI 1984, Kat. 3)

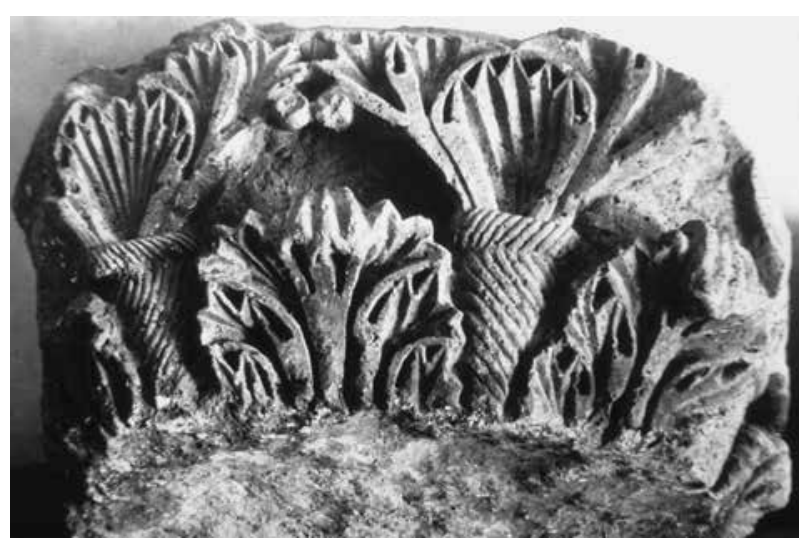

Abb. 44. Fragment eines Säulenkapitells, Esztergom, Vármúzeum (Burgmuseum) (MAROsi 1984, Kat. 8)

des Baus stammen, findet man außer den Pilasterkapitellen auch stilistisch verwandte Säulenkapitelle. Säulen- und Pilasterkapitelle sowie entsprechende Fragmente von Basen und Säulenschäften mögen darauf hinweisen, dass in dieser Bauphase - an der angenommenen Stelle, in den Arkaden des Chores - auch Rundsäulen (Abb. 43-44) eine Rolle gespielt haben. Gegebenenfalls mögen die Rundsäulen zusammen mit den Bündelpfeilern in einem Stützenwechsel alternierend verwendet gewesen sein. ${ }^{49}$

Die Kirchen des 11. Jahrhunderts wurden im 12. Jahrhundert ziemlich folgerichtig umgebaut. Dieser gewiss kostspielige Eingriff war in ganz Europa außer stilistischen und repräsentativen Gründen durch die Absicht einer festeren und feuersicheren, der römischen Tradition entsprechenden - kurz: monumentalen - Bauweise motiviert. Daher kann die Frage nach der Wölbung der Kathedrale von Esztergom auch mit Recht gestellt werden. Es gibt natürlich keine Gelegenheit mehr zur Beobachtung. Die erhaltenen, aus- 
schließlich dekorativen Steinskulpturen geben auch keinerlei Anhaltspunkte zu diesbezüglichen Schlussfolgerungen. In den Ostpartien waren die Apsiden und wahrscheinlich auch die Vorjoche der Seitenapsiden gewölbt. Nicht einmal die Wölbung des Chorjochs vor der ehemaligen halbkreisförmigen Apsis kann ausgeschlossen werden - hier kommt vor allem ein Tonnengewölbe wegen der Jochgliederung in schmalere querrechteckige Abschnitte in Betracht. Es scheint auf Grund der geometrischen Eigenschaften wahrscheinlich zu sein, dass ebenfalls ein Tonnengewölbe oder noch wahrscheinlicher eine flache Decke oder ein offener Dachstuhl über dem Chor errichtet wurde. Nach seiner Biographie, die im Sambucus-Kodex erhalten ist, ließ der Erzbischof Csanád Telegdi gleich nach seiner Einsetzung im Jahr 1329 den Chor der Kirche neu bauen und cum gloriosa testudine wölben. Hier handelt es sich aber allein um die Decke des ganzen Gebäudes. ${ }^{50}$ Es ist eine offene Frage, ob allein das Sanktuarium aus diesem Anlass gewölbt wurde, weil der Chor bereits eine Wölbung hatte. Von den großen Pilasterkapitellen mögen oberhalb des Mittelschiffes Gurtbögen ausgegangen sein. Eine andere Frage ist diejenige nach der Wölbung der Seitenschiffsjoche am wahrscheinlichsten durch Kreuzgewölbe -, was bereits im 12. Jahrhundert in Frage kommt, deren Vorhandensein jedoch nicht belegt ist.

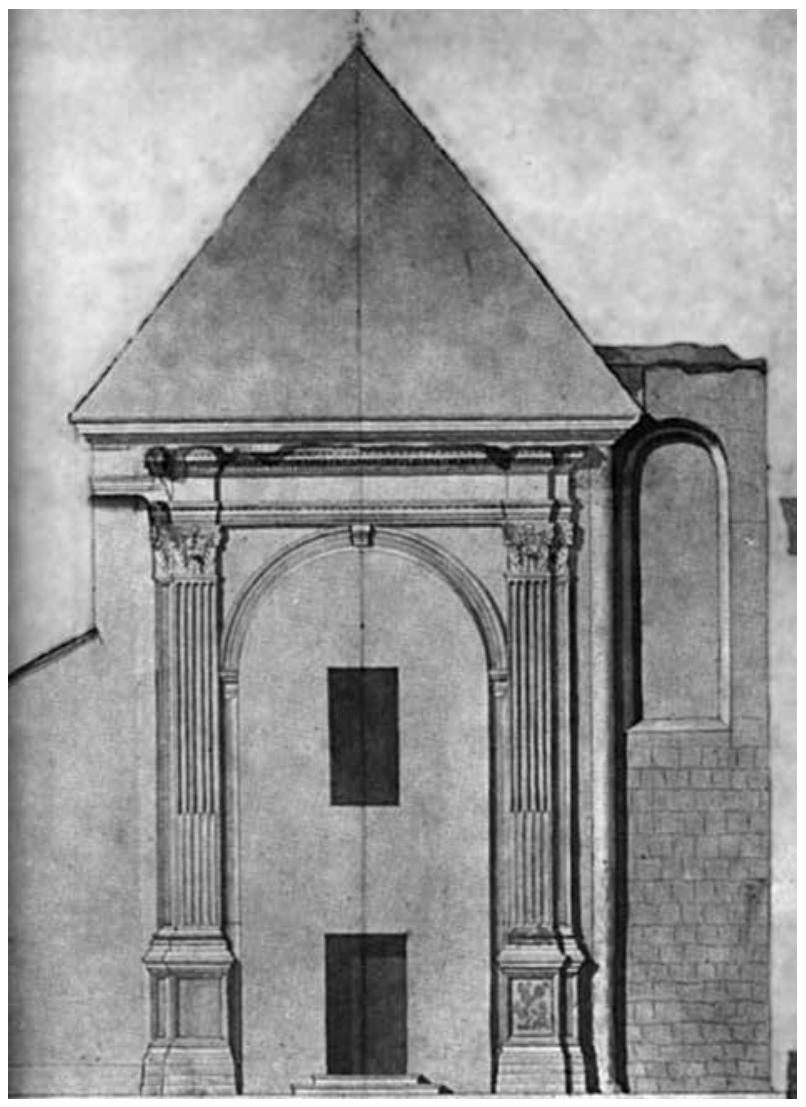

Abb. 45. Johann Baptist Packh: Zeichnung der einstigen Fassade der Bakócz-Kapelle in Esztergom, 1826. Budapest, Szépmúvészeti Múzeum (Balogh 1955, Abb. 51)

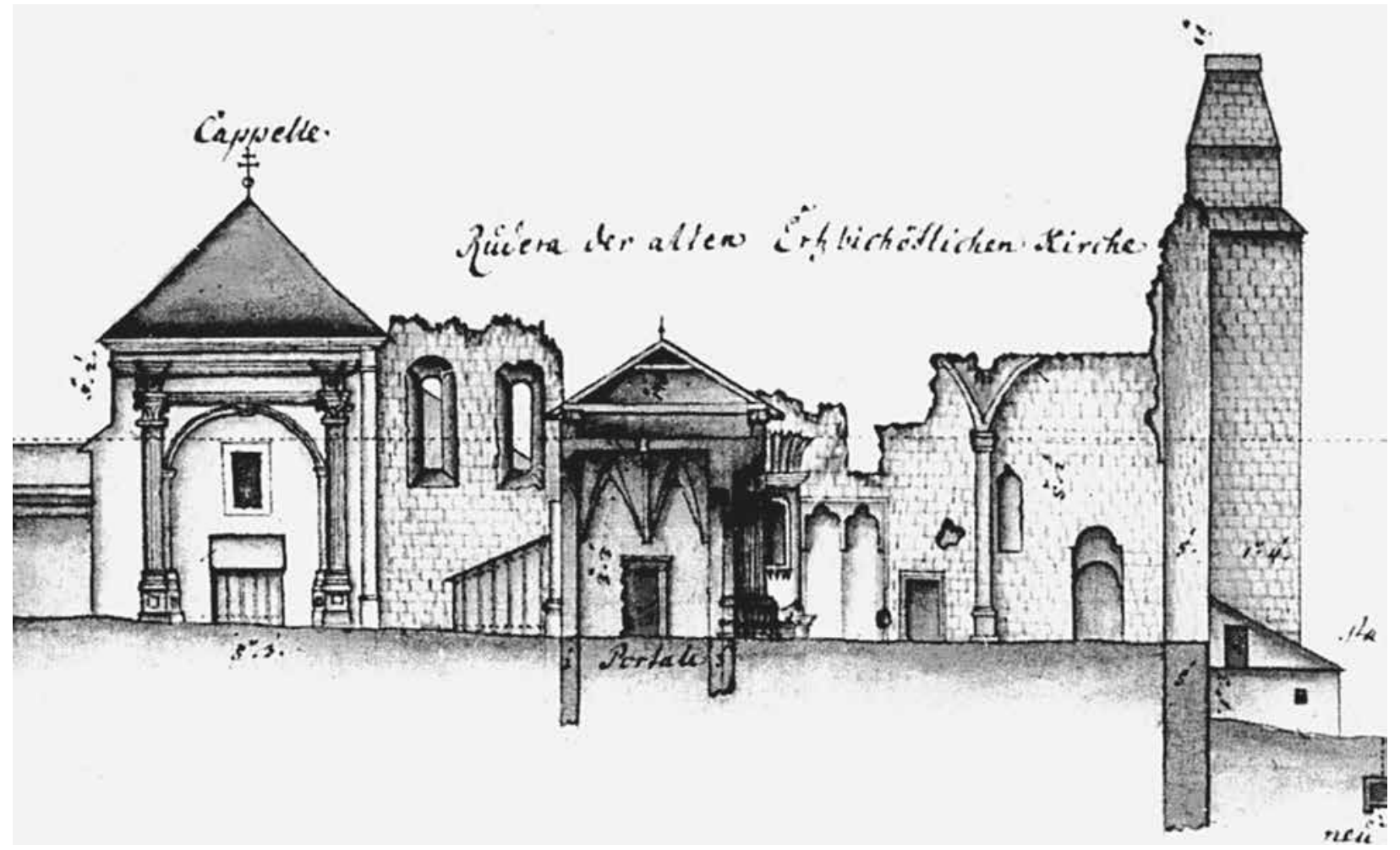

Abb. 46. Andreas Krey: Längsschnitt der Kathedrale von Esztergom, 1756 (Detail der Abb. 2) 
Auch die Darstellungen der drei tieferen, beinahe quadratischen westlichen Joche des Mittelschiffes, die möglicherweise einer Kreuzwölbung entsprachen, liefern eine eher widersprüchliche Zeugenaussage. Die Zeichnung des Johannes Pákh mit dem Pilaster westlich vom Eingang der Bakócz-Kapelle (Abb. 45), die Sándor Tóth im Kontext der Westteile der südlichen Langhauswand behandelt hat, widerspricht zum Beispiel den konventionellen Zeichen von Wandvorlagen, die man auf dem Máthes'schen Grundriss (Abb. 10) hier findet, wohl nicht aber der Langschnitt-

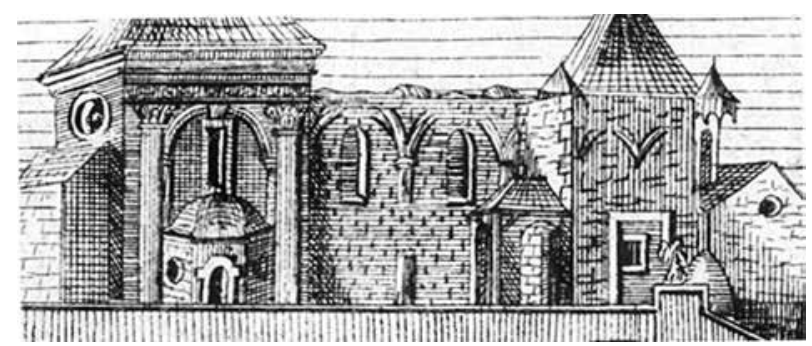

Abb. 47. Die Ruinen der Kathedrale von Esztergom von Norden (Máthes 1827: Detail der Abb. 3)

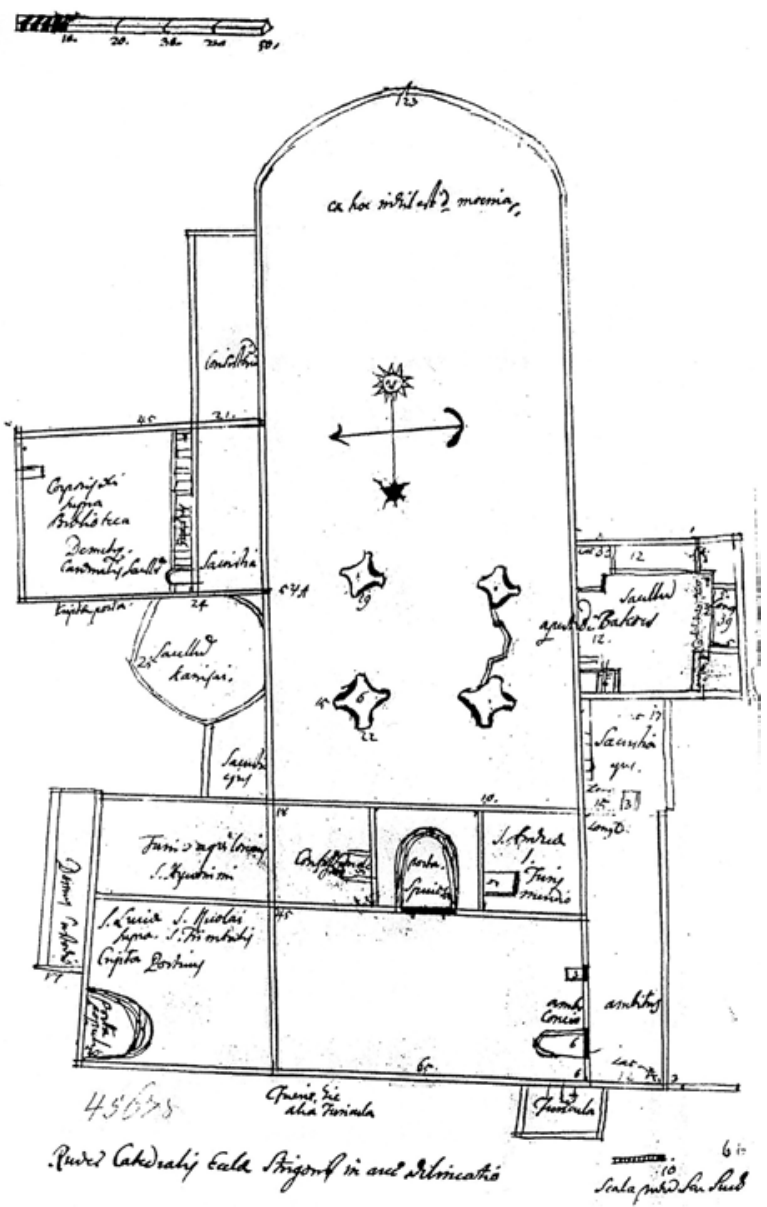

Abb. 48. György Széless: Grundrissskizze der Ruinen der Kathedrale von Esztergom, Federzeichnung, 1759
Zeichnung des Andreas Krey von 1756 (Abb. 46). Dem größten Widerspruch begegnet man zwischen der Aufnahme von Krey mit zwei Fenstern und ohne innere Wandgliederung einerseits und andererseits der Ansicht (Abb. 47), die Máthes von dem letzten Überrest dieses Details 1827 veröffentlicht hat. Diese Letztere zeigt einen wandgliedernden Pilaster und Reste von Schildbögen, die auf eine Wölbung des Seitenschiffes hinweisen. Leider handelt es sich hier um eine willkürliche Erweiterung des Gesehenen. Es ist klar, dass Krey, wenn er die Spuren der Wölbung gesehen

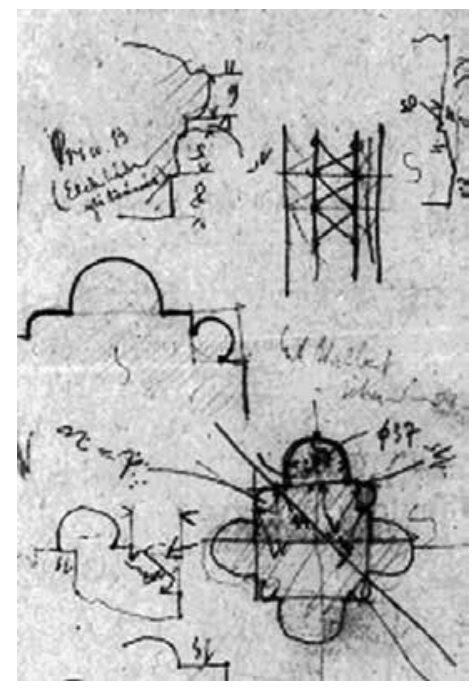

Abb. 49. Dezsô Várnai: Die Pfeiler der Kathedrale von Esztergom (nach Havasi 2008)

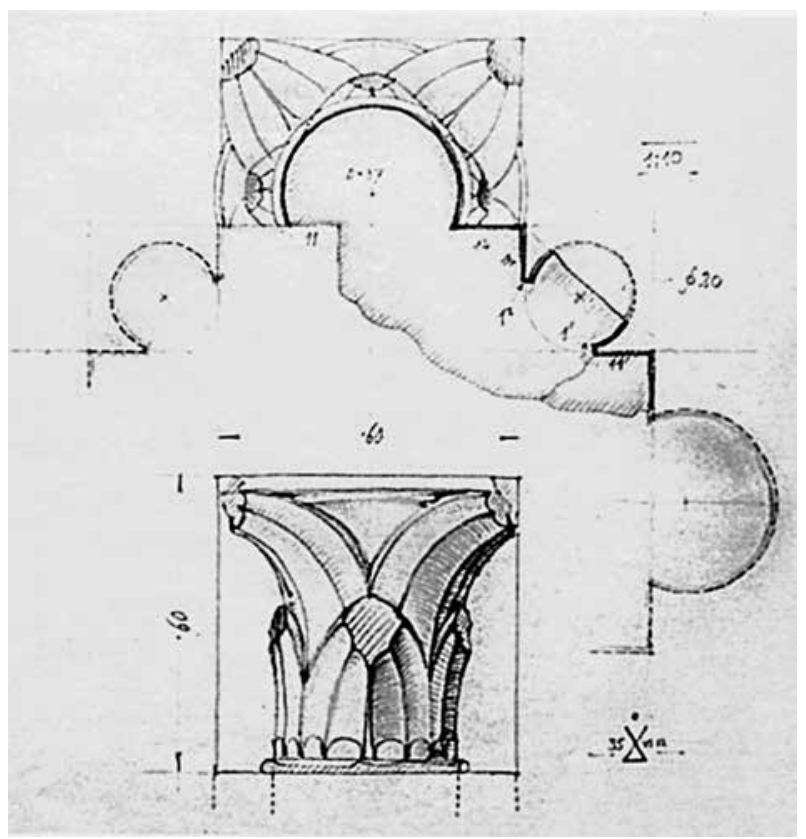

Abb. 50. Dezsô Várnai:

Die Pfeiler der Kathedrale von Esztergom (Budapest, Planarchiv des ehemaligen Denkmalamtes) 

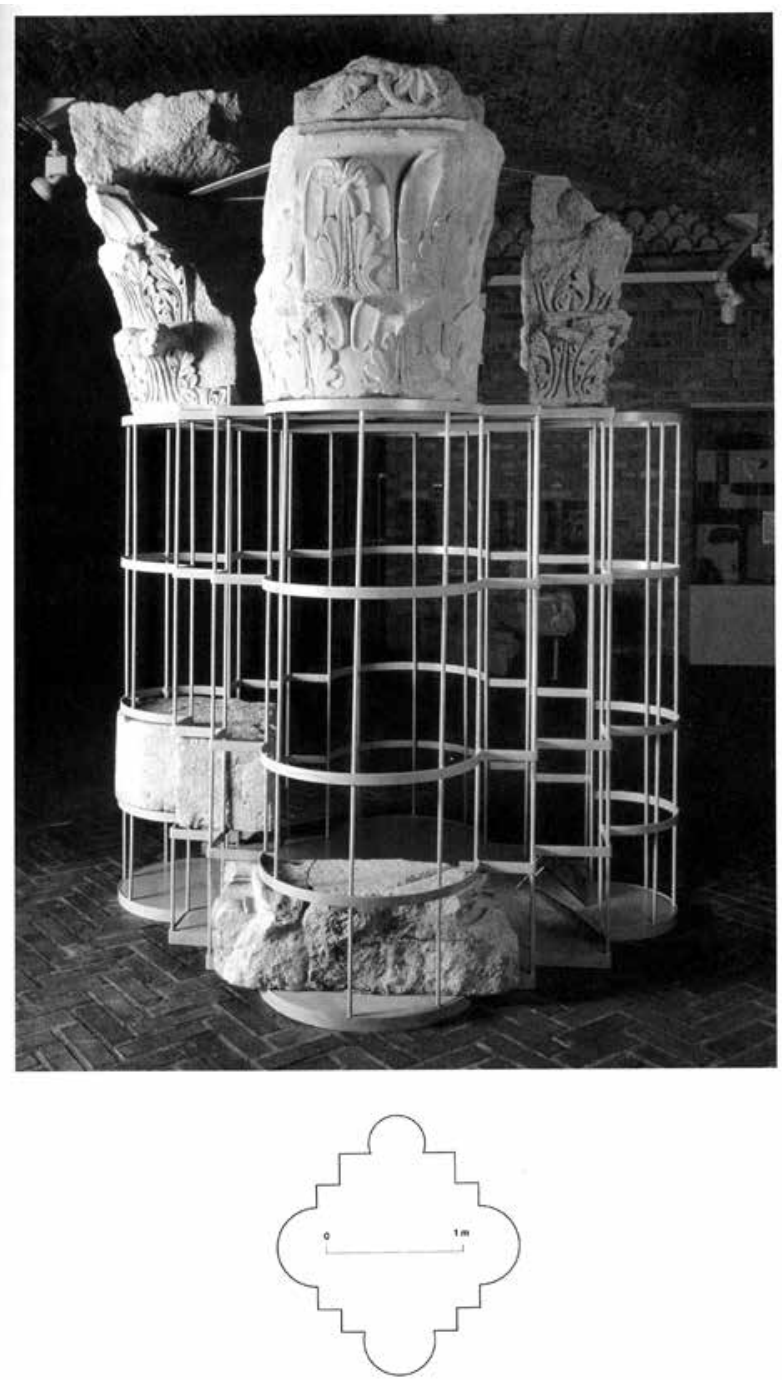

Abb. 51. Pfeilerrekonstruktion. Esztergom, Vármúzeum (Burgmuseum)

hätte, hätte sie ebenso dargestellt, wie ähnliche Details der Südwand der westlichen Vorhalle.

Die größte Authentizität kann man immer noch der dilettantischen Grundrissskizze zuschreiben, die Georg Széless 1759 gezeichnet hat (Abb. 48). In seiner Zeichnung wird die Disposition der Räume des Westteils und inschriftlich auch ihre Funktion angegeben. Bei dem Turmpaar behielt Széless - wie Krey und die Lithographie von 1827 - die spätmittelalterlichen Vermauerungen und Wölbung (bzw. deren Spuren), während die Räume unter den Türmen auf dem Máthes'schen Grundriss mit offenen Arkaden dargestellt - praktisch rekonstruiert - sind. Máthes' Zeichnung zeugt von einer gewissen Kenntnis darüber, wie der mittelalterliche Zustand ausgesehen bzw. auszusehen hatte. Wie vage hingeworfen und auch verpfuscht die mit vier Halbsäulen versehenen Schiffspfeiler bei

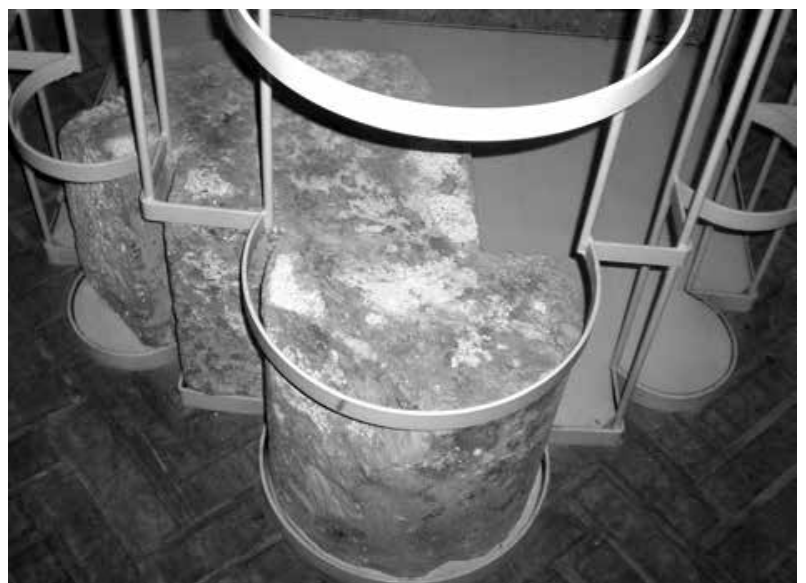

Abb. 52. Detail der Pfeilerrekonstruktion (vgl. Abb. 50)

Széless aussehen, mögen sie allein der Wahrheit entsprechen. In seinem Text hat Széless in diesem Kontext über vierpassförmige (!) Rosetten geschrieben. Jüngst hat Krisztina Havasi in einer äußerst gründlichen Analyse zwei Typen der in der Spätromanik in Ungarn als „idealtypisch“ geltenden Bündelpfeiler (Abb. 49-50; vgl. Abb. 52) unterschieden. Der erste Typ, zu dem auch die Pfeiler von Esztergom gehört haben, wird durch einen Kern über dem Grundriss in der Form eines um vier Halbsäulen erweiterten griechischen Kreuzes gekennzeichnet. Im zweiten Typ - im Zisterzienserbau von Pilis - wurden die quadratischen Pfeilerblöcke mit Dreivierteldiensten auf den Ecken versehen. ${ }^{51}$ Die erstere, weit verbreitete Form wurde in der neuesten Einrichtung des Lapidariums des Burgmuseums von Esztergom gezeigt. Die ähnlichen, aber keineswegs zusammengehörenden, in den Maßen auch unterschiedlichen Bruchstücke erschienen jedoch im Zeichen einer falsch verstandenen Anschaulichkeit (Abb. 51-52). Dieser Installation haben vor allem die Überreste von Bündelpfeilern als Quelle gedient, denn diese standen in größerer Menge als andere Materialien zur Verfügung.

Die Details bezeugen, dass sich diese Bauskulpturen - vor allem was die Verwendung von korinthisierenden Kapitelltypen betrifft - einerseits nach dem im östlichen Teil der Kirche vorherrschenden klassizisierenden Charakter orientiert haben (Abb. 53-55; vgl. $A b b$. 58). Andererseits ist es klar, dass dieselbe Werkstatt an der Kathedrale tätig war, die auch am Palastbau vom König Béla III. Mit gewissem Recht kann man auch eine längere Pause zwischen der Fertigstellung des Chors der Kanoniker um 1156 und dem Nachfolgebau vermuten. Für die Datierung der Bauarbeiten am königlichen Palast gibt es keine schriftlichen Belege. Béla III. kommt als Bauherr in Frage, denn er hatte 


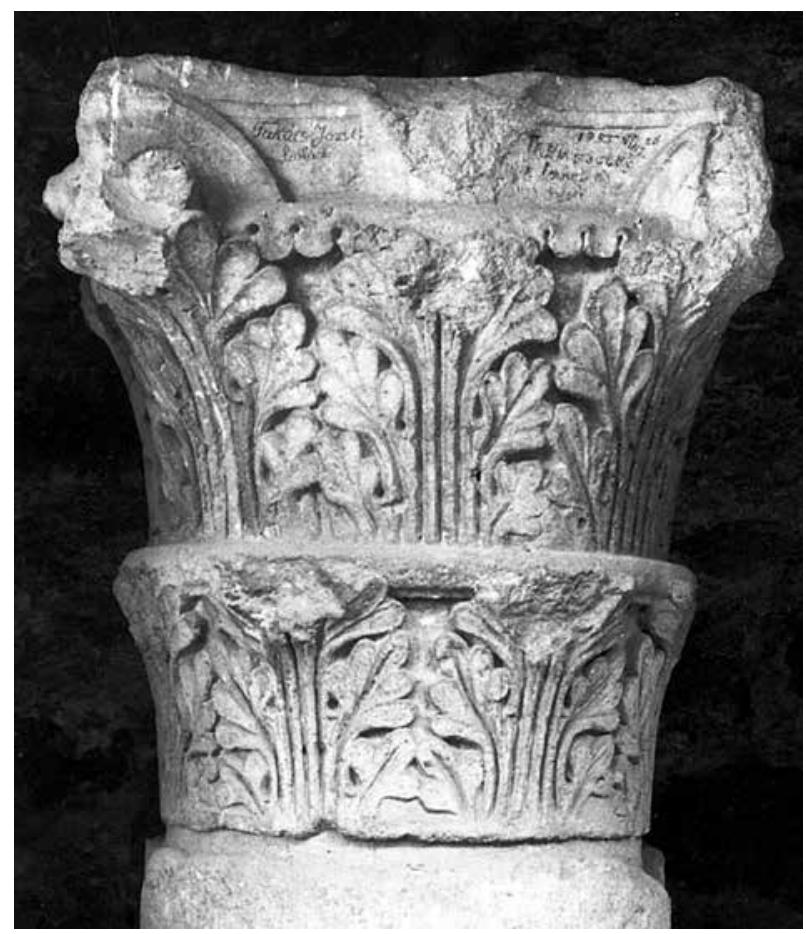

Abb. 53. Pilasterkapitell der Kathedrale von Esztergom. Esztergom, Vármúzeum (Burgmuseum) (Marosi 1984, Kat. 19)

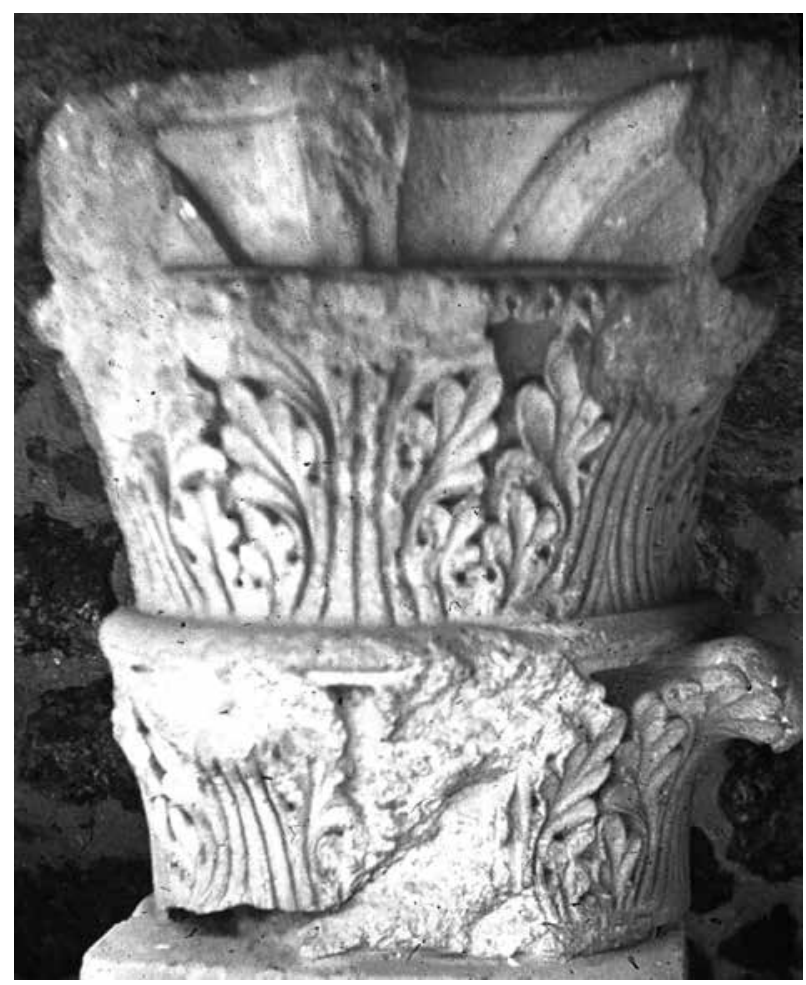

Abb. 54. Pilasterkapitell der Kathedrale von Esztergom. Depositum im Ungarischen Nationalmuseum (Magyar Nemzeti Múzeum), Budapest (MAROSI 1984, Kat. 20)

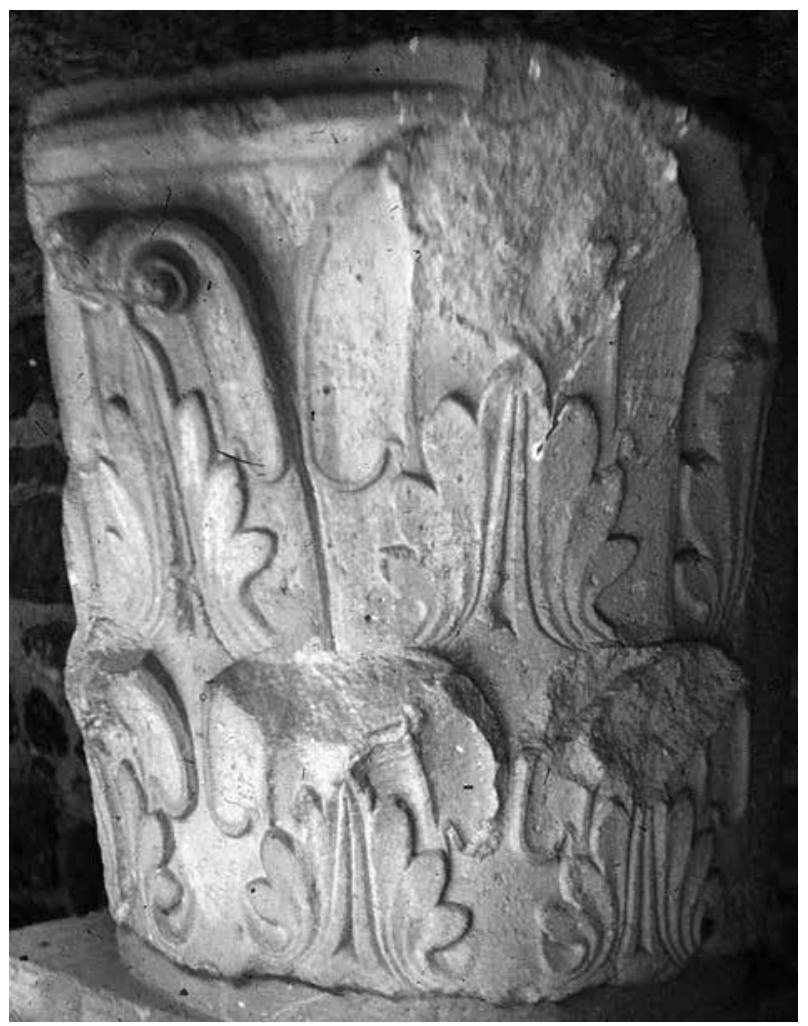

Abb. 55. Pilasterkapitell der Kathedrale von Esztergom, Vármúzeum (Burgmuseum) (MAROSi 1984, Kat. 18)

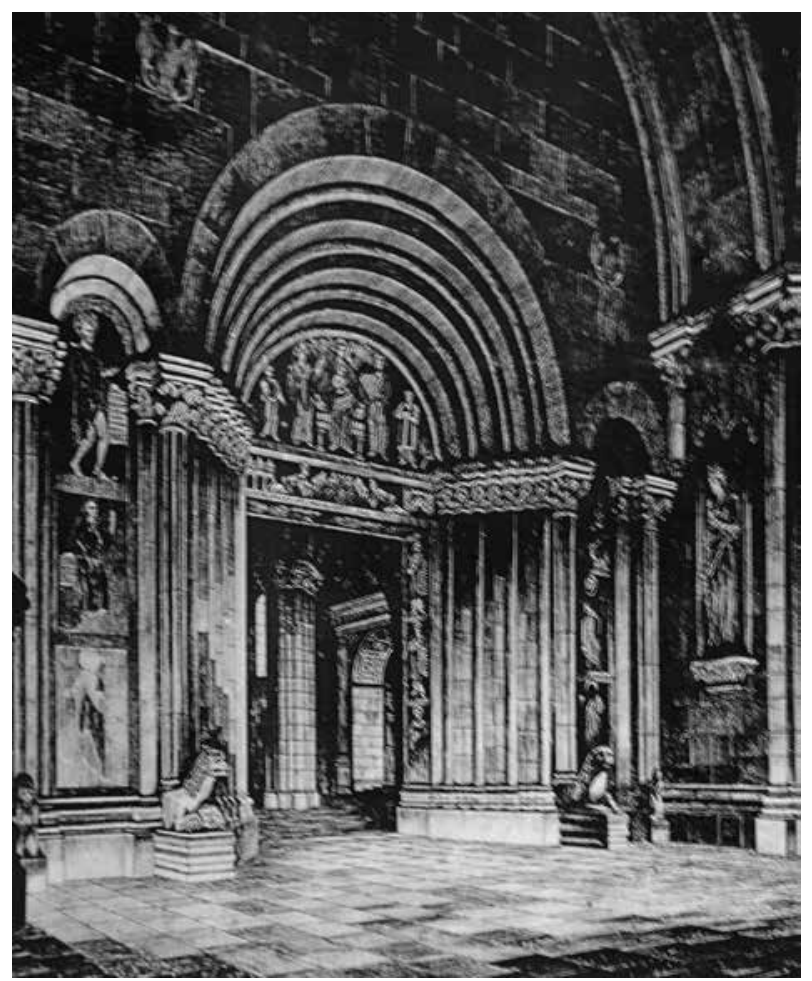

Abb. 56. Kálmán Lux:

Rekonstruktionszeichnung der Porta speciosa (vgl. Abb. 8) 


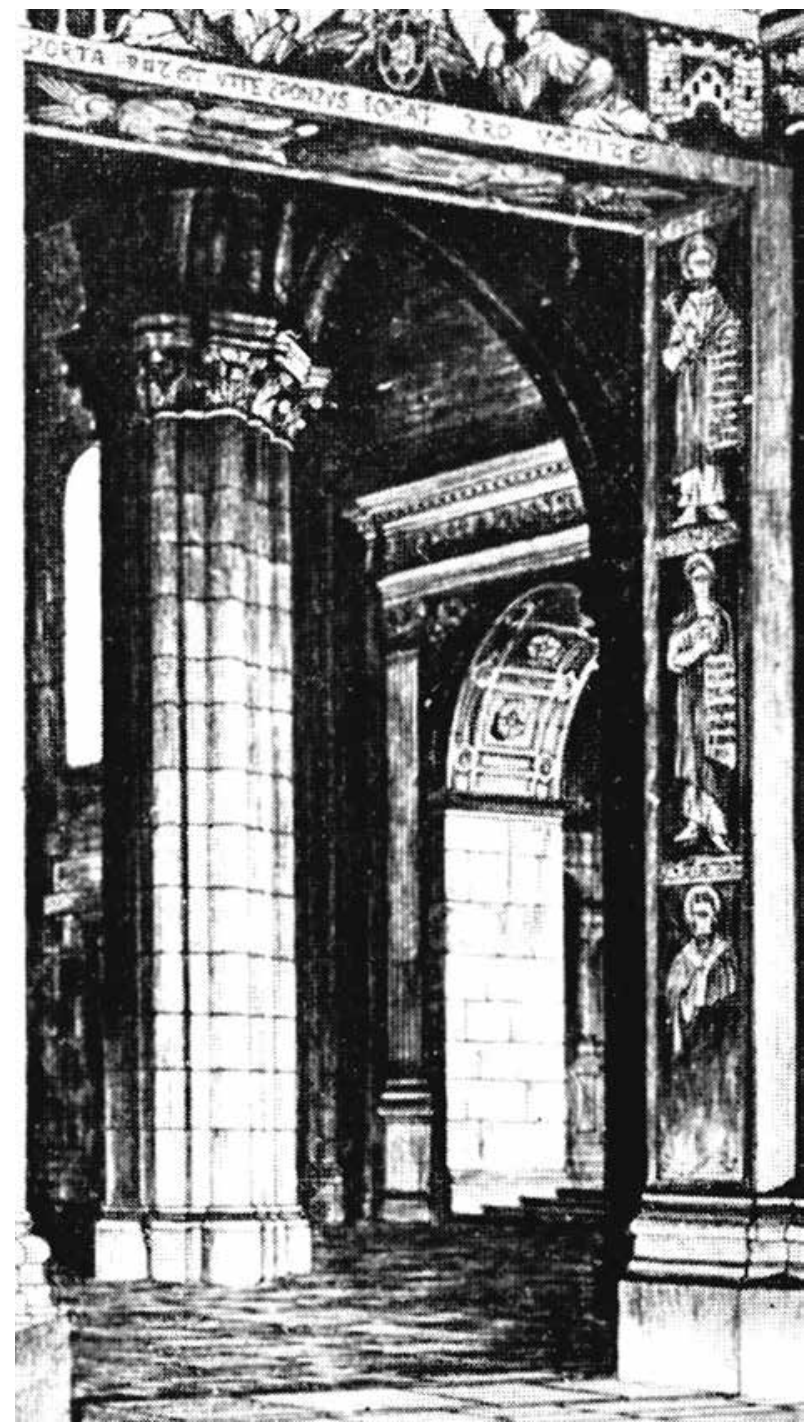

Abb. 57. Kálmán Lux: Rekonstruktionszeichnung der Porta speciosa, Detail

nach den chaotischen Regierungen der kurzlebigen Nachfolger von Géza II. eine konsolidierte Herrschaft - in den Augen von Betrachtern des 13. Jahrhunderts hatte er sogar das Attribut "Groß" verdient -, und weil er 1189 Kaiser Friedrich I. Barbarossa auf seiner Kreuzfahrt wohl hier empfangen hat. All dies ist als Grundlage einer Datierung freilich zu wenig. Im königlichen Palast findet man die meisten mit der Bauplastik der Kathedrale stilistisch verwandten Details im zweistöckigen Anbau, der südwestlich an den "Weißer Turm“ genannten Bergfried gebaut wurde, also wohl aus der früheren Periode des Palastbaus. Auf der anderen Seite muss man mit dem besonders in der früheren Periode seiner Regierung ausgesprochen feindlichen Verhältnis zwischen König Béla und dem Erzbischof Lukas (1158-1181) rechnen, einem hartnäckigen Vertreter der gregorianischen Reform und ehemaligem Pariser

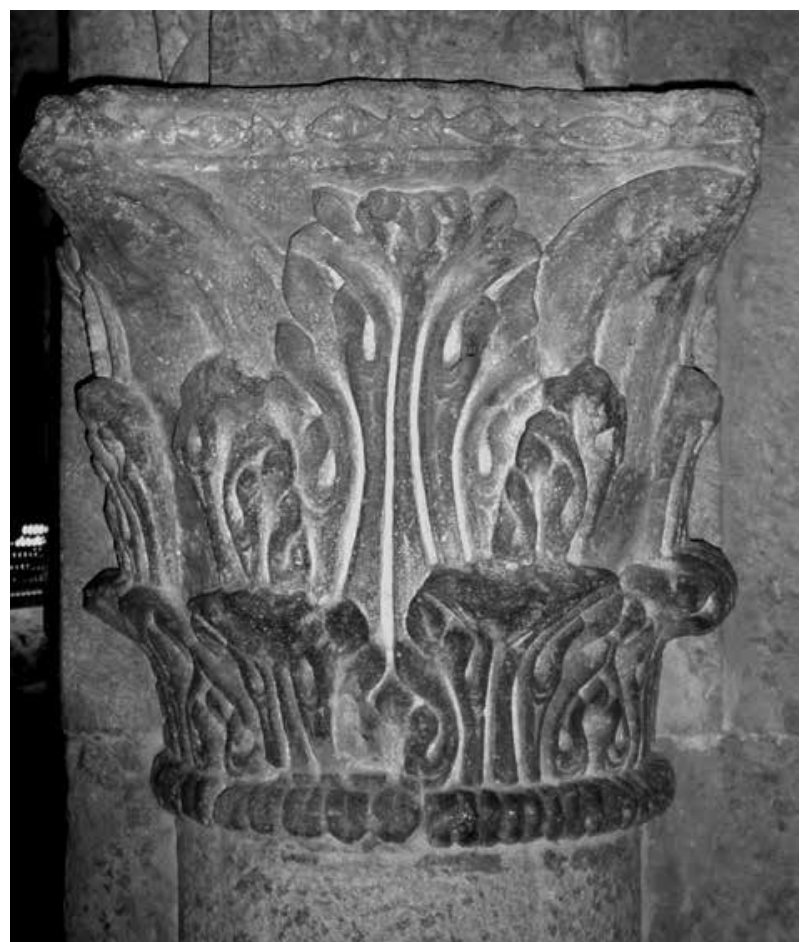

Abb. 58. Esztergom, königlicher Palast, „St. Stefanssaal“, Pilasterkapitell

Schulfreund des Thomas Becket von Canterbury. Der Anfang der 1180er Jahre würde als Ausgangspunkt für diese Bauchronologie prächtig entsprechen. Nach der Zeit der Spannung mit Lukas könnte man mit dem Palastbau wohl in der Periode begonnen haben, als Erzbischof Job, ein hoher Kleriker, der in ausgesprochen freundlichem Verhältnis zum König stand, ab Mitte der 1180er Jahre den Sitz von Esztergom innehatte. Sie wurden am Türsturz des Westportals, der Porta speciosa, als Vertreter von Regnum und Sacerdotium zusammen dargestellt (Abb. 4, 8, 56-57). ${ }^{52}$ Diese Stifterdarstellung galt wohl nicht nur für das Westportal, sondern den ganzen Westbau der Kathedrale.

Charakteristische Formelemente des gemeinsamen Stils der Westteile der Kathedrale und des Einstützenraums des Palastes (,St. Stephanssaal“) sind größere Pilasterkapitelle (Abb. 53-55) bzw. kleinere Kapitelle von Wandvorlagen mit den Reihen von einander schuppenartig bedeckenden rundlichen Blättern des Kompositkapitells (Abb. 58). Die Blätter wurden in einer sehr feinen Verwendung der Bohrtechnik bearbeitet. Hinter den Blätterreihen wachsen oben, an Stelle der korinthischen Voluten - gelegentlich oberhalb eines profilierten Rings, der den Abschluss des Unterteils bildet - zungenförmige Blätter, die oft in Knospen auslaufen, ähnlich wie auf frühgotischen Kapitellen. Zur Gruppe dieser Kapitelle gehört ein 


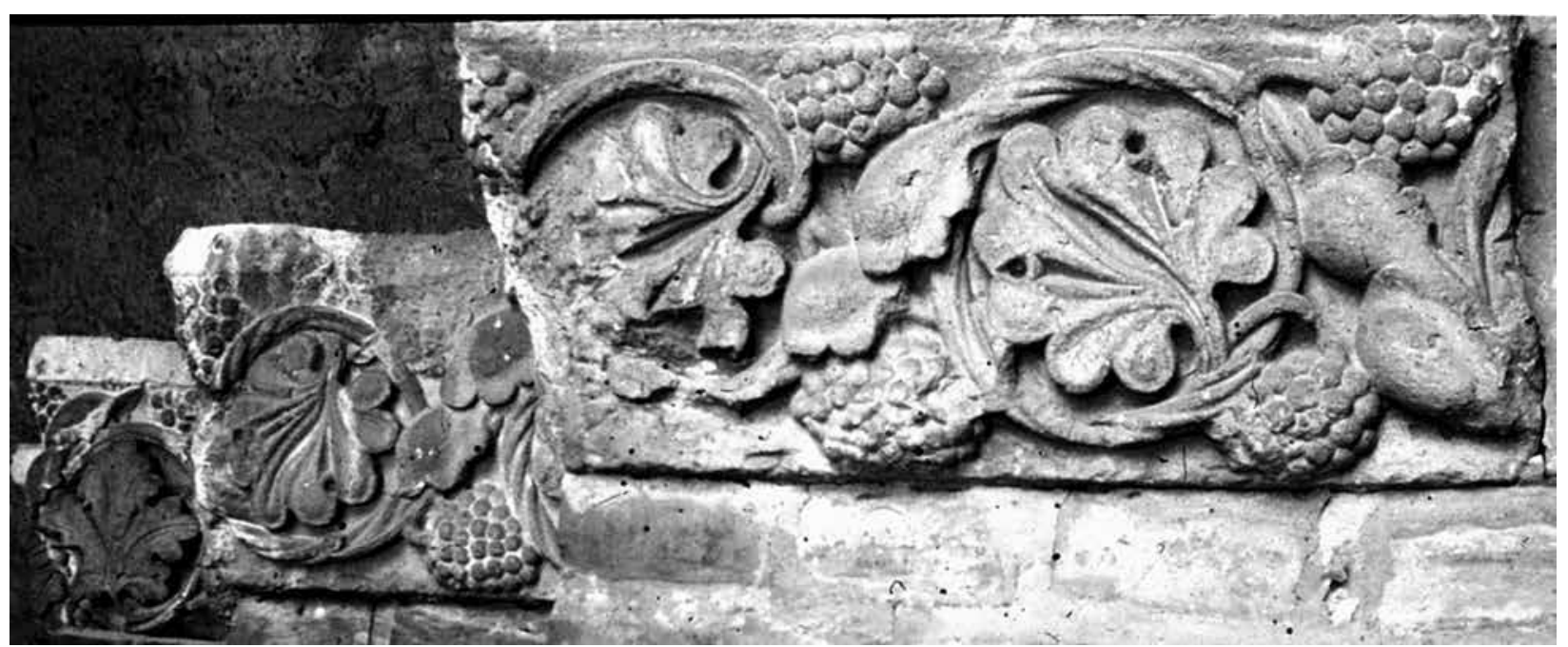

Abb. 59. Friesfragmente mit Blattranken. Esztergom, Vármúzeum (Burgmuseum) (Marosi 1984, Kat. 60)

feines Kapitell des Stephanssaals mit Tierprotomen statt Voluten und mit Blätterkränzen, dem eine sehr wichtige Rolle in der jüngeren kunsthistorischen Forschung angesichts der Klärung der Vermittlungswege der Frühgotik nach Esztergom zukam. Die Komposition dieses Kapitells erschien ursprünglich als eine mehr oder weniger originelle bildhauerische Erfindung. Zwei Kapitelle - das erste wohl aus Süditalien in The Cloisters in New York, das andere in einem Doppelfenster der Ghirlandina von Modena - haben es als einen Gemeinplatz in ein anderes Licht gestellt. ${ }^{53}$ Besonders durch die Zeugenaussage des Stücks in Modena, das zur Tätigkeit der Magistri campionesi am Dom und am Turm gehört, erscheint das Verhältnis der Bauskulptur emilianischer (antelamesker) Prägung der plastischen Teilen der Porta speciosa und der französisch anmutenden frühgotischen Bauskulptur anders als im Jahr 1984. Damals hat nämlich Willibald Sauerländer darauf hingewiesen, dass Emilia in der Vermittlung französischer Typen in der Skulptur

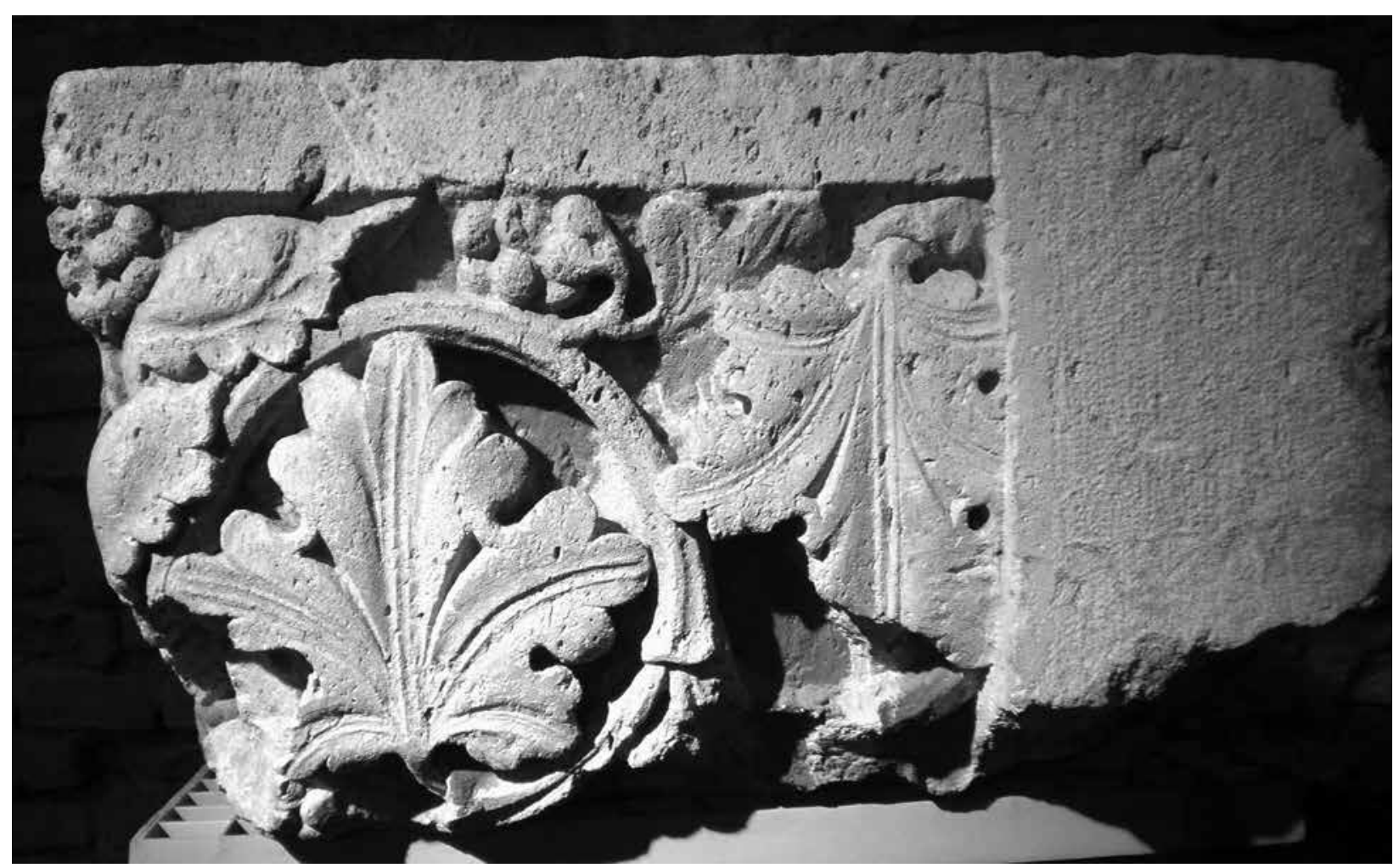

Abb. 60. Friesfragment. Esztergom, Vármúzeum (Burgmuseum), ehemaliges Lapidarium (MAROSI 1984, Kat. 60b) 


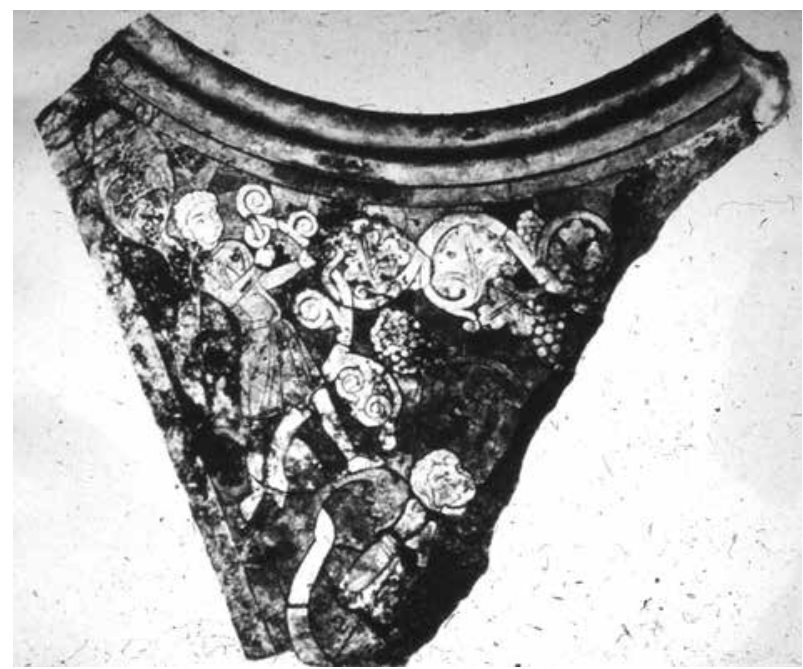

Abb. 61. Thronsessel, rechte Lehne. Esztergom,

Vármúzeum (Burgmuseum) (Foto: Sándor Beszédes, 1901)

eine Rolle gespielt haben könnte. ${ }^{54}$ Nun, durch die Ausdehnung der Geltung dieser These auch auf die Bauskulptur, wurde der allgemeine Charakter der an den Bauten vom König Béla III. tätigen Werkstatt einheitlicher als vorher bestimmt.

Auch sonst beurteilt man heute die Frage nach der Stellung der Bautätigkeit unter Béla III. in Esztergom - dank neuer Forschungen und Deutungen - anders, als vor zwei-drei Jahrzehnten. Dazu hat die Tatsache wesentlich beigetragen, dass diejenigen Stücke, die aus der Kathedrale und dem Palast stammen, im Lapidarium von Esztergom von anderen Stücken getrennt werden konnten, die aus dem Stift Dömös und dem Zisterzienserkloster von Pilis dorthin gelangt sind. In dieser Selektion haben geologisch-archäometrische Untersuchungen eine große Rolle gespielt. Dadurch wurden die Eigentümlichkeiten der Verwendung

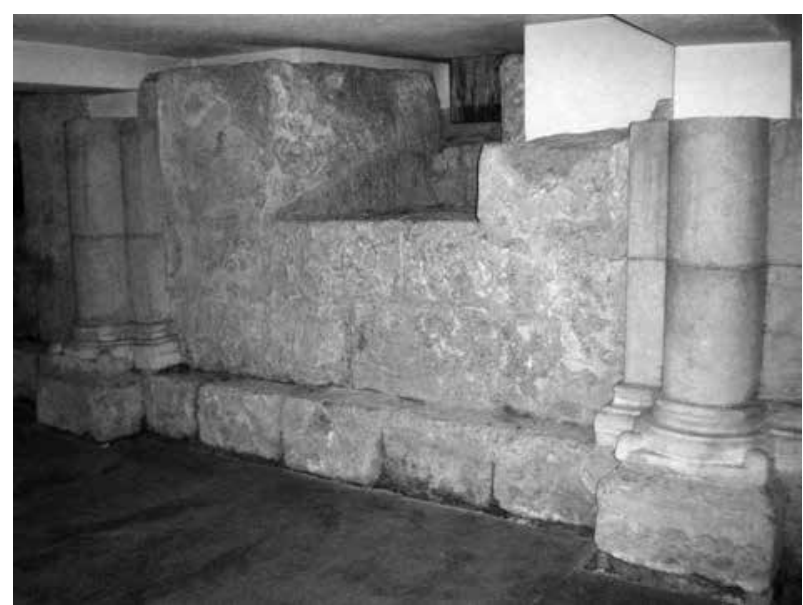

Abb. 63. Salzburg, Dom, Detail aus der Krypta des Konraddoms

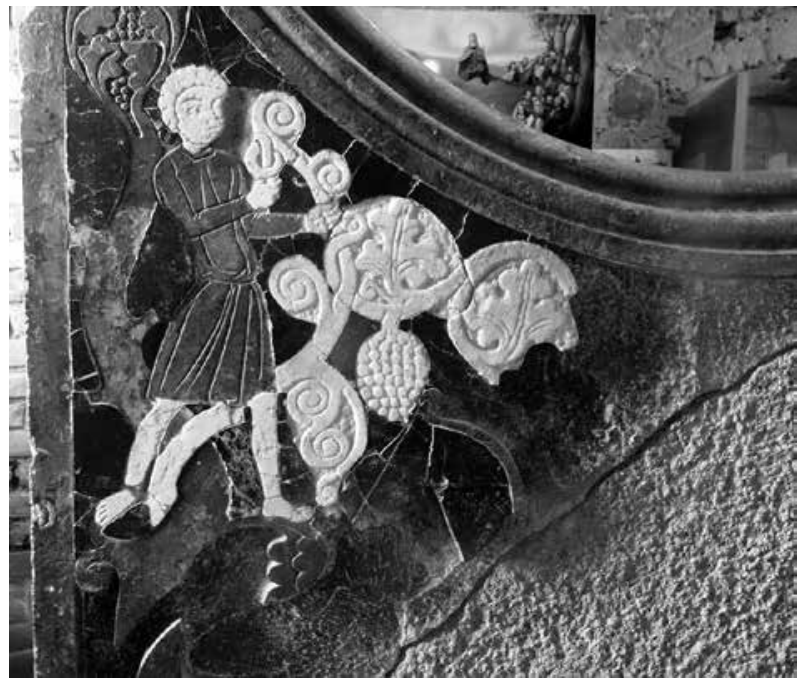

Abb. 62. Thronsessel, rechte Lehne. Esztergom,

Vármúzeum (Burgmuseum) (Foto: Pál Lôvei, 2017)

von verschiedenen Steinmaterialien an den einzelnen gleichzeitigen Baustellen untersucht. Die Fragmente, die aus Dömös im 19. Jahrhundert in verschiedenen Sammlungen zerstreut wurden, konnten auf Grund der Verwendung eines Andesittuffs identifiziert werden. ${ }^{55}$ Während in Esztergom im ganzen 12. Jahrhundert

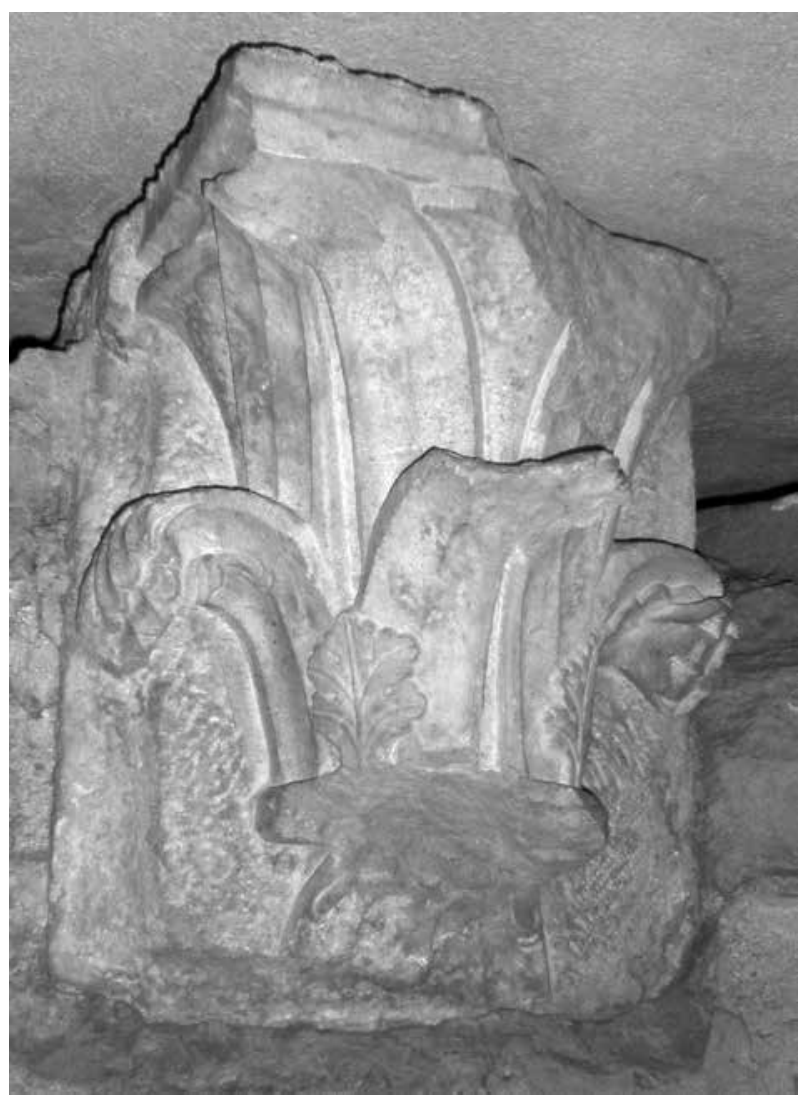

Abb. 64. Konsole aus dem Konradbau des Domes, Salzburg, Museum der Domgrabungen 


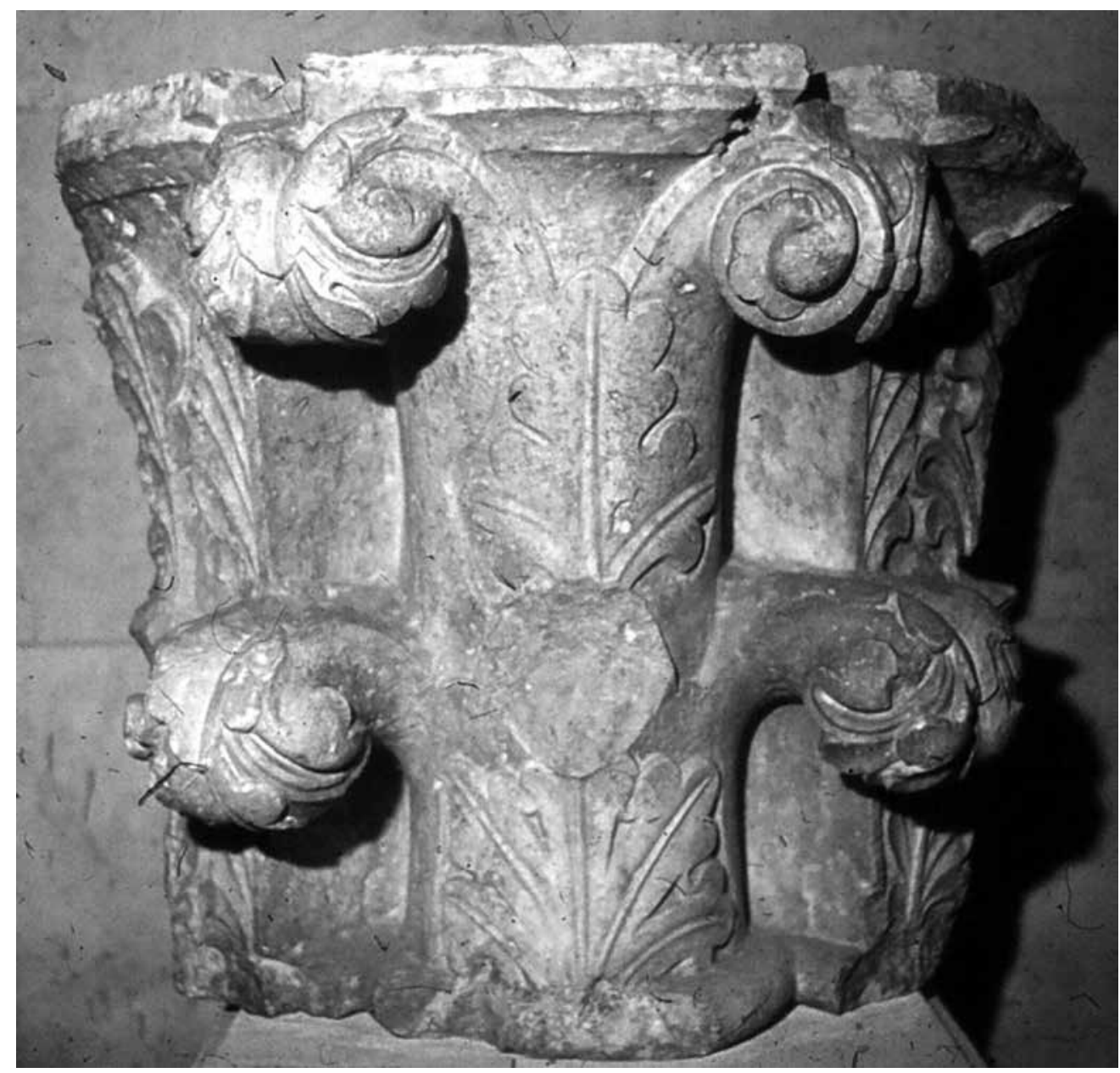

Abb. 65. Kalocsa II. Kathedrale, Pilasterkapitell. Budapest, Magyar Nemzeti Galéria (Ungarische Nationalgalerie)

Bauglieder aus unterschiedlichen harten Kalksteinen gehauen wurden, ${ }^{56}$ hat man in Pilisszentkereszt gegen und um 1200 zu gotischen Gliederungen und Ornamenten Sandstein benutzt. ${ }^{57}$ In demselben stilistischen Bereich kann eine weitere Anpassung an lokale Gegebenheiten und Materialquellen nachgewiesen werden. Im stilistischen Wirkungskreis von Pilisszentkereszt kommen dagegen ein harter Süßwasserkalkstein an der königlichen Burg von Óbuda sowie die sekundäre Verwendung von Steinen aus Römerdenkmälern von Aquincum (Óbuda) an der Kathedrale von Kalocsa vor - was wohl die Provenienz des in Óbuda verwendeten Materials beleuchtet. ${ }^{58}$ In Esztergom - besonders am Bau des königlichen Palastes - kann man ganz eindeutig einen Unterschied zwischen dem Stil des Weißen Turms und seines Anbaus sowie der Palastkapelle feststellen, deren Baugestaltung wohl Vorbilder der Pariser Gegend zu Grunde gelegt wurden. Gleichzeitig vermischen sich moderne Elemente in der ornamentalen Skulptur der Kapelle mit dem traditionellen Stil der älteren Werkstatt. Weder das Zisterzienserkloster in Pilis noch der königliche Palast in Óbuda oder die Kathedrale Kalocsa II weisen einen älteren Stil auf, sondern sie sind einheitlich frühgotisch. Deshalb ist eine zeitliche Priorität Esztergom beizumessen. Als diese Tatsache bekannt geworden ist, hat man die Gleichzeitigkeit der beiden Stile und sogar die Identität der in Esztergom und in Pilisszentkereszt tätigen Werkstatt auch angezweifelt. Als eigentliches Zentrum der Rezeption des frühgotischen Stils wurde das Marienkloster von Pilis angenommen, während man mit der Tätigkeit einer Werkstatt rechnete, die die französischen Initiativen mit Elementen des Antelami-Stils von Emilien vermittelt hat. ${ }^{59}$ Unserer Meinung nach handelt es sich hier um einen letzten Versuch, trotz dem Versagen der Konzeptionen der burgundischen Gotik oder der Frühgotikvermittlung der Zisterzienser ein letztes Stückchen der Zisterziensergotik doch zu bewahren.

Sehr charakteristische Bau- und Ornamentformen, die sowohl in Esztergom als auch in Pilisszentkereszt vorkommen, zeugen von einer und derselben 


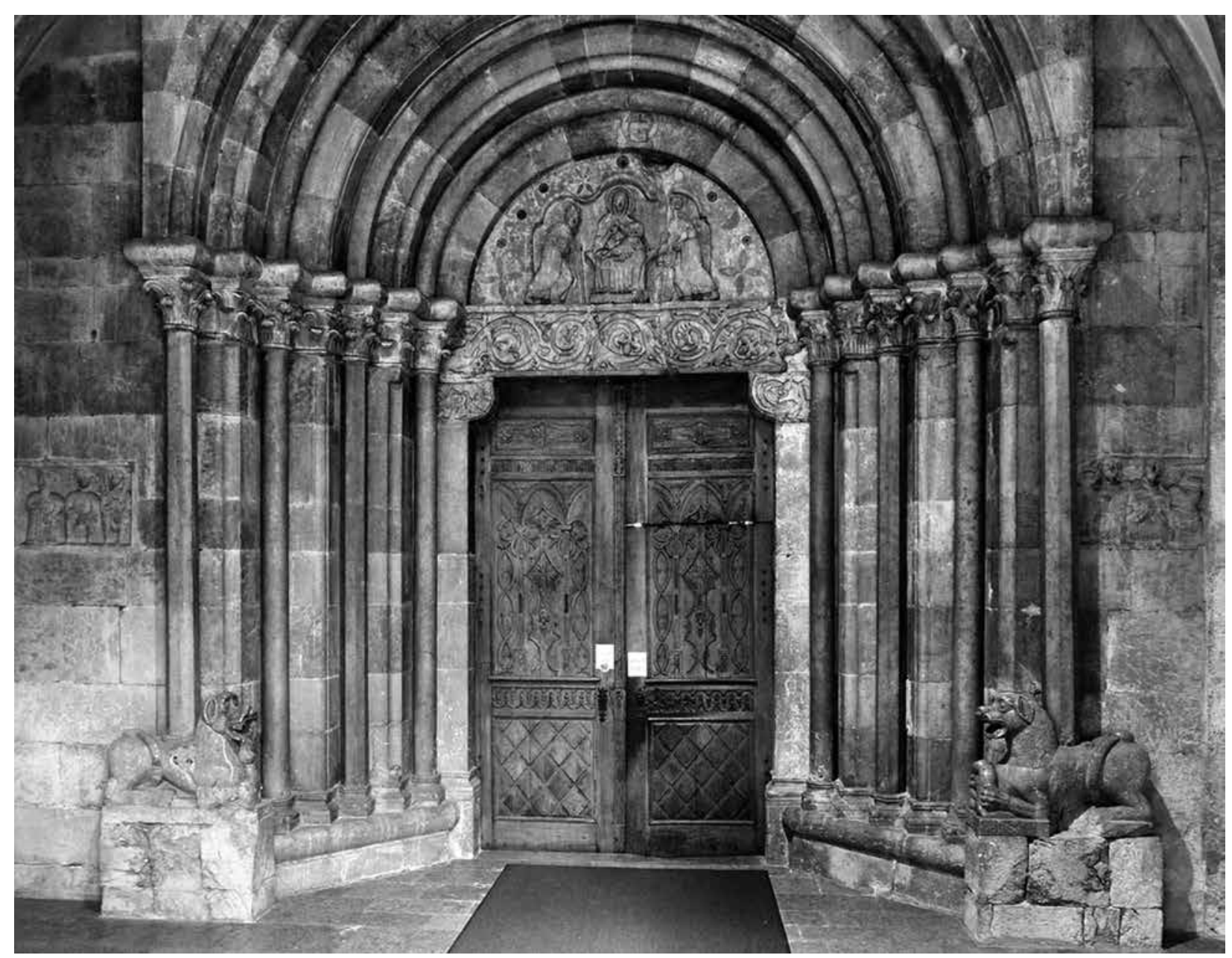

Abb. 66. Bad Reichenhall, Propsteikirche St. Zeno, Westportal

Werkstatt. Eine reiche Rankenornamentik in Esztergom, die eine Vorstufe des naturalistischen gotischen Ornaments bildet, ist durch einen großen Portalsockel, der jüngst als ein Überbleibsel des ehemaligen Westportals von Pilisszentkereszt identifiziert wurde, und durch Friesfragmente von Esztergom, die weiterhin als Fragmente - etwa Pfeilerfriese - aus der Adalbertskathedrale betrachtet werden (Abb. 59-60), vertreten. Dass sie ehemals in einer Portalrekonstruktion im Lapidarium von Esztergom gezeigt wurden, entspricht dem überaus rationalen Urteil, dass sie stilistisch einander nahe stehen. ${ }^{60}$ Krisztina Havas hat die Frage der Provenienz von Pilis oder Esztergom im Fall eines Achteckpfeilers, dessen Werkstücke (Abb. 81) sich in Esztergom befinden, offengelassen. Das ist auch der Fall bei einem Portalfragment, das ein Knospenkapitell mit einem Auflagenblatt schmückt (Abb. 87). Wenn diese aus Esztergom stammen würden, könnte man zumindest in gewissen Fällen den Gebrauch des Sandsteins in Esztergom auch annehmen. Das aus Sandstein fein gemeißelte
Kapitell in Esztergom stammt bestimmt aus dem gleichen Baukontext, wie ein Sockel aus hartem Kalkstein - wohl war die Auswahl der Materialien funktionell bedingt. ${ }^{61}$ Unterschiedliche Steinmaterialien in demselben baulichen Kontext, die abweichende Qualität aufweisen und sogar aus verschiedenen Lagen desselben Steinbruchs stammen mögen, sind auf Bedenken zurückzuführen, die auf bewusste Kriterien der Auswahl - wie zum Beispiel Festigkeit und Widerstandsfähigkeit - gegründet sind. ${ }^{62}$

Die formalen Argumente sind schwerwiegender. In Pilis gibt es keine Formen, die in einem frühgotischen Gesamtbild als störend erscheinen würden. Unter den Nachfolgebauten (in Bény/Biňa, SK, Kalocsa II, Ócsa) treten die Formen der hier als emilianisch bezeichneten Werkstatt zusammen mit den frühgotischen auf. Die Provenienz des Rankenfrieses mit einer Drachengestalt wurde wohl auf seinem ersten Stück aus Esztergom ebenso wenig angezweifelt, wie das stilistische Argument, dass dieses Stück bezüglich seiner engen stilistischen Nähe zum Weinrankenornament 
auf einer Seitenlehne des am wahrscheinlichsten erzbischöflichen Throns von Esztergom (Abb. 61-62; vgl. Abb. 60) aus derselben Werkstatt stammen soll. ${ }^{63}$ Nicht nur zwischen dem Bauschmuck der Palastkapelle und inkrustierten Marmorarbeiten kann eine Werkstattgemeinschaft angenommen werden, sondern diese Vermutung kann auch auf den Westbau der Kathedrale bezogen werden.

\section{DIE ROTMARMORVERKLEIDUNG DER KIRCHE}

Die Beschreibungen der Ruinen und zum Teil andere Schriftquellen berichten auch darüber, dass verblüffend große Wandflächen und vielleicht auch hohe Gewölbe der Kathedrale mit Marmor verkleidet wurden. Die Wände waren zumindest teilweise ebenso mit Inkrustationen geschmückt, wie der Fußboden. ${ }^{64}$ In der neueren Literatur wurde nachgewiesen, dass auch die Porta speciosa Teil einer auf die ganze Westfassade ausgedehnten bunten marmornen Wandverkleidung war. An dem Punkt, wo die Querschnittstruktur der Westmauer bei Máthes dargestellt wird, ist die Funktion der Schraffur als Mittel der zeichnerischen Rekonstruktion evident. Das Neue in der kunsthistorischen Beurteilung liegt darin, dass die Porta speciosa als eine selbstständige und höchst eigentümliche Vertreterin der französischen Figurenportale eines einheitlichen emilianischen Stils erscheint. ${ }^{65}$ Vor vier Jahrzehnten bildete die Annahme von zwei separaten charakteristischen Stilströmungen den Ausgangspunkt. Der
Unterschied liegt darin, ob eine frühere Stilvariante mit dem Personennamen „Benedetto Antelami“ in Zusammenhang gebracht und eine spätere als Tendenz der Renaissance of the $12^{\text {th }}$ Century angenommen werden kann - oder man sollte die beiden als ein und denselben Stil betrachten. Inzwischen ist das Wort antelami statt der Familie eines genialen Künstlers ein gemeinsamer Name der Steinmetzen unter anderen aus dem Intelvital geworden, die eine Rolle in der Vermittlung von Wechselwirkungen durch die Alpenpässe und besonders zwischen den Tälern der Rhône und dem Fluss Po gespielt haben, sich aber an der Verbreitung des frühgotischen Stils auch beteiligten. ${ }^{66}$ Am frühesten hatte Willibald Sauerländer auf die Möglichkeit der Vermittlung des Pariser Stils der Regierungszeit Philipps II. August durch Norditalien aufmerksam gemacht. ${ }^{67}$ Diese Erscheinung der Nachfolge eher von Saint-Denis, denn von Chartres, wurde von Peter Cornelius Claussen als „transperipherisch“

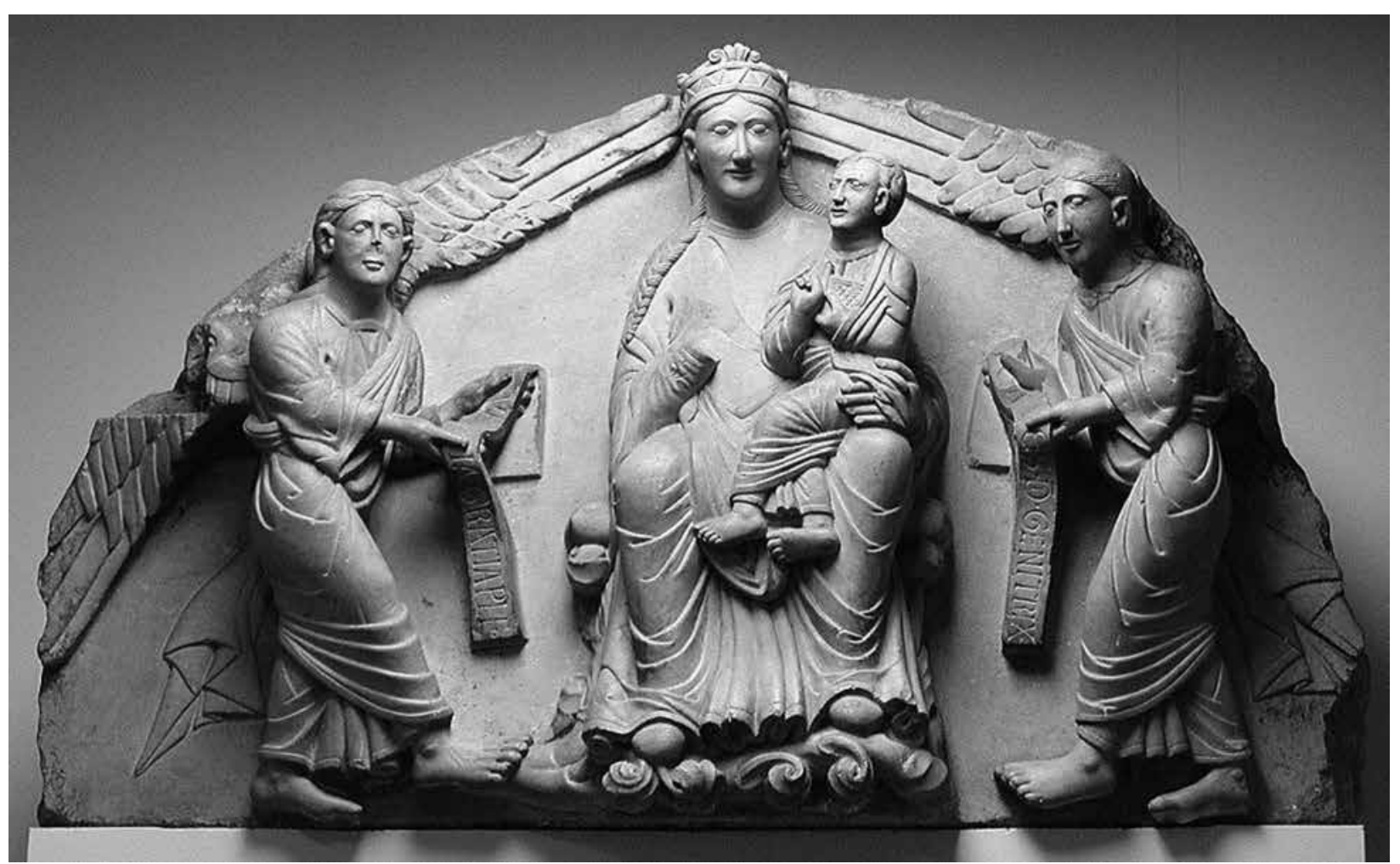

Abb. 67. Madonnenrelief. Salzburg, Museum Carolino Augusteum 


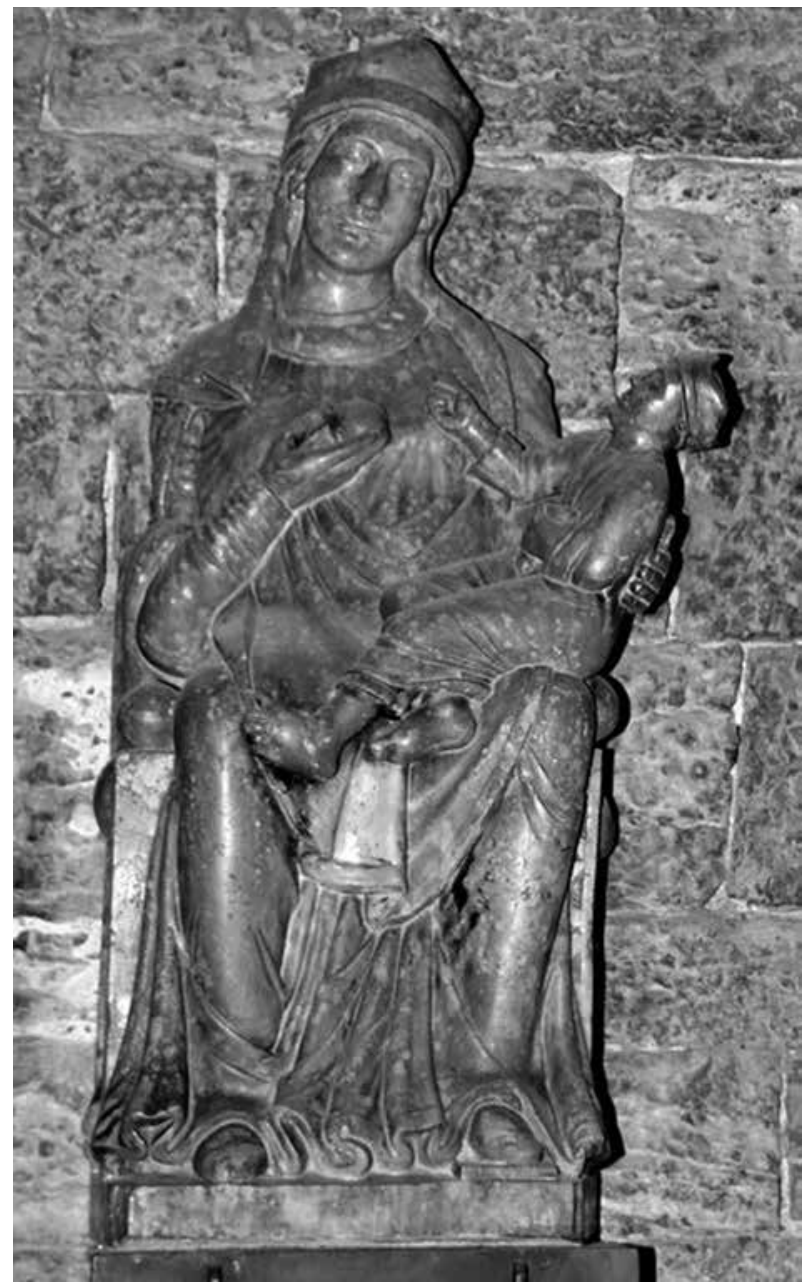

Abb. 68. „Madonna degli Annegati“, Trient (Trento), Kathedrale

bezeichnet. Dieser Stil wird durch eine Häufung reicher und bunter Wirkungselemente und eine Tendenz zur Materialpracht gekennzeichnet, weshalb er in Milieus, in denen man die Tradition der Spätromanik bewahrte, besonders populär sein konnte. ${ }^{68}$ Seine Tradition begann in Esztergom mit dem Bergfried des Palastes zusammen mit seinem Anbau sowie mit den Westteilen der Kathedrale.

Die emilianischen Beziehungen von Esztergom stehen keineswegs allein in Mitteleuropa: Gleichzeitig mit ihm erreichten sie den Salzburger Dom, dessen Neubau nach norditalienischen Vorbildern - dem Dom zu Parma - unter Erzbischof Konrad III. begann und der ähnlich geschmückt wurde. ${ }^{69}$ Vom Konradbau des Salzburger Doms wurden in den Grabungen allein Grundmauern und untere Mauerteile ans Tageslicht gebracht (Abb. 63). Sie zeigen Reste einer sehr qualitätsvollen frühgotischen Gliederung auf, meist aus sehr präzise behandeltem, rot gefärbtem und hartem weißem Kalkstein. ${ }^{70}$ Diese hochwichtige
Salzburger Denkmalgruppe wurde zuerst von Imre Takács mit ihren ungarischen Zeitgenossen in Parallele gestellt (Abb. 64-65). Er wies eine sowohl typologische als auch - zum Teil durch das harte Material bedingte - stilistische Ähnlichkeit der frühgotischen Fragmente aus der 1219 geweihten Krypta des Doms Salzburg II und aus der Kathedrale Kalocsa II nach. ${ }^{71}$ Die von ihm entdeckte Parallele führt also in die Esztergom-Nachfolge hinüber.

Was im Fall der Parallele Salzburg-Kalocsa auf stilistischer Grundlage nahegelegt wurde, kann also typologisch-motivisch bekräftigt werden. Es handelt sich nämlich um den Umkreis der siebenbürgischen Zisterzienserabtei Kerz (Kerc, Cărta, RO). ${ }^{72}$ Die Pfarrkirche zu Holmwegen (Halmágy, Halmăgiu, RO) weist nicht nur den - wohl durch Kalocsa II vermittelten Salzburger Konsolentypus, sondern auch eine figürliche Bauskulptur auf: Zwei figürliche Konsolen unter den Dienstbündeln der Südwand des Chors (Abb. 137138), als deren Vorbilder am ehesten die in Kalocsa befindlichen Figurenkonsolen (Abb. 145-146) mit viel Derbheit in den Figuren und einem primitiven Schematismus in den Draperien in Frage kommen. Für die folgenden Erörterungen scheint es von einer gewissen Bedeutung zu sein, dass die sitzenden Figuren in Kalocsa eine Ähnlichkeit mit den Figuren in St. Zeno von Reichenhall (Abb. 147) aufweisen..$^{73}$ Der gemeinsame Nenner mit der nicht sehr entfernt liegenden bayerischen Kirche und mit ihrem reich gegliederten bunten Westportal ist wiederum Salzburg, die Kirche in Reichenhall (Abb. 66) erscheint nämlich auch als ein Nachfolger des Salzburger Doms.

Nicht nur frühgotische Bauglieder, sondern auch wichtige dekorative Werke gehören zum Kreis von Salzburg II. Es handelt sich um eine sehr qualitätsvolle Werkstatttätigkeit, die wohl längere Zeit ausgeübt wurde. Das Tympanon mit Madonna zwischen zwei Engeln im Salzburger Museum Carolino Augusteum wahrscheinlich aus der Domkirche (Abb. 67; vgl. $A b b$. 68) steht wohl im Mittelpunkt einer Werkgruppe, die im 13. Jahrhundert alle bedeutenderen Salzburger Kirchen umfasste. ${ }^{74} \mathrm{Zu}$ diesen mit weißem und rotem Marmor ausgebildeten Portalen gehören das südliche Portal der Franziskanerkirche (ehemals Marienkirche des Klosters von Benediktinernonnen, Weihe: 1223; Abb. 69), das Westportal der Peterskirche (Weihedatum: 1227) und das Tympanon mit Maria und den Stiftern sowie der Türsturz eines früheren Portals, die eine sekundäre Verwendung im spätgotischen Südportal der Frauenklosterkirche von Nonnberg fanden. ${ }^{75}$ Dieser Produktion von prächtigen Portal- 


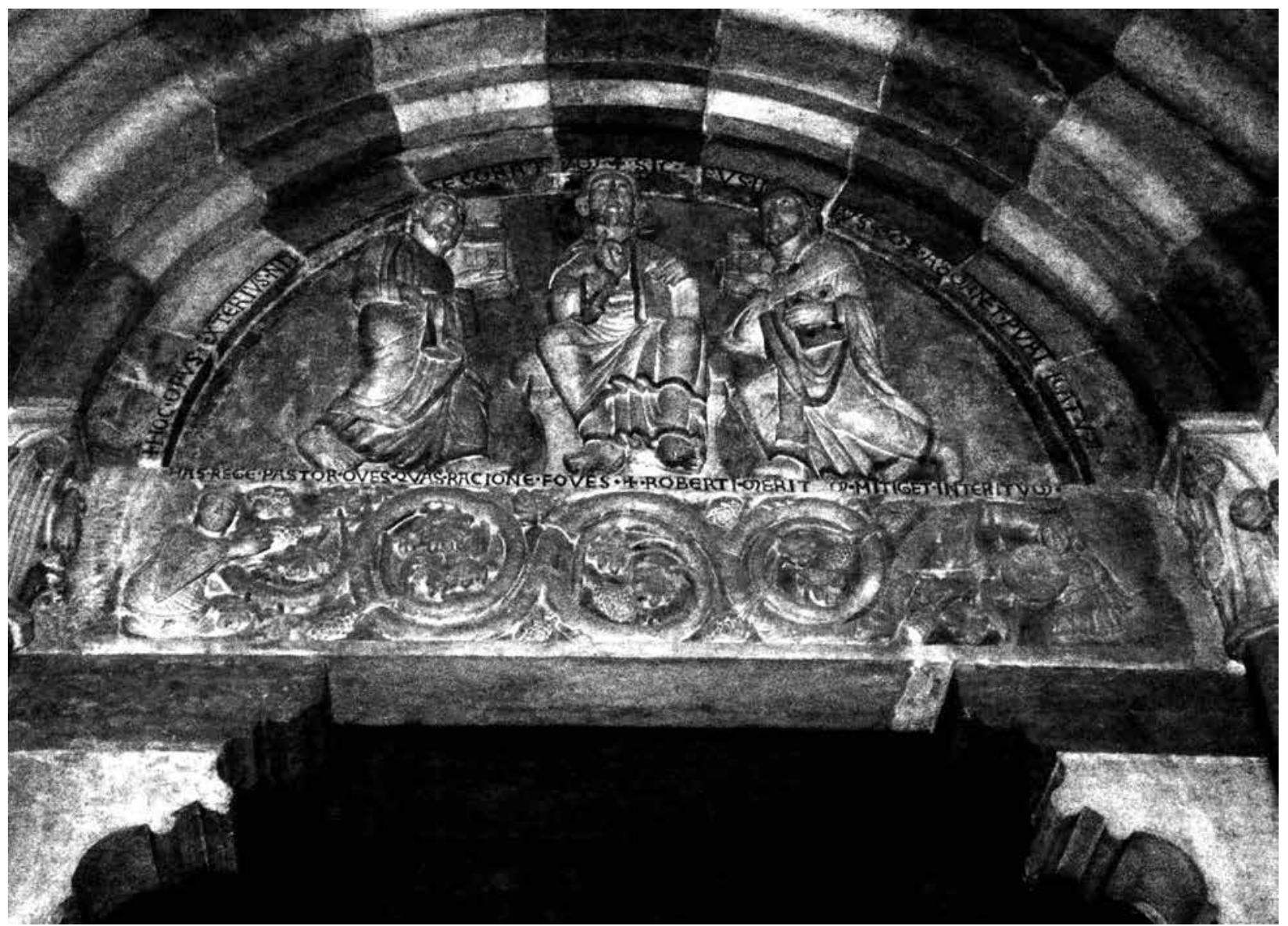

Abb. 69. Salzburg, Franziskanerkirche, Südportal, Tympanon

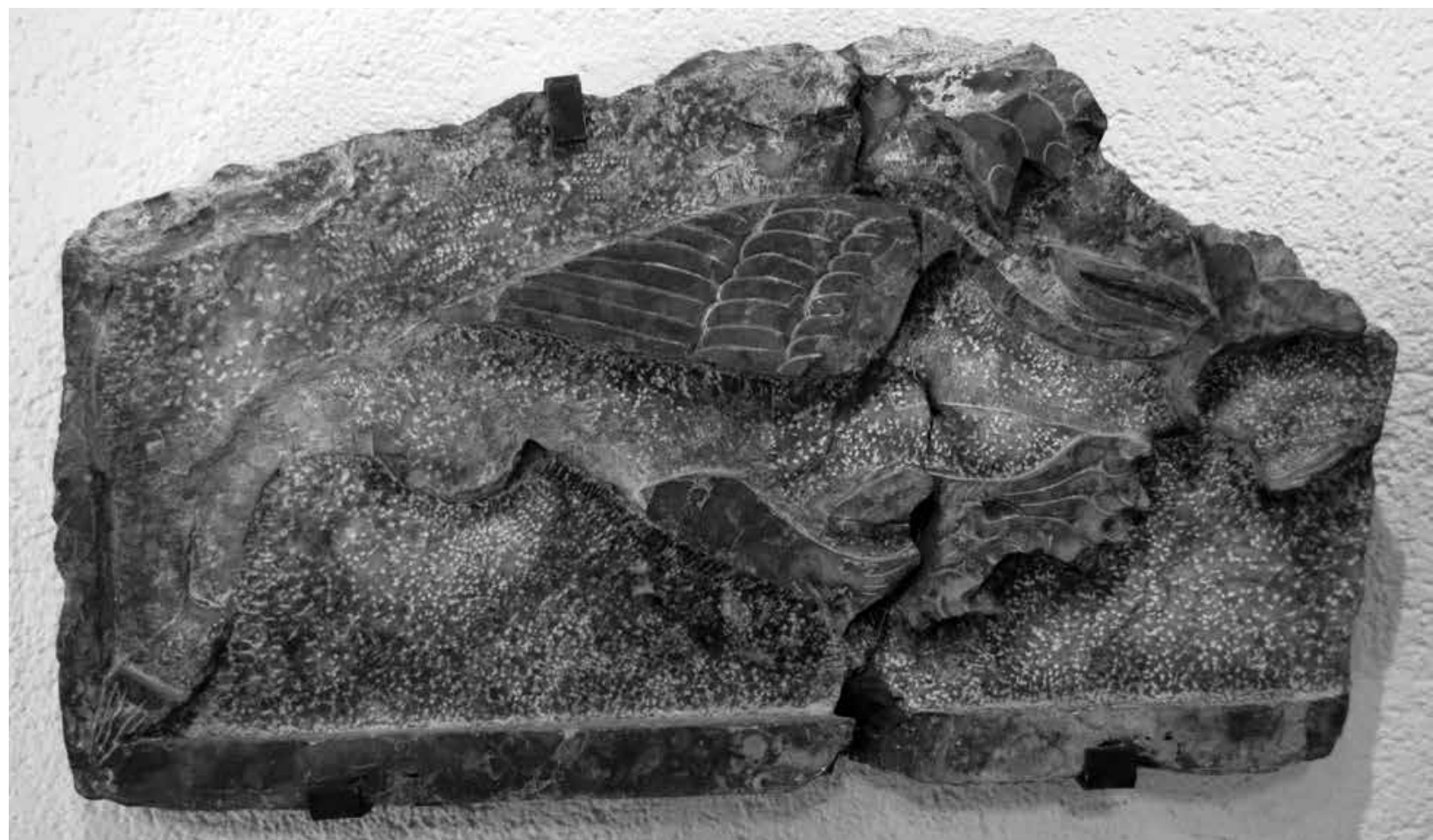

Abb. 70. Inkrustierte Platte mit Ketos aus einer Tierkampfszene. Esztergom, Vármúzeum (Burgmuseum) (MArosi 1984, Kat. 45; Foto: Imre Takács) 


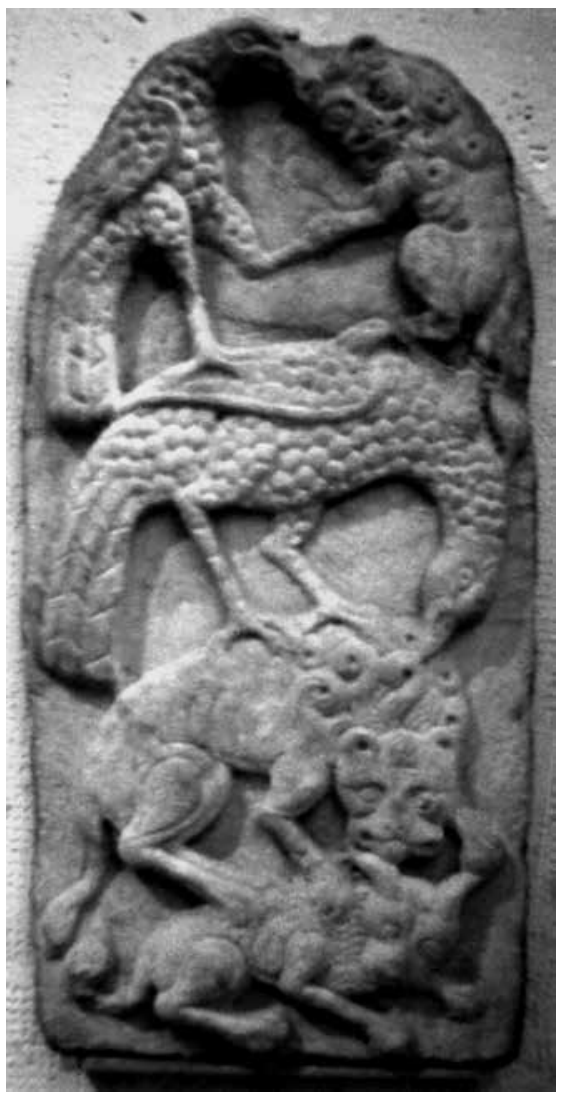

Abb. 71. Tierkampfszene aus Venedig. Paris, Louvre

architekturen schließt sich auch das Westportal von St. Zeno in Reichenhall (1228; Abb. 66) an. Stilistisch kann man diese Werke denselben norditalienisch-emilianischen Einflüssen zuschreiben, die für Esztergom ebenfalls als stilistische Quelle angenommen werden. Im Marientympanon findet man eine Madonnenfigur, deren Vorbild - wenn nicht eben das Werk desselben antelamesk geschulten Bildhauers -, die „Madonna degli Annegati“ (Abb. 68), sich in der Kathedrale von Trient (Trento) befindet.

Esztergom galt eine Zeit lang als ein frühes und ziemlich alleinstehendes Beispiel der Rezeption der Frühgotik in Mitteleuropa. Diese Stelle erscheint nun im Licht der Verwandtschaft mit den ähnlich ausgestalteten gleichzeitigen Werken aus Salzburg. Es handelt sich nicht nur um eine stilistische Beziehung, sondern um ähnliche repräsentative Absichten in der Verwendung von rötlich gefärbten Kalksteinen, Rotmarmoren,$^{76}$ die als Ersatz von Porphyr in Norditalien, in der Umgebung von Verona, auch verwendet wurden. In Esztergom kann man damit rechnen, dass die stilistisch nach Norditalien orientierte Werkstatt in der Erschließung der Marmorbergwerke in der Hügellandschaft Gerecse unweit von Esztergom eine

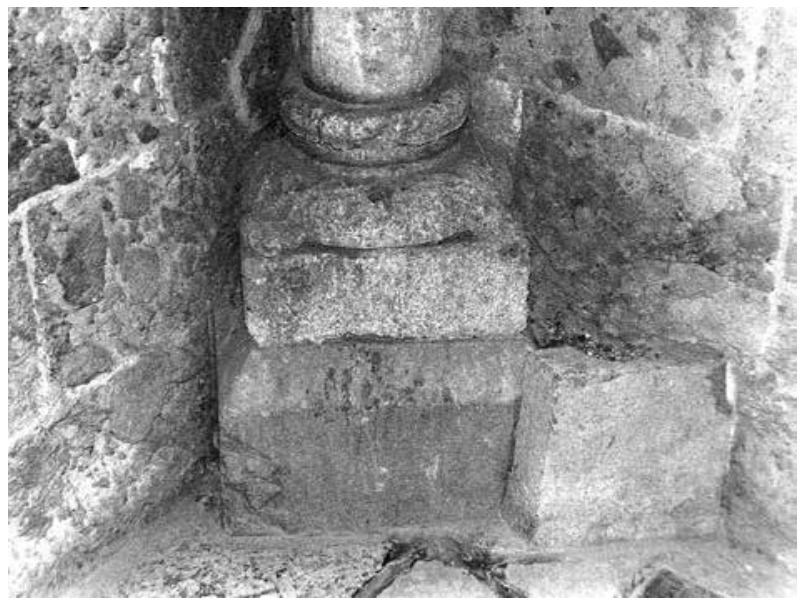

Abb. 72. Basis eines Winkeldienstes, Esztergom, Palastkapelle, nördlicher Nebenraum (Foto: Imre Takács)

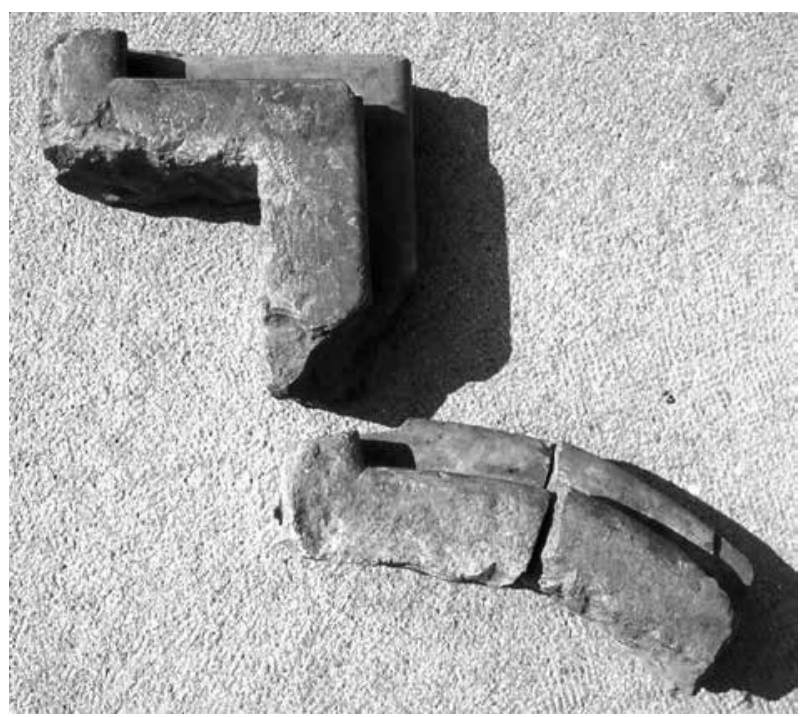

Abb. 73. Zusammenstellung der Marmorverkleidung einer Säule (Foto: Krisztina Havasi)

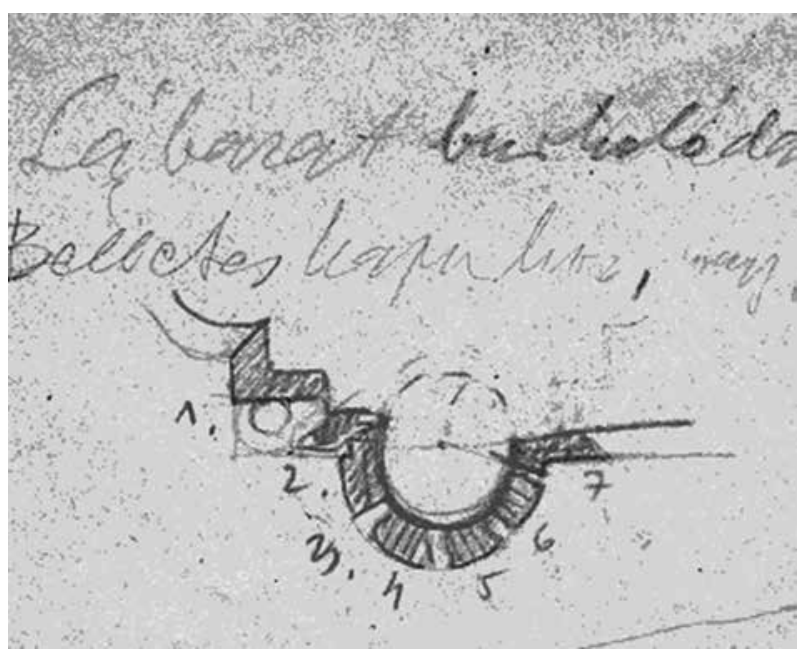

Abb. 74. Dezsô Várnai: Rekonstruktion einer Säule mit Marmorverkleidung (nach HAVASI 2008) 
Rolle gespielt hat. Diese Bergwerke gehörten zu einer ziemlich entfernt liegenden königlichen Burg und wurden Anfang des 13. Jahrhunderts zusammen mit den Burgleuten, unter denen wohl mit den Spezialisten des Marmorbruchs und der Marmorbearbeitung

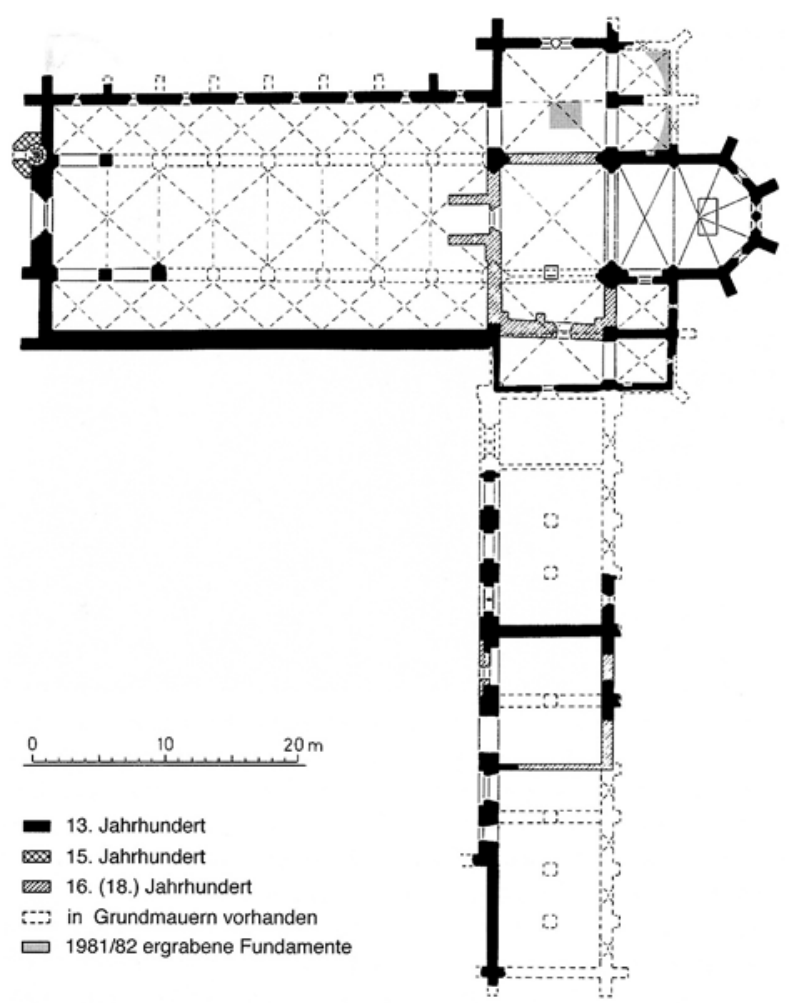

Abb. 75. Kerz (Kerc, Cărta, RO), Grundriss der Ruinen der Zisterzienserabtei

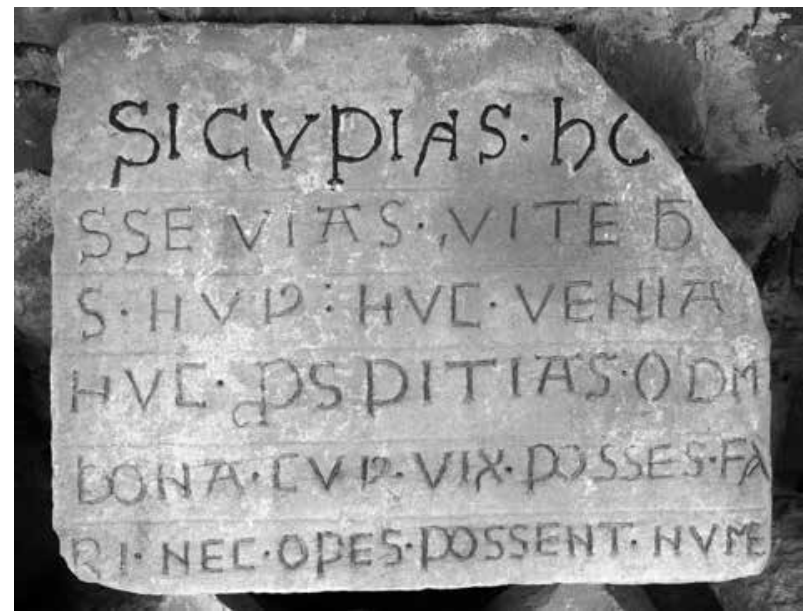

Abb. 76. Kerz, Ruinen der Zisterzienserabtei, Inschriftentafel (Foto: Imre Takács) zu rechnen ist, dem Erzbischof überlassen. ${ }^{77}$ Welche Rolle solche Spezialisten in Salzburg im Betrieb der Marmorbergwerke gehabt haben, ist nicht bekannt.

Eine ikonographische Übereinstimmung kann veranschaulichen, dass es nicht nur eine oberflächli-

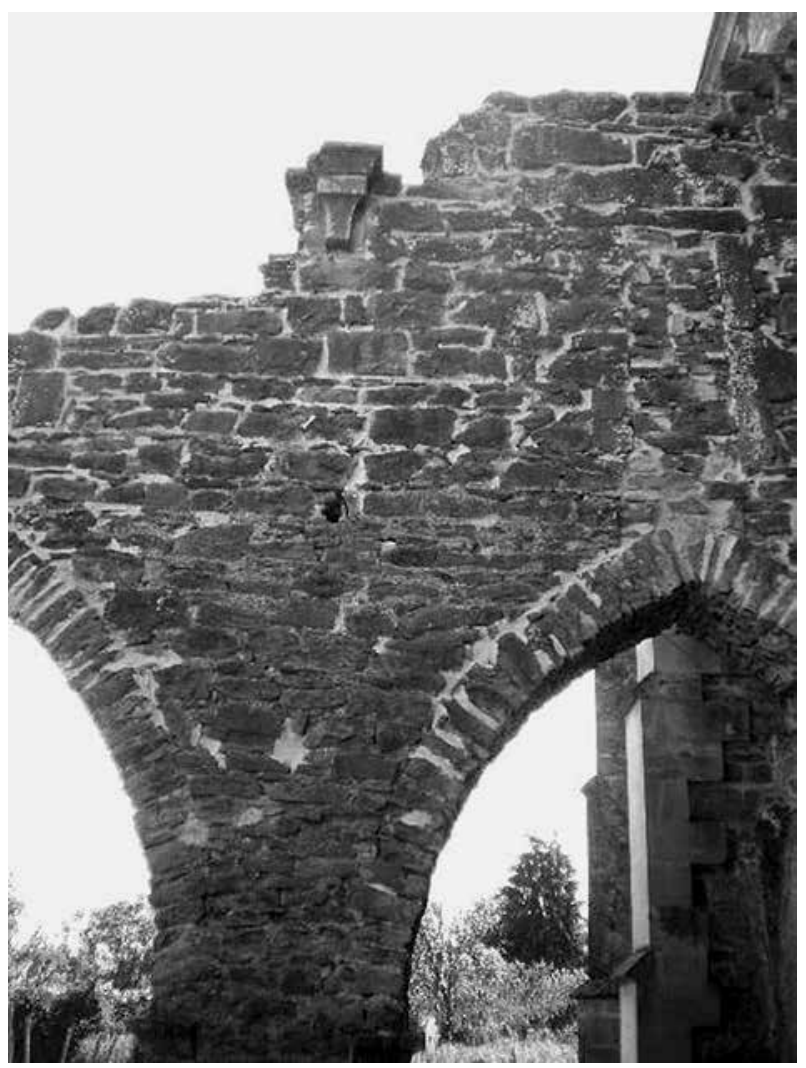

Abb. 77. Kerz, Kirchenruine, die Reste der westlichen Arkade der südlichen Langhausseite

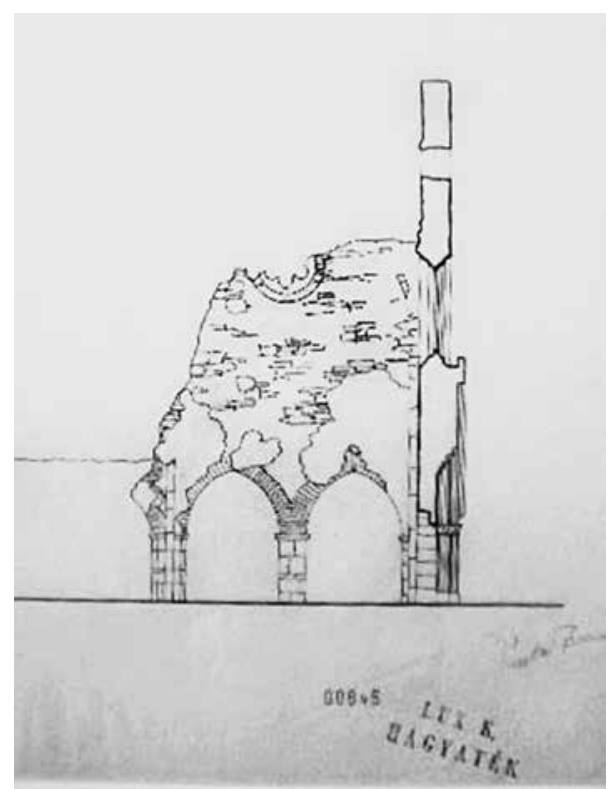

Abb. 78. Kerz, Kirchenruine

(wie Abb. 77). Aufnahmezeichnung, 1911 


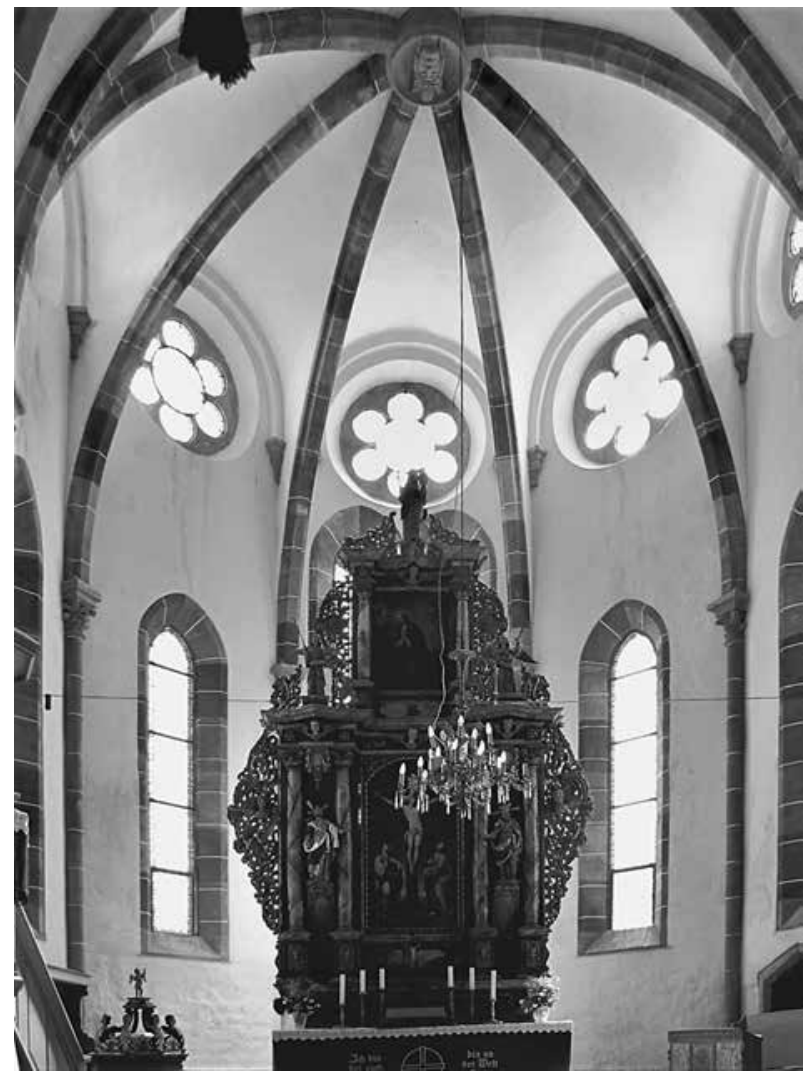

Abb. 79. Kerz, Zisterzienserabtei, Chorinneres (Foto: Imre Takács)

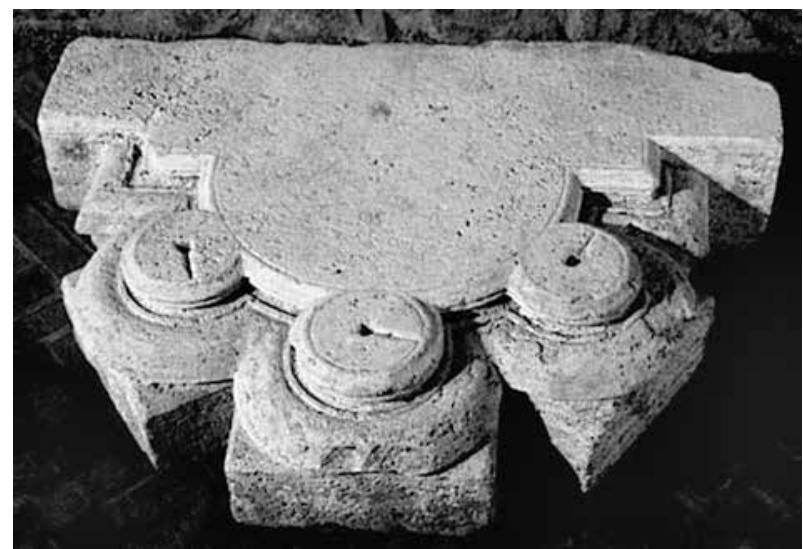

Abb. 80. Basis eines Wanddienstbündels der St. Stefanskirche von Esztergom.

Esztergom, Vármúzeum (Burgmuseum)

che Parallele der Materialverwendung und der Technik zwischen Salzburg und Esztergom bestand. In Esztergom konnte auf Grund der Ikonographie eine inkrustierte Szene als Seitenlehne eines Bischofstuhls identifiziert werden, wohl aus der Kathedrale (Abb. 61-62). Eine Fotoaufnahme vom Anfang des 20. Jahrhunderts zeigt das Fragment noch mit zwei Figuren, von denen die weißen Einlagen einer der Figuren inzwischen verloren gingen. Ursprünglich hat die Inkrustation einen

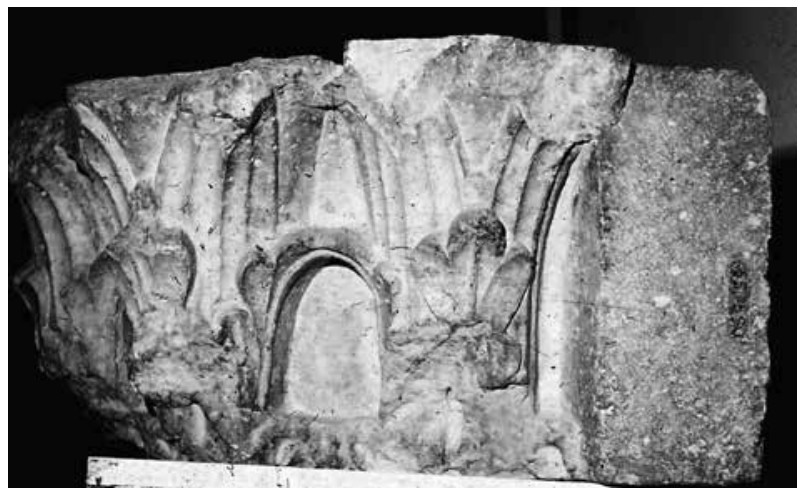

Abb. 81. Kapitell eines Wanddienstbündels aus Pilisszentkereszt. Esztergom, Vármúzeum (Burgmuseum)

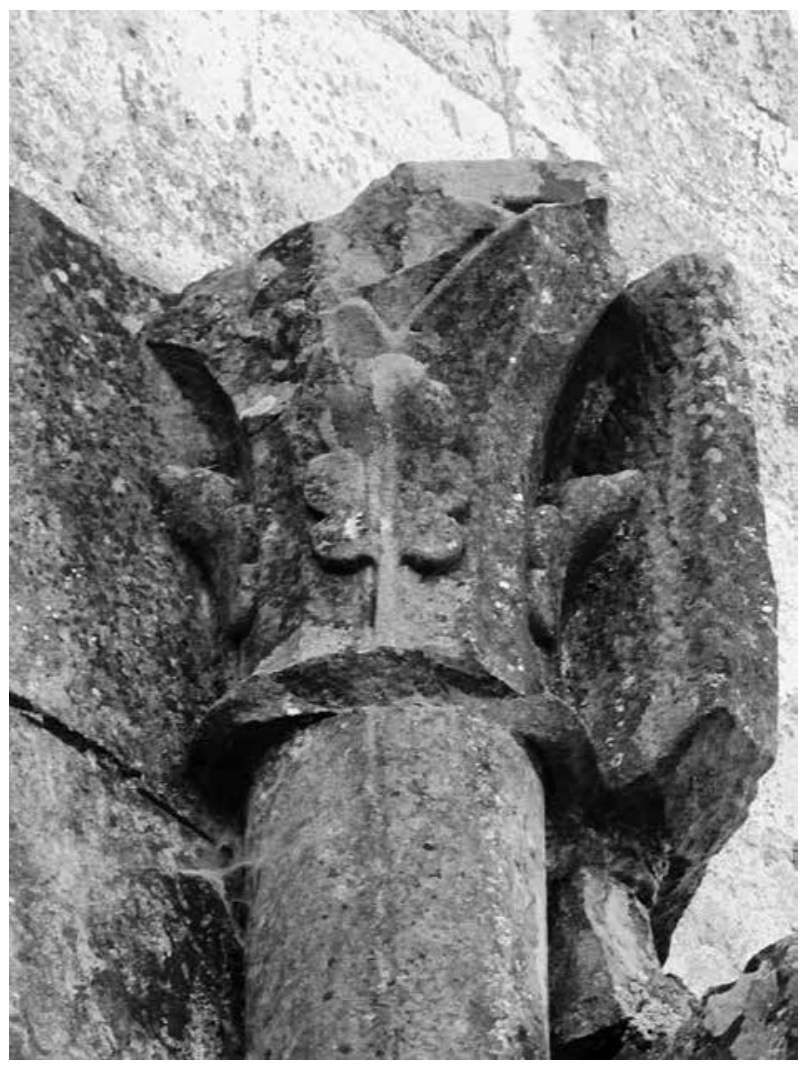

Abb. 82. Kerz, Winkelkapitell, nördlicher Querschiffarm der Klosterkirche (Foto: Imre Takács)

Bogenschützen dargestellt - diese Figur ist bis auf die rotmarmornen Teile verschwunden -, der auf einen mit einem Messer Weinranken schneidenden Winzer schießt. Diese Szene wurde als Allegorie der bischöflichen Pflege gedeutet, die dem Angriff des Bösen ausgeliefert wird. ${ }^{78}$ Diese Deutung kann durch die bisher nie erwähnte Analogie am Türsturz des Südportals der Salzburger Franziskanerkirche (Abb. 69) bestätigt werden, auf dem links ein Bischof und rechts der Bogen- 


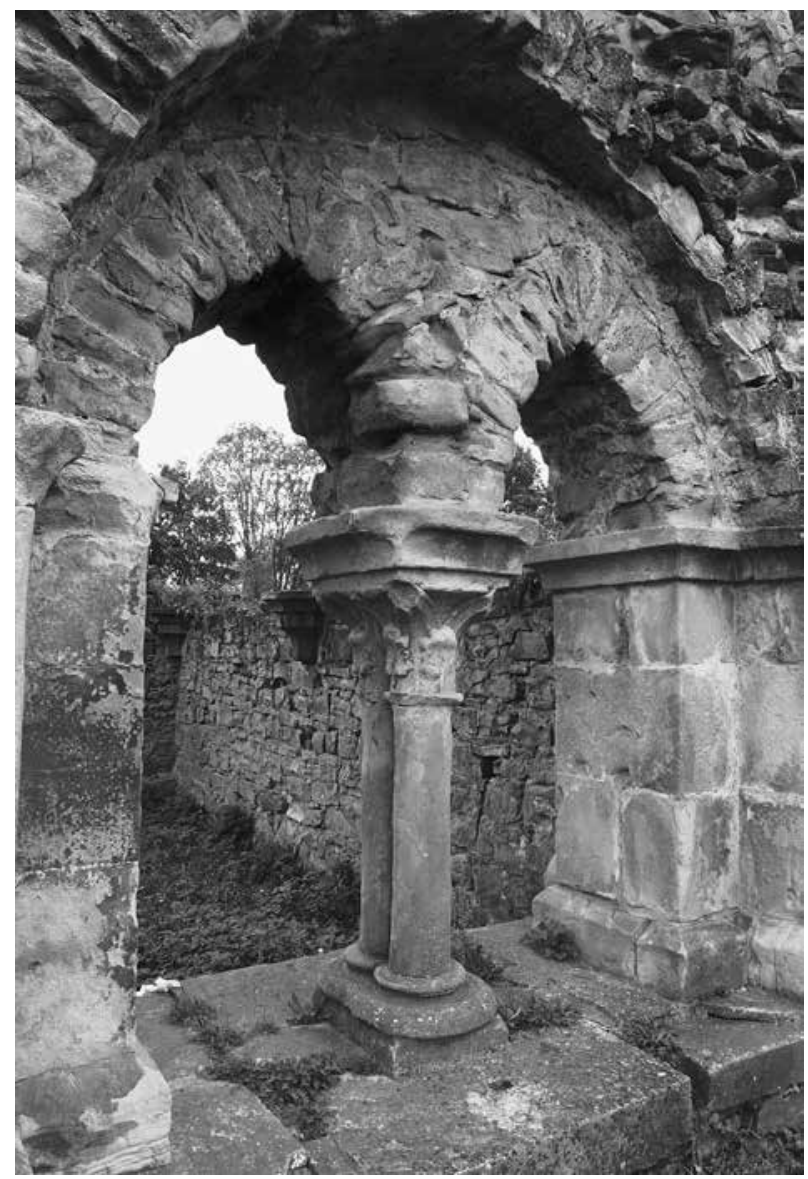

Abb. 83. Kerz, Klosterruine, Westfassade des Klosterflügels, Doppelfenster schütze an beiden Enden einer Ranke mit Trauben das ist wohl die Wildnis der Welt - zu sehen sind. Die Darstellung wird durch eine Inschrift gedeutet, die auf die Verdienste des Heiligen Rupert hinweist: HAS . REGE . PASTOR . OVES . QVAS . RACIONE . FOVES + ROBERTI . MERITVM . MITIGET . INTERITVM . ${ }^{79}$ Den Rahmen bildet die Majestas Domini mit den Heiligen Peter und Rupert, die Baumodelle in der Hand halten, wodurch auf das Benediktinerstift St. Peter hingewiesen wird, dem das ursprüngliche, 1223 geweihte Nonnenkloster untergeordnet wurde. ${ }^{80}$

Weder die Ursache noch das Ziel der Bautätigkeit in Esztergom unter Béla III. ist eindeutig. Die einfachste Erklärung wäre ein von Ost nach West fortschreitender Arbeitsvorgang. In diesem Fall wäre es aber problematisch, wie der 1156 gestiftete Marienaltar als Laienaltar und gleichzeitig als Matutinaltar funktioniert hat. Man soll aber nicht vergessen, dass Bau I - oder ein Teil davon - schon während der Bauarbeit wohl brauchbar gewesen ist. Ein weiterer problematischer Punkt ist das Vorkommen des Rotmarmors in den Ostpartien und selbst am Gewölbe des Chors. Die Ostteile sollten nämlich bei einem normalen Arbeitsgang schon in der ersten Hälfte des 12. Jahrhunderts fertiggestellt werden. Oben wurde bereits erklärt, dass man wegen des angeblichen Feuers kaum mit zwei Bauperioden im 12. Jahrhundert rechnen kann - etwa mit Bau II, der stilistisch belegt werden kann, und nach dem Brand

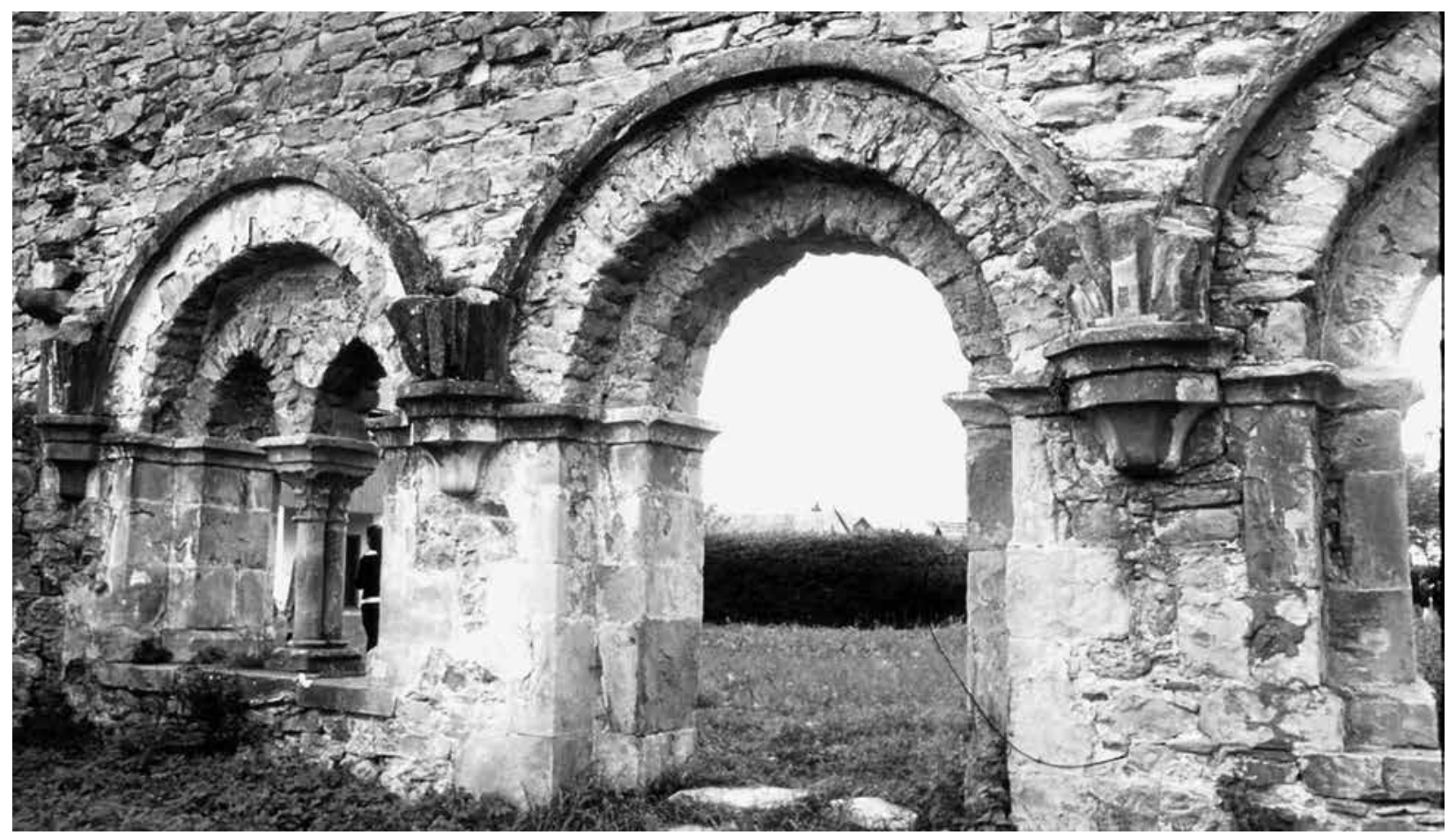

Abb. 84. Kerz, Klosterruine, Westfassade des Kapitelsaals 


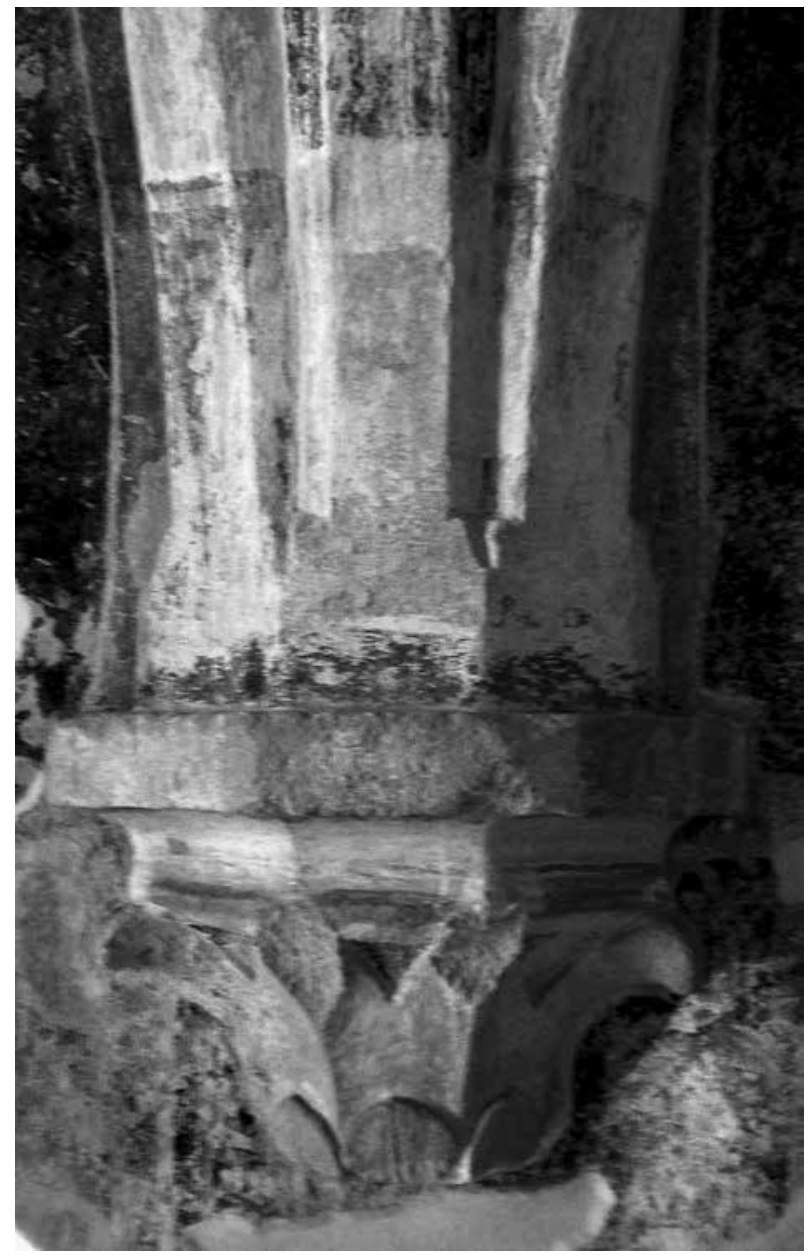

Abb. 85. Veszprém, „Gisela-Kapelle“, Wanddienst der Unterkirche

mit Bau III. Man könnte sich diesen Bau des späten 12. Jahrhunderts mit einer modernen Wölbung - etwa mit Kreuzrippenwölbung - vorstellen, aber außer den tieferen Langhausjochen besitzt man dafür keine Belege. Es scheint jedoch wahrscheinlich zu sein, dass die Arbeit auf den ganzen Bau ausgedehnt wurde. Darüber berichten vor allem Zeugenaussagen über Wandverkleidungen und Fußbodenbelage. Mit den Wandverkleidungen kann eine ursprünglich inkrustierte Rotmarmorplatte mit der Darstellung eines Drachen - wohl eines Ketos der ikonographischen Tradition der Antike (Abb. 70) - in Zusammenhang gebracht werden. Sie mag eine Darstellung byzantinischen Typs (doch nicht Stils) eines mehrfigürlichen Tierkampfes gewesen sein, der zum Beispiel im Kreis von Venedig besonders beliebt war (Abb. 71).

Im Jahr 2000 haben sich sowohl Pál Lóvei als auch Imre Takács in ihren Tagungsbeiträgen mit der Technik der nachträglichen Verkleidung von Mauern beschäftigt, die aus einem anderen Material errich-

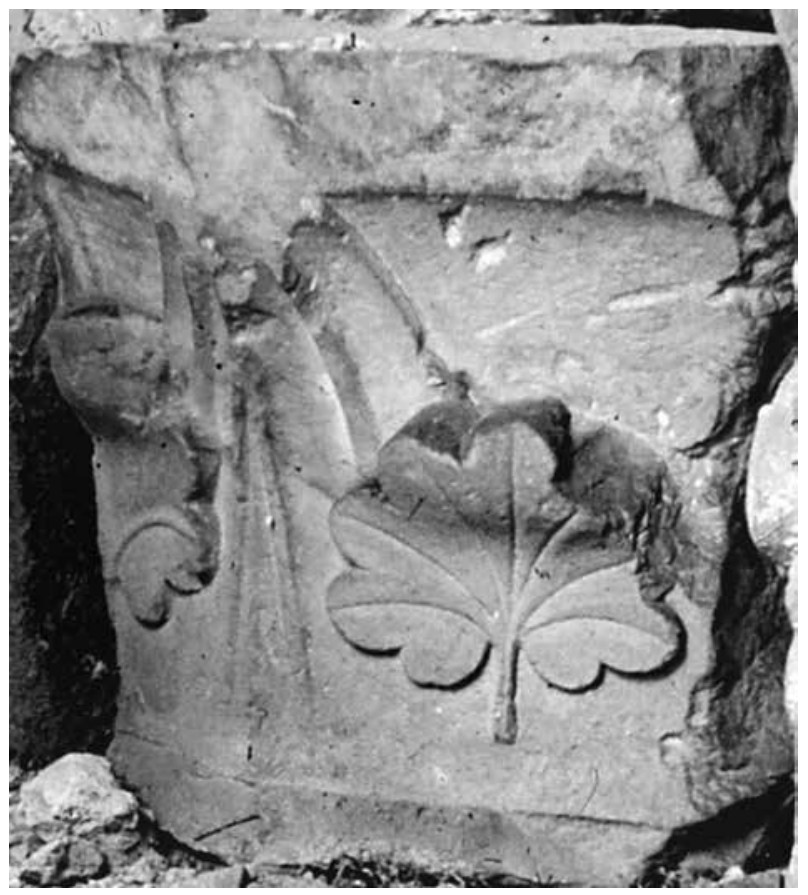

Abb. 86. Fragment vom Kapitell eines achteckigen Pfeilers aus Pilisszentkereszt (?).

Esztergom, Vármúzeum (Burgmuseum)

tet wurden. Sie haben nachgewiesen, dass mit dieser Technik ausgeführte Werke bis heute im nördlichen Nebenraum der Kapelle des königlichen Palastes am Sockel einer Wandvorlage und an einer Nische vorhanden sind (Abb. 72). ${ }^{81}$ Später hat Krisztina Havasi Beobachtungen über Spuren der Befestigung einer rotmarmornen Verkleidung durch Dübel an einem Sockelfragment veröffentlicht (Abb. 73), zusammen mit einer Rekonstruktionszeichnung von Dezsổ Várnai (Abb. 74) ${ }^{82}$ Imre Takács hat sogar im Kontext der Kritik des Máthes'schen Grundrisses Bedenken wegen der Ummantelung der Mauer ausgedrückt. ${ }^{83}$ Er hält für wahrscheinlich, dass das westliche Turmpaar zu Bau I gehört habe und erst nachträglich, durch eine Ummantelung in die Komposition des 12. Jahrhunderts integriert worden sei. Diese Kombinationen, die auf ein Minimum der Belege gegründet wurden, bieten einen wenig sicheren Boden für weitere Schlussfolgerungen.

Dieselben Überlegungen betreffen auch die Rekonstruktionsvorstellungen der westlichen Vorhalle der Kathedrale - bis auf die Grundzüge, die auf dem Längsschnitt von Krey vorkommen, wie Überreste der Wölbung bzw. die Sedilien der Südwand (Abb. 46). ${ }^{84}$ Hier sind die Bogenformen vor dem Portal ebenfalls ziemlich schwer zu deuten. Im Allgemeinen, wie sie am sonst sehr authentischen Ölgemälde der Porta speciosa des Bischofs Klimó (Abb. 4) dargestellt wurden, 
sind die Architekturen, die einen Rahmen für das Portal bilden, nicht unbedingt Abbildungen von seitdem verschwundenen Details, sondern sie sind barockgotische Fantasien (Abb. 8, Abb. 56-57). Ohne jede Stütze von Bauresten können solche Darstellungen allein mit einer Überinterpretierung in die Baugeschichte hineingebaut werden.

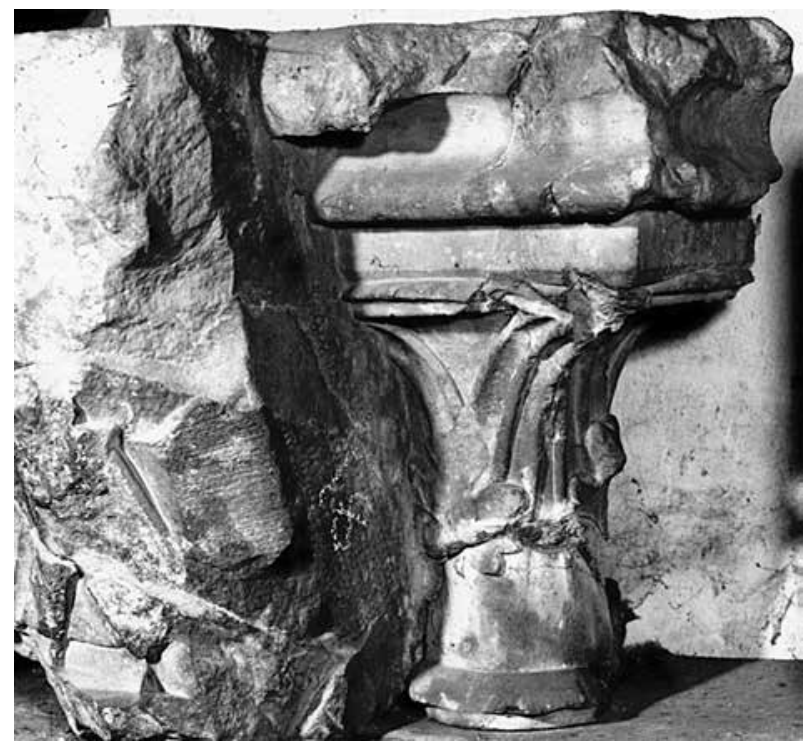

Abb. 87. Portalfragment aus Pilisszentkereszt. Esztergom, Vármúzeum (Burgmuseum)

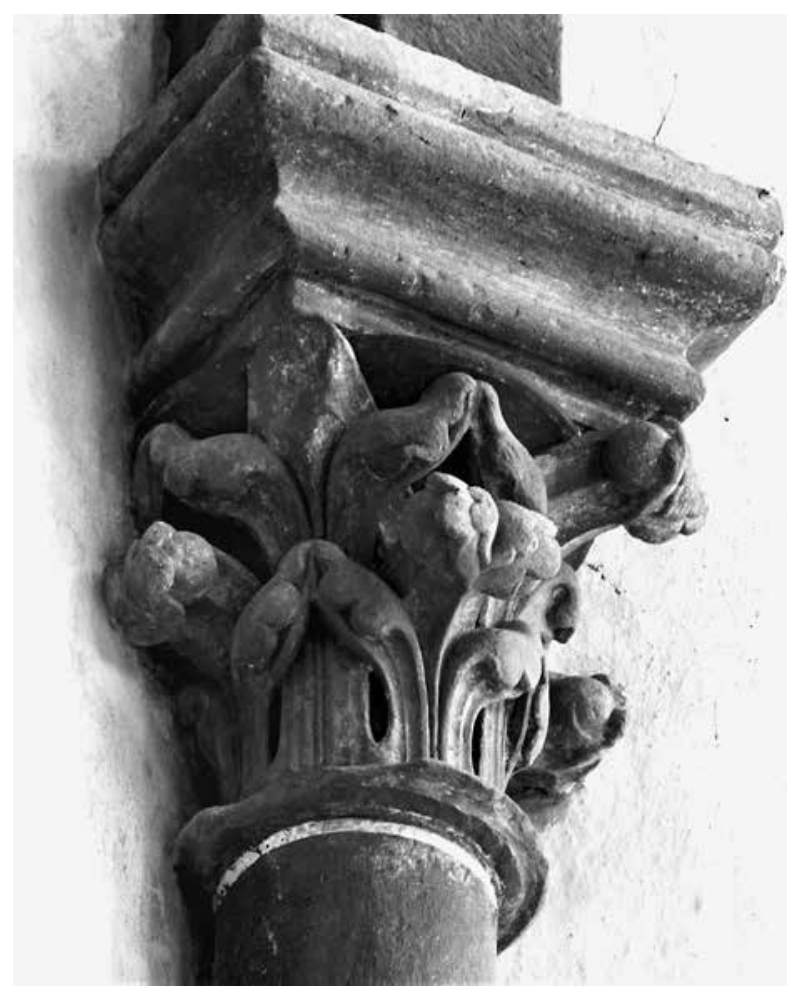

Abb. 88. Kerz, Chor der Klosterkirche, Kapitell eines Eckdienstes (Foto: Imre Takács)
Außer Beiträgen, die durch Quellen des 13. Jahrhunderts und der Prozessionsliturgie nach dem Ordinarius belegt wurden, hat der Historiker László Solymosi kürzlich mit einer wichtigen Angabe zur Funktion der Vorhalle Wesentliches beigetragen, als er über die feierlichen Rechtsprozesse im Mittelalter vor dem Domkapitel und deren Veränderungen

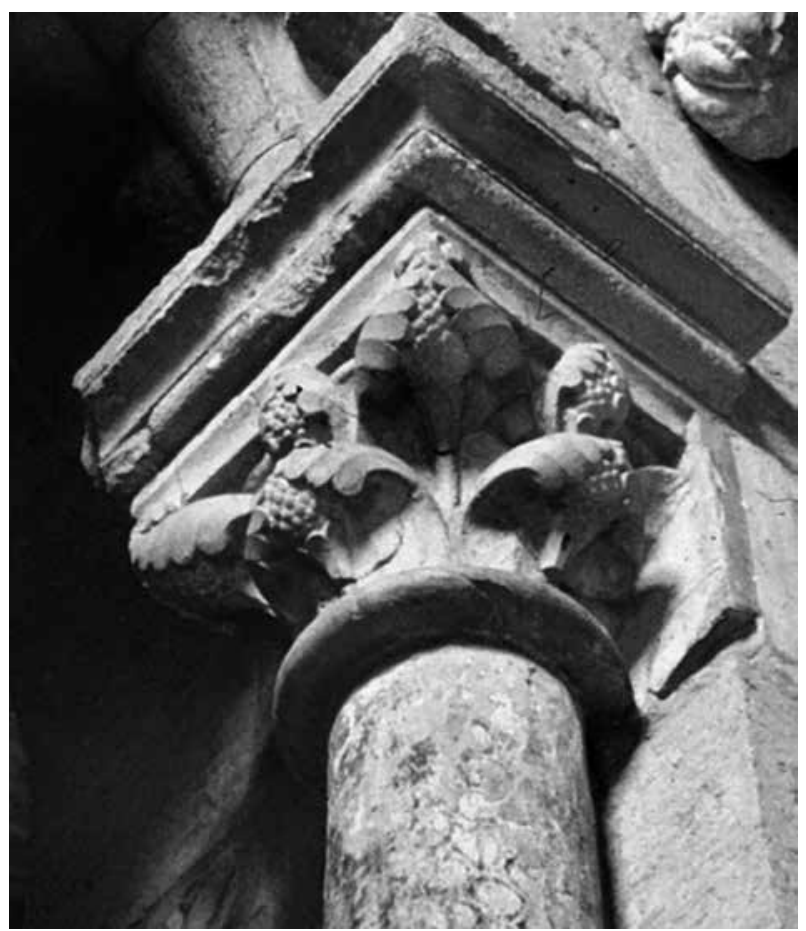

Abb. 89. Burg Esztergom, Kapitell der Nordtür der Palastkapelle

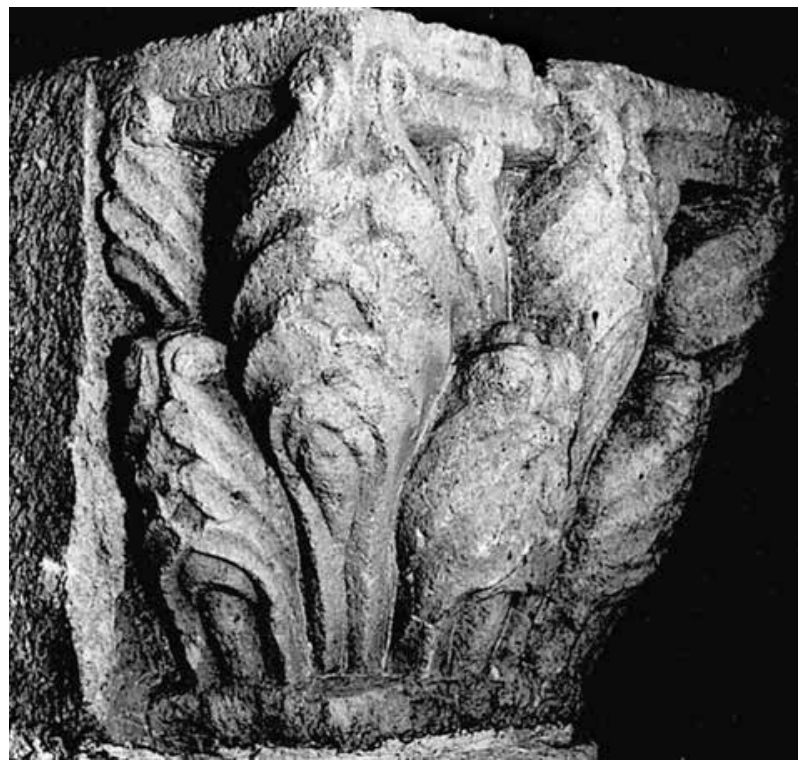

Abb. 90. Eckdienstkapitell aus Vértesszentkereszt. Museum Tata 
schrieb. Dass die Angelegenheiten im Beisein der Domherren nach der hohen Messe vor dem Altar des Heiligen Petrus erledigt wurden, ist 1329 noch belegt, während die Präsenz von zumindest vier
Kanonikern in der Vorhalle der Kathedrale im Visitationsprotokoll von 1397 vorgeschrieben wird. Im Protokoll wird dieser Raum als porticus seu cimiterium erwähnt. ${ }^{85}$

\section{EXKURS \\ ZUR CHRONOLOGIE DER FRÜHEN GOTIK IM LANDESZENTRUM: DAS ZEUGNIS DES ZISTERZIENSERBAUS IM SIEBENBÜRGISCHEN KERZ ${ }^{86}$}

1.

Die Datierung der Gründung der Zisterzienserabtei von Kerz (Abb. 75) auf 1202, die in der älteren historischen Literatur als nicht beweisbar, aber höchstwahrscheinlich angenommen wurde, ${ }^{87}$ pflegte man ebenso wenig zu bezweifeln als die Tatsache, dass sie als Tochter der 1179 gegründeten Abtei Egres auf königliche Initiative gegründet wurde. ${ }^{88}$ Die Urkunde des Königs Andreas II. (1205-1235), in der die Donation des Klerikers Gocelinus für die Abtei Kerz 1223 genehmigt wurde, hat zugleich auch eine andere königliche Donation nach 1205 bestätigt. ${ }^{89}$ Damals hat der Woiwode Benedictus von Siebenbürgen (1202-1206 bzw. 120890), Sohn des Korlát, die Grenzen der Güter der Abtei festgestellt, die aus dem Gebiet der Blacci (Walachen, Rumänen) ausgesondert wurden (terram exemptam de Blaccis ${ }^{91}$ ). Während man wenig von der Verwirklichung der Klostergründung durch König Emmerich von Ungarn (1196-1204) weiß, bezieht sich die Reihe der mit der Donation von 1223 beginnenden urkundlichen Nachrichten auf einen Kolonisationskontext der Zisterziensergründung zusammen mit der Ansiedlung der Rumänen, der Mission der Kumanen sowie der kurzen Existenz des Deutschen Ritterordens in Siebenbürgen. ${ }^{92}$ Der Historiker György Györffy hat in einer kurzen Bemerkung einen auch für die Kunstgeschichte maßgebenden Kontext angedeutet, nach dem die sächsischen Siedler im 13. Jahrhundert sowohl in ihrer Gründungszeit als auch nach den Zerstörungen der Mongolen 1241 entscheidend für die Zisterzienserabtei gewesen seien: „Die Erbauer der Abtei, die die erste Donation vom sächsischen Gebiet erhielten (1203), mögen Sachsen von Hermannstadt gewesen sein. Die Beziehung zum Sachsenland wurde 1264 verstärkt, als die Freiheiten der Hermannstädter vom Jungkönig Stefan ihren Völkern verliehen wurden. ${ }^{\prime 93}$ Es ist sicher, dass Kerz in den Beschlüssen des Generalkapitels von Cîteaux als sehr entlegenes Kloster vorkommt, von dem schon 1207 und 1208 geklagt wurde, dass sein Abt bereits seit zehn Jahren nicht zur Versammlung gekommen sei und dass er deshalb entweder begünstigt oder gerade sanktioniert werden müsse. ${ }^{94}$ Inwieweit man die Gesetzgebung des Ordens in Kerz gekannt haben mag, kann eine eher realistische Bemerkung bezeugen: „Es ist sogar auszuschließen, dass sie die aktuellen Statuten des Jahres jeweils besorgt haben." 95

Aus der Frühzeit des Klosterbaus kann eine Inschrift (Abb. 76) stammen, die vor Kurzem offensichtlich beim Ordnen der Baufragmente der Kerzer Abtei zum Vorschein kam. ${ }^{96}$ Die Inschrift beinhaltet ebenso wenige unmittelbare Daten zur Baugeschichte, wie die anderen, zur Verfügung stehenden schriftlichen Quellen. Auf Grund des Wortlauts und der epigraphischen Eigenschaften erwies sie sich aber als ein wichtiges Zeugnis des frühen Klosterlebens in der Abtei.

Der Inschriftenstein beträgt $54 \times 70 \mathrm{~cm}$ und die Breite beläuft auf $17 \mathrm{~cm}$ - daher ist er wohl eher als eine Tafel als ein Quader zu bezeichnen. Seine Oberfläche wurde durch fünf Linien in sechs Zeilen geteilt, in denen der oben mit größeren Buchstaben in breiteren Abständen eingemeißelte Text nach unten mit immer kleineren Buchstaben und dichter erscheint (um den Text innerhalb der gegebenen Fläche zu unterbringen). Die Tafel weist moderne Veränderungen - etwa Bemalung der Buchstaben - und auch Beschädigungen, vor allem das Fehlen der oberen Ecke auf der rechten Seite, auf. Als problematisch kann die Ergänzung der Fehlstellen und in gewissen Fällen auch die Auflösung der Abkürzungen erscheinen. Die hypothetische Lesung ist:

SI CVPIAS - HO[hic?] ... [e] SSE • VIAS - VITE . $\mathrm{B}$ [ona]

$\mathrm{S} \cdot \mathrm{HVI}(\mathrm{us}):$ HVC $\cdot$ VENIA[s?]

HVC $\cdot$ P(ro)SPITIAS · Q(u) ID(a? - e?)M

BONA · CVI(us). VIX · POSSES - FA

RI $\cdot$ NEC $\cdot$ OPES $\cdot$ POSSENT $\cdot$ NVME[rari]

Bei der Ergänzung und der Interpretation des sonst ungegliederten, sogar die Grenzen der Wörter außer Acht lassenden Texts können End- und Binnenreime helfen (cupias - vias, venias - prospitias, fari - 
nume[rari], wegen Platzmangels nicht vollständig). Die hypothetische Deutung kann etwa sein: „Wenn du hoffst, dass die guten Wege dieses Lebens hier seien, komm hierher, und wirst hier so viele verschiedene Güter haben, dass du es nicht sagen kannst, und der Reichtum kann nicht gezählt werden." Durch die Inschrift wird der Eintretende auf die spirituellen Vorteile des Mönchslebens und des Klosters aufmerksam gemacht, wohl in dem Sinne - und vielleicht auch im Textkontext - wie der Anfangssatz des Buchs De vera religione vom Heiligen Augustin: cum omnis vitae bonae ac beatae via in vera religione sit constituta... ${ }^{97}$

In der Inschrift herrschen Antiquabuchstaben (in gewissen Fällen - 'A', eckiges und bogenförmiges ' $\mathrm{C}$ ' sowie Alternativen von kapitalem ' $\mathrm{H}$ ' und 'B' mit unzialem ' $h$ ' und 'b'). In zwei Fällen gibt es eine Abkürzung durch enklavenartig verwendetes 'I'. Der Endbogen vom 'P' steht für 'pro-', eine Verzweigung vom 'I' für das Suffix des Genitivs. Einheitlich erscheinen 'BO', 'PO' und 'ME' (Ligaturen). Eine horizontale Linie oberhalb des unzialen 'b' kann auch als Ligatur gedeutet werden. Aufgrund dieser epigraphischen
Eigenschaften kann die Inschrift auf die Zeit um oder kurz nach 1200, also auf die Gründungszeit der Abtei, datiert werden. ${ }^{98}$

2.

Die Konzeption einer "Werkstatt von Kerz" wurde implizit auf zwei Feststellungen - in der Tat: Hypothesen - gegründet: Die erste ist auf die Existenz einer Zisterzienserbaukunst in typologischem oder auch stilistischem Sinn gerichtet und die zweite auf die Beschäftigung der für den Orden tätigen Meister in der gegebenen Region auch außerhalb des Ordens. In dieser Hinsicht erschien eine vorsichtige Formulierung von Géza Entz über „eine Werkstatt, die unmittelbar mit der königlichen Kunsttätigkeit verbunden war" als bahnbrechend. Entz hat sich dabei auch mit der Tätigkeit dieser Werkstatt „von nicht monastischem Charakter" in siebenbürgischen Bereichen, die „etwas mit dem König zu tun haben", beschäftigt. Offensichtlich vermied er klare Bezeichnungen, wie etwa

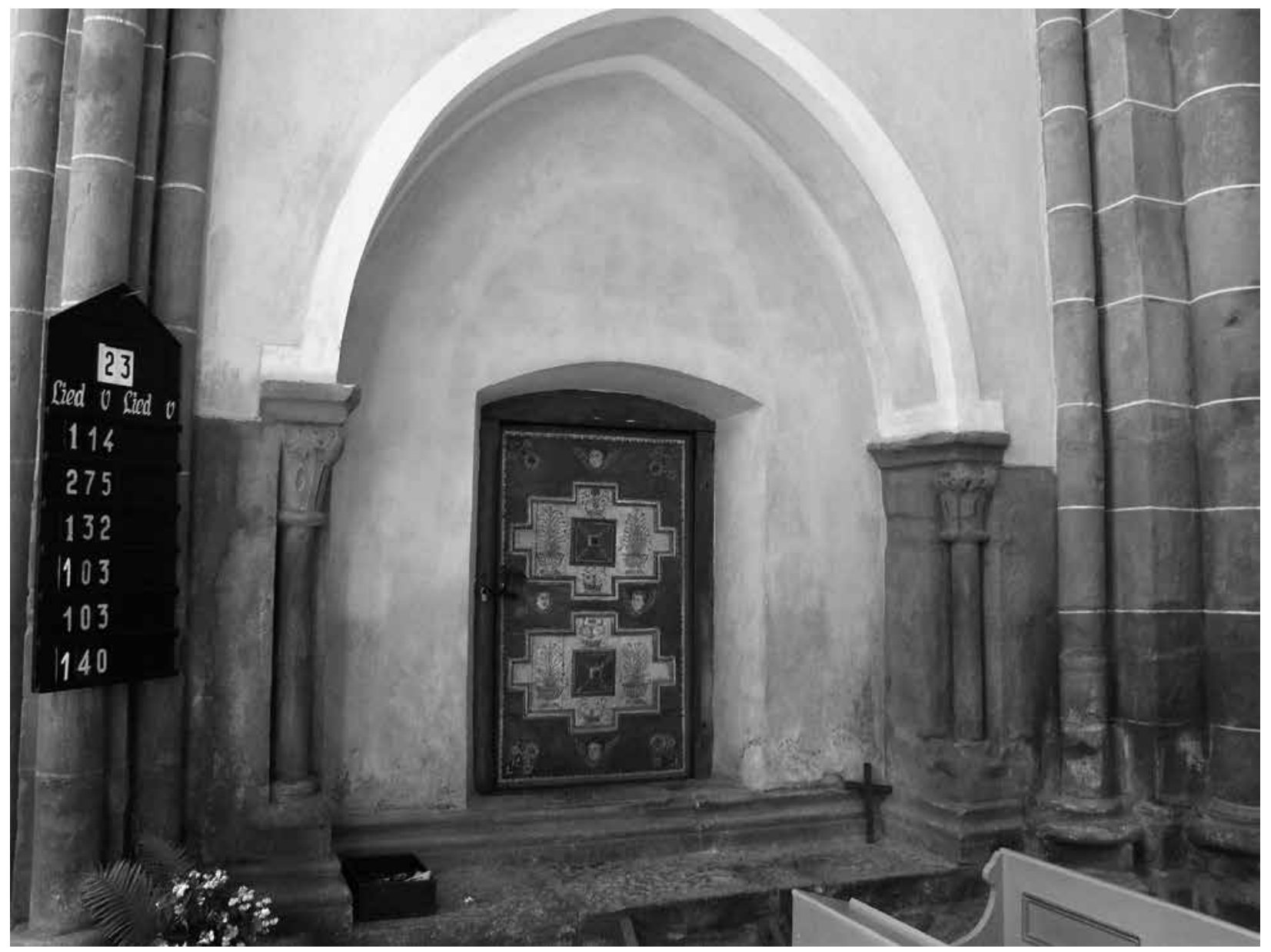

Abb. 91. Kerz, südliche Nische im Chor der Abteikirche (Foto: Imre Takács) 


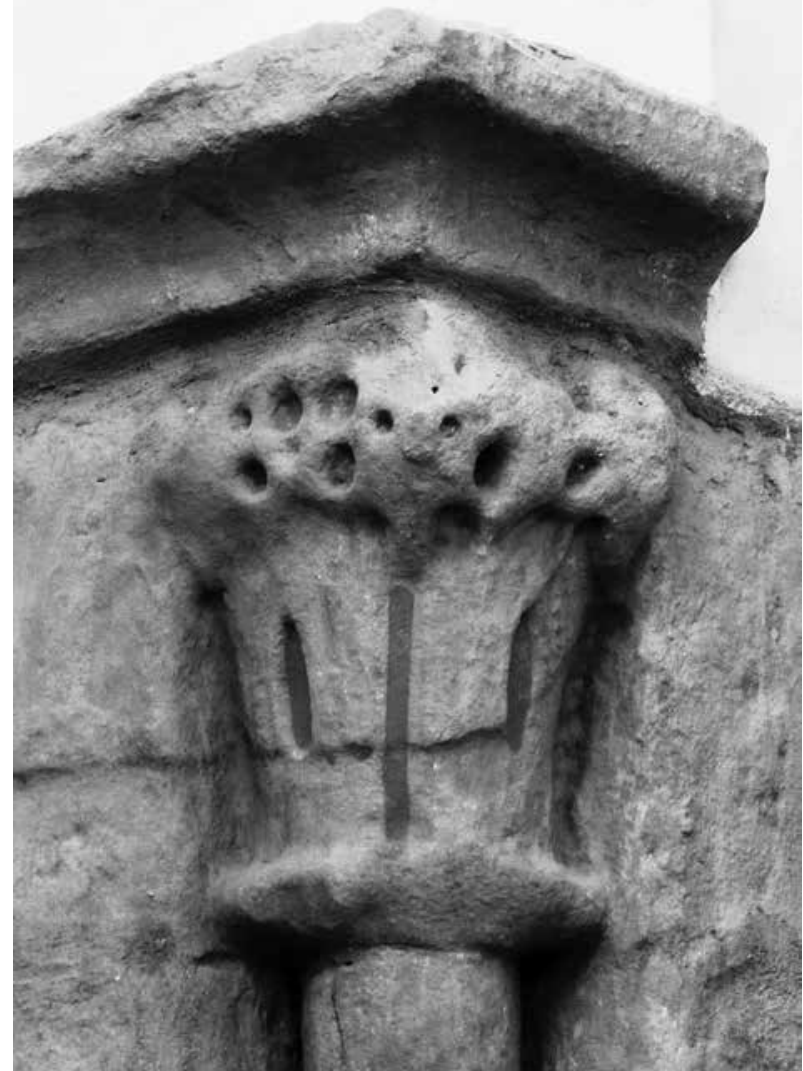

Abb. 92. Kerz, Abteikirche, Chor, Kapitell der südlichen Nische (vgl. Abb. 91) (Foto: Imre Takács)

„königliche Repräsentation“ oder „Hofkunst“ bei der Charakterisierung des komplizierten Bezugssystems zwischen dem Kloster königlicher Gründung, den privilegierten Siedlungen und den durch die RegaleRechte zur königlichen Aufsicht gehörenden Orten des Salz- und Silberbergbaus. ${ }^{99}$ Für die Zeit erscheint dieser grundlegende Aufsatz als neuartig erstens durch die Annahme des Laiencharakters der Werkstatt und zweitens dadurch, dass ihre Parallelen in der Pariser Region, insbesondere unter Dorfkirchen, gesucht wurden. Dank dieser Gedanken ist der Kerz-Aufsatz von Entz eines der bedeutenden Werke der Entdeckung der frühen Gotik in Ungarn.

Diese Bedeutung erscheint am klarsten im Vergleich mit den dominierenden Ansichten der Architekturgeschichte der Zeit. Entz hat die alte Konzeption des „Übergangsstils“ verworfen und auch neuere Grundideen von der "burgundischen Gotik“, ${ }^{100}$ der „Half Gothic“ und der Zisterziensergotik ${ }^{101}$ vermieden. Die ungarische Forschung übernahm eine Deutung der Zisterzienserbaukunst, die in der westlichen Kunstgeschichte der 1950er und 1960er Jahre als Ausdruck eines Wunschbildes der europäischen Einheit (NATO, EU) erschien. ${ }^{102}$

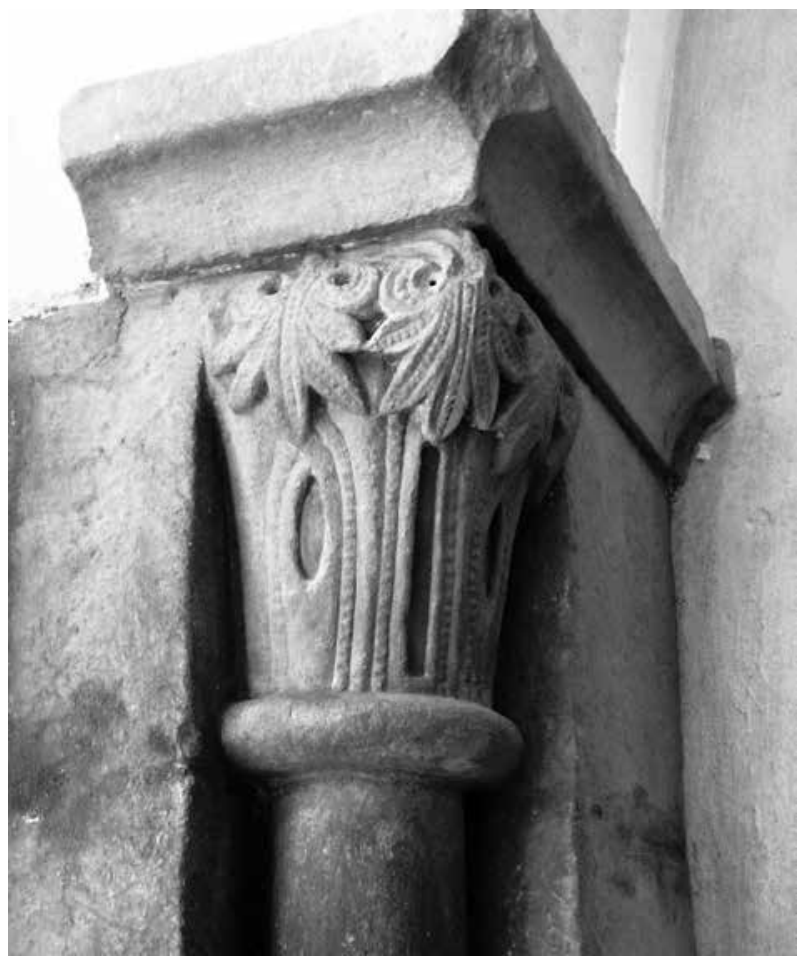

Abb. 93. Kerz, Abteikirche, Chor, Kapitell der südlichen Nische (vgl. Abb. 91) (Foto: Imre Takács)

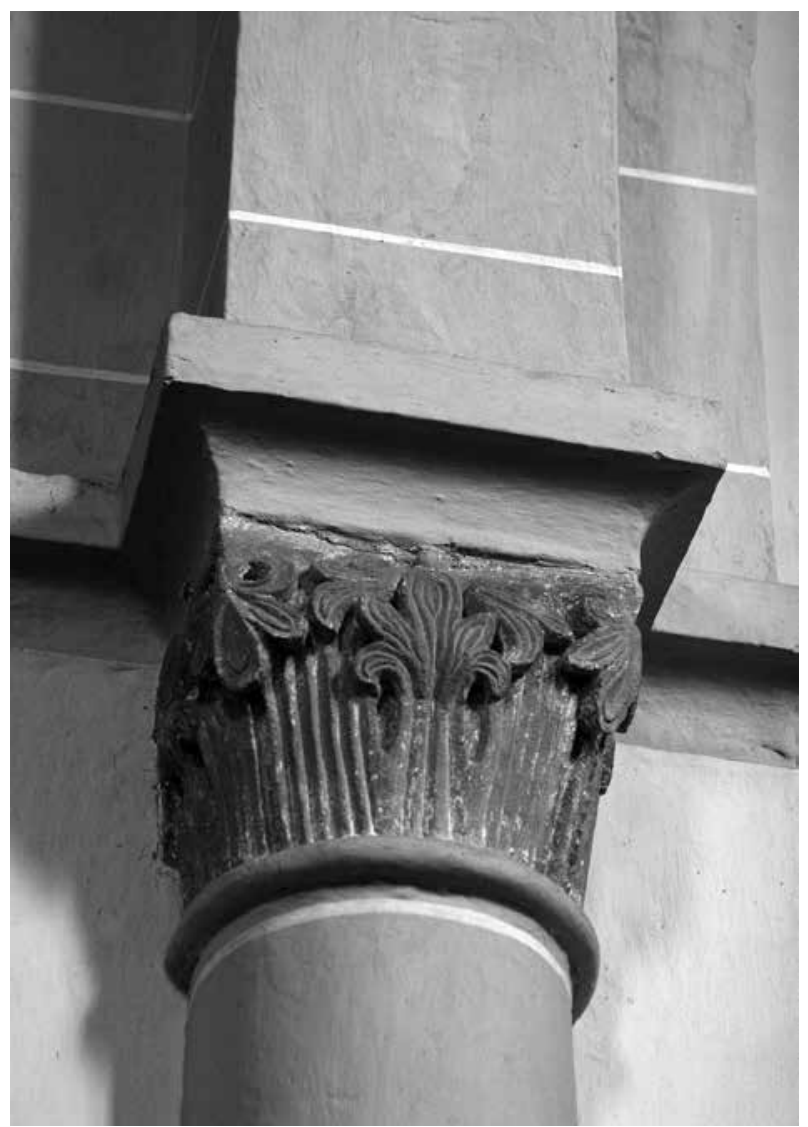

Abb. 94. Honigsberg (Szászhermány, Hărman, RO), Pfarrkirche, Triumphbogenkapitell 


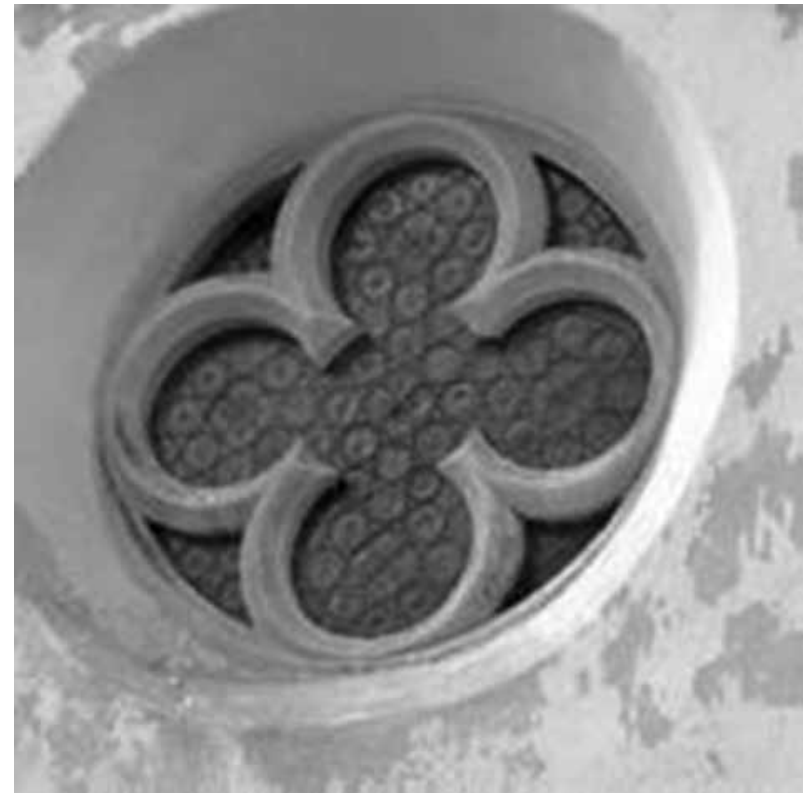

Abb. 95. Honigsberg, Pfarrkirche, Rundfenster im Obergaden des Mittelschiffs

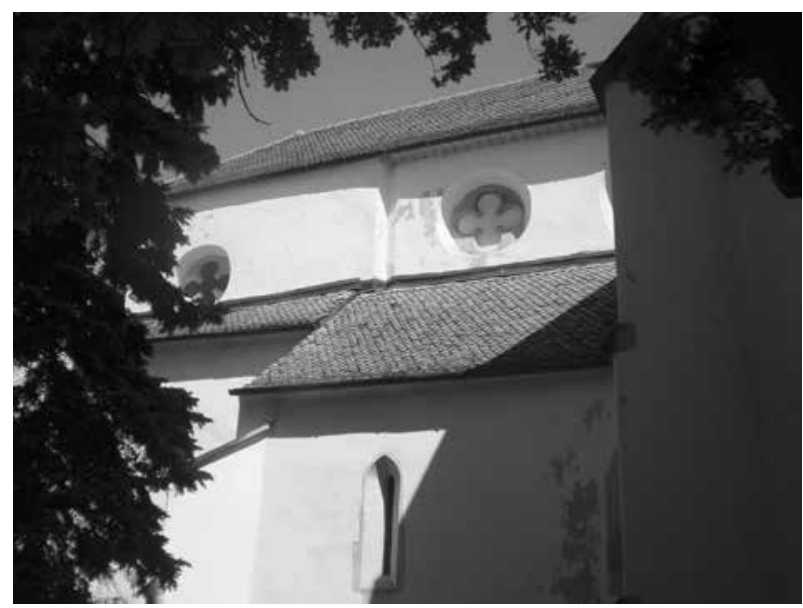

Abb. 96. Tartlau, Pfarrkirche, Langhaus von Süden

Matthias Untermann hat die dem so genannten bernhardinischen Grundriss zugeschriebenen funktionalistischen und modularen Deutungen als eine „NachBauhaus"-Erscheinung gekennzeichnet. Seine gründliche historiographische Analyse der kunstwissenschaftlichen Theoriebildung kann hier statt einer eingehenderen Analyse stehen, da Untermann u. a. Wichtiges zur Beurteilung der Architektur von Kerz beigetragen hat. ${ }^{103}$ Untermann hat sich statt des bestimmenden Einflusses der Vorschriften der Gesetzgebung des Ordens eher auf die Bedeutung der Verfolgung baulicher Modelle in der Zisterzienserarchitektur fokussiert, die von Richard Krautheimer als „Ikonographie der Baukunst" bezeichnet wurde. ${ }^{104}$ Wohl geht es genauer um eine Ikonologie der Bauten, die sich auf den seit

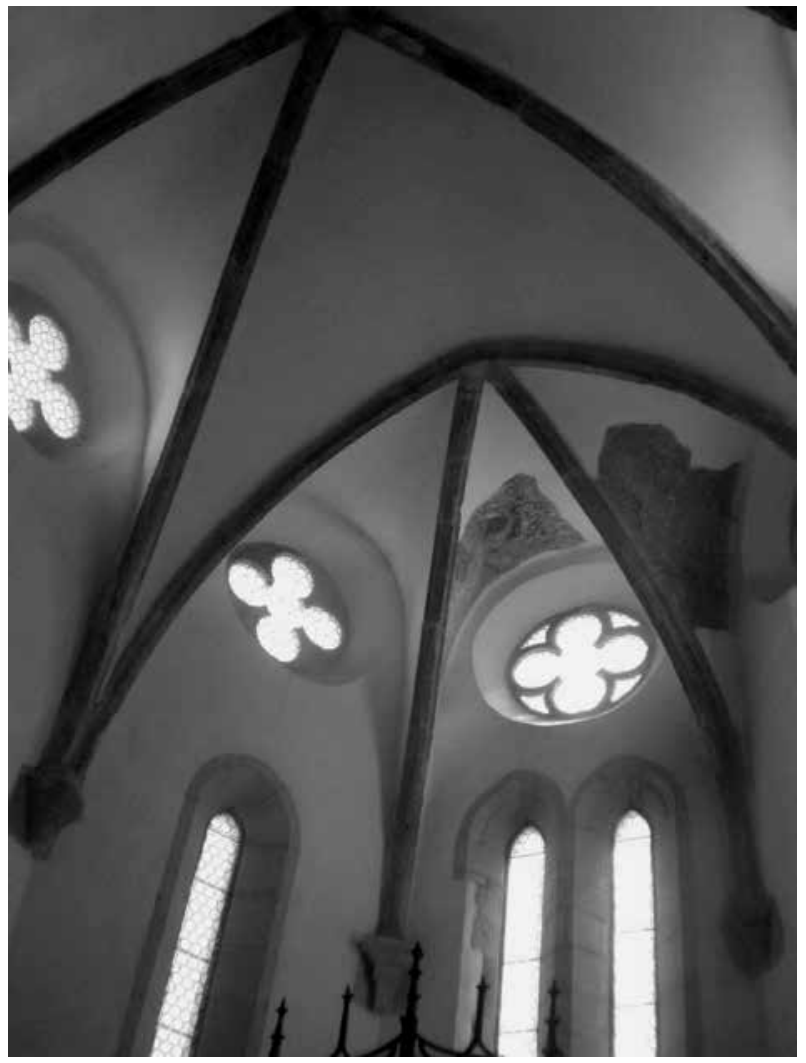

Abb. 97. Tartlau, Pfarrkirche, Inneres des Ostchors

1200 häufig von den Generalkapiteln benutzten Ausdruck forma ordinis bezieht. Der Ausdruck umschließt die drei Grundsätze des Zisterzienser-Bewusstseins, die Einheitlichkeit (uniformitas), den habitus sowie die Vermeidung des Überflüssigen (superfluum). ${ }^{105}$ Für die ungarischen Monumente der Zisterzienserbaukunst gilt die dritte von Untermanns drei Generationen zwischen 1180 und 1240, wobei er unter dem Titel „Traditionen und Neuerungen" Erscheinungen behandelt, die das Ende der Glanzzeit und die Gotikrezeption gleichzeitig bezeichnen. Auch im Bestand der Zisterzienserbauten von Ungarn spielt der traditionelle, jedoch modernisierte bernhardinische Typus (Zirc und Pilisszentkereszt bzw. Bélapátfalva) die vielleicht wichtigste Rolle, ${ }^{106}$ dessen polnische Parallele dort „Kolonisationstypus“ genannt wird. ${ }^{107}$ Die Umstände der Kolonisation kommen in Kerz besonders nachdrücklich in Betracht: Hier sind die Querschiffarme mit zwei Kapellen versehen, wie bei den größeren königlichen Gründungen Zirc und Pilis. ${ }^{108}$ Untermann hat den um ein Joch verlängerten Chor - ähnlich wie im ungarischen Szentgotthárd, höchstwahrscheinlich im Kloster Marienberg (Borsmonostor, Klostermarienberg, A), allerdings mit geradem Abschluss des Chors, und wohl auch in Pétervárad (Petrovaradin, Novi Sad, 


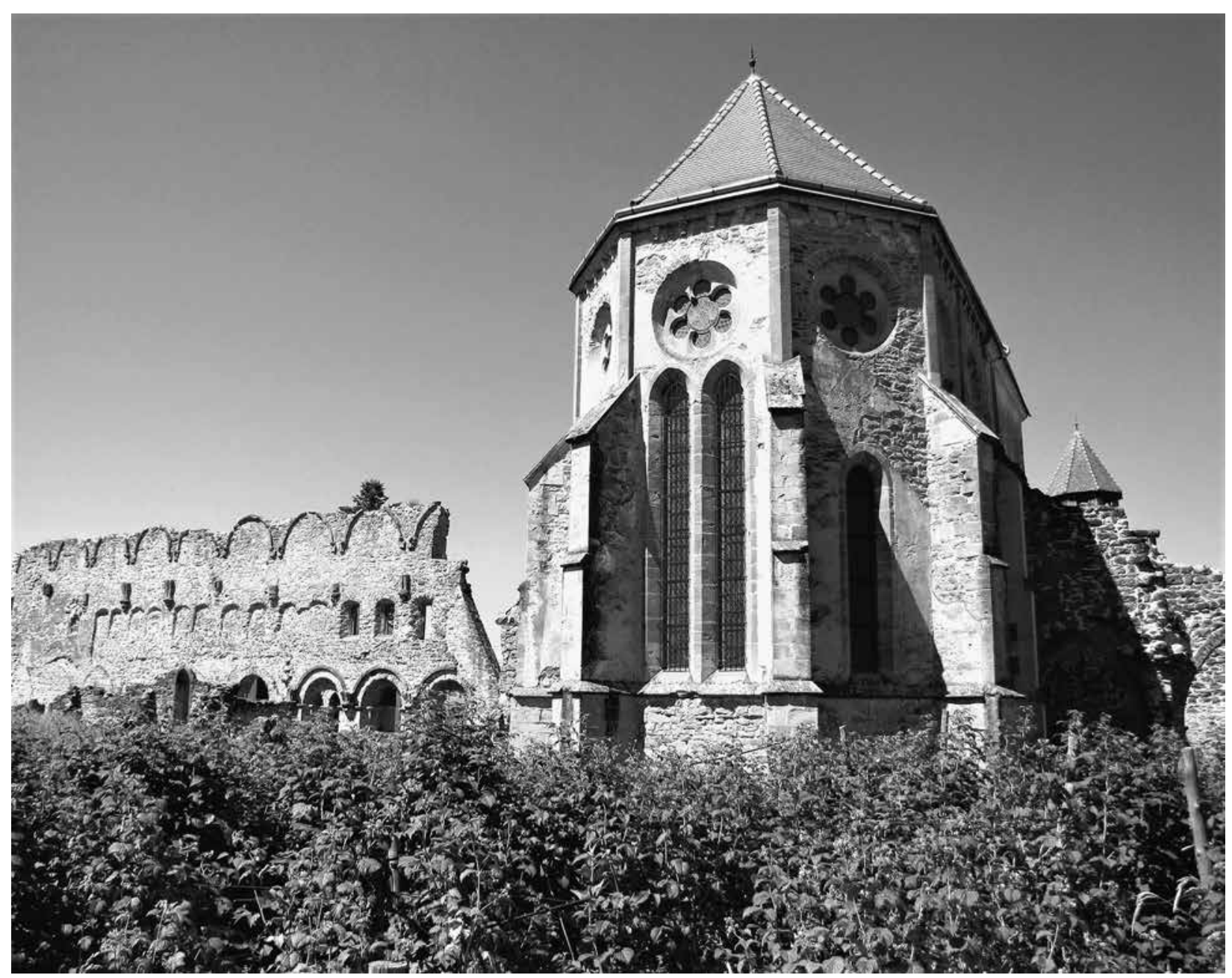

Abb. 98. Kerz, Chor, Ansicht von Nordost (Foto: Imre Takács)

SRB $)^{109}$ - als eine modernisierte Variante des bernhardinischen Typs in sein typologisches System eingegliedert. ${ }^{110}$ Als eine Parallele für den gotisch gewölbten 5/8 Chor hatte bereits Géza Entz die Abteikirche San Martino al Cimino bei Viterbo angeführt. ${ }^{111} \mathrm{Im}$ italienischen Kirchenbau, wo Spuren einer ursprünglich geplanten sechsteiligen Wölbung im ersten Mittelschiffsjoch zu finden sind, scheint eine Verwandtschaft mit dem siebenbürgischen Zeitgenossen noch wahrscheinlicher zu sein. ${ }^{112}$ Der einzig erhaltene Teil der Gliederung des Kerzer Langhauses (Abb. 77-78) zeigt, wie der lokale Gebrauch der Maurerarbeit unter Verwendung von Bruchsteinen durch feinere Steinmetzarbeiten der Wölbung abgelöst wurde. (Von der Wölbung zeugen in diesem Teil allein ein Kragstein und ein Rundfenster.)

Der Bautypus und auch die Details der wohlerhaltenen Chorpartie der Abteikirche von Kerz (Abb. 79) bestätigen die Hypothese von Entz, wonach ihre Architektur auf eine Herkunft aus den königlichen
Zentren in der Mitte Ungarns hinweist. Es handelt sich vor allem um Fragmente von Esztergom aus der Zeit um oder nach 1200, wie eine Basis eines in der Technik der fûts-en-delit ausgeführten Dienstbündels, die der ehemaligen Kirche des Heiligen Stephan des Protomärtyrers zugeordnet werden konnte (Abb. 80). ${ }^{113}$ Ähnliche gotische Fragmente kommen auch in Esztergom vor, ${ }^{114}$ aber in noch größerer Zahl in der Bauskulptur aus dem ehemaligen Zisterzienserkloster von Pilis, die nicht nur Grabungsfunde sind, sondern es gibt auch Stücke, die als Baumaterial in der Neuzeit nach Esztergom transportiert wurden. Es geht um eine Reihe von Baugliedern aus dem Kreuzgang und der Kirche des Klosters (Abb. 81). ${ }^{115}$ Ihre Provenienz wurde von neueren Forschungen geklärt - und die Annahme angeregt, dass allein die Zisterzienserabtei von Pilis Schauplatz dieser Architektur war. Es ist wohl wahrscheinlicher, dass um 1200 dieselbe Werkstatt sowohl in Esztergom als auch am nahe gelegenen Zisterzienserbau tätig war. Unter den Dienstkapitellen 


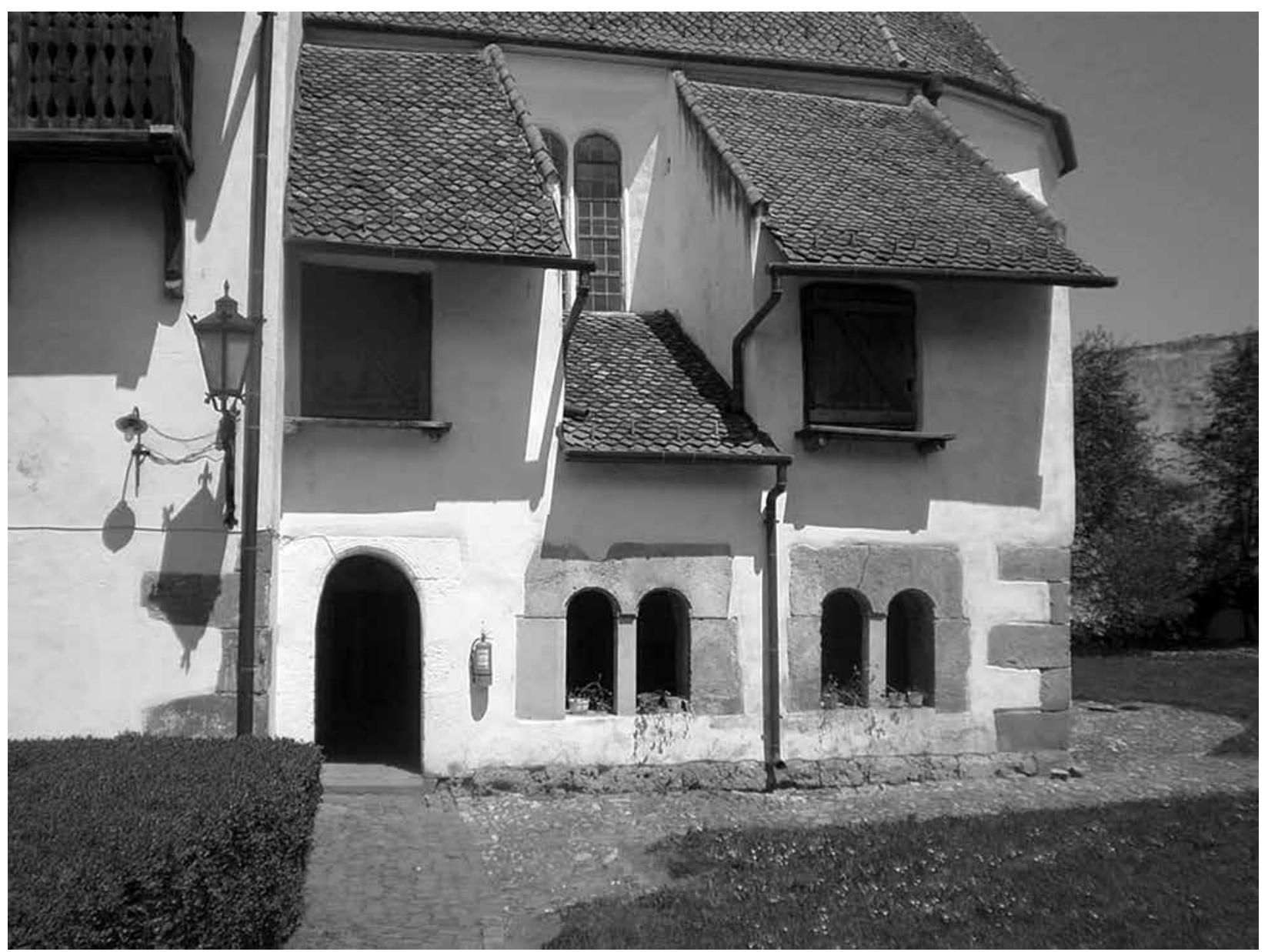

Abb. 99. Honigsberg, Pfarrkirche, Ansicht der Ostpartie von Süden (Budapest, Planarchiv des ehemaligen Denkmalamtes)

des Kerzer Chors (Abb. 79) dominieren Kelchkapitelle mit spitzen Blättern, in der Südwestecke des nördlichen Querschiffarms gibt es jedoch ein Kelchkapitell mit Knospen und aufgesetzten Blättern (Abb. 82), ${ }^{116}$ dessen Typus im Bauschmuck des Klosterbaus - in situ am Doppelfenster des Kapitelsaals (Abb. 83) - herrscht. Der Klosterbau mag jünger als der Chor sein (Abb. 84), was sich auch in seiner Verwandtschaft mit der so genannten "Giselakapelle" von Veszprém (Abb. 85), einem Bau der 1230er Jahre, ausdrückt. Den im Chor von Kerz befindlichen Kapitellformen haben bestimmt ähnliche Stücke aus Pilisszentkereszt - wie Werkstücke eines achteckigen Pfeilers (Abb. 86) ${ }^{117}$ und ein feingliedriges Kapitell auf der rechten Seite einer Portalöffnung (Abb. 87) ${ }^{118}$ - als Vorbilder gedient. Unter den Dienstkapitellen des Chorhaupts findet man in Kerz ein einziges Stück mit Halbpalmetten, die eine Blattknospe bilden, eine besonders zierliche Bildhauerarbeit (Abb. 88), deren Vorbild wohl in Esztergom (Abb. 89) ${ }^{119}$ und weitere Verwandten an Bauten des ersten Viertels des 13. Jahrhunderts zu finden sind:

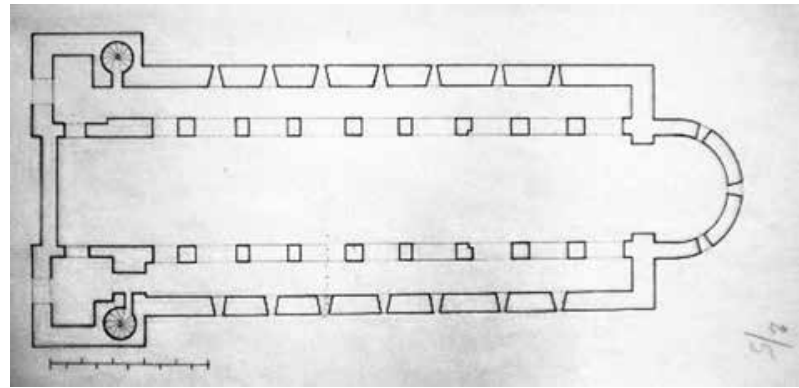

Abb. 100. Mühlbach (Szászsebes, Sebeş, RO), Grundrissrekonstruktion der Pfarrkirche, Bau I (Lívia Varga: VARGa 1984, Abb. 2)

Ócsa, Chorquadrat; ${ }^{120}$ Vértesszentkereszt, Kapitelle (Abb. 90); ${ }^{121}$ ein Kragstein in Pannonhalma. ${ }^{122}$ All diese Parallelen sind nur motivisch-typologisch, nicht stilistisch. Der ehemalige Prämonstratenserbau in Ócsa hat eine Art Mittelstellung zwischen der Richtung der frühen Gotik in der Mitte des Landes in Esztergom und an der Zisterze bzw. den späteren Bauten der königlichen Burg in Óbuda sowie der Kathedrale Kalocsa II eingenommen, wie seine Bauornamentik es klar zeigt. 


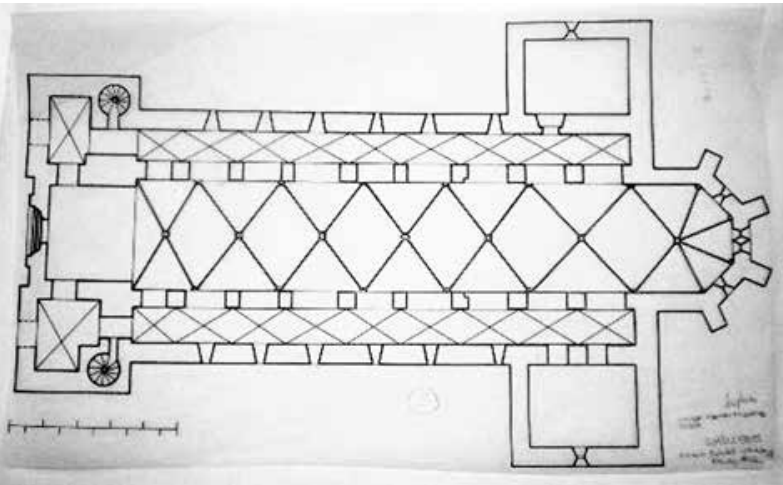

Abb. 101. Mühlbach, Grundrissrekonstruktion der Pfarrkirche, Bau II (Lívia Varga: VARGA 1984, Abb. 3)

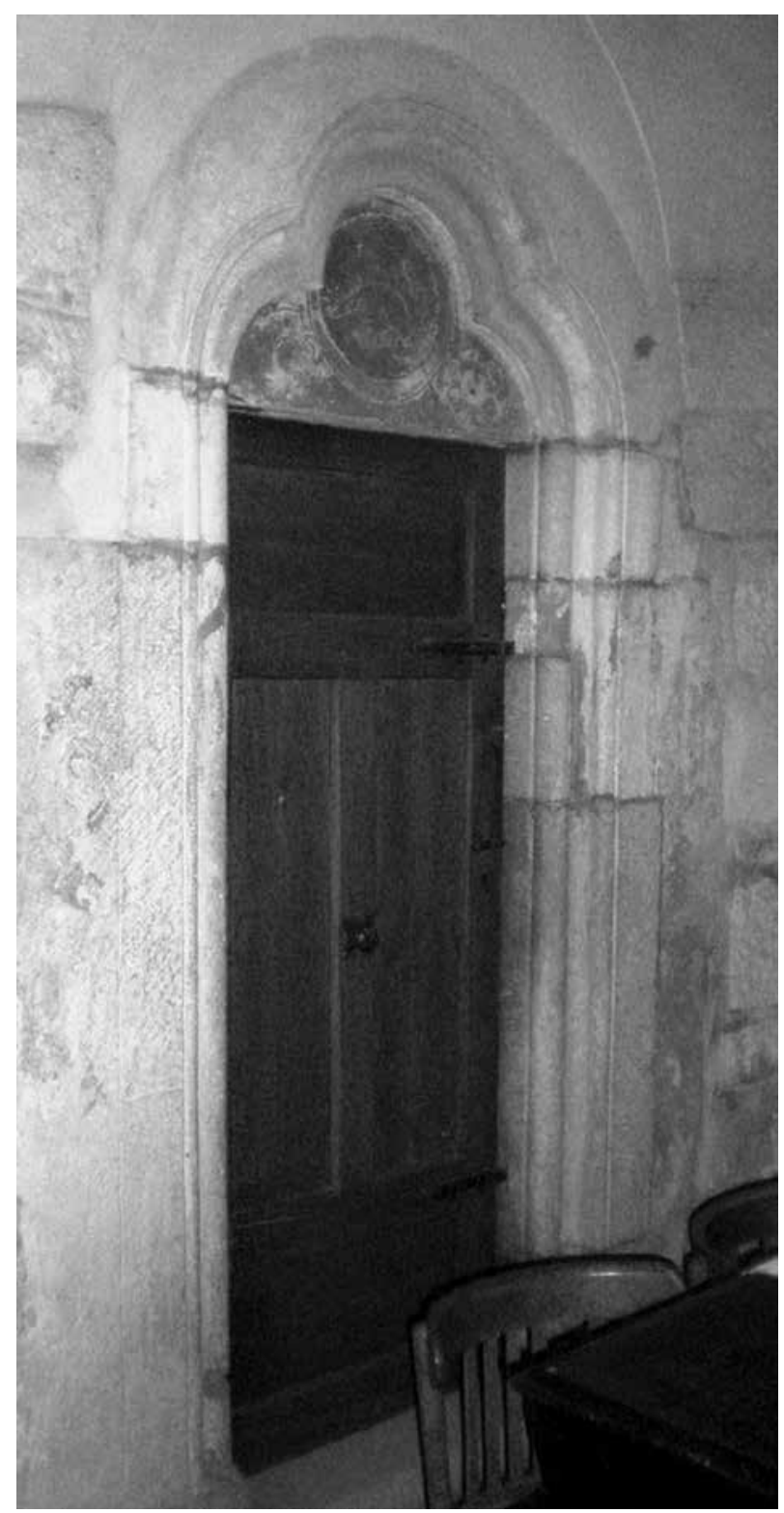

Abb. 102. Mühlbach, Pfarrkirche, Sakristeitür

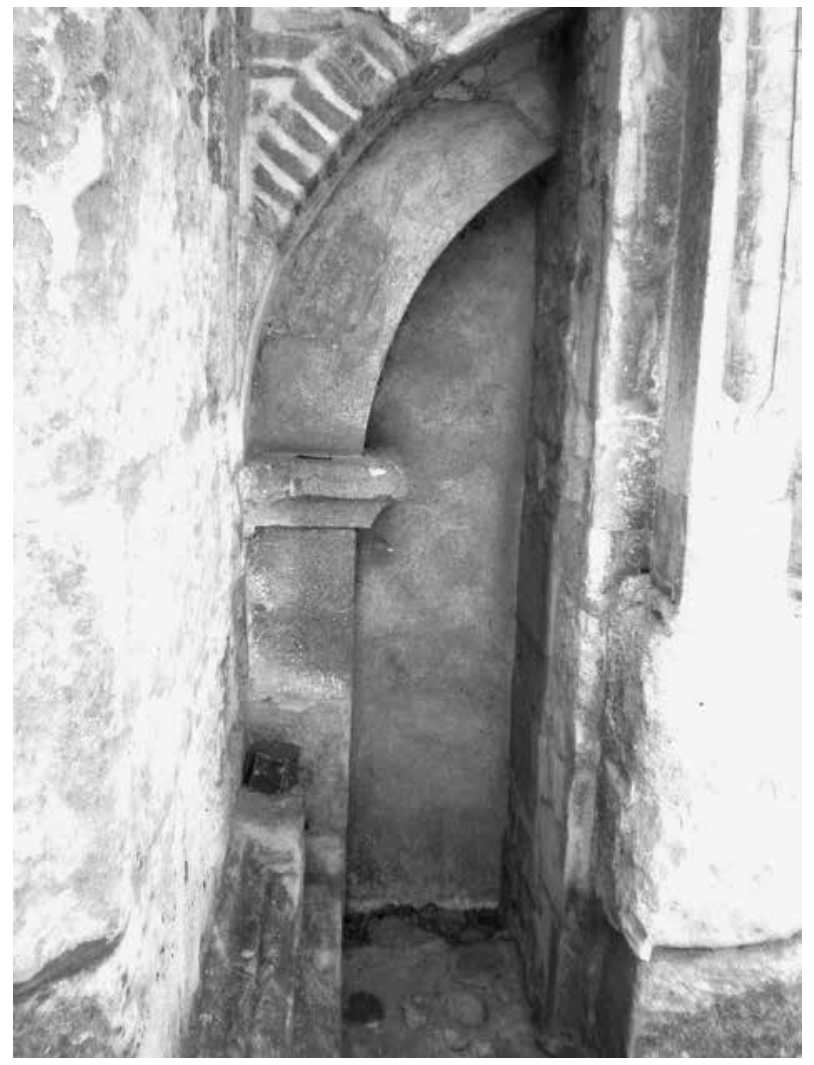

Abb. 103. Mühlbach, Pfarrkirche, südliches Chorportal, Fragment

Ungeachtet der jüngst aufgetauchten Unterscheidung zwischen dem "konservativen“ - wohl einfach nur als Fortsetzung einer älteren Bautätigkeit begonnenen - Werkstattbetrieb in Esztergom und einem unabhängigen „modernen“ am Zisterzienserkloster in Pilis scheint die jüngere Gruppe, deren Schwerpunkt in der kunsthistorischen Literatur um 1220 angesetzt wird, ${ }^{123}$ weniger Bedeutung für Kerz gehabt zu haben. Diese Datierung entspricht der von der Mehrheit der Fachliteratur vertretenen Meinung, nach der Kerz bei dem Mongolensturm von 1241 bereits fertiggestellt sein sollte.

Im sonst einheitlichen Bauschmuck frühgotischer Prägung des Kerzer Chors vertreten die Blockkapitelle der großen südlichen Nische des Chorjochs (Abb. 91-93) einen älteren („romanischen“) Stil, dessen sowohl geographisch als auch stilistisch nahe lokale Parallele in Honigsberg (Szászhermány, Hărman, RO) nachgewiesen werden kann. ${ }^{124}$ Die Kapitelle des Honigsberger Triumphbogenpfeilers (Abb. 94) weisen eine ähnliche Blattbehandlung und auch ähnliche Diamantenreihen wie die Nischenkapitelle von Kerz auf, die vor dem Auftritt der frühgotischen Gliederung von der Arbeit lokaler Bauleute 


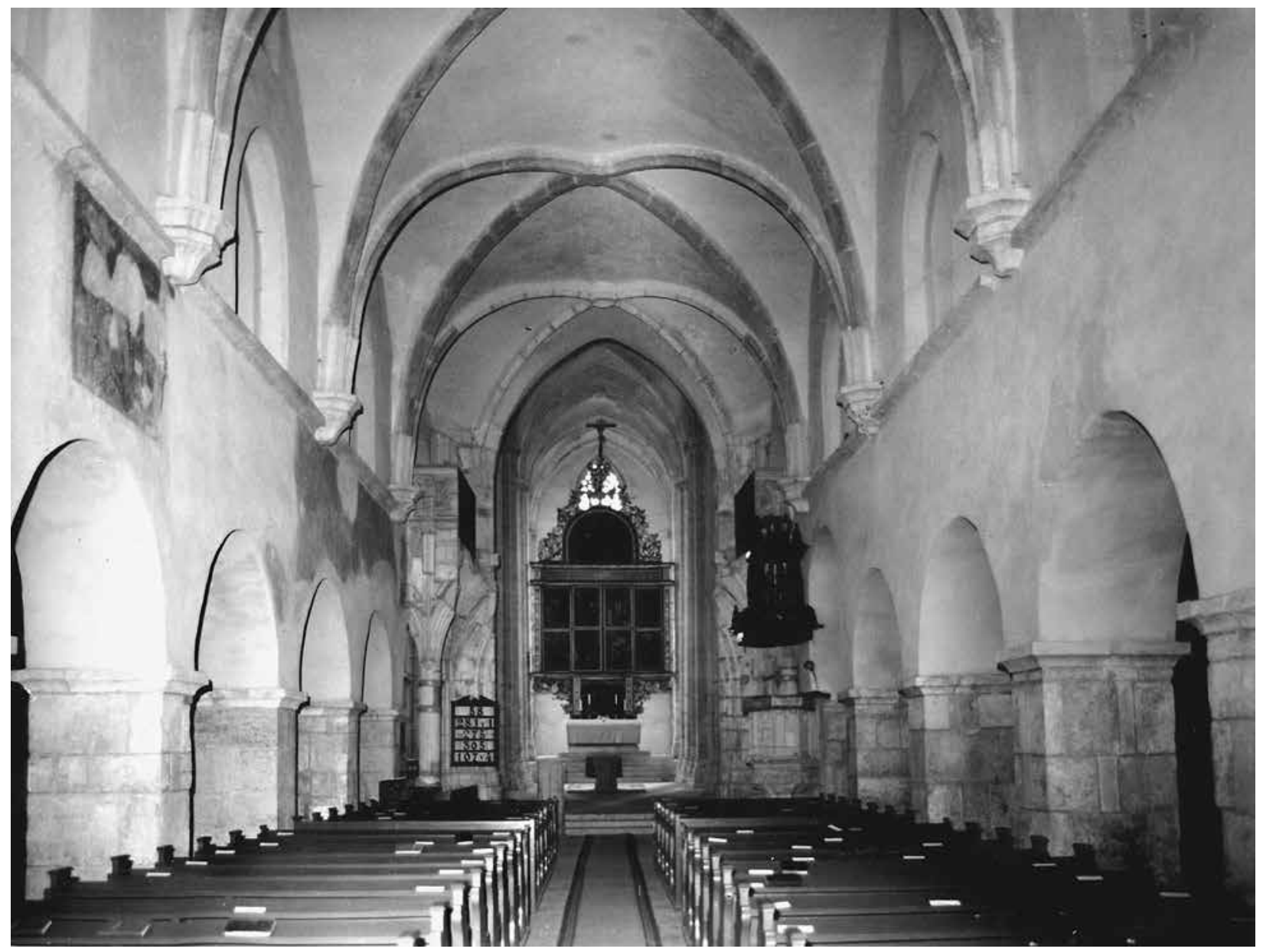

Abb. 104. Mühlbach, Pfarrkirche, Inneres des Langhauses von Westen (nach VARGA 1984, Abb. 26)

zeugen mögen. Auch die einfache Bildung der Langhauspfeiler weist auf die Zusammenarbeit mit lokalen Bauleuten hin. Es ist allerdings fraglich, wie das Honigsberger Langhaus, an dessen Obergaden vierpassförmig gegliederte Rundfenster (Abb. 95) - wobei ihre genauen Parallelen sich auch in Tartlau befinden (Abb. 96-97) - von Beziehungen zu Kerz zeugen, sich zu den Ostpartien der Kirche (Abb. 98) verhält. Die anzunehmenden Beziehungen zu Honigsberg betreffen nicht nur die Frage der Datierung, sondern sie mögen auch zur konkreten Kenntnis der lokalen Baupraxis beitragen, die beim Zisterzienserbau in Anspruch genommen wurde. Es scheint, dass die parallel mit dem Mittelschiff der Chorpartie gebauten gewölbten Nebenräume wie in Honigsberg (Abb. 99) ihre Wurzel auch in Kronstadt (Brassó, Braşov, RO), Tartlau (Prázsmár, Prejmer, RO), Mühlbach (Szászsebes, Sebeş, RO) und Szék (Sic, RO) ${ }^{125}$ in lokalen Bautraditionen hatten.

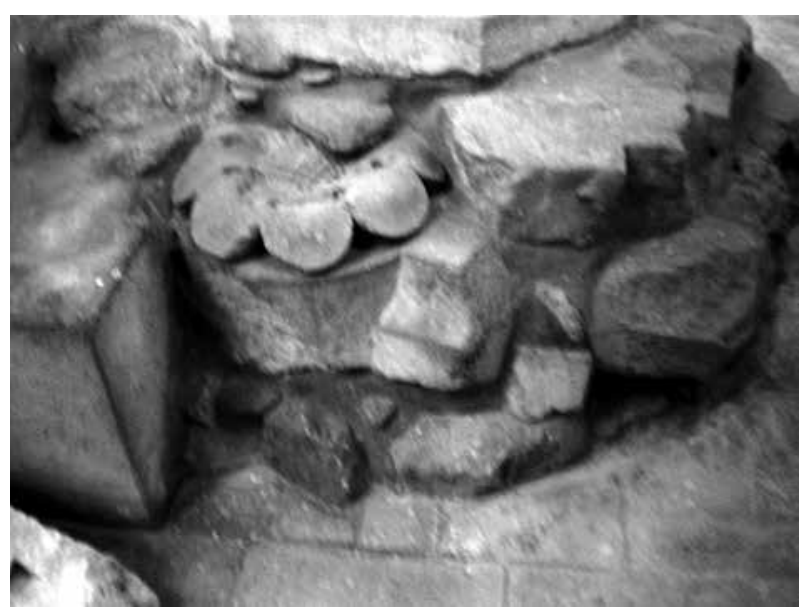

Abb. 105. Mühlbach, Pfarrkirche, Schlussstein des 13. Jahrhunderts in der Grundmauer eines Pfeilers des Hallenchors 
3.

Die Unterscheidung regionaler Eigenschaften von den „Kerzern“ spielt in der Baugeschichte der Pfarrkirche von Mühlbach eine Rolle. Ihre Bedeutung besteht darin, dass sie ein städtischer Bau im Kerngebiet der

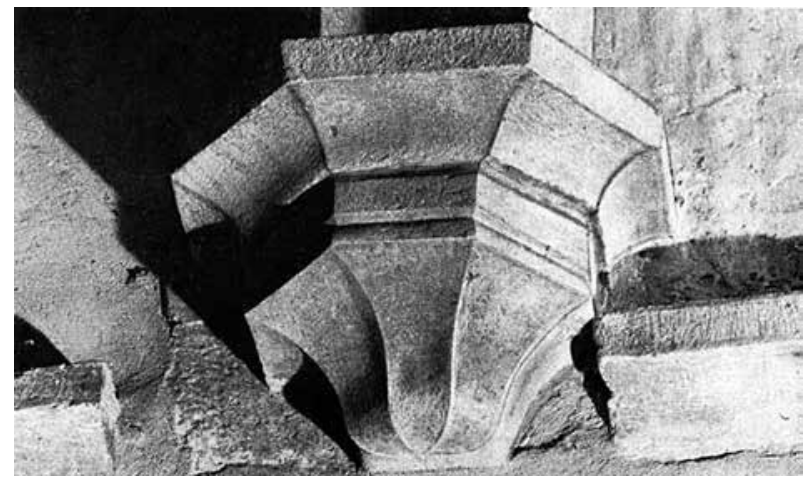

Abb. 106. Mühlbach, Pfarrkirche, Konsole des Mittelschiffsgewölbes

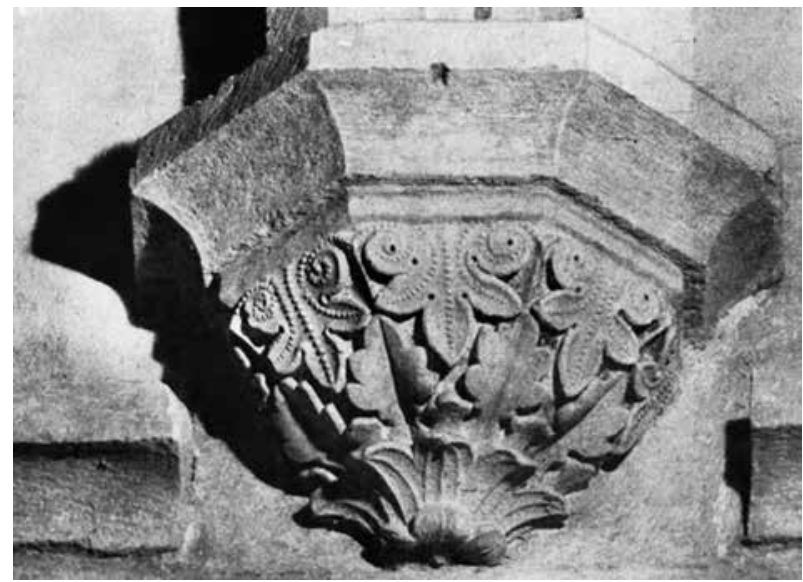

Abb. 107. Mühlbach, Pfarrkirche,

Konsole des Mittelschiffsgewölbes (VARGA 1984, Abb. 29)

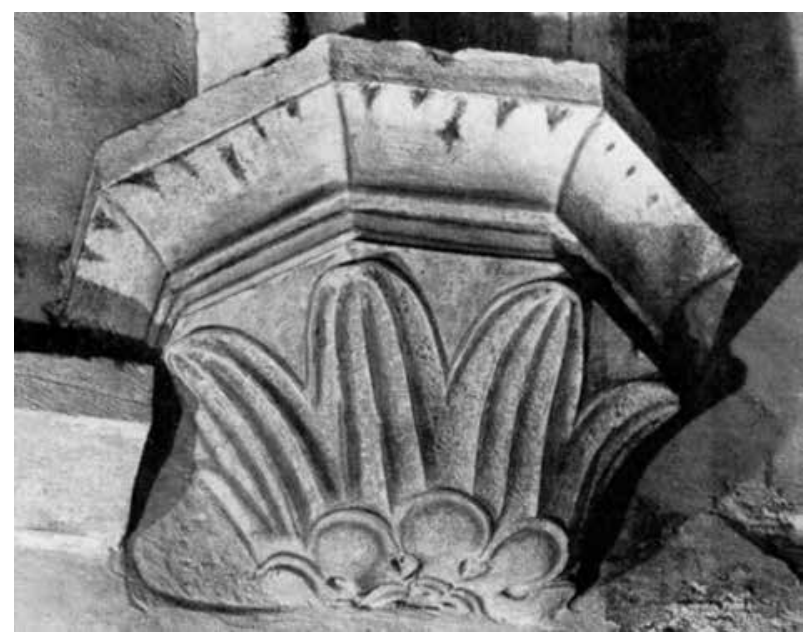

Abb. 108. Mühlbach, Pfarrkirche,

Konsole des Mittelschiffsgewölbes (VARGA 1984, Abb. 29) sächsischer Siedlung ist. Für ihre Periodisierung und Rekonstruktionsvorstellungen würden die Ergebnisse der Bauforschung von 1960-1962 Anhaltspunkte geben, wenn sie nicht fehlerhaft wären ${ }^{126}$ und keine Widersprüche zu den gleichzeitigen Rekonstruktionszeichnungen aufgewiesen hätten. ${ }^{127}$ Radu Heitel hatte einen Erstbau aus dem zweiten Drittel des 13. Jahrhunderts angenommen - wobei die Entstehung des Baus vor oder nach dem Mongolensturm nicht präzisiert wurde -, dessen Rekonstruktion gewiss auf eigenwillig gedeutete Mauerzüge gegründet wurde. ${ }^{128}$ Die Beziehungen zu Kerz hat Heitel auf die zweite Jahrhunderthälfte datiert und angenommen, dass die Kirche nach dem Mongolensturm mit einer Kreuzrippenwölbung bedeckt wurde, von der auch ein Schlussstein unter einem Pfeiler des Hallenchors des 14. Jahrhunderts gefunden wurde. ${ }^{129}$ Die Verfasserin der Monographie der Mühlbacher Pfarrkirche, Lívia Varga, hat wohl kaum weniger willkürlich eine querschiffartige Erweiterung in der zweiten Bauperiode angenommen (Abb. 100-101). Sie hat vermutet, dass diese zweite Periode allein in einem Planwechsel bestand. ${ }^{130}$ Das Südportal des späteren Hallenchors, zusammen mit seiner Vorhalle, mag wohl gleichzeitig mit dem ehemals zweigeschossigen Sakristeibau auf

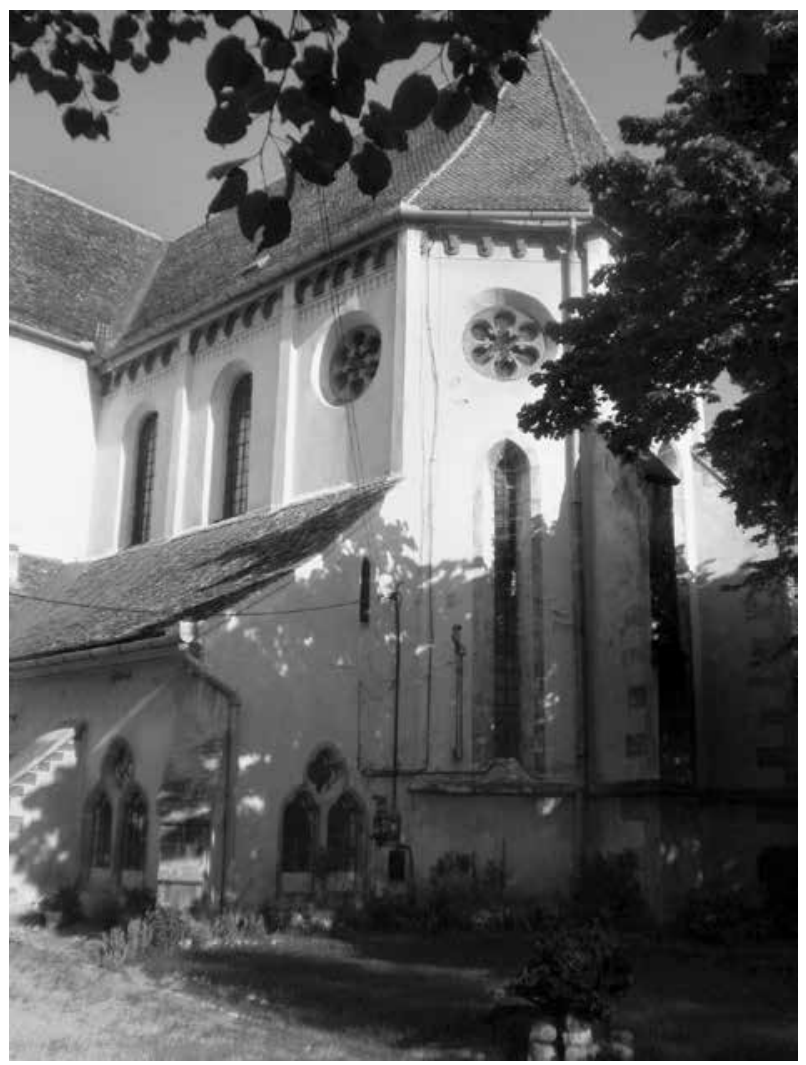

Abb. 109. Kronstadt (Brassó, Braşov, RO),

Pfarrkirche St. Bartholomä, Chor, Ansicht von Südost 


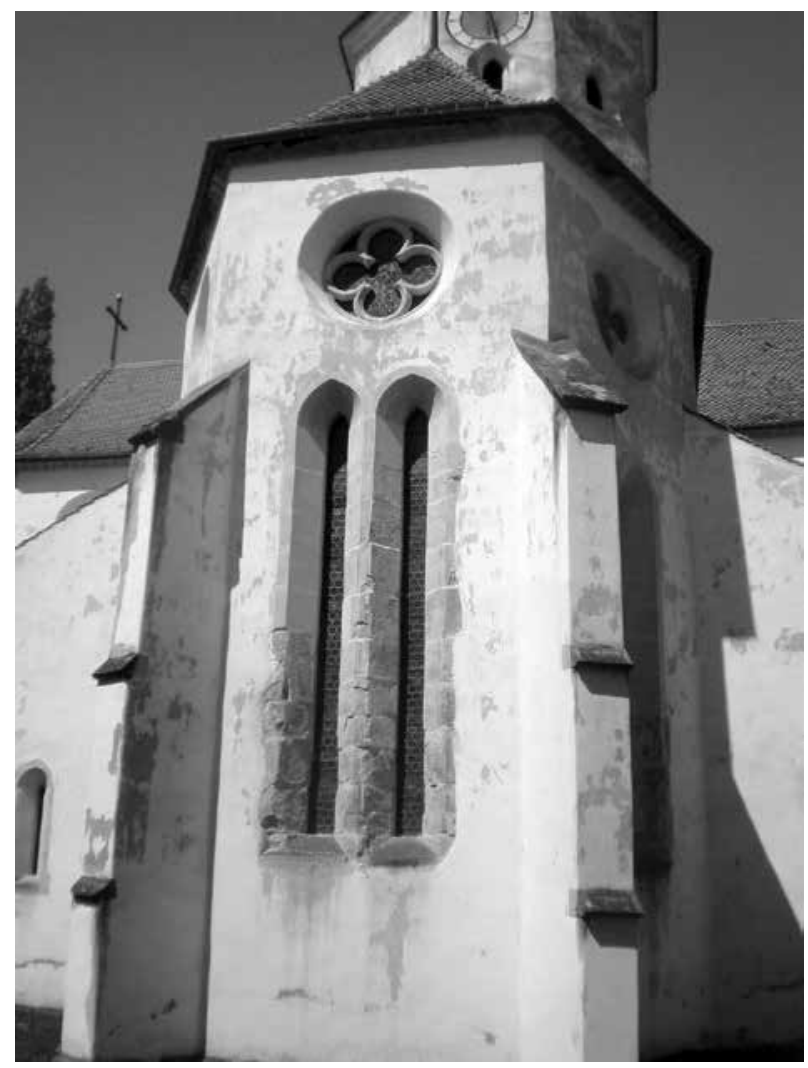

Abb. 110. Tartlau (Prázsmár, Prejmer, RO), Pfarrkirche, Ostansicht

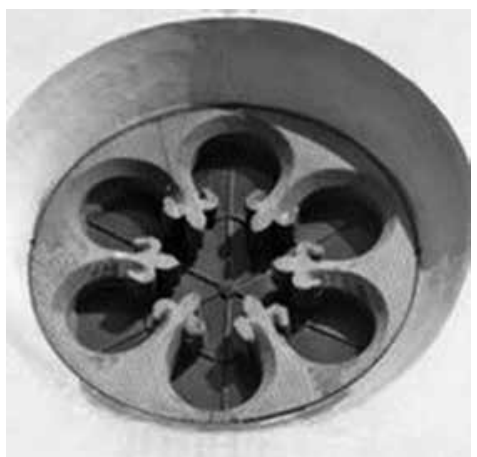

Abb. 111. Kronstadt, St. Bartholomä, Rundfenster der östlichen Chorwand

der Nordseite erbaut worden sein. Die Rahmung der dreipassförmig geschlossenen Sakristeitür ist sekundär in die nördliche Chormauer hineingebaut worden, wo die Rahmung und der Entlastungsbogen auf der äußeren Seite von Lívia Varga sehr genau beobachtet wurde (Abb. 102). ${ }^{131}$ Diese Beobachtungen werden durch eine Erhöhung des Bodenniveaus im Chor belegt, die im Bereich des Südportals auch zu bemerken ist. Hier, westlich vom spätgotischen Portal wurden Reste eines Rundbogenportals ohne eingestellte Säulen entdeckt (Abb. 103). Das in Quaderwerk ausgeführte Portalge-

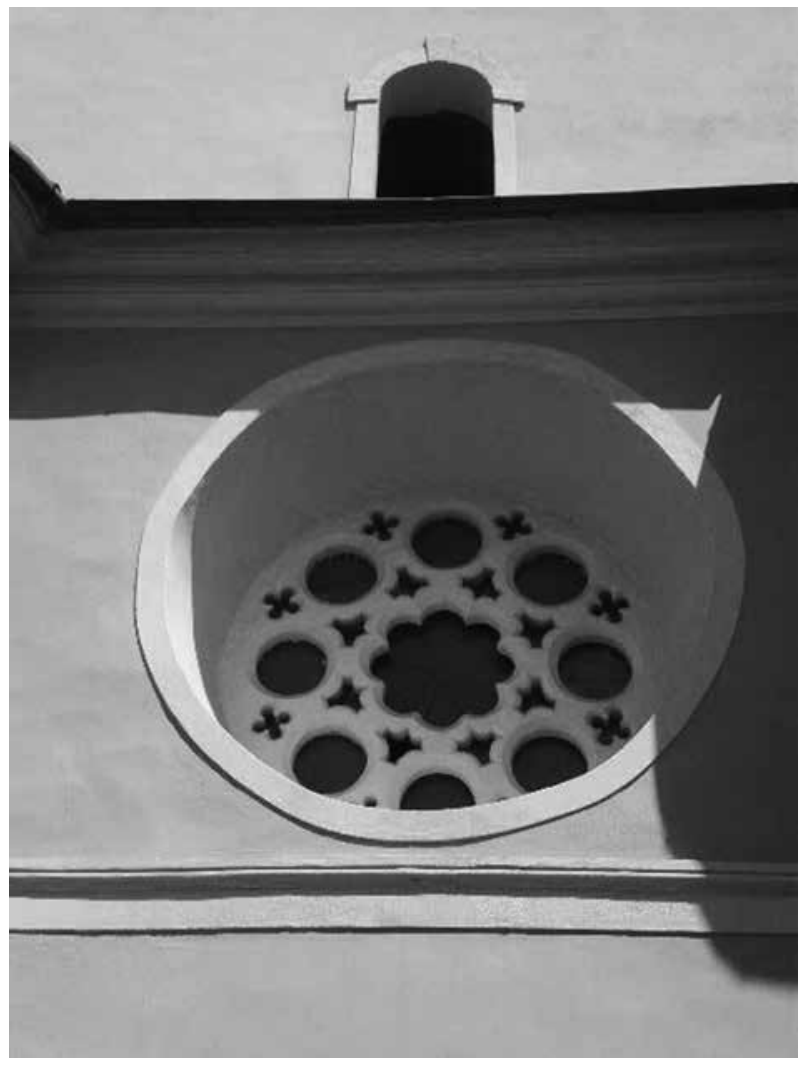

Abb. 112. Neustadt-Burzenland

(Keresztényfalva, Cristian, RO), Pfarrkirche, Westrose

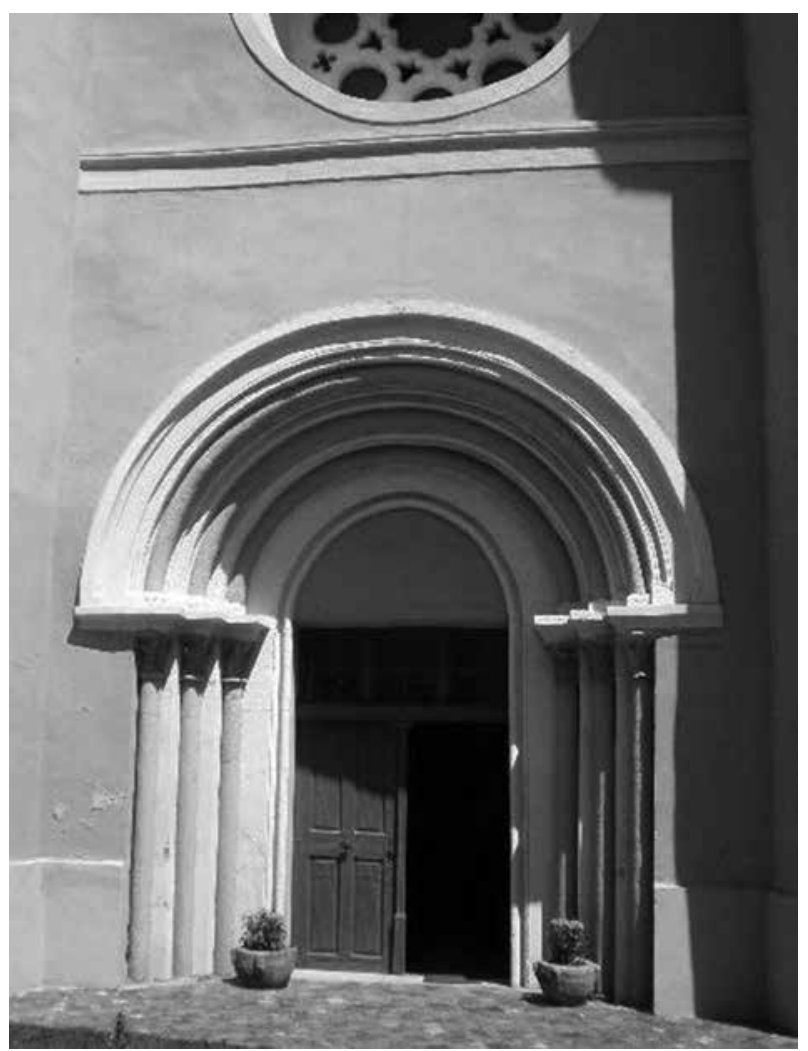

Abb. 113. Neustadt-Burzenland, Pfarrkirche, Westportal 


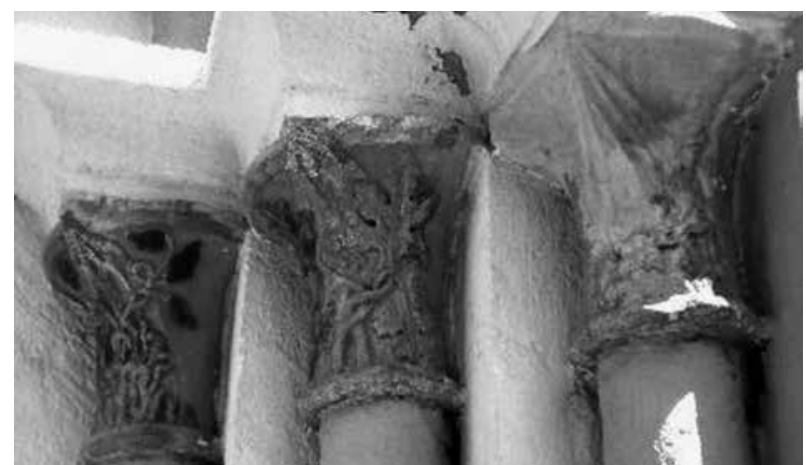

Abb. 114. Neustadt-Burzenland, Pfarrkirche, Westportal, südliches Gewände

wände zusammen mit der Archivolte entspricht genau dem Mauerwerk der Türöffnung des Kapitelsaals von Kerz (Abb. 84). Technik und Profilierung verbinden das Mühlbacher Portalfragment mit dem sorgfältig ausgeführten Quaderwerk des Langhauses (Abb. 104; aus der „ersten“ Bauperiode).

Obwohl die Hypothesen der Periodisierung und der Datierung des Baus von Lívia Varga kaum mehr als gültig zu sein scheinen, ist ihre Annahme über die Zugehörigkeit von Mühlbach „" und „II“-bzw. Ia und Ib: ungewölbtes und gewölbtes Langhaus (Abb. 105) zu einer ursprünglichen Konzeption und deren Änderung wohl zutreffend. Im Allgemeinen scheint Mühlbach eindeutig ein Zeitgenosse von Kerz zu sein, wobei kein Einfluss des Mongolensturms in der Baugeschichte der Kirche angenommen werden kann. An einigen Konsolen der Mittelschiffswölbung (Abb. 106-

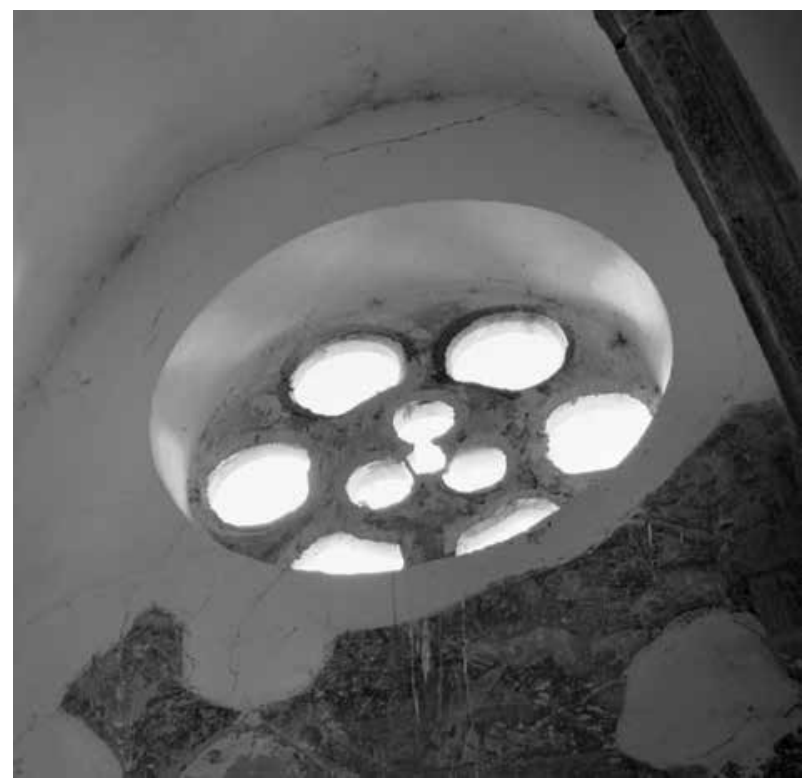

Abb. 116. Szék (Sic, RO), Pfarrkirche, Rundfenster des Chores (Foto: Pál Lôvei)

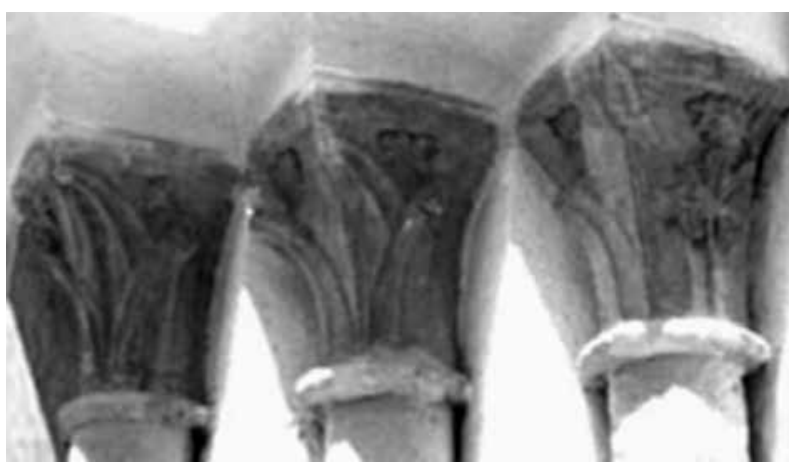

Abb. 115. Neustadt-Burzenland, Pfarrkirche, Westportal, nördliches Gewände

108) von Mühlbach erscheinen diejenigen Ornamentformen, die Kerz und Honigsberg verbinden. ${ }^{132}$

4.

König Béla IV. von Ungarn hat 1240 eine Donation zugunsten des Zisterzienserordens getan. ${ }^{133}$ Die Urkunde betrifft vier Kirchen des Burzenlandes - Marienburg (Földvár, Feldioara, RO), Petersberg (Barcaszentpéter, Sânpetru, RO), Honigsberg und Tartlau -, mit deren Einkünften und Patronatsrechten zu den Kosten des jährlichen Generalkapitels von Cîteaux beigetragen wird. Bis die Pfarrrechte nach dem Verschieden der aktuellen Besitzer vakant werden, sollten die Zisterzienser jährlich 100 Mark Silber beziehen. Es ist seit Langem klar, dass die Urkunde

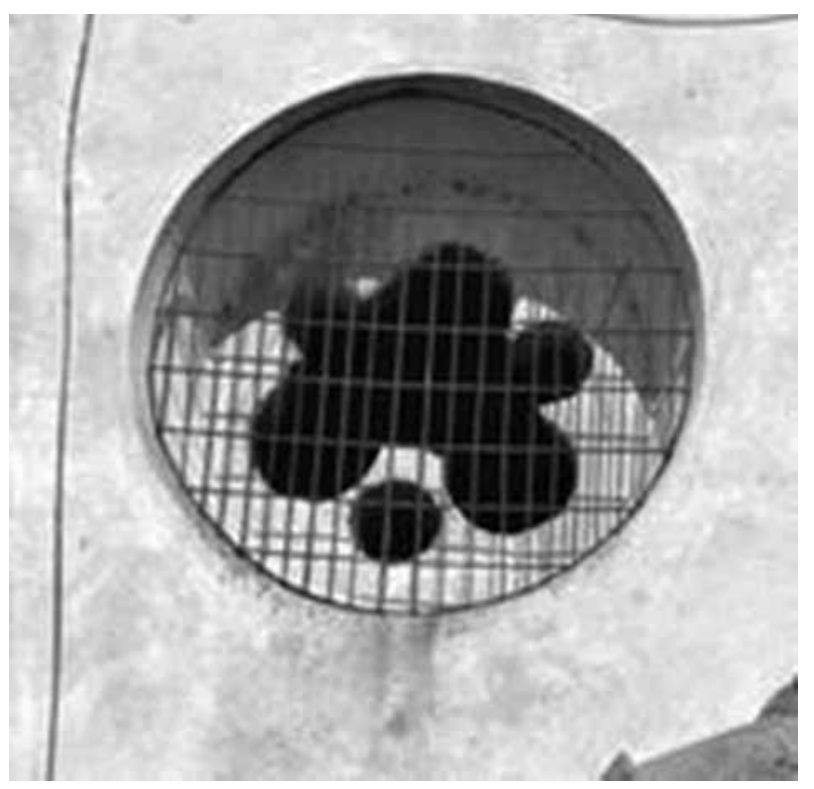

Abb. 117. Marienburg (Földvár, Feldioara, RO), Pfarrkirche, Rundfenster des Langhauses 


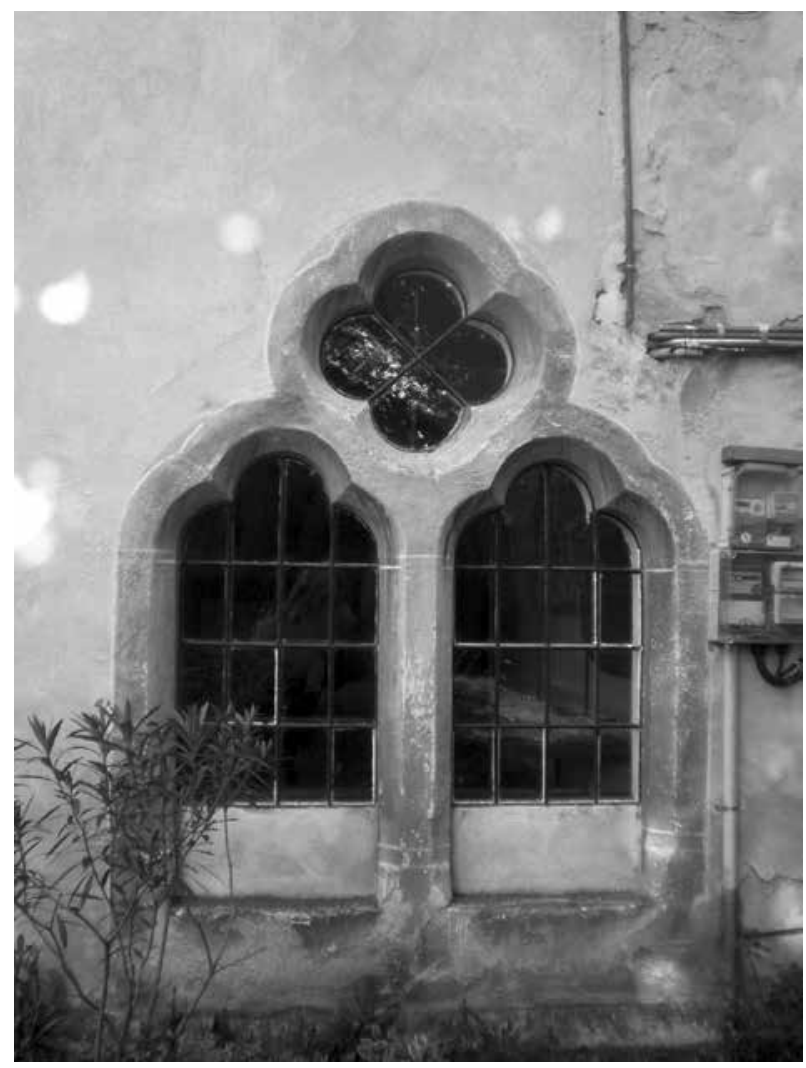

Abb. 118. Kronstadt, St. Bartholomä, Fenster des Nebenraums des Chores

keineswegs auf die benachbarte Zisterzienserabtei von Kerz bezogen werden kann. ${ }^{134}$ Allein Marienburg ist als ihr Besitz erwähnt worden. ${ }^{135}$ Allerdings gibt es kein Zeichen dafür, dass die Donation irgendwann durchgeführt wurde, wofür die Wirren des Mongolensturms eine genügende Erklärung geben können. Die Erwähnung einer Sedisvakanz von Esztergom - in der Tat erst $1241^{136}$ - scheint zumindest verdächtig zu sein. Die Donation von 1240 beweist dabei nichts außer der Tatsache der Existenz dieser Pfarren, ebenso wie auch aus der 1223 bezeugten Schenkung der Pfarrkirche von Michelsberg (Kisdisznód, Cisnădioara, RO) keine kunsthistorischen Konsequenzen bezüglich der Kerzer Abtei zu ziehen sind.

Von den Denkmälern, an denen die kunsthistorische Literatur eine stilistische Verwandtschaft mit dem Kerzer Bau festgestellt hat, kann allein ihr Bestehen mit Wahrscheinlichkeit ausgesprochen werden. Selbst die Belege für ihren historischen Kontext fehlen, die man für die Zisterzienser besitzt. Das Kloster der Prämonstratensernonnen in Kronstadt ist allerdings im Klosterverzeichnis des Ordens aus Ninive bezeugt - woraus eine um ein Jahrzehnt frühere Gründungszeit erfolgen würde, wenn die Hypothese von György Györffy stichhaltig wäre. Nach seiner Behauptung

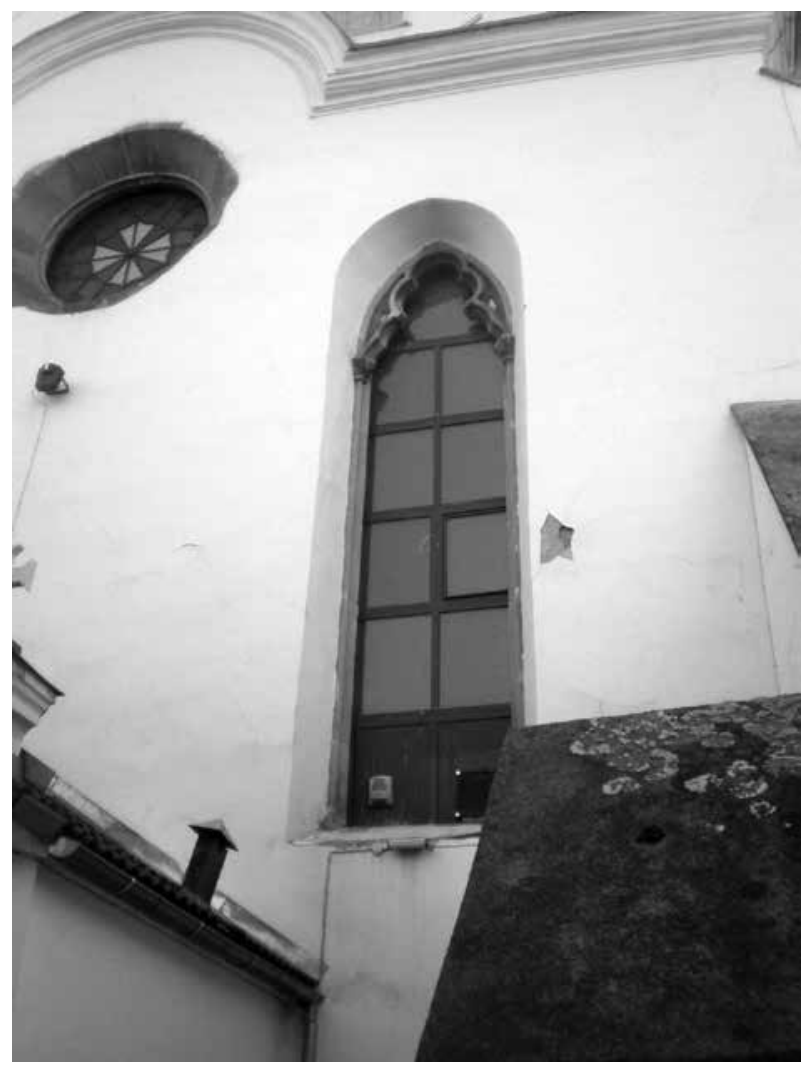

Abb. 119. Bistritz, Minoritenkirche, Westfassade, Maßwerkfenster

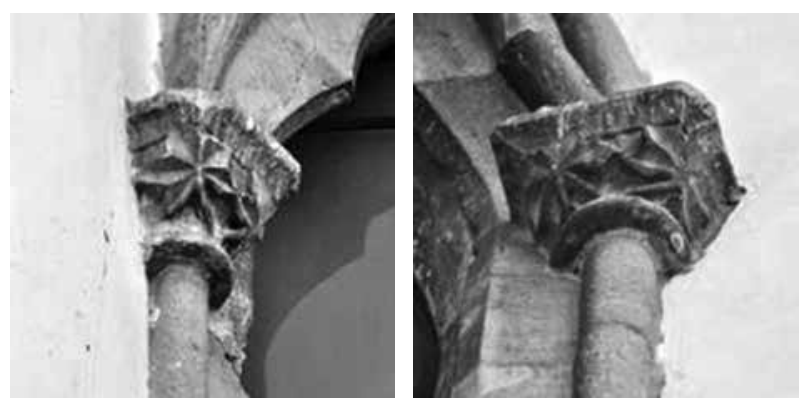

Abb. 120-121. Bistritz, Minoritenkirche, Westfassade, Maßwerkfenster, Gewändekapitell (vgl. Abb. 119)

könne das Kloster mit der im Verlauf des Mittelalters dem Heiligen Bartholomäus geweihten Pfarrkirche der äußeren Stadt gleichgesetzt werden. Der Historiker Györffy hat sich bei der Formulierung seines Lokalisierungsvorschlags auf den Stil des Baus berufen, was ein Kunsthistoriker nicht tun darf. ${ }^{137}$ Die Existenz der Mühlbacher Pfarrkirche wird zuerst 1245 durch die Erwähnung ihres Pfarrers, eines Domherrn von Hermannstadt (Nagyszeben, Sibiu, RO), bezeugt. ${ }^{138}$ Für Szék ist die Erwähnung der dort privilegierten Siedler 1291 kunsthistorisch überaus verspätet, ${ }^{139}$ wogegen die durch ihren Silberbergbau bekannt gewordene Stadt Roden (Radna, Rodna, RO) zumindest vor ihrer 


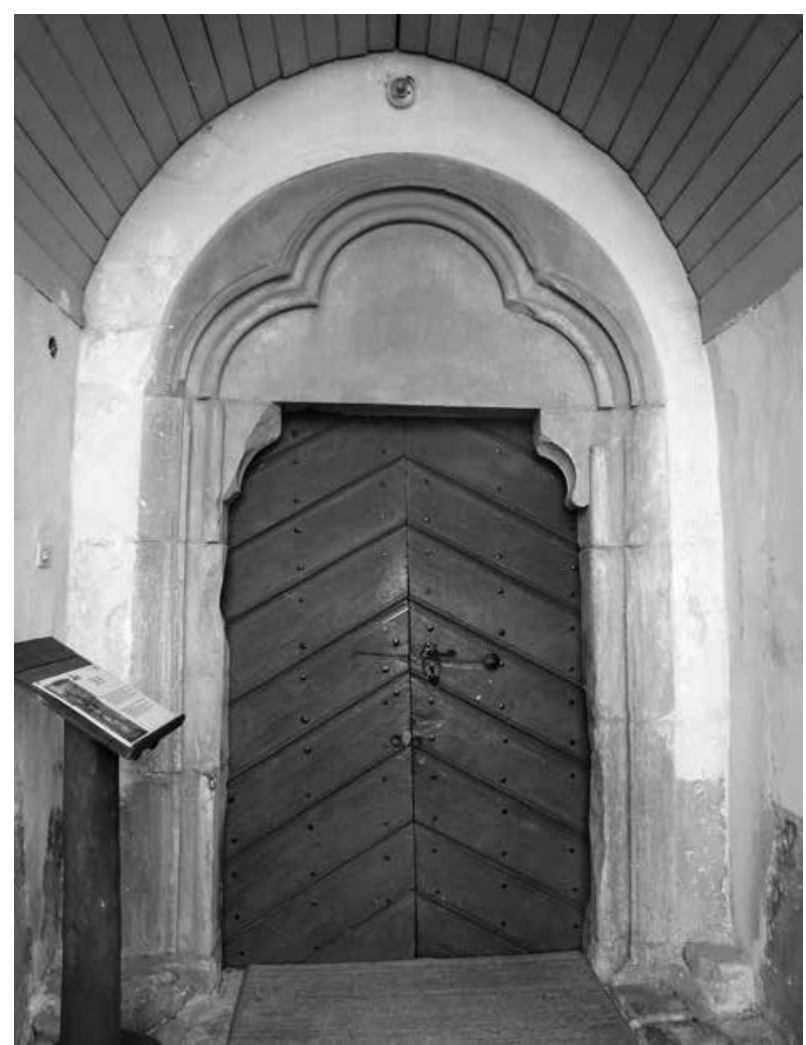

Abb. 122. Kerz, Westportal des Chors (Foto: Imre Takács)

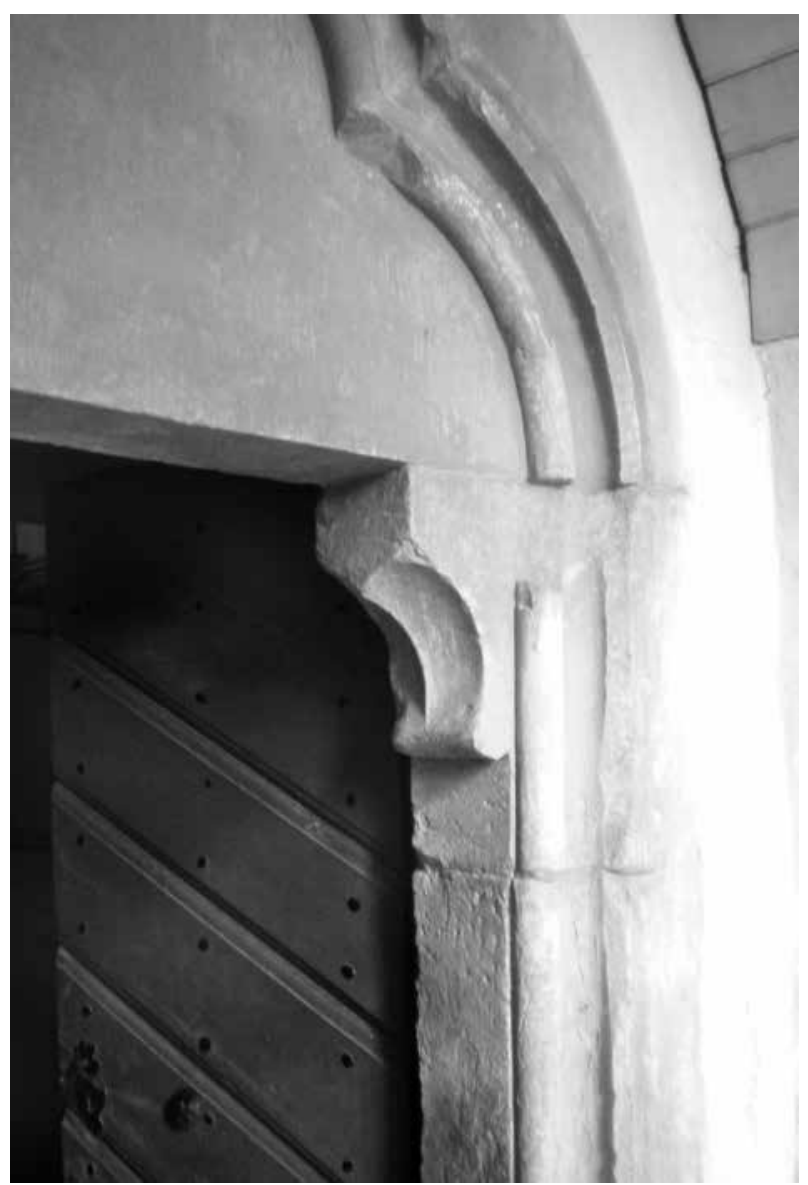

Abb. 123. Kerz, Westportal des Chors, Detail

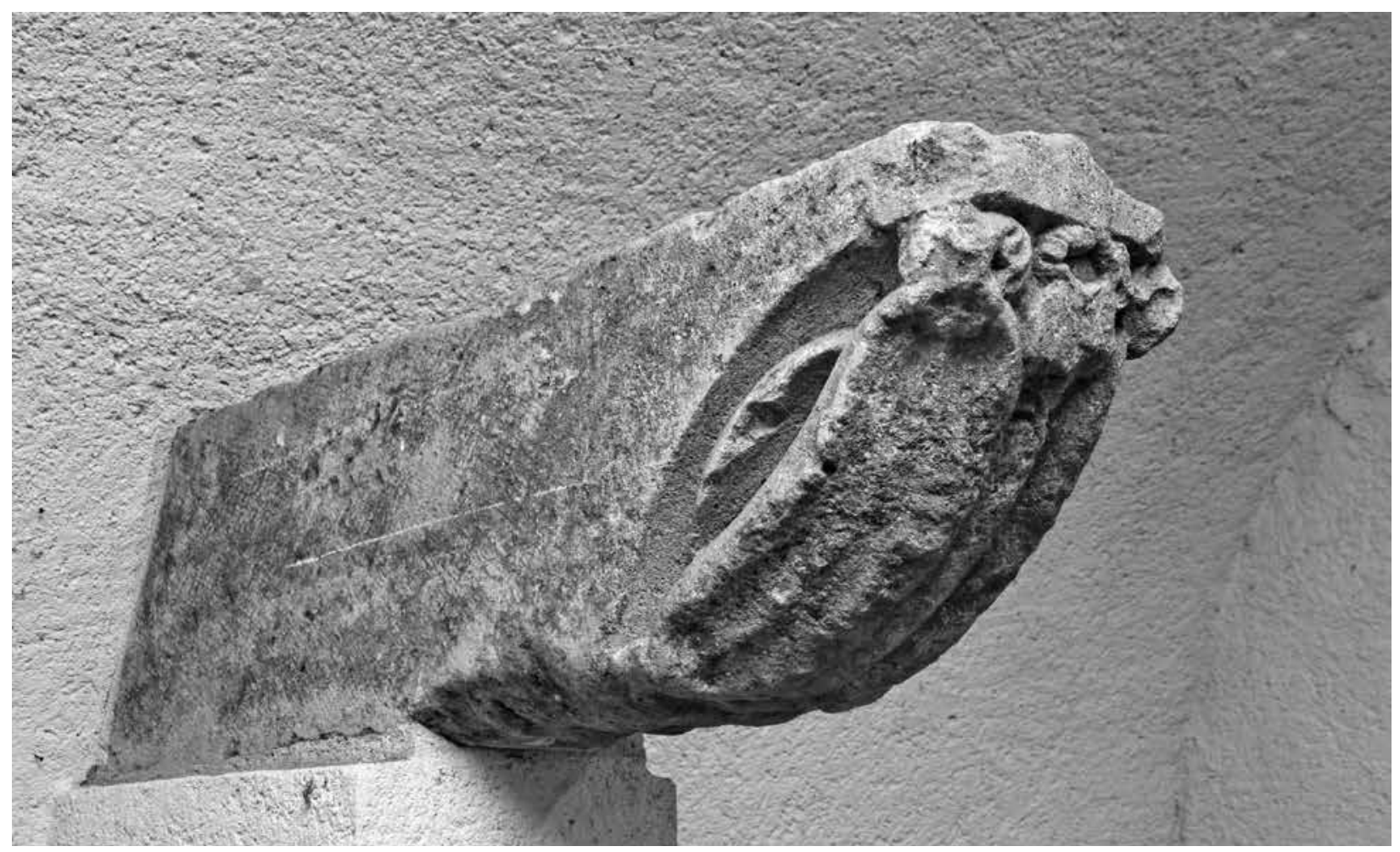

Abb. 124. Konsole aus Zirc im ehemaligen Lapidarium von Tihany (Foto: Péter Hámori) 


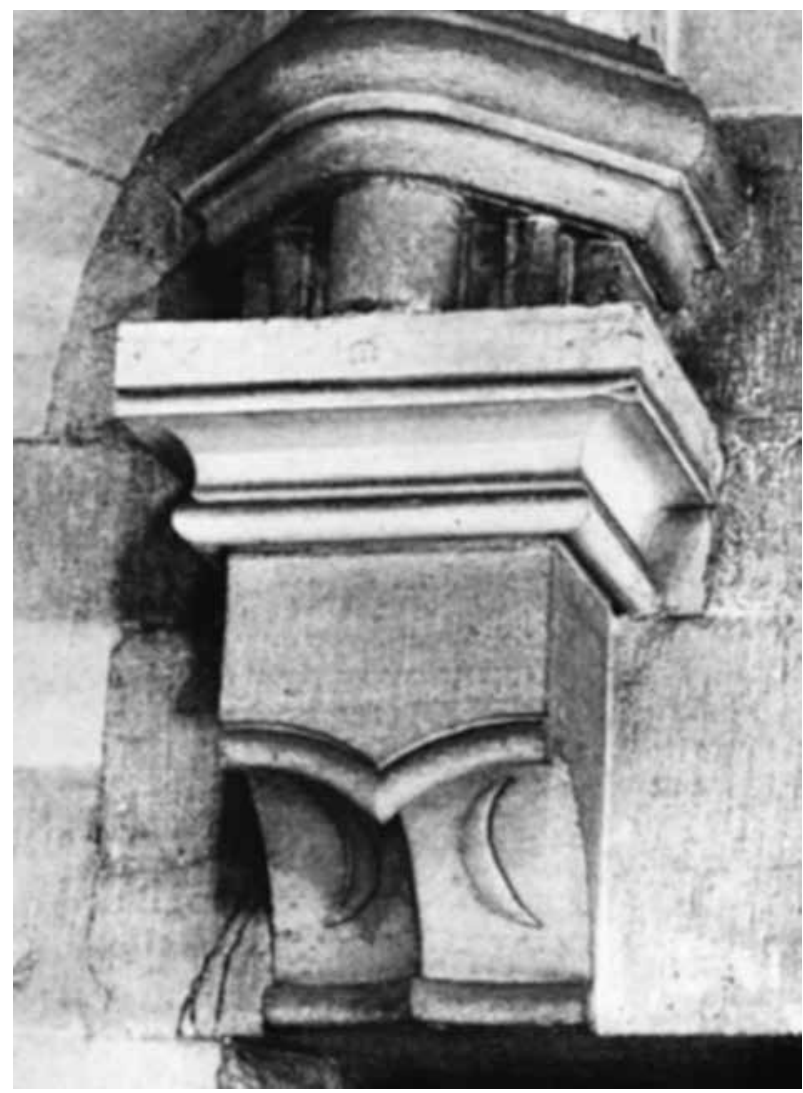

Abb. 125. Magdeburg, Dom, „Bischofsgang“, Konsole

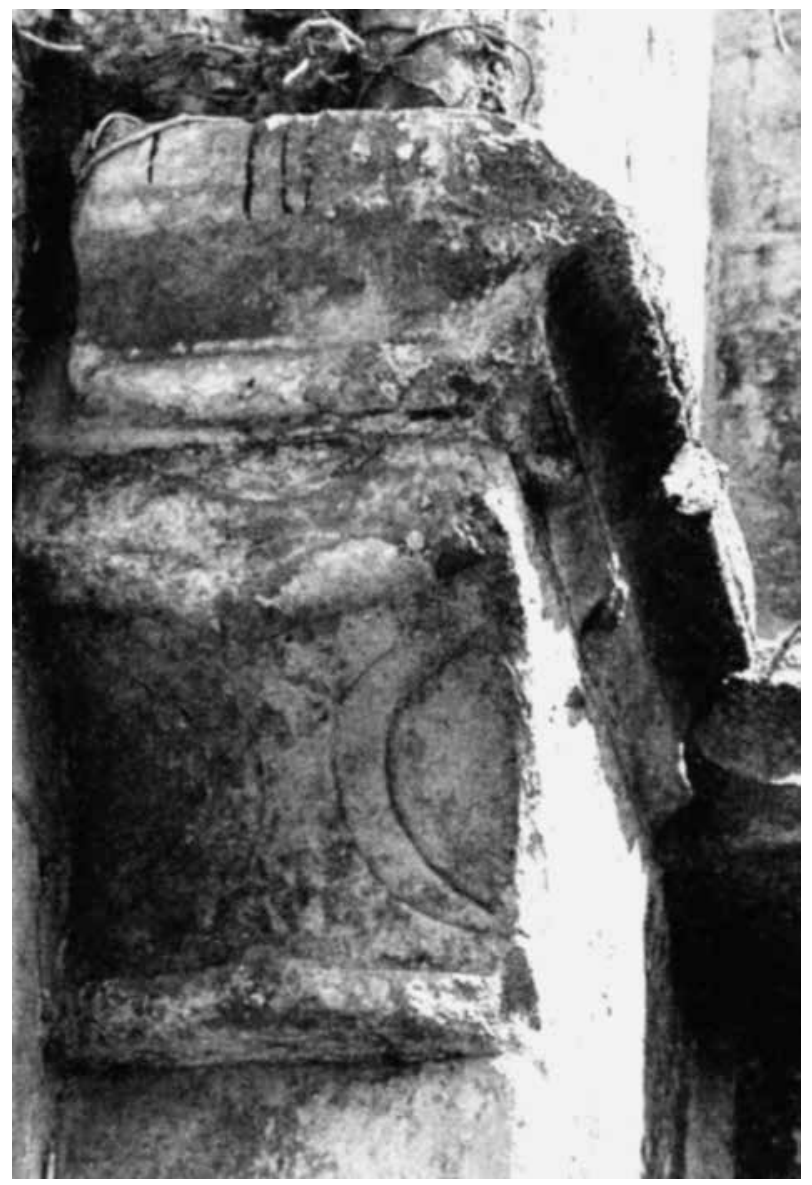

Abb. 126. Walkenried, Stiftsruine, Konsole

östlichen Chorwänden wie in Kerz (Abb. 78), Kronstadt (Abb. 109) und Tartlau (Abb. 110) sowie an basilikalen Bauten über Rundbogenfenstern der Seitenschiffe und Rundfenstern im Obergaden des Mittelschiffs. Meist wurde die Steinplatte durch Vierpässe durchbrochen (Tartlau, Honigsberg, Bistritz; Abb. 95-97), es gibt aber auch sechspassförmige Fensterformen (Kerz bzw. lilienförmige Maßwerknasen von Kronstadt; Abb. 111). Tibor Rostás nimmt an, dass die Reste des großen Rundfensters der ersten Bauperiode von Kerz im dortigen Depot der Skulpturenfragmente zu finden wären. In diesem Fall erscheint rätselhaft, wie wir auf diese Fragmente trotz der vollständigen Überarbeitung der Westfassade durch ein großes Maßwerkfenster stoßen könnten. ${ }^{144}$ Der Rekonstruktion hat das Rundfenster auf der Westfassade der Kirche des benachbarten Neustadt-Burzenland (Keresztényfalva, Cristian, $\mathrm{RO}$ ) als Grundlage gedient (Abb. 112) ${ }^{145}$ - der Hypothese entsprechend, wonach der Bauschmuck von Neustadt-Burzenland zusammen mit dem Westportal (Abb. 113-115) ebenfalls zum Kerzer Kreis gehört. Den Dreipassfenstern des Chorjochs von Szék - ein ähnliches Stück befindet sich im südlichen Teil der Westfas- 


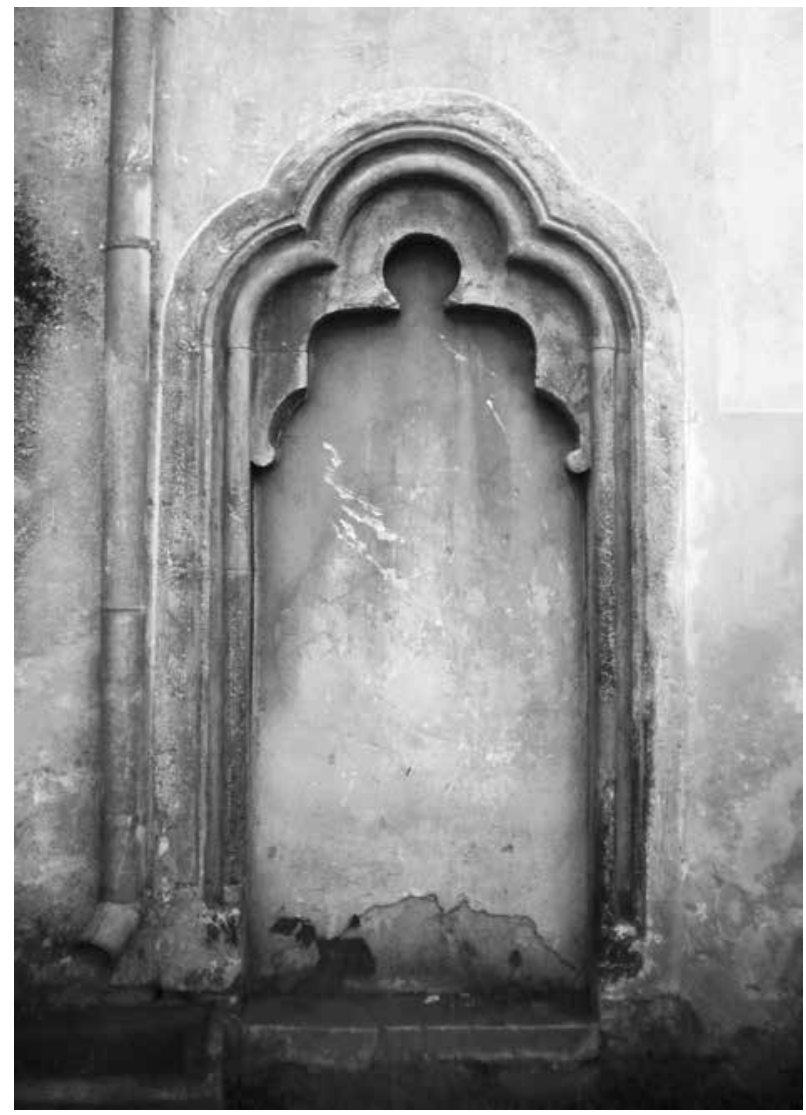

Abb. 127. Kronstadt, St. Bartholomä, nördliches Langhausportal

sade von Kronstadt - wurde die kompliziertere Form der nordöstlichen Chorseite gegenübergestellt, wo eine Rahmung in Sechspassform mit einem dreipassförmig durchbrochenen Ring (Abb. 116) umschlossen wird. ${ }^{146}$ In Marienburg gibt es auch eine komplexe Form: auf dem Dachboden des nördlichen Seitenschiffes ein durch Dreipässe gegliedertes Rundfenster mit dreipassförmig durchbrochener Steinplatte in den Bogendreiecken (Abb. 117). Es erscheint fraglich, ob die Rundfenster, deren ursprüngliche Füllung verloren gehen konnte, zum ursprünglichen Schmuck der Obergaden gehören. ${ }^{147}$ Es bleibt fragwürdig, ob dieses einzige Detail - unabhängig von seiner ursprünglichen Form - zur Annahme der künstlerischen Beziehung zu Kerz genügt, wenn die Reihe der Zwillingsöffnungen der ehemaligen Emporen eine solche Folgerung nicht unterstützt. ${ }^{148}$ Eine weitere Frage ist, ob auch andere Bauelemente am Obergaden mit Rundfenstern - zum Beispiel in Draas (Homoróddaróc, Drăuşeni, RO) ${ }^{149}$ ebenfalls mit Plattenmaßwerk geschmückt waren. Die gründliche, auch archäologische Funde umfassende Forschung, die Rostás für die Publikation der prächtigen Plattenfenster der Dominikanerkirche von Csázma (Čazma, CRO) durchgeführt hat, kann genau zeigen, dass dieser Typus noch relativ spät, im Ungarn des 13. Jahrhunderts allgemein verbreitet war. ${ }^{150}$

Eine Formvariante des Vierpassfensters kann belegen, dass es in ihrer Entstehungszeit neben dem Plattenmaßwerk bereits eine modernere Alternative gegeben hat. Es handelt sich um das Rundfenster oberhalb zweier Lanzetten an der Ostwand von Tartlau (Abb. 97, $A b b .110)$ und um das am südlichen Obergaden der Pfarrkirche von Honigsberg (Abb. 95). Beide sind durch vierpassförmige echte Maßwerke gegliedert, ${ }^{151}$ etwa der Form entsprechend, die Villard de Honnecourt an den Umgangskapellen von Reims registriert hat. ${ }^{152}$ Für die alternativen Formvarianten, die bei der Ausgestaltung der Hochgotik eine Rolle gespielt haben, sind ebenfalls Villards Transkriptionen der Westrose von Chartres bzw. derjenigen in Lausanne lehrreich. ${ }^{153}$ Die Logik dieser Interpretationen hat Robert Suckale in der Art und Weise der Zitation aufgezeigt, wie die Zisterzienser die Vorbilder - in Frankreich besonders der Kathedralen der Diözesen - rezipiert haben. ${ }^{154}$ Es ist fraglich, ob solche Vorbilder in der Bautätigkeit des siebenbürgischen Bistums oder in der der Landeszentren - wohl im Fall der sächsischen Siedlungen, deren Exemtion eine Unterordnung dem Erzbistum von Esztergom bedeutete - zu suchen sind. Die Unterschiede zwischen der Orientation der Baudenkmäler des OltTals und des Someschtals können möglicherweise auf Differenzen ihrer Lage hinweisen.

Im 13. Jahrhundert erschienen isolierte Beispiele von modern anmutenden Maßwerken im Umkreis

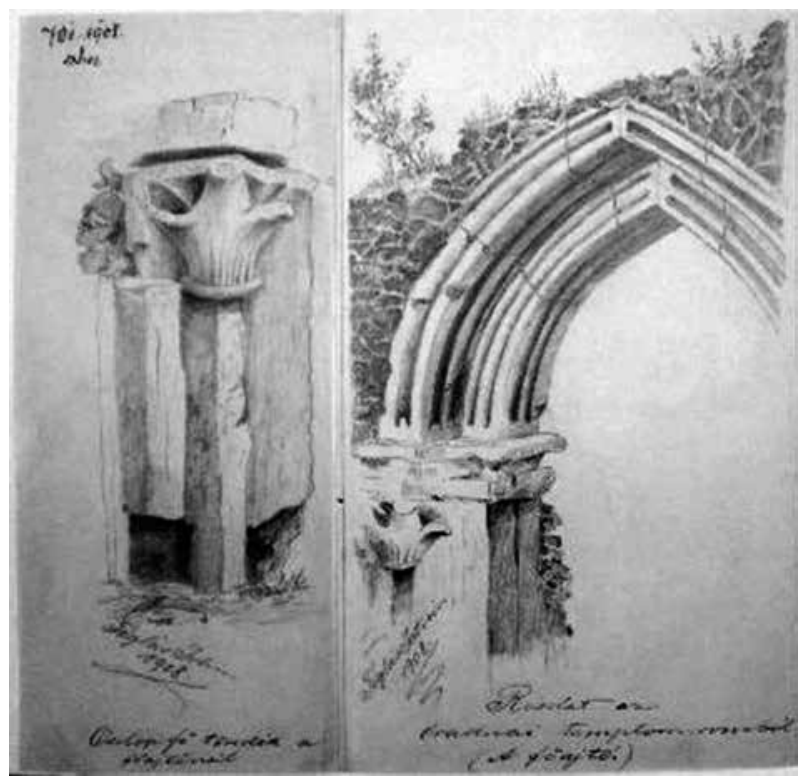

Abb. 128. Roden (Radna, Rodna, RO), Pfarrkirchenruine, Westportal. Aufnahmezeichnung, 1908

(Budapest, Planarchiv des ehemaligen Denkmalamtes) 


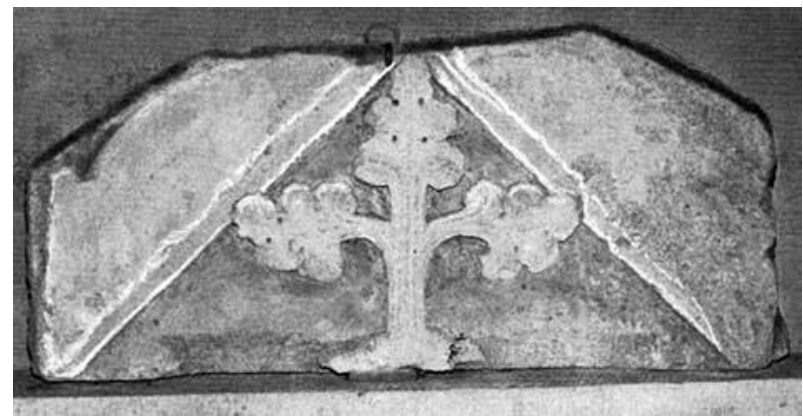

Abb. 129. Mühlbach, Pfarrkirche, Giebel einer Nische (VARGA 1984, Abb. 80)
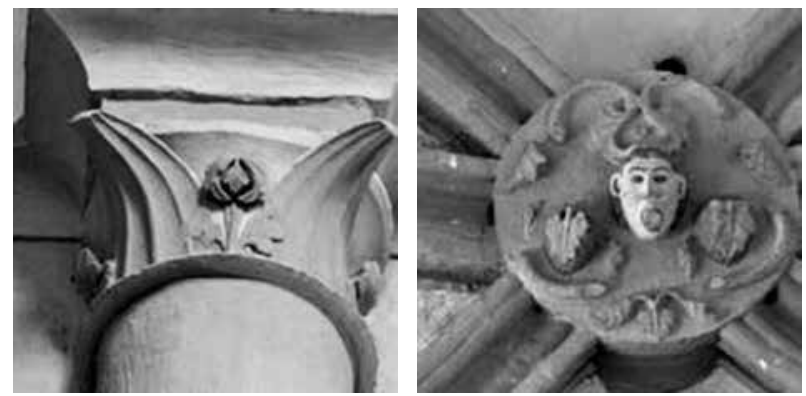

Abb. 130. Kronstadt, St. Bartholomä, Chor, Dienstkapitell Abb. 131. Kronstadt, St. Bartholomä, Chor, Gewölbeschlussstein

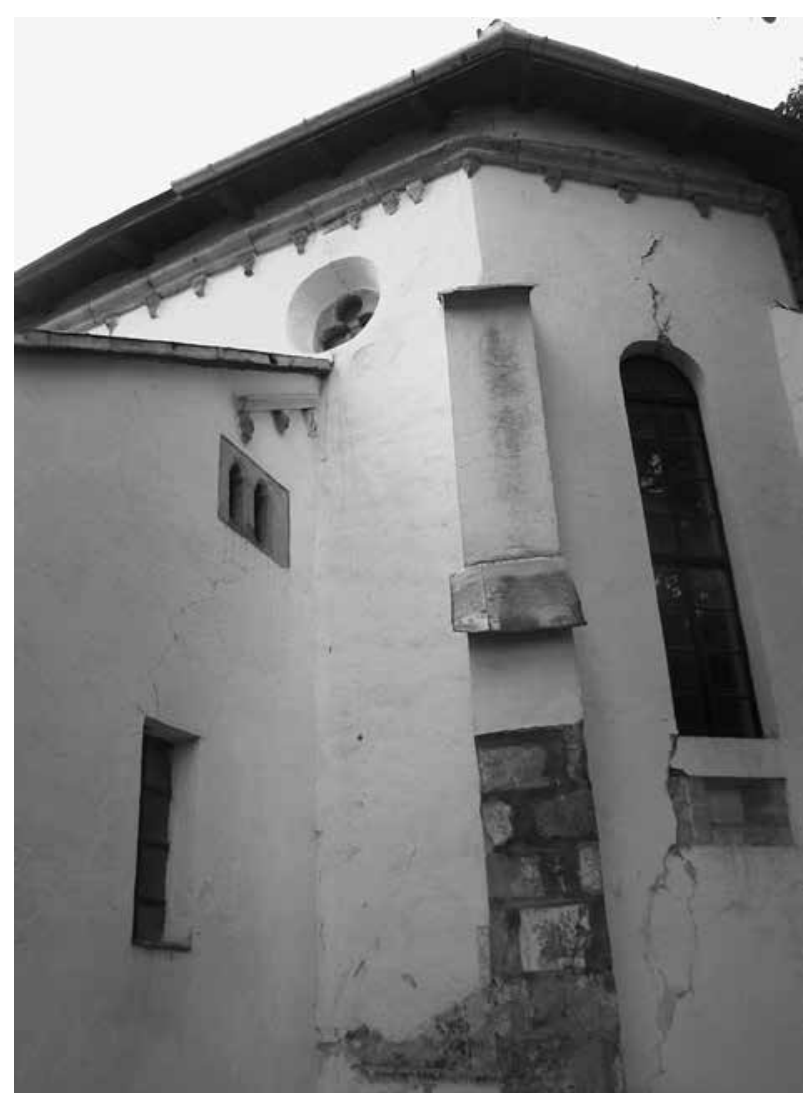

Abb. 132. Szék, Pfarrkirche, Chor, Ansicht von Südost (Foto: Pál Lôvei)

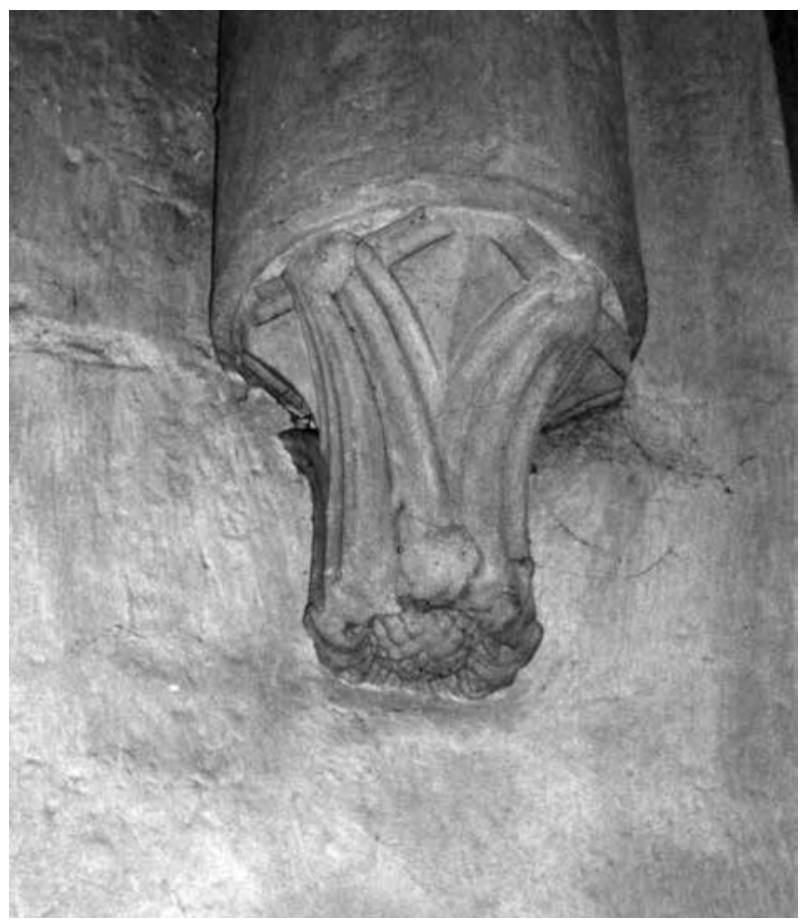

Abb. 133. Kronstadt, St. Bartholomä, Konsole an der östlichen Querschiffwand

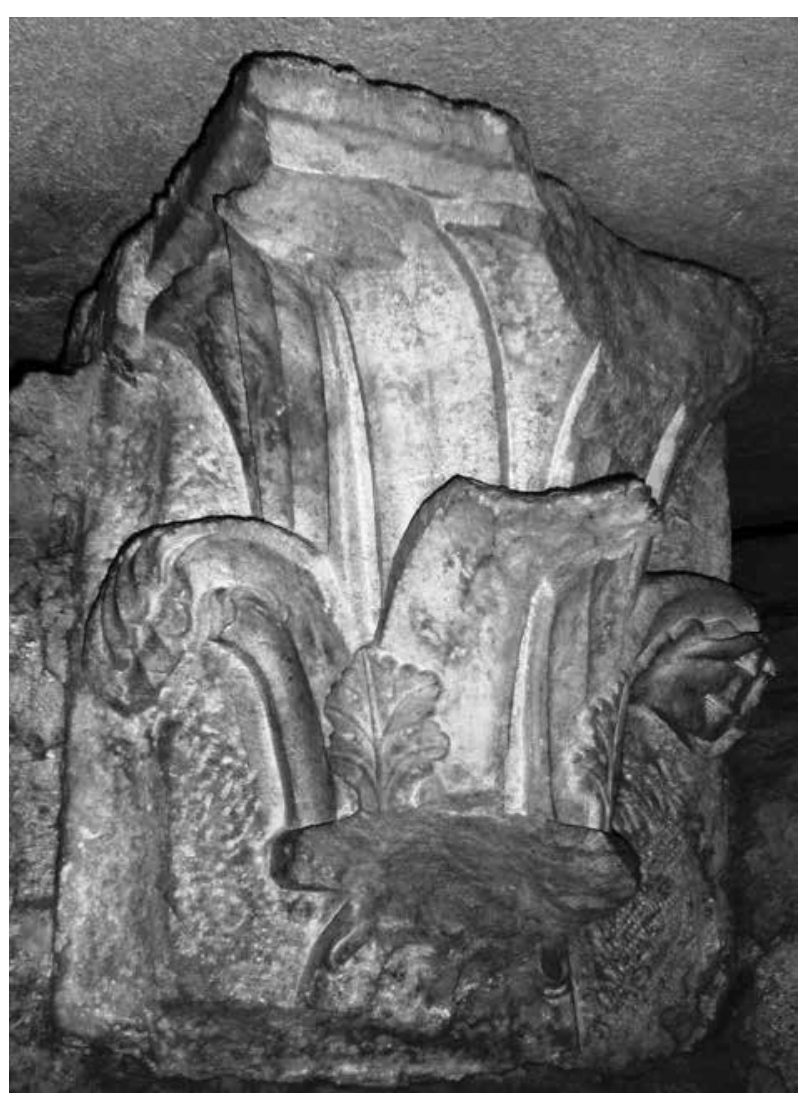

Abb. 134. Salzburg, Dom, Konradsbau, Konsole 


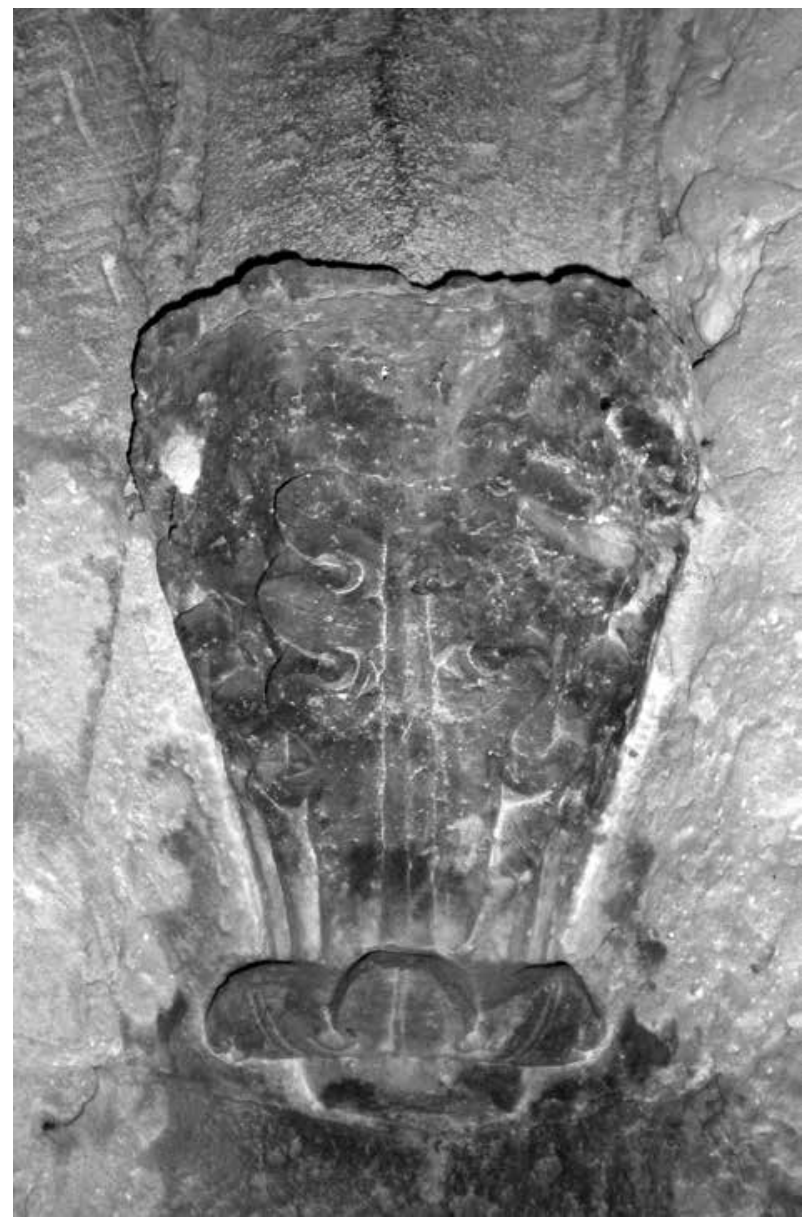

Abb. 135. Ócsa, ehemalige Prämonstratenserkirche, Konsole im nördlichen Nebenraum des Querschiffs

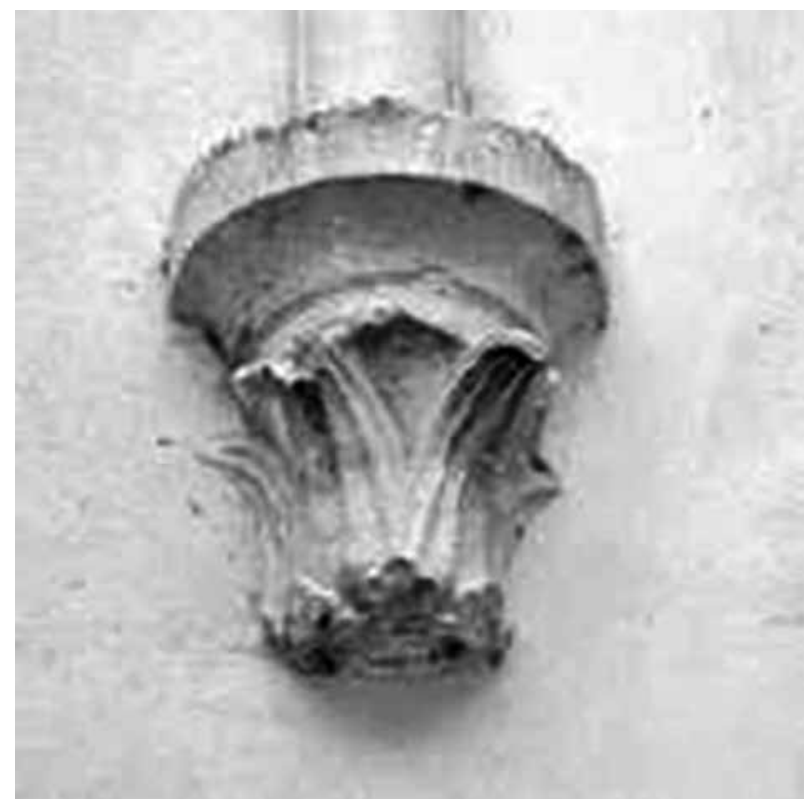

Abb. 136. Holmwegen (Halmágy, Halmăgiu, RO), Pfarrkirche, Konsole an der Chorwand von Kerz. Zu diesen gehören zwei Maßwerkfenster des südlichen Nebenraumes von St. Bartholomä in Kronstadt (Abb. 118), deren Stellung in einem Vergleich mit Pariser Werken um 1220 - Turmgalerien von NotreDame, Royaumont, Tours ${ }^{155}$ bzw. die Pfarrkirche StPierre et St-Paul zu Gonesse ${ }^{156}$ - als überaus modern erscheint. Eine ähnliche Stellung zeigt die östliche Fenstergruppe des südlichen Nebenraumes zu Holmwegen, die allerdings Spuren späterer Veränderungen

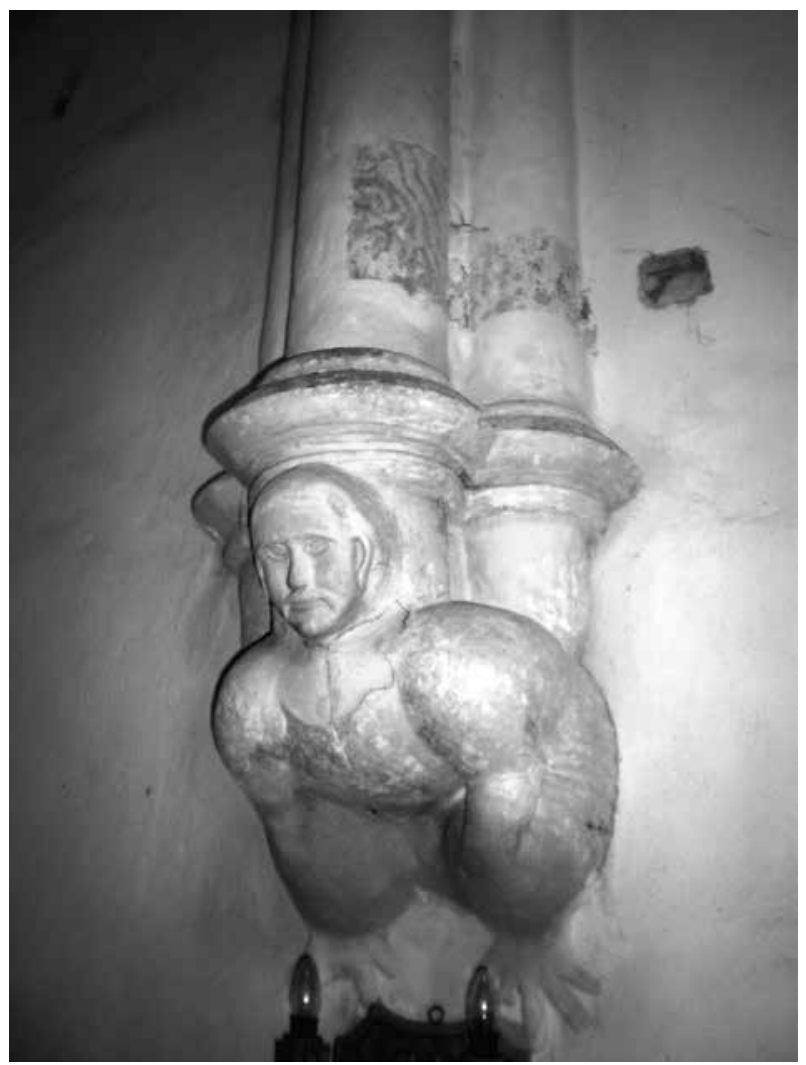

Abb. 137. Holmwegen, Pfarrkirche, figürliche Konsole am südlichen Triumphbogenpfeiler

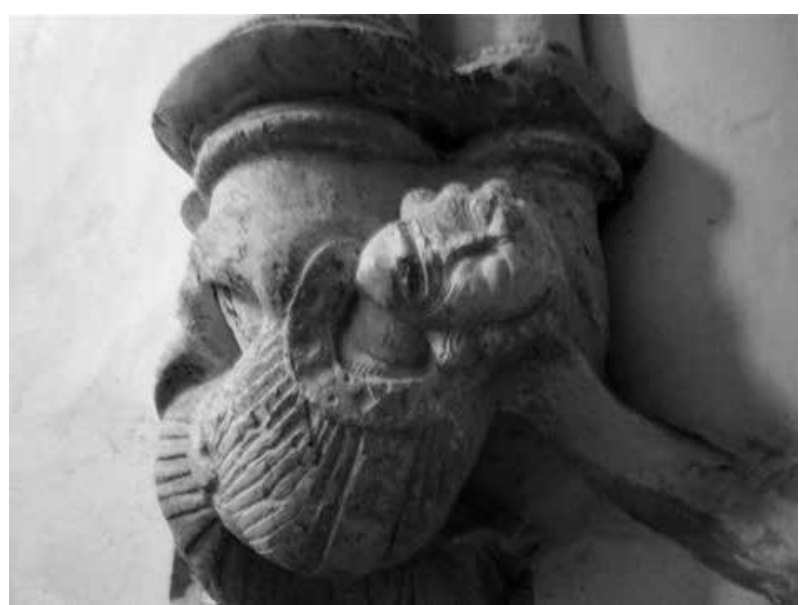

Abb. 138. Holmwegen, Pfarrkirche, figürliche Konsole am nördlichen Triumphbogenpfeiler 
aufweist. Das einzige Denkmal in der nach Kerz orientierten Gruppe, die echte Fenstermaßwerke hat zumindest auf der Westfassade, da die Chorfenster die traditionelle Gruppierung von runden und Lanzettfenstern aufweisen (Abb. 119-121) -, ist die Minoritenkirche von Bistritz. ${ }^{157}$ Die Fenstermaßwerke, deren Stil der ersten urkundlichen Erwähnung der Franziskaner aus dem Jahr 1268 in Bistritz genau entspricht, gehören zu den frühen ungarischen Beispielen im dritten Viertel des 13. Jahrhunderts. Sie gehören nicht mehr in die Problematik der Werkstatt von Kerz.

\section{6.}

Die Plattenmaßwerke im Kreis von Kerz als die spektakulärsten Werke gehören zu den Monolitgliedern, deren Verbreitung und Bedeutung Sándor Tóth in einem grundlegenden Aufsatz beschrieb. ${ }^{158}$ In dieser Publikation hat er einen weiten geographischen Kontext und eine tief ins 14. Jahrhundert reichende Chronologie geschaffen. Für den Verfasser hat das Studium der Steinskulptur der Kathedrale von Veszprém den Ausgangspunkt gebildet. ${ }^{159} \mathrm{Zu}$ diesem Typus von Rahmungen gehört vor allem das Portal, das - mehr oder weniger genau wiedererrichtet - seit dem Umbau des Kerzer Chors zu einer protestantischen Kirche als Westportal dient (Abb. 122-123). Seine Umrahmung wird von einem oben dreipassförmig geschlossenen, ohne Unterbrechung herumlaufenden Profil gebildet, das unten hornförmig ausläuft. Auf den beiden oberen Steinblöcken erscheinen die beiden Konsolen unter dem Türsturz als besonders fein gestaltete Details. ${ }^{160}$ Sie bestehen aus zwei Hohlkehlen, die von einem Grat getrennt werden. Ihre geometrische Eleganz erscheint - etwa im Vergleich

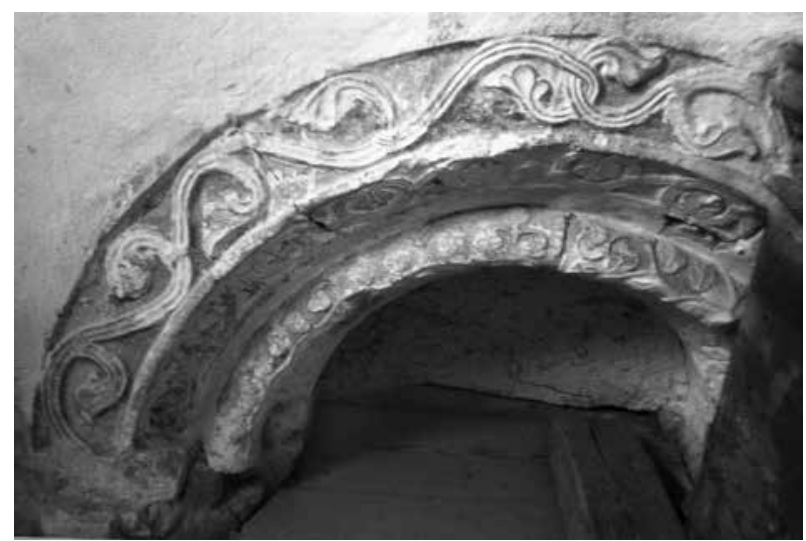

Abb. 139. Holmwegen, Pfarrkirche, südliche Nische des Chors, Detail mit einem verwandten Stück aus Zirc im ehemaligen Lapidarium von Tihany ${ }^{161}$ (Abb. 124) - als ausgezeichnete Leistung eines gebildeten Steinmetzen. Es ist ein glücklicher Umstand, dass eine verhältnismäßig nahe Parallele ein gewisses Licht auf diesen Meister wirft, denn solche Parallelen, die etwas mehr als allgemeine Zusammenhänge betreffen, sind sehr selten. In diesem Fall legen eine mit zwei Mondsicheln verzierte Konsole (Abb. 125) in der Chorempore des Doms von Magdeburg (Bischofsgang, nach 1232, dem Todesjahr des Erzbischofs Albrecht II.), ${ }^{162}$ ihre Verwandte in Walkenried (Baubeginn um 1207-1209, ziemlich fortgeschritten um 1240;163 Abb. 126) sowie weitere Beispiele in Maulbronn (Herrenrefektorium) und Ebrach ein mögliches Quellgebiet nahe. Das Portal von Kerz wurde wohl an den Ostpartien der Kirche sekundär verwendet. Es handelt sich um die innerste Schicht eines Portals, dessen Öfnung - wie auf dem

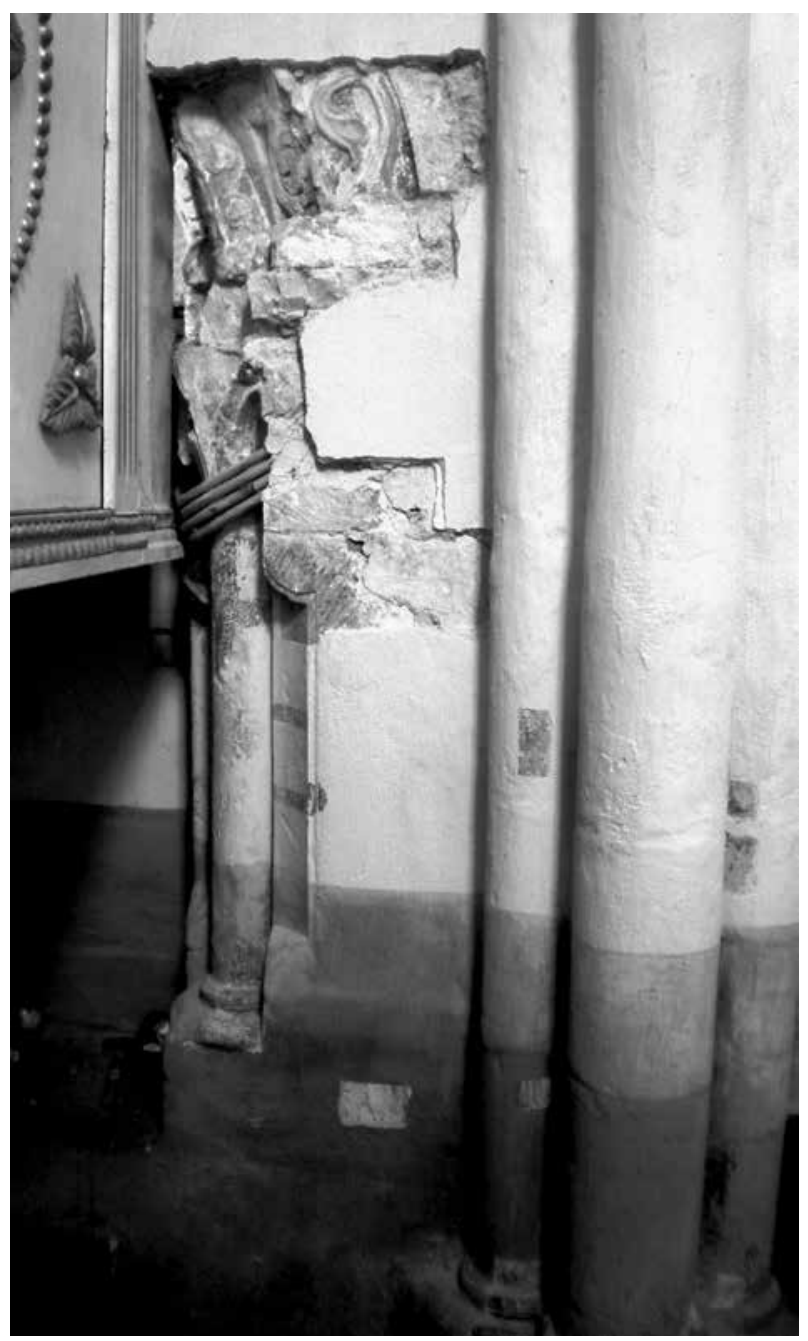

Abb. 140. Holmwegen, Pfarrkirche, südliche Nische des Chors, Gewände 

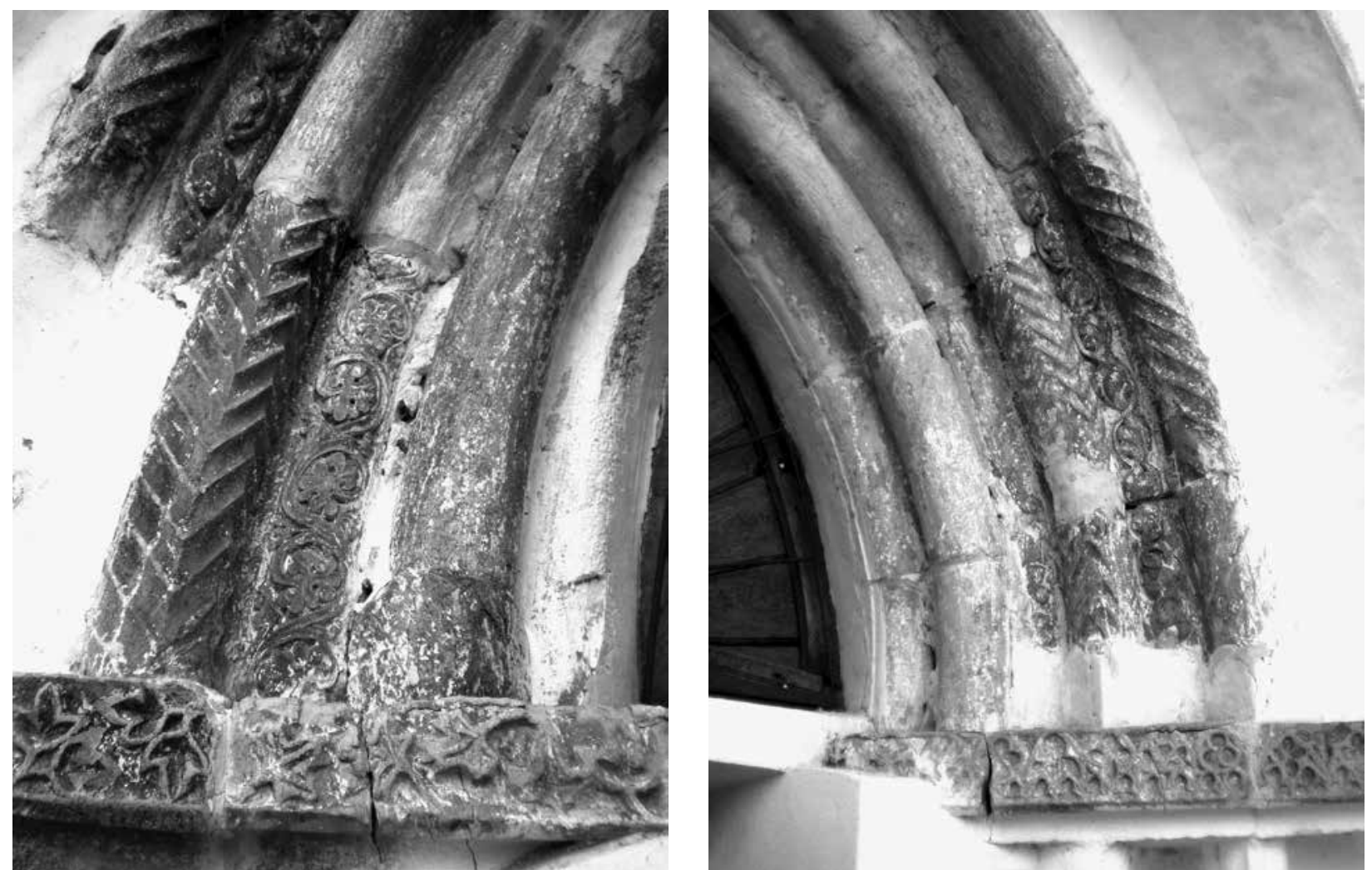

Abb. 141-142. Holmwegen, Pfarrkirche, Archivolte des Westportals, Details

Sockel zu sehen ist - ursprünglich von Dreiviertelsäulen flankiert wurde.

Dieses Portal hat eine ganze Reihe von mehr oder weniger treuen Nachfolgern beeinflusst. Ein ähnliches Portal mit einem Kreuz im Tympanon befindet sich in der Südmauer des Chors in Bistritz und - in sekundärer Stelle - in Roden. Die anderen Beispiele sind Nebeneingänge im Inneren, zum Teil an Ort und Stelle erhalten: in Mühlbach (Abb. 102), in Kronstadt ${ }^{164}$ und in Holmwegen (ohne Tympanon, mit einfach abgefaster Rahmung). ${ }^{165}$ Es gibt eine seltsame, beinahe manieristisch anmutende Variation auf das Thema: eine dreipassförmige Rahmung an der Nordseite des Kronstädter Langhauses (Abb. 127), deren seltsame Form vielleicht auch mit der Veränderung des Entwurfs - und wohl des Meisters - zusammenhängt, die um die Zeit der Ausführung der oberen Chorpartien erfolgte. ${ }^{166}$ Der Rundbogenfries oberhalb der Chormauer auf dem sonst Kerz unmittelbar nachfolgenden Bau kann dieser Planänderung zugeschrieben werden.

Die Umrahmungen von Öffnungen durch eine tiefe Hohlkehle, die in Hornausläufen endet, sind in Ungarn gegen Ende des 12. Jahrhunderts erschienen ${ }^{167}$ und sind in der ersten Hälfte des 13. Jahrhunderts öfters zu begegnen. Sie bildeten eine wichtige morphologische Charakteristik derjenigen westungarischen Werkstatt,

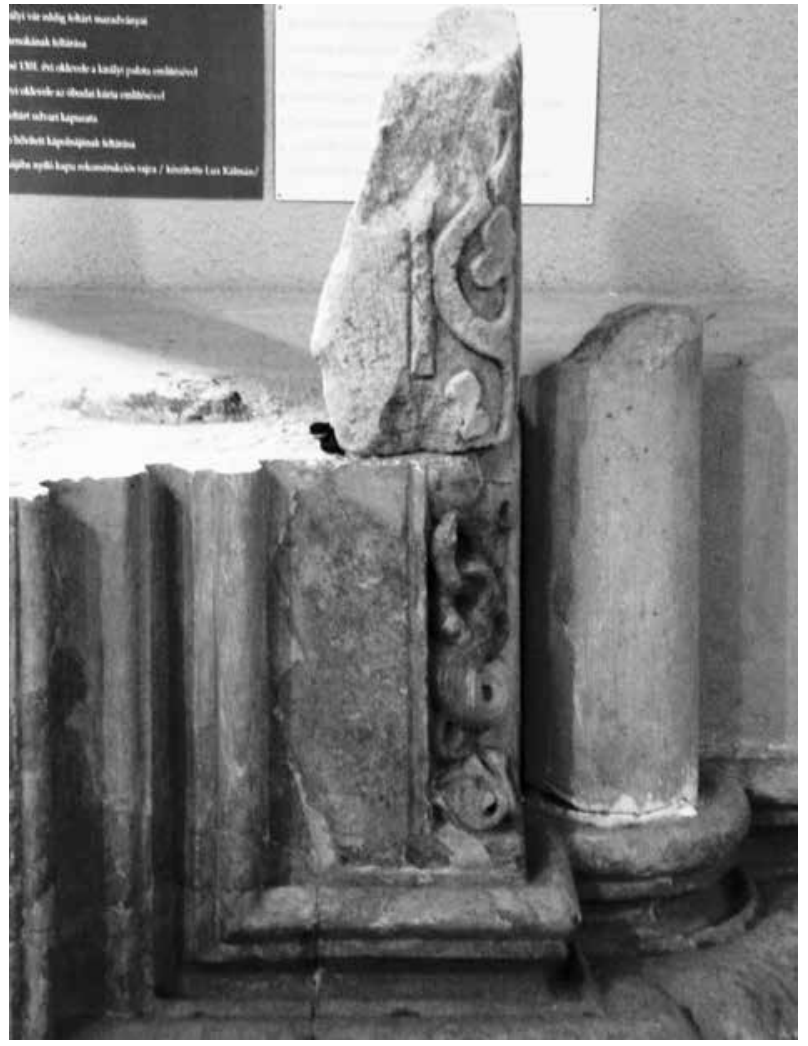

Abb. 143. Óbuda, Königliche Burg, Portalfragment (durch ein wiedergefundenes Stück ergänzt). Budapesti Történeti Múzeum (Historisches Museum Budapest) 


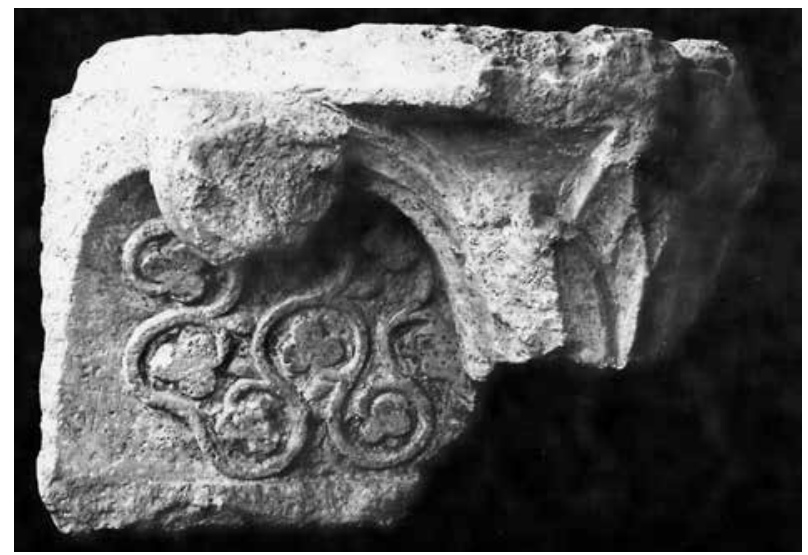

Abb. 144. Portalfragment aus der Kathedrale Kalocsa II Paks, Városi Múzeum (Städtisches Museum)

deren Zentrum in Veszprém war. ${ }^{168}$ An der so genannten "Gisela-Kapelle" auf der Nordwand des Obergeschosses wurde nicht nur eine genaue Parallele der siebenbürgischen Portalformen zu Tage gefördert, ${ }^{169}$ sondern die ganze Formenwelt war analog gestaltet. Dass dieser Portaltypus im 13. Jahrhundert weder verspätet noch altmodisch gewesen ist, zeigt, dass er auch auf den Ostseiten beider Transeptarme der Kathedrale zu Amiens Verwendung fand. Der Kommentar zur Typenwahl, die gleichzeitig mit den Westportalen geschah, ist ernst zu nehmen: „... die Baumeister sind

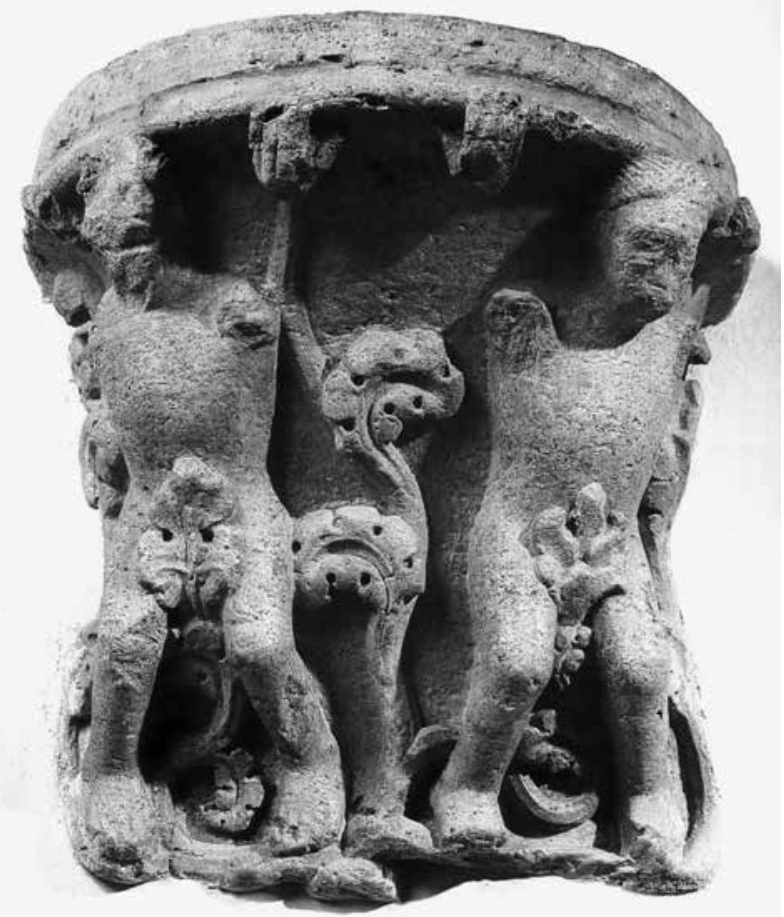

Abb. 145. Konsole mit Atlanten aus der Kathedrale Kalocsa II. Kalocsa, Erzbischöflicher Palast nicht Erfüllungsgehilfen eines Stils, wie es sich manche Architekturhistoriker nachträglich zurechtlegen. Im Gegenteil: Sie stufen vielfältig und genau die Formen nach der Ranghöhe des Ortes ab." ${ }^{170}$ Es kann zum Teil durch den üblicherweise von Osten nach Westen vorgehenden Bau bedingt sein, dass kaum Haupteingänge des 13. Jahrhunderts im Kreis von Kerz bekannt sind. Auch deshalb wäre die Rekonstruktion der ursprünglichen Form des Kerzer Westportals wichtig. Sonst gibt es nur zwei Westportale, beide aus späterer Zeit: das mit einem dreifachen Gewände gebildete Mühlbacher Portal in einem gegiebelten Portalrisalit und dasjenige von Roden (Abb. 128), das entgegen seines heute sehr fragmentarischen Zustands 1908 noch in einer ähnlichen Struktur und mit Kelchkapitellen über den Säulen gezeichnet werden konnte. ${ }^{171}$

Außer Portalen gehören Rahmungen miteinander verbundener Öffnungen zu dieser Gattung der Steinmetzarbeiten: etwa Fenstergruppen am Westturm von Mühlbach, ${ }^{172}$ Zwillingsfenster in Szék und Roden. ${ }^{173}$ Sándor Tóth hat diese zum einfacheren Gliederungstypus gerechnet, den er auf der Sakristeitür von Urwegen (Szászorbó, Gârbova, RO) auch fand. ${ }^{174}$ Die Kleinarchitektur des Kerzer Chores - ein Lavabo - hat ihm Anlass zur Darstellung des Zusammenhangs der einfacheren und der reicheren Stilvarianten geboten. Mit diesen

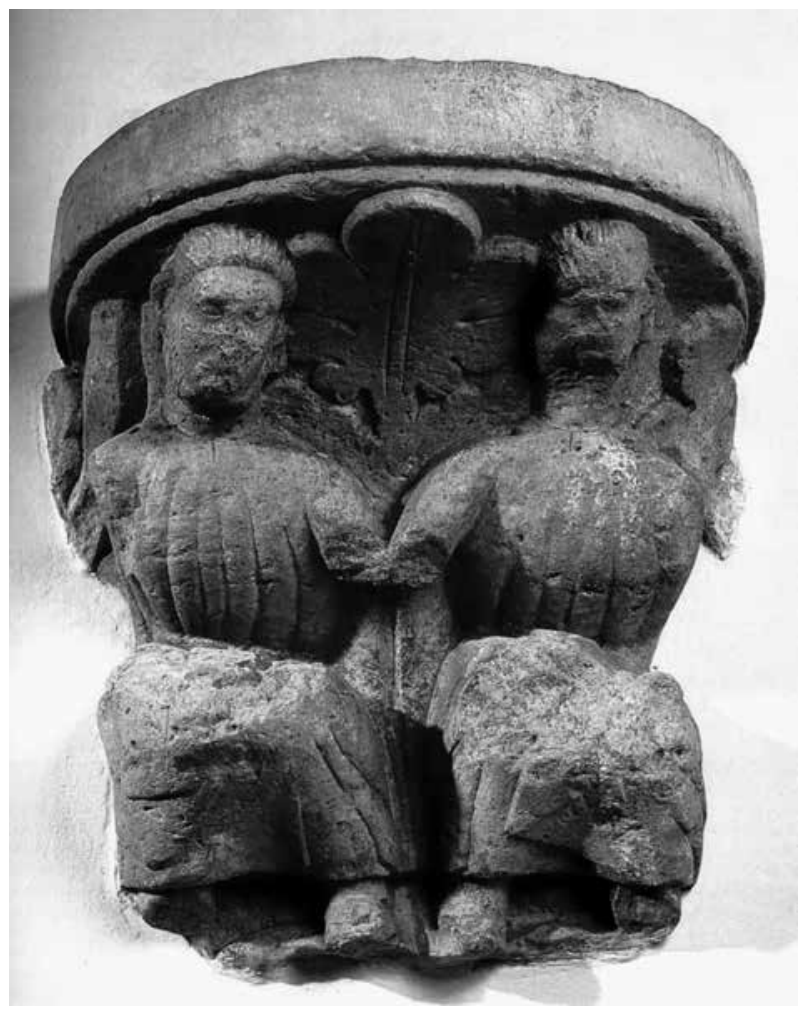

Abb. 146. Konsole mit sitzenden Figuren aus der Kathedrale Kalocsa II. Kalocsa, Erzbischöflicher Palast 
kann ein giebelförmiger Stein in Mühlbach in Verbindung gebracht werden, der mit einer Darstellung des lebendigen Kreuzes verziert ist (Abb. 129). Seine Form und die Abfassung der unteren Kante weisen darauf hin, dass das Stück wohl als Bekrönung einer Wandnische (Sakramentshaus, Armarium) diente. ${ }^{175}$

\section{7.}

Mehr oder weniger genau kann die Bautätigkeit in Kerz - und wohl auch in Mühlbach - zwischen den ersten Jahren des 13. Jahrhunderts und den 1230er Jahren datiert werden, die sowohl ausländische (Magdeburg, Walkenried, Maulbronn, Ebrach) als auch inländische Parallelen (Veszprém) aufweist. 1241, beim Mongolensturm, mag das Kloster vor nicht sehr Langem beendet gewesen sein. Mit dem skulptierten Schmuck des Kerzer Chors sind die Chöre der Kirchen von Kronstadt und von Holmwegen - beide wohl Pfarrkirchen - am nächsten verwandt. Die Kir- che St. Bartholomä (Abb. 109), die auch in der Anlage der Zisterze folgt, weist ähnliche Gliederungsformen auf: Kelchkapitelle (Abb. 130) mit spitzen Blattzungen und - auf den größeren Dienstkapitellen, etwa unter dem Triumphbogen - Blattaufsätzen sowie Palmetten, die plastischer als diejenigen in Kerz ausgeführt sind. Wie in Kerz, gehen die Schildbögen bei den Seitenwänden von hoch gelegenen geometrischen Konsolen aus. Bei all diesen Übereinstimmungen gehört das Chorgewölbe zu einer anderen Formenwelt: Die Rippenprofile sind anders gestaltet, die Schlusssteine weisen zerstreute Blätter und eine Maske auf (Abb. 131). Auf dem Äußeren wird die Mauerkrone durch einen Rundbogenfries abgeschlossen (Abb. 109), nicht durch ein Gesims auf geometrischen Konsolen, wie in Kerz (Abb. 98) und bei seiner direkten Nachfolge (Abb.132). Nach dem Abschluss der Arbeit an dem Chor - und wohl den Ostpartien - sowie an der Ostwand des Querschiffs und an geringeren Teilen der Mauer des Langhauses (vgl. Nordportal) scheinen die Arbeiten wegen des Mongolensturms für eine längere Zeit ein-

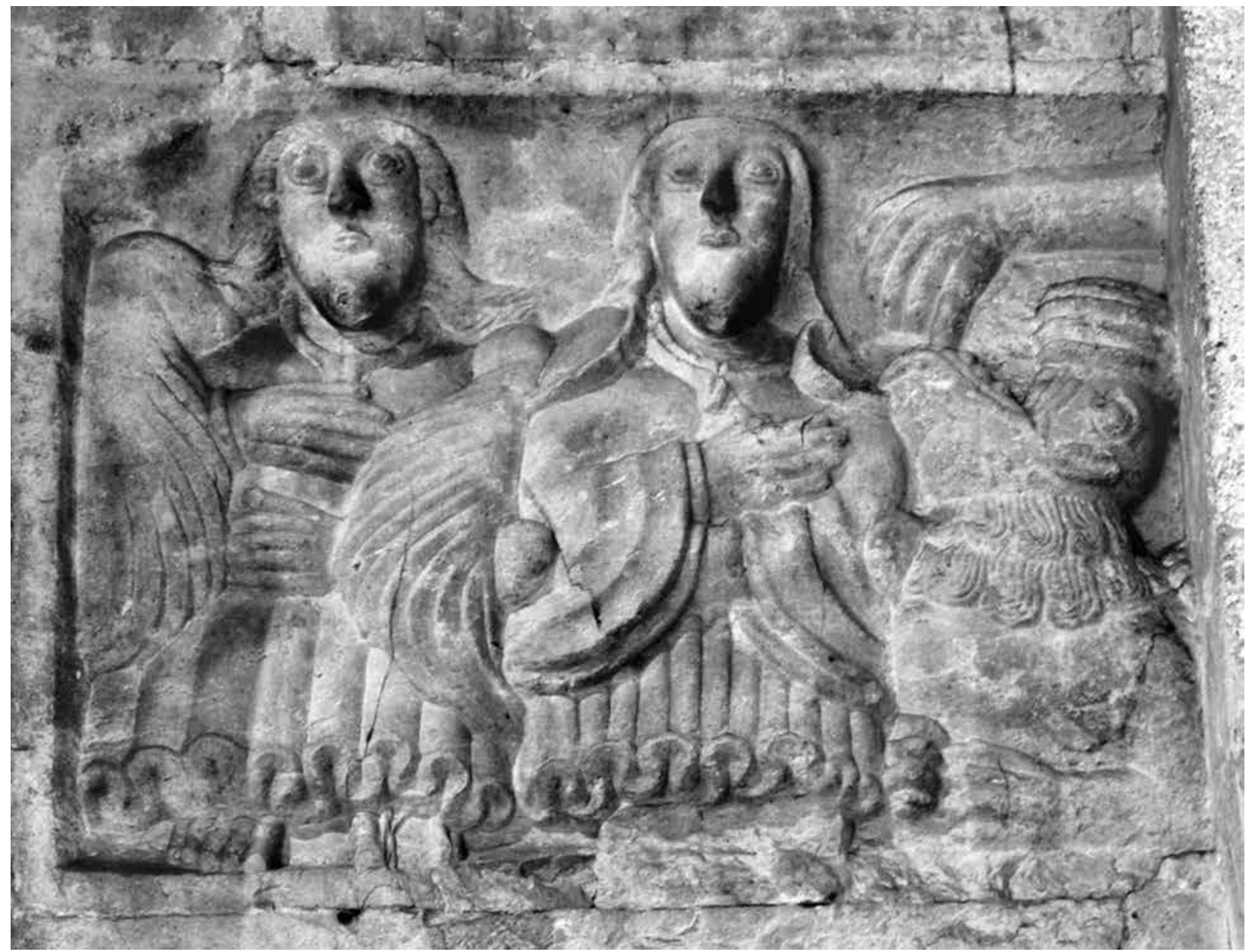

Abb. 147. Relief bei dem Westportal der Propsteikirche St. Zeno in Bad Reichenhall 


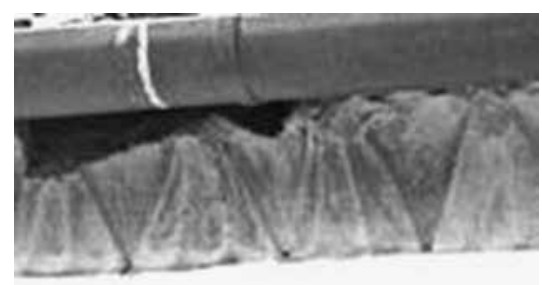

Abb. 148. Tartlau, Pfarrkirche, Kranzgesims, Detail

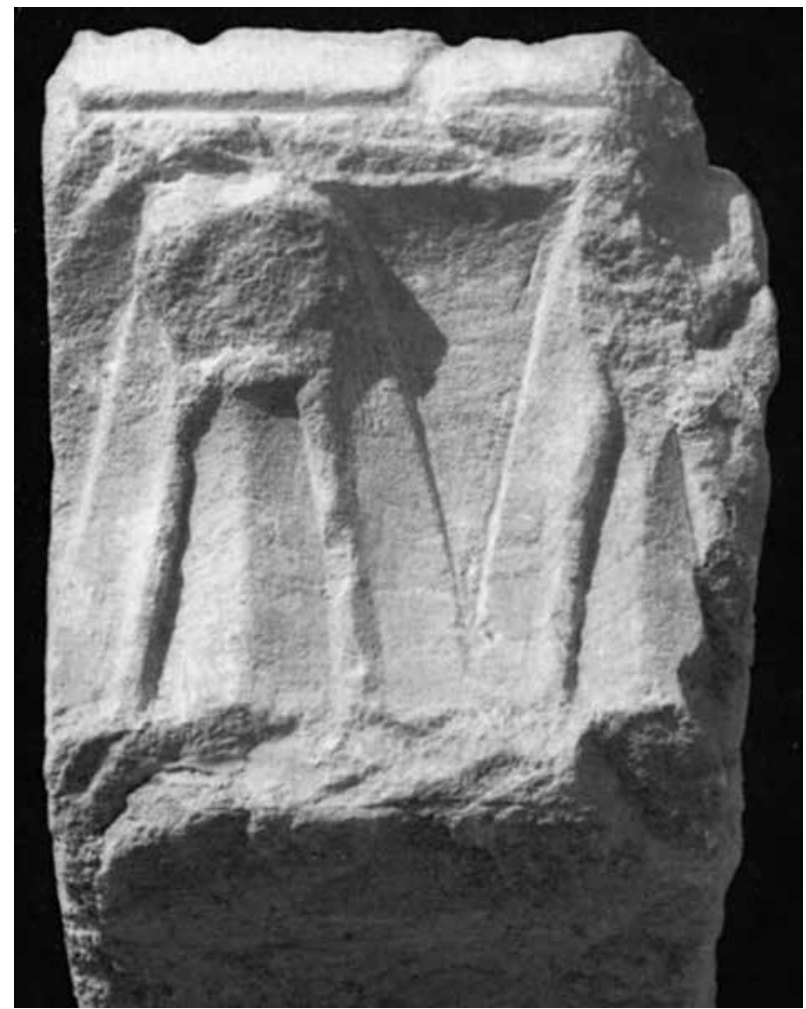

Abb. 149. Pannonhalma, Abteikirche, Kranzgesims, Detail

gestellt gewesen und erst später nach Westen fortgesetzt zu sein.

Auf der Ostwand des Querschiffs findet man einen merkwürdigen Konsolentypus unter den Dreivierteldiensten, die die seitlichen Gurtbögen der Vierung tragen (Abb. 133). Diese entsprechen den Kelchkapitellen mit spitzen Blättern, die unten mit plastischen Rosetten enden, so wie die kleinen Konsolen unter den Schild-

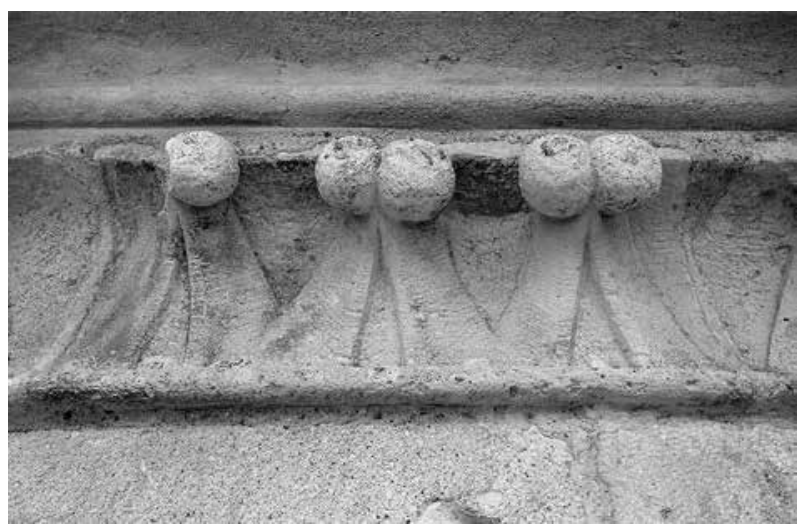

Abb. 150. Gyulafehérvár

(Weißenburg/Karlsburg, Alba Julia, RO), Kathedrale, Hochchor, Kranzgesims in Sekundärverwendung (Foto: Attila Mudrák)

bögen des Chors von Kerz bzw. diejenigen im Mittelschiff von Mühlbach (Abb. 108). Eine Eigenart ihrer Komposition ist ihre Kernform, die bis auf eine geringe Scheibe für den Anschluss des runden Dienstes als ein verkehrter Pyramidenstumpf gebildet ist. Ihre quadratische Deckplatte ist so profiliert, wie man die Kelche zu gestalten pflegt. Offensichtlich handelt es sich um eine freie Kombination von Formen, eine Variante von Kapitellen und Konsolen. Die Improvisation wurzelt im Typus des kapitellförmigen Kragsteins, der im mitteleuropäischen Formenschatz weit verbreitet war. ${ }^{176} \mathrm{Im}$ Allgemeinen könnte man eine Gotikrezeption vermuten, in der man neben Denkmälern des Rheingebiets (Chor von Sponheim, Trier, Limburg an der Lahn) mit süddeutschen frühgotischen Denkmälern - darunter Zisterzienserbauten - rechnen kann, ohne Näheres über die Wege der Vermittlung zu wissen. Die nächste Analogie - allein für ein winziges Detail, die Rosette unter der Konsole - hat aus dem Grabungsfund der Reste der 1219 geweihten Salzburger Domkrypta (Abb. 134) anlässlich der Bearbeitung der Kathedrale Kalocsa II Imre Takács in ungarischem Kontext erörtert. ${ }^{177}$ Ein ähnliches Stück befindet sich in Ócsa, in einer Ecke des nördlichen Nebenraumes des Querschiffs (Abb. 135). Vorerst kann man den allgemeinen Formenschatz und

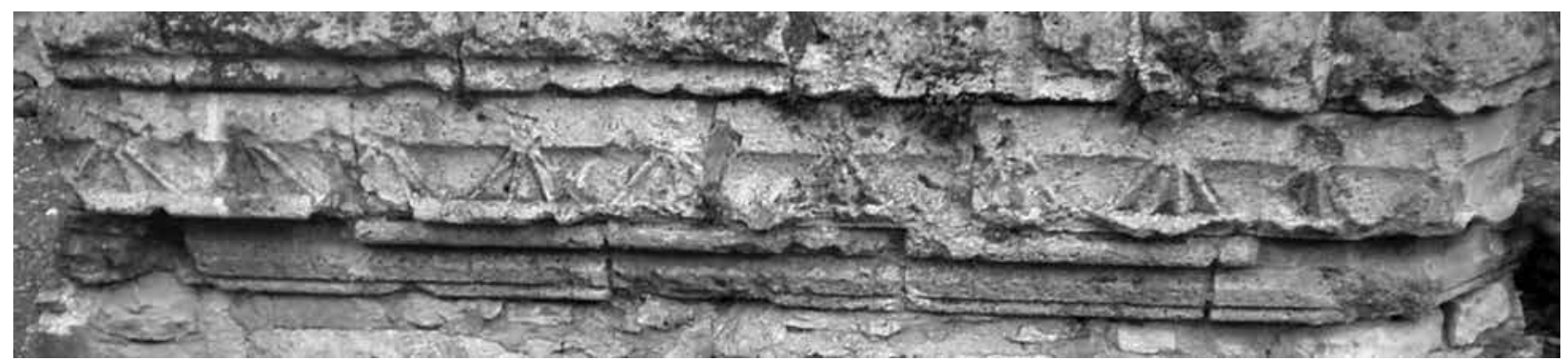

Abb. 151. Budapest, Margareteninsel, Dominikanerinnenkloster, Gesimsstück in Sekundärverwendung 


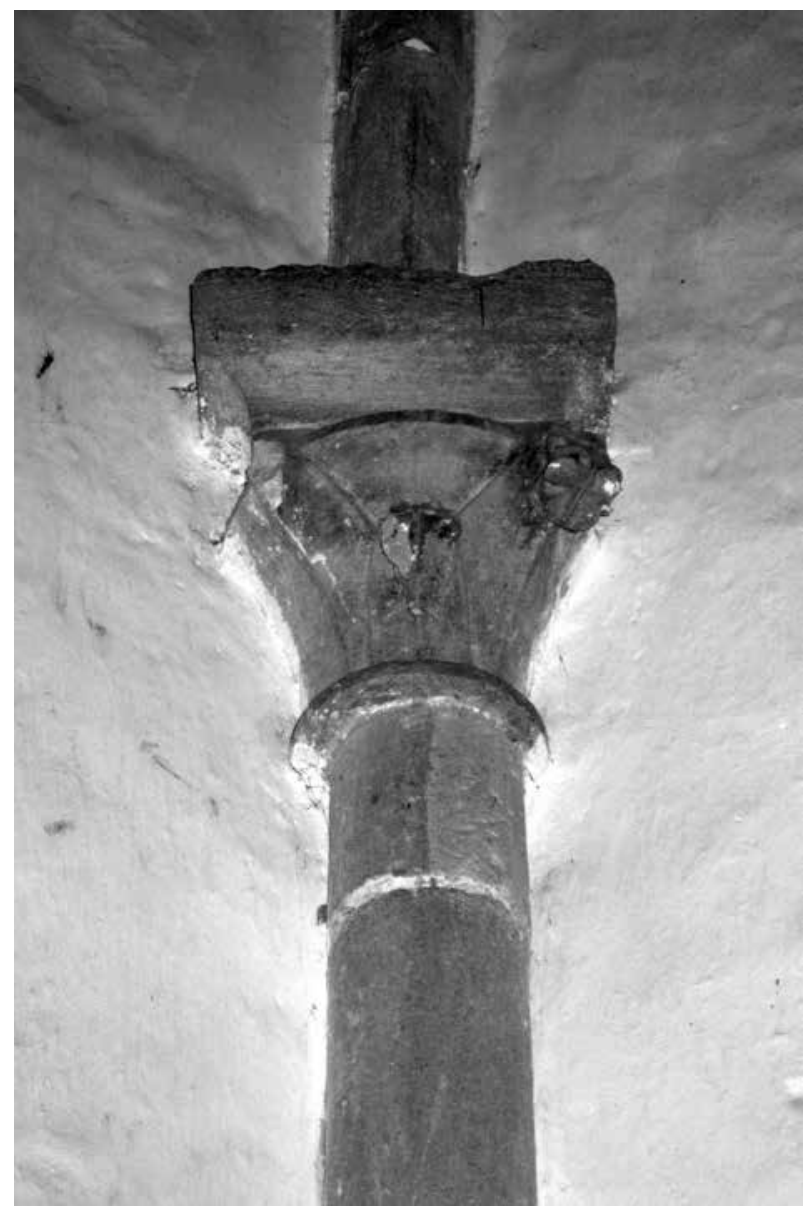

Abb. 152. Szék, Pfarrkirche, Chor, Kapitell eines Eckdienstes (Foto: Pál Lôvei)

die individuellen Züge schwer unterscheiden. Das Problem der Differenzierung wurzelt nicht nur in den Mängeln unserer Kenntnisse, sondern auch in einer zunehmenden Neigung zur Typisierung, die Hand in Hand mit der Erscheinung der Gotik geht.

Paarstücke dieser Konsole befinden sich unter den Querrippen der sechsteiligen Gewölbe des Chorjochs von Holmwegen (Abb. 136). ${ }^{178}$ Die Ähnlichkeit zwischen den Werkstätten beider Formen braucht nicht näher begründet zu werden. Die Konsolen von Holmwegen kennzeichnen wohl eine logischere Ausgestaltung als die Originallösung. Es wurzelt klar im Charakter der Pfarrkirche zu Holmwegen, die jede Spur einer Strenge der Zisterzienser vermied. Ihre Wandvorlagen sind reicher, mit Schaftringen geschmückt (Abb. 137-138). Es gibt hier eine strengere, dabei auch figürliche Dekoration. Ein Archivoltstück der Rahmung der großen Nische der Südwand des Chors (Abb. 139-140) ist seit Langem bekannt: Es wurde oft im Kontext der Ornamentik der Skulptur der Kathedrale von Pécs erwähnt, was bei der Frühdatierung der

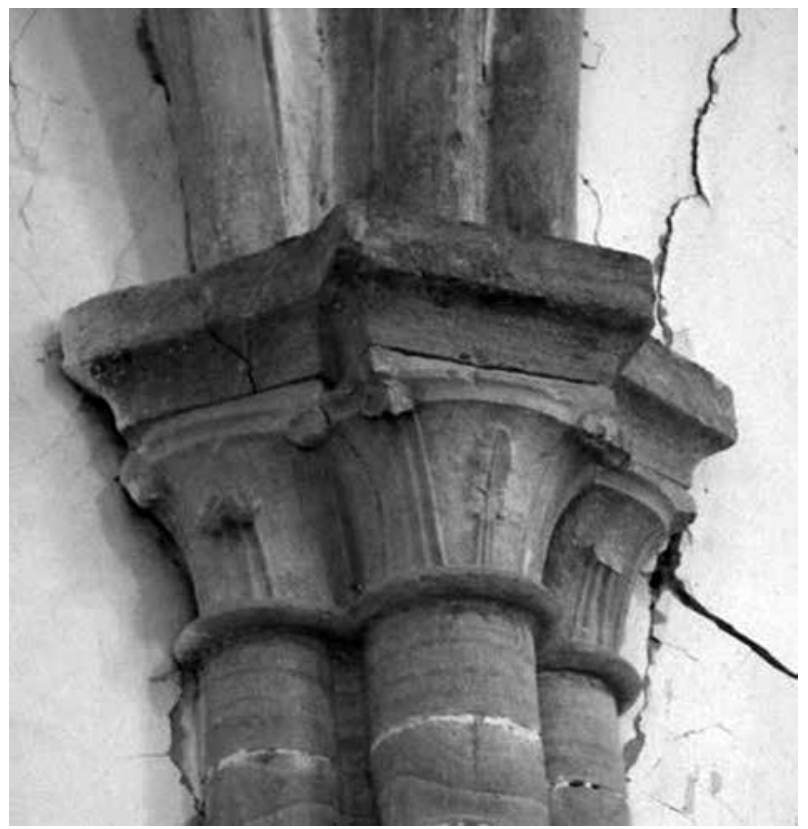

Abb. 153. Szék, Pfarrkirche, Chor, Wanddienstbündel, Kapitell

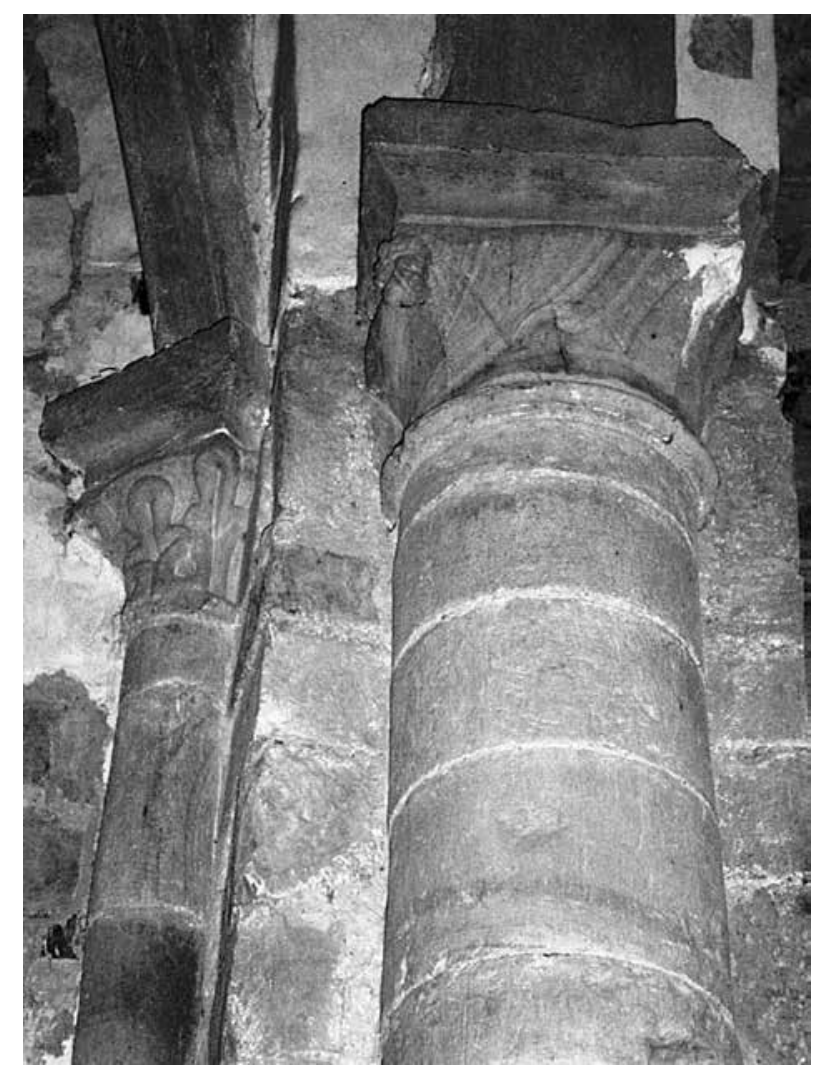

Abb. 154. Szék, Pfarrkirche, Triumphbogenpfeiler, Kapitelle

Letzteren und der Spätdatierung von Holmwegen eher enigmatisch erschien. ${ }^{179}$ Diese große, fast ein Jahrhundert umfassende zeitliche Entfernung wurde in der neueren Literatur wesentlich vermindert. ${ }^{180}$ Die für 


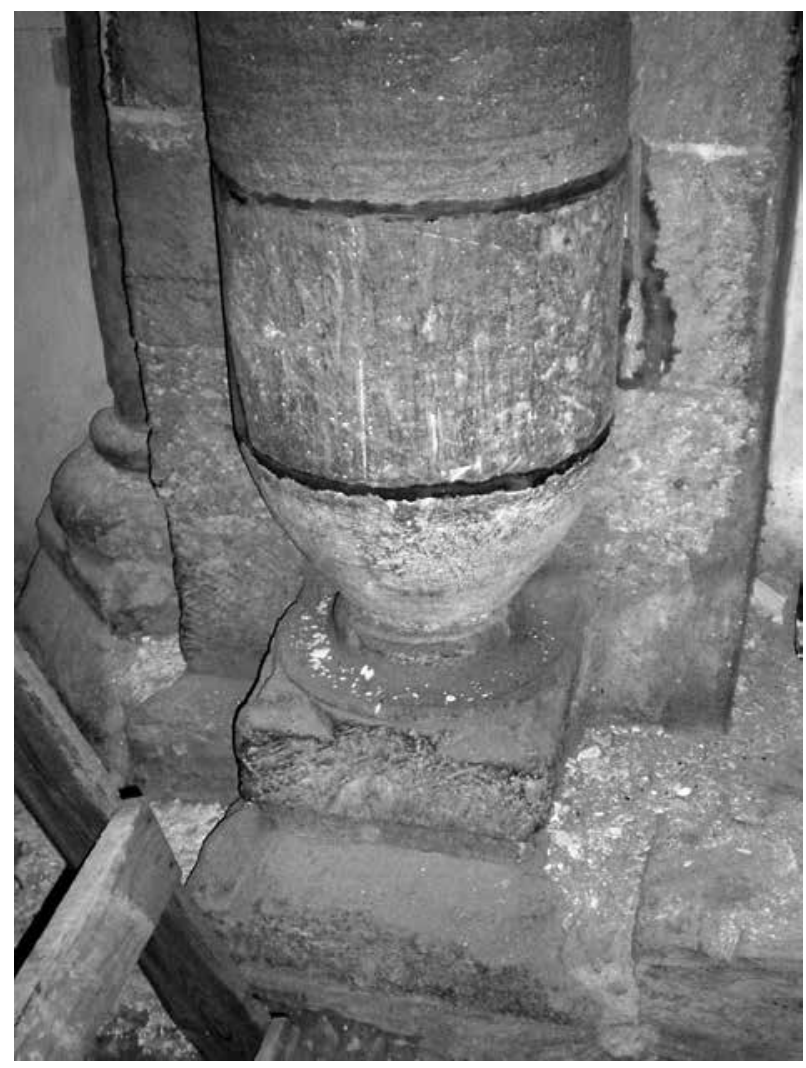

Abb. 155. Szék, Pfarrkirche, Triumphbogenpfeiler, Gewändedienst, Basis einer Dreiviertelsäule

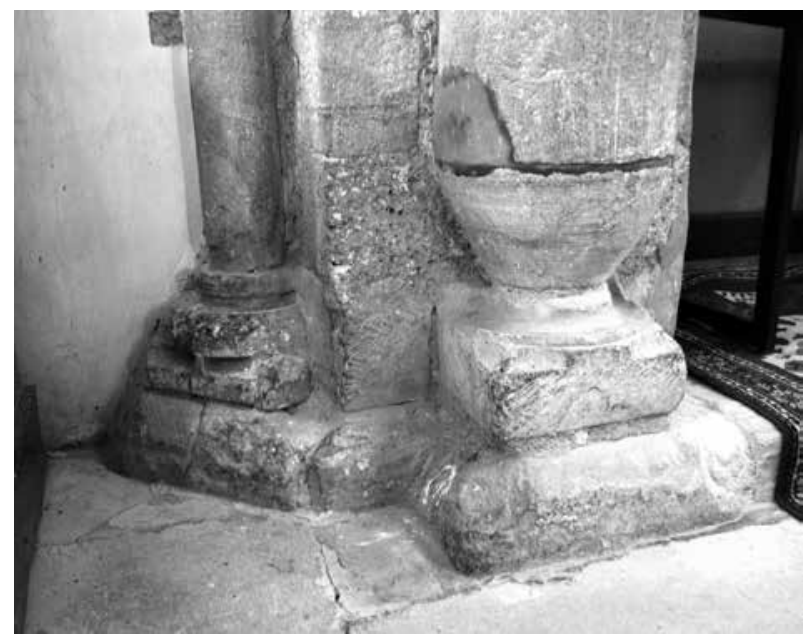

Abb. 156. Szék, Pfarrkirche, Triumphbogenpfeiler, Gewändedienst, Basis einer Dreiviertelsäule (Foto: Pál Lôvei)

hochromanisch gehaltene Parallele hat die Forscher irregeleitet, indem ihre Aufmerksamkeit statt der verschiedenartigen Behandlung der Details auf scheinbare Ähnlichkeiten gelenkt wurde. Offensichtlich wurden ähnliche dekorative Skulpturen beim Umbau des Westportals der Kirche - vielleicht während einer

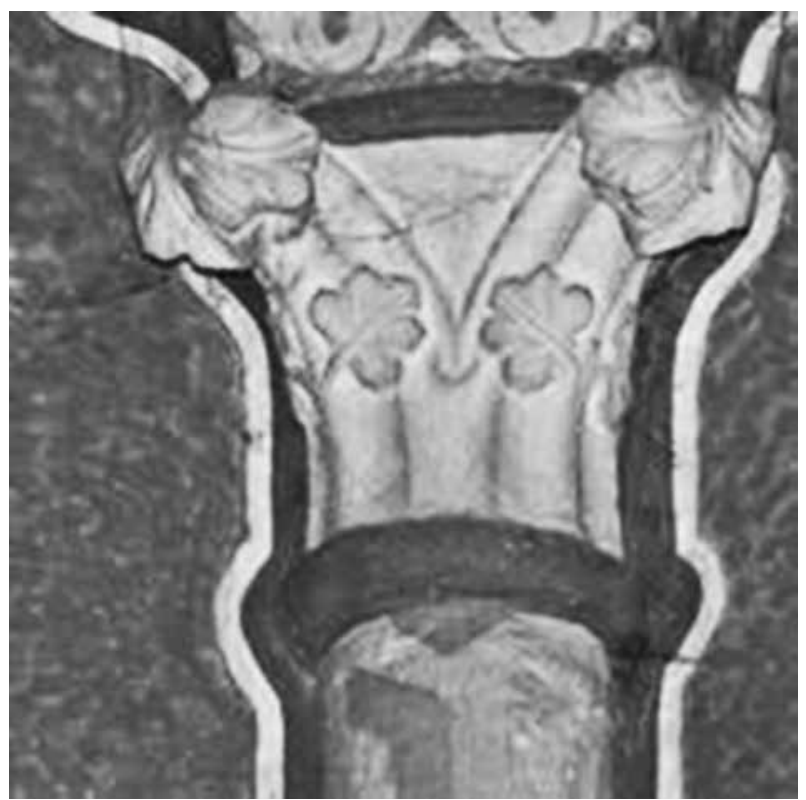

Abb. 157. Bistritz (Beszterce, Bistrița, RO), Minoritenkirche, Chor, Kapitell eines Eckdienstes

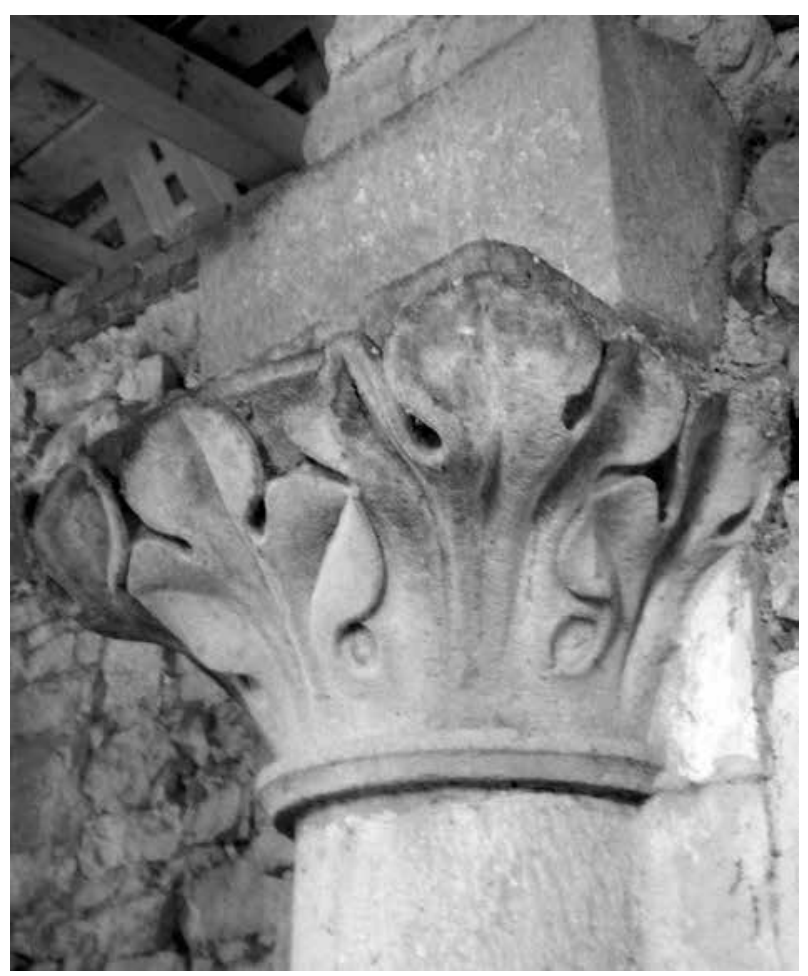

Abb. 158. Néma (Nima, RO), Pfarrkirche, Wanddienstkapitell

mittelalterlichen Reparatur - sekundär verwendet (Abb. 141-142). ${ }^{181}$ Die Spuren weisen auf die zentrale Region des Landes hin. Es scheint, dass Schlüsselbedeutung einer dekorativen Skulptur aus Óbuda, die zum Westportal der königlichen Burg gehört hatte und jüngst wiedergefunden wurde (Abb. 143), beige- 


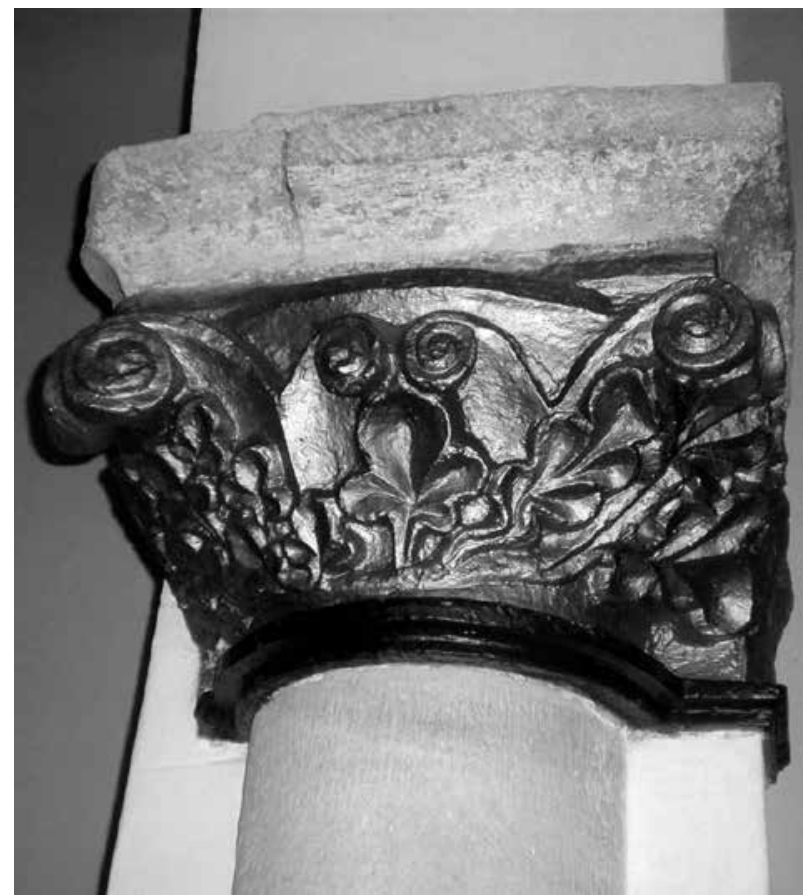

Abb. 159. Schlosswall (Bálványosváralja, Unguraş, RO), Pfarrkirche, Wanddienstkapitell

messen werden soll. ${ }^{182}$ Ein Fundstück aus Paks gehört zu einem Portal der Kathedrale Kalocsa II (Abb. 144). Es erscheint mit seinem fragmentarischen Knospenkapitell und Rankenschmuck mit kleinen Dreipassblättchen als ein charakteristisches Stück dieses offensichtlich von dem Schmuck des Klosters Pilisszentkereszt ausgehenden Kreises. ${ }^{183}$ Die Funde aus Paks haben viel zu den Beständen aus Kalocsa beigetragen, die als Vorbilder der Kapitellskulptur von Kerz auch eine Rolle gespielt haben mögen. ${ }^{184} \mathrm{Da}$ der unter dem Barockbau der Kathedrale zugeschüttete Bau II jüngst freigelegt wurde, kann man hoffen, dass die Publikation diesbezüglich auch weitere Kenntnisse liefern wird. ${ }^{185}$ Während man in Kerz einen Reduktionsprozess - vor allem der Ornamentik - bemerkt, kommen diese Formen in Holmwegen zur Geltung, wobei dort dem Blätterschmuck eines Pfeilersockels oder einer Konsole von Kalocsa gefolgt wurde. ${ }^{186}$ Die Feigenblätter, die an einem im erzbischöflichen Palast aufbewahrten Kragstein von Kalocsa Adam und Eva bedecken, haben offensichtlich die Kreuzdarstellung des Nischengiebels in Mühlbach beeinflusst ( $A b b$. 145; vgl. Abb. 129). ${ }^{187}$

Die Kragsteinfiguren von Kalocsa (Abb. 145-146) haben nicht nur typologisch, sondern auch stilistisch für die Atlanten des Triumphbogens in Holmwegen (Abb. 137) Pate gestanden. Derjenige auf der Nordseite erinnert in seiner Kleidung an die Konsole mit dem

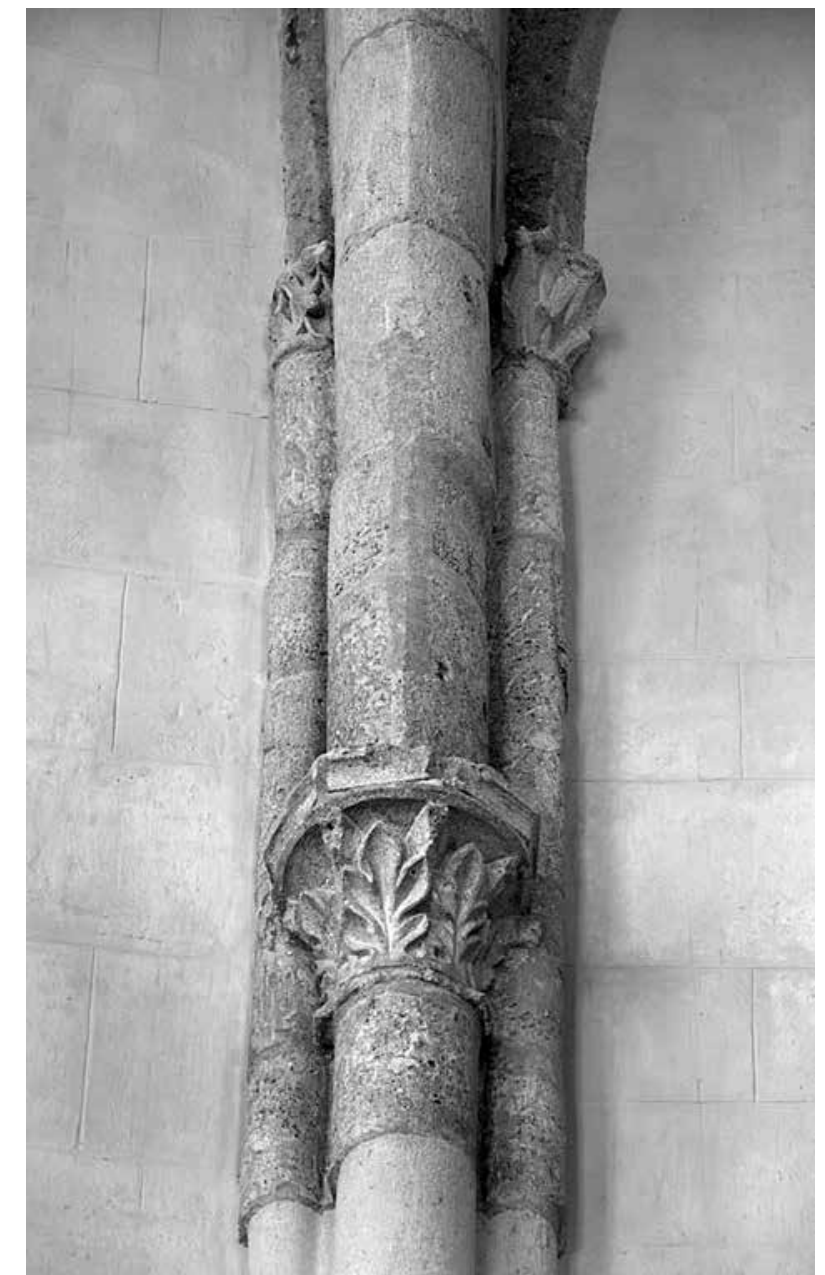

Abb. 160. Gyulafehérvár, Kathedrale, Hochchor, Dienstkapitell (Foto: Attila Mudrák)

sitzenden Paar, während die Ausdruckskraft des südlichen eine Parallele im Gesicht einer Atlasfigur von Kalocsa findet. Für den Darstellungstypus und besonders für die Derbheit des Figurenstils von Kalocsa findet man im Salzburger Kreis wohl in Reichenhall Parallelen (Abb. 147). ${ }^{188}$ Es gibt Bemühungen, Holmwegen in die Mitte einiger figürlicher Darstellungen zu stellen, die aber vorerst gar nicht als zwingend erscheinen. ${ }^{189}$

8.

Die Tartlauer Kirche, die wegen ihrer eigentümlichen bauikonologischen Stelle mit der Hypothese des Deutschen Ritterordens in Zusammenhang gebracht und daher viel umstritten wurde, hat ebenfalls auf den Chor von Kerz zurückgegriffen. Die bereits früher angenommene zentrale Anlage wurde hier durch die Freilegung des westlichen Polygons im Laufe einer Restaurierung in den 1970 er Jahren nachgewiesen. ${ }^{190}$ Wegen der spät- 
mittelalterlichen Brandschäden und der darauffolgenden spätgotischen Reparatur können hier nur wenige stilistische Kriterien zu Datierungsfragen herangezogen werden. Fest steht, dass der Zentralbau grundsätzlich Elemente des Kerzer Kirchenbaus benutzt hat. Es fällt aber auf, dass manche Züge der frühgotischen Gliederung in Tartlau verändert wurden: Die Gewölbe der Polygonchöre sind mit Rippen versehen, die auf den Gurtbogen der sechsteilig gewölbten Vorjoche hinauslaufen (Abb. 97). Eine ähnliche Rippenkonstruktion eigentlich ein 3/8 Schluss - findet man wohl vor 1235 am Mittelchor von Ócsa. Eine andere - und ebenfalls als eine Vereinfachung zu verstehende - Änderung in der von Kerz übernommenen Konstruktion ist, dass die Kirche ohne Schildbögen gewölbt wurde und so die kleinen Konsolen auch entfielen.

Obwohl eine ganze Reihe der Details verloren ging, ist das herumlaufende Kranzgesims der Tartlauer Kirche gut dokumentiert. Während Kerz (Abb. 78) ein Gesims auf Konsolen aufweist, ist ein Kranzgesims in Tartlau bezeugt (Abb. 148), das durch eine Reihe stehender Blätter mit Knospen besetzt ist. Es handelt sich bestimmt um eine Gliederungsform, die als wesentlich jünger erscheint: Das Beispiel der Benediktinerabteikirche zu Pannonhalma (Abb. 149) kann zwar mit dem 1224 bezeugten Weihedatum in Zusammenhang gebracht werden, das ursprüngliche Kranzgesims der Kathedrale von Gyulafehérvár (Abb. 150), das auf den im 18. Jahrhundert erneuerten Hochchor wieder versetzt wurde, zeugt aber ebenso von einem späteren Datum, wie ein Stück in sekundärer Verwendung in dem Dominikanerinnenkloster auf der Margareteninsel bei Buda (Abb. 151). ${ }^{191}$ Es sei daran erinnert, dass auch das echte Maßwerk des Rundfensters der östlichen Chorwand auf eine relativ jüngere Entstehungszeit des Tartlauer Baus (Abb. 110) hinweist.

Die ehemalige Pfarrkirche der ehemals blühenden Salzbergwerkstadt Szék ist ebenfalls eine - zwar sowohl geographisch als auch zeitlich entferntere Nachfolgerin von Kerz. Die Außenwände ihres Chors weisen am Kranzgesims die Kerzer Lösung (Abb. 98) auf: gerader Balken auf Konsolen (Abb. 132) ${ }^{192}$ Die morphologische Verwandtschaft kann als Zeichen der Zugehörigkeit des Baus zum Kreis von Kerz am klarsten ebenfalls am Chor in Szék nachgewiesen werden (Abb. 152-154). In den Ecken des Chorhaupts mit 5/8 Schluss dienen je drei Dreivierteldienste ohne Lisenenunterlagen - wie in Holmwegen, wo auch dieselbe Profilierung der Rippen vorkommt ${ }^{193}$ - als Vorlagen für die Kreuzrippengewölbe - im Unterschied zur geradezu obligaten Verwendung von sechsteili- gen Gewölben auf älteren Bauten in diesem Kreis. ${ }^{194}$ Die Wanddienste bei den Triumphbogenpfeilern weisen eine überaus nachlässige Formgebung auf, ${ }^{195}$ die ebenso die Folgeerscheinung einer weitgehenden Provinzialisierung sein kann, wie die unregelmäßig verzerrte Konstruktion des Grundrisses. ${ }^{196}$ Besonders auf Grund der Gliederung der Triumphbogenpfeiler kann man auf Anomalien während des Baus schließen. Solche Unregelmäßigkeiten sind beim Sockeln des Triumphbogens evident (Abb. 155-156). Über den Postamenten wurden ausgezeichnet und sauber gehauene attische Basen für den Anschluss von Schäften mit einem Durchmesser von $16 \mathrm{~cm}$ eingebaut. In der Tat wurden darüber beiderseits Dreivierteldienste mit einem Durchmesser von $37 \mathrm{~cm}$ hineingebaut. Der Maßunterschied zwischen den Basen und dem aufgehenden Mauerwerk wurde durch umgekehrte Kegelstümpfe ausgeglichen, als ob die Wanddienste des Triumphbogens wie Bleistifte "gespitzt" gewesen wären. Es handelt sich offensichtlich nicht einfach um einen Planwechsel, vielmehr um eine Notlösung. In der Zeitschrift Technika schrieb der anonyme Verfasser, dass es „das Ergebnis eines späteren Eingriffs, aber auch eine ursprüngliche Lösung sein kann, denn man muss sich hierzulande damit abfinden, dass man einer außerordentlichen Formgebung begegnet, die von den morphologischen Regeln abweicht" ${ }^{197}$ In diesem Text wird allein die Mannigfaltigkeit der Knospenkapitelle erwähnt, ihr provinzieller Stil aber verschwiegen. Bei ihren missverstandenen Formen, Unregelmäßigkeiten und verzerrten Proportionen findet man Steinmetzarbeiten guter Qualität, regelmäßig gestaltete Knospenkapitelle auf den Eckdiensten des Chors. Man hat den Eindruck, als wenn die Arbeit nach der Wegfahrt eines erfahrenen Steinmetzen einem ungebildeten Nachahmer anvertraut gewesen wäre oder fertig erworbene Steinmetzarbeiten ohne Sachkenntnis versetzt wären.

Was in Szék als eine auf der Hand liegende Erklärung für den provinziellen Stil erscheint, nämlich die späte Entstehungszeit wohl im dritten Viertel des 13. Jahrhunderts, ist für die Minoritenkirche in Bistritz sicher. ${ }^{198}$ Die Beziehungen des Baus zu Kerz sind vor allem am Chor nachweisbar, während auf Grund ihres unterschiedlichen Erhaltungszustands sogar der - sicher abwegige - Gedanke aufgetaucht ist, dass die beiden Bauteile nichts Gemeinsames hätten. ${ }^{199}$ Der reiche Skulpturenschmuck des Chors zeugt eher typologisch als stilistisch von einem Anschluss an die Vorbilder von Kerz. Die Wanddienste des Chorschlusses mit Kelchkapitellen, die Blattauflagen zieren, sowie die großen Schlusssteinscheiben mit Blätterschmuck 
(Abb. 157) daselbst gehören zum traditionellen Formenschatz. ${ }^{200}$ Es gibt andere ornamentale Lösungen, wie die Rankengeflechte mit kleinteiligem Blattwerk, die die Laibungskapitelle des Westportals von Neustadt-Burzenland schmücken (Abb. 113-114). Sowohl das Dientskapitell als auch ein Schlussstein über dem zweiten Chorjoch vertreten diesen Stil in Bistritz. ${ }^{201}$ Trotz ihrer Lage im Burzenland, nahe zu Kronstadt und nicht weit von Kerz, erscheint die Kirche von Neustadt-Burzenland - auch in der Gestaltung der komplizierten Konstruktion eines Plattenmaßwerks (Abb. 112) - entgegen anderen Meinungen nicht als Denkmal einer Spätphase des Kerzer Stils, sondern sie zeigt moderne Stilerscheinungen, die von einer lebendigen Plastizität und einer freieren Entfaltung der Formen gekennzeichnet sind.

Als die Quelle dieser Stilvariante und der Weg ihrer Einflüsse wurde kürzlich in einer sehr genauen Analyse der Hochchor zu Gyulafehérvár nachgewiesen. Krisztina Havasi vermochte für den Bau der siebenbürgischen Kathedrale eine Rezeption bereits in der Kapitellskulptur (,mit den großen Blättern“) im Langhausbau nachzuweisen, wozu es stilistische Voraussetzungen schon seit den 1230er Jahren (Bamberg) gab. ${ }^{202}$ Auf diese Weise wurde die Aufmerksamkeit der Forschung auf diese Stilerscheinung gerichtet, die Néma (Nima, RO; Abb. 158), Schlosswall (Bálványosváralja, Unguraş, RO; Abb. 159) und Dees (Dés, Dej, $\mathrm{RO}$ ) im Someschtal vertraten. (Diese hatten folglich nichts mit dem Kreis um Kerz und im Olt-Tal zu tun.) Diesem Wirkungskreis mag sich Bistritz um 1260 angeschlossen haben. ${ }^{203}$ Diese Hypothese kann die Ableitung des Stils der Fensterfragmente der Bistritzer Minoritenkirche und ihrer kleinen Kapitelle (Abb. 119-121) auch von Gyulafehérvár unterstützen: von den Fenstern des Chors ${ }^{204}$ und von der Wandnische, die als Modell dieses Stils gilt (Abb. 160). ${ }^{205}$ Der Skulpturenschmuck des Hochchors von Gyulafehérvár hat in Szék auch in der Transformation des ornamentalen Stils von Kerz eine Rolle gespielt. In diesem Sinne kann dort nicht nur von Provinzialisierung als einer passiven Erscheinung, sondern auch von einem aktiven stilistischen Wechsel die Rede sein. Die seltsam erscheinenden Formen von Szék mögen Vorbilder in Gyulafehérvár gehabt haben. ${ }^{206}$ Möglicherweise kann das allein durch Fotografien belegte Kapitell des Westportals von Roden (Abb. 128) auch auf Vorstufen aus Gyulafehérvár zurückgeführt werden. ${ }^{207}$

\section{KONKORDANZ DER ORTSNAMEN}

Bény (Biňa, SL)

Bistritz (Beszterce, Bistrița, RO)

Borsmonostor (Klostermarienberg, A)

Csázma (Čazma, KR)

Dees (Dés, Dej, RO)

Draas (Homoróddaróc, Drăușeni, RO)

Gyulafehérvár (Weißenburg/Karlsburg, Alba Julia, RO)

Holmwegen (Halmágy, Halmăgiu, RO)

Honigsberg (Szászhermány, Hărman, RO)

Kerz (Kerc, Cărta, RO)

Kronstadt (Brassó, Braşov, RO)

Marienburg (Földvár, Feldioara, RO)
Michelsberg (Michelsberg, Cisnădioara, RO)

Mühlbach (Szászsebes, Sebeş, RO)

Néma (Nima, RO)

Neustadt-Burzenland (Keresztényfalva, Cristian, RO)

Petersberg (Barcaszentpéter, Sânpetru, RO)

Pétervárad (Petrovaradin-Novi Sad, SRB)

Roden (Radna, Rodna, RO)

Schlosswall (Bálványosváralja, Unguraş, RO)

Szék (Sic, RO)

Tartlau (Prázsmár, Prejmer, RO)

Urwegen (Szászorbó, Gârbova, RO)

\section{LITERATUR}

Andreas II. 2012 - II. András és Székesfehérvár [Andreas II. und Székesfehérvár], hrsg. von Kerny, Terézia - SMOHAY, András, Székesfehérvár, 2012.

Árpád-kori 1978 - Árpád-kori kôfaragványok [Steinskulpturen der Árpádenzeit], Ausstellungskatalog, hrsg. von TóтH, Melinda - MAROsi, Ernô, Budapest-Székesfehérvár, 1978.

BeHLing 1978 - Behling, Lottlise: Gestalt und Geschichte des Maßwerks, Köln-Wien, $1978^{2}$

Bogyay 1985 - Bogyay, Thomas von: [Besprechung von Marosi 1984], Kunstchronik 38/1. 1985. 28-35.
BRANNER 1965 - BRANNER, Robert: St Louis and the Court Style in Gothic Architecture, London, 1965.

BuZÁs 2004 - BuZÁs Gergely: Az esztergomi vár román kori és gótikus épületei [Die romanischen und gotischen Bauten der Burg Esztergom], in Esztergom, Vármúzeum 2004, 7-44.

CD - Codex diplomaticus Hungariae ecclesiasticus ac civilis IXI., ed. FeJÉr, Georgius, Budae, 1829-1844.

Claussen 1994 - Claussen, Peter Cornelius: Zentrum, Peripherie, Transperipherie. Überlegungen zum Erfolg des gotischen Figurenportals an den Beispielen Chartres, 
Sangüesa, Magdeburg, Bamberg und den Westportalen des Domes S. Lorenzo in Genua, in Studien zur Geschichte der europäischen Skulptur im 12./13. Jahrhundert, hrsg. von BECK, Herbert und Hengevoss-DürKop, Kerstin, Frankfurt a. M., 1994. I. 665. ff.

CSÁNYI-LuX 1943 - CSÁNYI, Károly - LuX, Géza: Árpádkori templom romjai Óradnán [Kirchenruinen aus der Árpádenzeit in Roden] (A M. Kir. József Nádor Mủegyetem Középkori Építészeti Tanszékének közleményei 20.), Technika 1943/2, Sonderdruck.

Das Burzenland 1928 - Das Burzenland, dritter Band, Kronstadt I. Teil, hrsg. von Jekelius, Erich, Kronstadt, 1928.

Das Burzenland 1929 - Das Burzenland, vierter Band, Die Dörfer des Burzenlandes I. Teil, hrsg. von JeKelius, Erich, Kronstadt, 1929

De Paolis-Oberti 1978 - De Paolis, Marta - Oberti, Maria Cristina: L'abbazia di S. Martino al Cimino, in I Cistercensi e il Lazio. Atti delle giornate di studio dell'Istituto di Storia dell'Arte dell'Università di Roma. 17-21 Maggio 1977, Roma, 1978. 169-175.

Dél-Alföld 2000 - A középkori Dél-Alföld és Szer [Südungarn und Szer im Mittelalter], hrsg. von KolLÁr, Tibor, Szeged, 2000.

Dél-Magyarország 2000 - Építészet a középkori Dél-Magyarországon [Architektur im mittelalterlichen Südungarn], hrsg. von Kollár, Tibor, Budapest, 2010.

DERCSÉNYI 1943 - DerCsÉNYI, Dezsô: XI. századi királyi kőfaragóműhely Budán [Eine königliche Bildhauerwerkstatt des 11. Jahrhunderts in Buda], Budapest Régiségei XIII. Budapest, 1943. 257-293.

DerCSÉNYI 1956 - DercsénYI, Dezsô: A pécsi műhely kora [Das Zeitalter der Werkstatt von Pécs], in A magyarországi múvészet a honfoglalástól a XIX. századig [Die Kunst in Ungarn von der Landnahme bis zum 19. Jahrhundert], hrsg. von DercsÉnYI, Dezsô, Budapest, 1956. 31-48.

Die Zisterzienser 1980 - Die Zisterzienser. Ordensleben zwischen Ideal und Wirklichkeit, Ausstellungskatalog, hrsg. von Elm, Kaspar - Joerissen, Peter - Roth, Hermann Josef, Bonn, 1980.

Dumitrache 1983 - Dumitrache, Mariana: Bauforschung und Denkmalpflege. Siebenbürgische Grabungen der letzten Jahre an mittelalterlichen Baudenkmälern, in MACHAT 1983, 41-54.

EnTz 1958 - EnTz, Géza: A gyulafehérvári székesegyház [Die Kathedrale zu Karlsburg], Budapest, 1958.

ENTZ 1963a - ENTZ, Géza: A kerci (cîrţai) cisztercita építőmúhely [Die Zisterzienserwerkstatt von Kerz], Mũvészettörténeti Értesítô XII. 1963. 121-147.

ENTz 1963b - ENTz, Géza: Le chantier cistercien de Kerc (Cîrța), Acta Historiae Artium IX. 1963. 3-38.

EnTz 1966 - EnTz, Géza: Les pierres sculptées de la cathédrale de Kalocsa, Bulletin du Musée Hongrois des BeauxArts No 28. 1966. 31-56.

ENTz 1968 - ENTz, Géza: Die Baukunst Trassilvaniens im 11.13. Jahrhundert, I. Teil, Acta Historiae Artium XIV. 1968. 3-48; II. Teil, Historische Angaben, ebd. 127-175.

ENTz 1994 - ENTz, Géza: Erdély építészete a 11-13. században [Baukunst in Siebenbürgen im 11.-13. Jahrhundert], Kolozsvár, 1994.

ENTZ 1996 - ENTZ, Géza: Erdély építészete a 14-16. században [Baukunst in Siebenbürgen im 14.-16. Jahrhundert], Kolozsvár, 1996.
EnTZ-Sebestyén 1947 - Entz, Géza - K. SebestyÉn, József: A széki református templom [Die reformierte Kirche von Szék], Kolozsvár, 1947.

Esztergom, Vármúzeum 2004 - Az Esztergomi Vármúzeum kôtárának katalógusa [Katalog des Lapidariums des Burgmuseums von Esztergom], hrsg. von BuzÁs, Gergely - Tolnai Gergely, Esztergom, 2004. (Az Esztergomi Vármúzeum Füzetei 2.)

FleischHAUer 2006 - FleischHAUER, Carsten: Eine mittelalterliche Präfiguration der europäischen Einigungsidee? Die Erforschung der Zisterzienserarchitektur im westlichen Nachkriegsdeutschland, in Kunstgeschichte nach 1945. Kontinuität und Neubeginn in Deutschland, KölnWeimar-Wien, 2006. 77-87.

Fôszentély 2012 - A gyulafehérvári székesegyház fôszentélye [Der Hochchor der Kathedrale von Karlsburg], hrsg. von Papp, Szilárd, Budapest, 2012.

FRACCARO DE LONGHI 1958 - FRACCARO DE LONGHI, Lelia: L'architettura delle chiese cistercensi italiane, Milano, 1958.

FuHrmann 1960 - Fuhrmann, Franz: Das romanische Marientympanon im Salzburger Museum Carolino Augusteum. Zur Frage seiner Entstehungszeit, Salzburger Museum Carolino Augusteum. Jahresschrift 5. 1959. Salzburg, 1960. 49-103.

GEREVICH 1938 - GEREVICH, Tibor: Magyarország románkori emlékei [Romanische Denkmäler in Ungarn], Budapest, 1938.

Geschichte der bildenden Kunst in Österreich 1998 - Geschichte der bildenden Kunst in Österreich Bd. 1. Früh- und Hochmittelalter, hrsg. von FiLLiTz, Hermann, München-New York, 1998.

Gombos 1938 - Catalogus fontium historiae Hungaricae aevo ducum et regum ex stirpe Arpad descendentium ab anno Christi DCCC usque ad annum MCCCI, ed. GomBos, Albinus Franciscus, I-III, Budapest, 1937-1938.

GosebruCH 1983 - GosebruCH, Martin: Vom oberrheinischsächsichen Weg der Kathedralgotik nach Deutschland, Göttingen, 1983. (Schriftenreihe der Kommission für Niedersächsische Bau- und Kunstgeschichte bei der Braunschweigischen Wissenschaftlichen Gesellschaft Bd. 1)

GÖTz 1968 - GÖTz, Wolfgang: Zentralbau und Zentralbautendenz in der gotischen Architektur, Berlin, 1968.

GYÖRFFY I, 1963 - GYÖRFFY, György: Az Árpád-kori Magyarország történeti földrajza [Historische Geographie von Ungarn in der Ârpádenzeit] I, Budapest, 1963, $1987^{2}$.

GYÖRFFY II, 1987 - GYÖRFFY, György: Az Árpád-kori Magyarország történeti földrajza [Historische Geographie von Ungarn in der Ârpádenzeit] II, Budapest, 1987.

HAHNloser 1972 - HAHnloser, Hans R.: Villard de Honnecourt. Kritische Gesamtausgabe des Bauhüttenbuches ms. fr. 19093 der Pariser Nationalbibliothek, Zweite, revidierte und erweiterte Auflage, Graz, 1972.

Havasi 2006 - Havasi, Krisztina: Az óbudai királyi, utóbb királynéi vár kőemlékei. Kutatási helyzetkép, 2004 [Die Steindenkmäler der königlichen, später Königinnenburg in Alt-Ofen. Ein Forschungsbericht], Budapest Régiségei XL. 2006. 221-252.

Havasi 2007 - Havasi, Krisztina: Az óbudai királyi, utóbb királynéi palota Szent Erzsébet-kápolnája [Die St.-Elisabeth-Kapelle der königlichen, später Königinnenburg in Alt-Ofen], Studia Franciscana Hungarica 2007. 1-16. 
HAVASI 2008 - Havasi, Krisztina: A pilisszentkereszti ciszterci apátság töredékei Esztergomban [Fragmente aus der Zisterzienserabtei Pilisszentkereszt in Esztergom], Mũvészettörténeti Értesítô 56. 2008. 169-232.

HAVASI 2012 - Havasi, Krisztina: A gyulafehérvári székesegyház 13. századi fôszentélye [Der Hochchor der Karlsburger Kathedrale aus dem 13. Jahrhundert], in Fôszentély 2012, 87-128.

HegEdưs 2015 - HEGEDƯs, András: Esztergom rubintként ragyogó temploma. A Szent Adalbert-székesegyház történetének egy elfelejtett forrása [Die Kirche von Esztergom, die wie Rubin strahlt. Eine vergessene Quelle zur Geschichte der Adalbertskathedrale], Magyar Sion N. F. 9. 2015. 132-138.

Heitel 1964 - Heitel, Radu: Monumentele medievale din Sebeş-Alba [Mittelalterliche Denkmäler in Mühlbach], Bucureşti, 1964.

Hervai 1984 - Hervai, Ferenc L.: Repertorium historicum ordinis Cisterciensis in Hungaria, Roma, 1984.

Horwath 1929 - HoRWATH, Walter: Die Baugeschichte der sächsischen Kirchenburgen und Kirchen, in Das Burzenland 1929, 113-158.

Horwath 1935 - HoRwath, Walter: Der Emporenbau der romanischen und frühgotischen Kirchen in Siebenbürgen, Siebenbürgische Vierteljahresschrift 58. 1935. $69 \mathrm{ff}$.

HuNYADi 2012 - HunYADI, Zsolt: A német lovagrend a Barcaságban: régi nézetek, új megfontolások [Der Deutsche Ritterorden im Burzenland: alte Ansichten, neue Bedenken], in Andreas II. 2012, 116-128.

István 2013 - István, a szent király. Tanulmánykötet és kiállítási katalógus Szent István tiszteletérôl halálának 975. évfordulóján [Stefan, der heilige König. Sammelband und Ausstellungskatalog über die Verehrung des Heiligen Stefan zur 975. Wiederkehr seines Todestags], Székesfehérvár, 2013.

KegleVich 2008 - KegleVich, Kristóf: A ciszterci nagykáptalan és a magyar apátságok a középkorban [Das Ordenskapitel der Zisterzienser und die ungarischen Abteien im Mittelalter], Magyar Egyháztörténeti Vázlatok 20/1-2. 2008. 9-41.

KimPEL-SuCKALE 1985 - KimPEL, Dieter - SuCKALE, Robert: Die gotische Architektur in Frankreich 1130-1270, München, 1985.

KleIN 1976 - Klein, Albert: Baugeschichte der evangelischen Kirche in Mühlbach, in Studien 1976, 23-59.

Koszta 1993 - Koszta, László: A ciszterci rend története Magyarországon a kolostoraik alapítása idején 11421270 [Geschichte des Zisterzienserordens in Ungarn in der Zeit seiner Klostergründungen 1142-1270], Magyar Egyháztörténeti Vázlatok 5/1-2. 1993. 115-128.

KôFALVI 1980 - KôFALVI, Imre: Kôfaragókról és kôbányákról [Über Steinmetzen und Steinbrüchen], Építés - Épitészettudomány XII/1-4. 1980. 241-282.

Körmendi 2008 - Körmendi, Tamás: Az Imre, III. László és II. András királyok uralkodására vonatkozó nyugati elbeszélő források kritikája [Kritik der westlichen narrativen Quellen über die Regierungszeiten der Könige Emmerich, Ladislaus III. und Andreas II.], PhD Dissertation 2008 - doktori.btk.elte.hu/his/kormendi/diss.pdf

Kötzsche 1973 - Kötzsche, Dietrich: Der Welfenschatz im Berliner Kunstgewerbemuseum, Berlin, 1973.
KRASSER 1976 - KRASSER, Harald: Zur Geschichte der Erforschung der Mühlbacher Stadtpfarrkirche, in Studien 1976, 13-22.

KRAUTHEIMER 1942/1969 - KRAUTHEIMER, Richard: Introduction to an 'Iconography' of Mediaeval Architecture, Journal of the Warburg and Courtauld Institutes 5. 1942. 1-33; bzw. in Studies in Early Christian, Mediaeval and Renaissance Art, New York-London, 1969. 115-150.

KuTHAN 1982 - KuTHAN, Jiři: Die mittelalterliche Baukunst der Zisterzienser in Böhmen und in Mähren, München, 1982.

LEKAI 1980 - LEKAI, Louis J.: Studien, Studiensystem und Lehrtätigkeit der Zisterzienser, in Die Zisterzienser 1980, 165-170.

LÓVEI 2000/2004 - LÕVEI, Pál: „Virtus, es, marmor, scripta”, Vörös márvány és bronzbetû [Rotmarmor und Bronzebuchstaben], in Ráckeve 2000, 53-71.

LÔVEI 2001 - LÓVEI, Pál: "Virtus, es, marmor, scripta", Red Marble and Bronze Letters, Acta Historiae Artium 42. 2001. 39-55.

LÔVEI 2015 - LÔVEI, Pál: Uralkodói kôanyagok. A király és az elit díszítőkỏ-használata a középkori Magyarországon [Materialien von Herrschern. Der König und die Elite und der Gebrauch von dekorativen Gesteinen im Ungarn des Mittelalters], in In medio regni Hungariae. Régészeti, müvészettörténeti és történeti kutatások „az ország közepén", hrsg. von BENKó, Elek - Orosz, Krisztina, Budapest, 2015. 79-109.

LÔVEI 2017 - LÔVEI, Pál: Bíbor Esztergom - A Szent Adalbert-székesegyház, a Bakócz-kápolna és a királyi/érseki palota vörös márványa [Purpurne Esztergom - Der rote Marmor der Adalbertskathedrale, der Bakócz-Kapelle und des Palastes des Königs/Erzbischofs], in Metropolis Hungariae 2017. 96-106.

MACHAT: Beiträge 1983 - Beiträge zur siebenbürgischen Kunstgeschichte und Denkmalpflege, hrsg. von MACHAT, Christoph, München, 1983. (Beiträge der Tagung in Regensburg 1981)

MACHAT 1977 - MaCHAT, Christoph: Die Bergkirche zu Schässburg und die mittelalterliche Baukunst in Siebenbürgen, München, 1977.

MACHAT 1983 - MACHAT, Christoph: Über den rheinischen Charakter der Kerzer Zisterzienserbauten, in MACHAT: Beiträge 1983, 34-40.

Magyarországi múvészet 1987 - Magyarországi múvészet 1300-1470 körül [Kunst in Ungarn 1300 - um 1470], hrsg. von Marosi, Ernô, Budapest 1987. (A magyarországi mûvészet története 2.)

MARosi 1971 - Marosi, Ernô: Einige stilistische Probleme der Inkrustationen von Gran (Esztergom), Acta Historiae Artium XVII. 1971. 171-229.

MArosi 1972 - MArosi, Ernô: Egy gótikus Madonna Somogyvárról és a Szent Egyed-apátság kerengôje [Eine gotische Madonna aus Somogyvár und der Kreuzgang der St. Ägidiusabtei], Mũvészettörténeti Értesítô XXI. 1972. 93-103.

MAROSI 1983 - MAROSI, Ernô: Einflüsse der Regensburger Frühgotik in Ungarn und in Siebenbürgen, in MACHAT: Beiträge 1983, 13-22.

MAROSI 1984 - Marosi, Ernő: Die Anfänge der Gotik in Ungarn. Esztergom in der Kunst des 12.-13. Jahrhunderts, Budapest, 1984. 
MAROSI 1985 - MAROSI, Ernô: A pilisi monostor szerepe a XIII. századi magyarországi múvészetben [Die Rolle des Klosters von Pilis in der Kunst des 13. Jahrhunderts in Ungarn], Studia Comitatensia 17. Régészeti tanulmányok Pest megyéból, Szentendre, 1985. 555-562.

Marosi 1993 - Marosi, Ernô: Mitteleuropäische Herrscherhäuser des 13. Jahrhunderts und die Kunst, in Künstlerischer Austausch / Artistic Exchange, Akten des XXVIII. Internationalen Kongresses für Kunstgeschichte Berlin, 15.-20. Juli 1992, hrsg. von GaEhtgens, Thomas W., 1993. II. 15-30.

Marosi 1994 - Marosi, Ernő: Esztergom középkori Szent Adalbert-székesegyháza - Tíz év múltán [Die mittelalterliche St. Adalbertskathedrale in Esztergom - nach zehn Jahren], Limes '94/3. 14-28.

Marosi 2000a - Marosi, Ernô: Az esztergomi Porta speciosa [Die Porta speciosa von Esztergom], in Szent Adalbert 2000, 155-163.

Marosi 2000b - MARosi, Ernô: Szermonostor gótikus kerengôjének szobrai [Die Statuen des gotischen Kreuzgangs vom Kloster Szer], in Dél-Alföld 2000, 107-122.

MAROSI 2001a - Marosi, Ernô: Még egyszer az esztergomi Porta speciosáról [Noch einmal über die Porta speciosa von Esztergom], in „Lux Pannoniae”. Esztergom az ezeréves kulturális metropolisz konferencia [Tagung Esztergom, die tausendjährige Metropole der Kultur], 2000. június 15-16-17., hrsg. von HoRváTH, István, Esztergom, 2001. 47-56.

Marosi 2001b - Marosi, Ernő: Bencés építkezések a 13. században [Benediktinerbauten im 13. Jahrhundert], in Paradisum plantavit 2001. 275-288.

Marosi 2002/2005 - Marosi, Ernô: Historizmus az 1200 körüli mũvészetben Magyarországon (Akadémiai székfoglaló, elhangzott 2002. április 11-én) [Historismus in der Kunst Ungarns um 1200 (Akademische Antrittsrede am 11. April 2002)], in Székfoglalók. Társadalomtudományok 2001 [Antrittsreden. Gesellschaftswissenschaften], hrsg. von Vizi, E. Szilveszter, Magyar Tudományos Akadémia, Budapest, 2005. 269-298.

Marosi 2012 - Marosi, Ernô: A gótikus udvari mûvészet kérdése és II. András [Die Frage der gotischen Hofkunst und König Andreas II.], in ANDREAS II. 2012, 174-189.

Marosi 2013 - Marosi, Ernô: A romanika Magyarországon [Die Romanik in Ungarn], Budapest, 2013.

Marosi 2017 - Marosi, Ernô: „Esztergom II.” A 12. századi Szent Adalbert-székesegyház a múvészettörténetben [„Esztergom II“. Die St. Adalbertskathedrale des 12. Jahrhunderts in der Kunstgeschichte], in Metropolis Hungariae 2017. 70-95.

MArosi, Figurenportal 1994 - MAROSI, Ernő: Das Figurenportal in Ungarn vor und nach 1200, in Studien zur Geschichte der europäischen Skulptur im 12./13. Jahrhundert, hrsg. von BECK, Herbert - HeNGEVOSS-DÜRKOP, Kerstin, Frankfurt a. M., 1994. I. 725-738.

MÁtHes 1827 - MÁTHES, Joannes Nep.: Veteris arcis Strigoniensis, monumentorum ibidem erutorum, aliarumque antiquitatum lythographicis tabulis ornata descriptio, Strigonii, 1827

Messerer 1978 - Messerer, Wilhelm: Romanische Portale in Salzburg und Reichenhall, Mitteilungen der Gesellschaft für Salzburger Landeskunde 117. 1977/78 [1978]. 107-142.
Metropolis Hungariae 2017 - Metropolis Hungariae, hrsg. von HeGEDŨs, András, Esztergom, 2017. (Strigonium Antiquum VIII.)

Mons Sacer 1996 - Mons Sacer 996-1996, Pannonhalma 1000 éve [Tausend Jahre von Pannonhalma], hrsg. von TAKÁCS, Imre, Pannonhalma, 1996.

Morres 1928 - Morres, Eduard: Die Pfarrkirche von St. Bartholomae, in Das Burzenland 1928, 107-121.

MORRES 1929 - MORRES, Eduard: Die Kirchenbauten, in Das Burzenland 1929, 163-190.

MRT 5. 1979 - Magyarország Régészeti Topográfiája 5. Komárom megye régészeti topográfiája. Esztergom és a dorogi járás [Archäologische Topographie Ungarns 5. Das Komitat Komárom, Esztergom und der Bezirk Dorog], verf. Horváth, István - H. Kelemen, Márta - Torma, István, Budapest, 1979.

Mũvészet Magyarországon 1987 - Mũvészet Magyarországon 1300-1470 körül [Die Kunst in Ungarn um 13001470], hrsg. von MAROSI, Ernő, Budapest, 1987.

Oszvald 1957 - Oszvald, Ferenc: Adatok a magyarországi premontreiek Árpád-kori történetéhez [Angaben zur Geschichte der Prämonstratenser im Ungarn der Árpádenzeit], Müvészettörténeti Értesítô VI. 1957. 231-254.

Pannonia Regia 1994 - Pannonia Regia. Müvészet a Dunántúlon 1000-1541 [Kunst in Transdanubien], hrsg. von MiKÓ, Árpád - TAKÁCS, Imre, Budapest, 1994.

Paradisum plantavit 2001 - Paradisum plantavit. Bencés monostorok a középkori Magyarországon [Benediktinerklöster im mittelalterlichen Ungarn], Ausstellungskatalog, hrsg. von TAKÁCS, Imre, Pannonhalma, 2001

PL - Migne, Patrologiae cursus completus. Series Latina, Paris, $1815-1875$.

Ráckeve 2000 - Maradandóság és változás. Mũvészettörténeti konferencia, Ráckeve 2000, hrsg. von BODNÁr, Szilvia et al., Budapest, 2004.

RAFFAY 2000 - RAFFAY, Endre: Az aracsi templom [Die Kirche zu Arača], in Dél-Alföld 2000, 449-474.

RAFFAY 2006 - RAFFAY, Endre: Esztergom, Vértesszentkereszt, Forum Könyvkiadó, Újvidék, 2006.

RAFFAY 2010 - RafFay, Endre: Az esztergomi Szent Adalbert-székesegyház és a magyarországi gótika kezdetei [Die St. Adalbertskathedrale von Esztergom und die Anfänge der Gotik in Ungarn], in Ars perennis. Fiatal müvészettörténészek II. konferenciája, Budapest 2009. Tanulmányok, hrsg. von TüskÉs, Anna, Budapest, 2010. 23-29.

REISSENBERGER 1894 - REISSENBERgER, Ludwig: Die Kerzer Abtei, Hermannstadt, 1894.

RÓMER 1877 - RÓMER, Flóris Ferenc: Kirándulás a kertzi apátsághoz Erdélyben [Ausflug zur Abtei Kerz in Siebenbürgen], Archaeologiai Közlemények 9. 1877. 1-11.

ROSTÁs 1998 - Rostás, Tibor: A besztercei volt minorita, ma görög katolikus templom [Die ehemalige Minoriten-, jetzt griechisch-katholische Kirche zu Bistritz], Müemlékvédelmi Szemle VIII. 1998/2. 63-90.

Rostás 2000a - Rostás, Tibor: Udvari múvészet Magyarországon a 13. század második negyedében és közepén, avagy a Gizella-kápolna hazai kapcsolatrendszere [Hofkunst in Ungarn im zweiten Viertel und in der Mitte des 13. Jahrhunderts oder das einheimische Beziehungssystem der Giselakapelle von Veszprém], Müemlékvédelmi Szemle X. 2000/1-2. 5-52. 
RostÁs 2000b - RostÁs, Tibor: A veszprémi úgynevezett Gizella-kápolna épülete a 13. században [Der Bau der so genannten Giselakapelle von Veszprém im 13. Jahrhundert], in Tanulmányok Tóth Sándor 60. születésnapjára, hrsg. von Rostás, Tibor - Simon, Anna, Budapest, 2000. 61-81.

RostÁs 2002 - RostÁs Tibor: A halmágyi evangélikus templom [Die evangelische Kirche in Holmwegen], in Arhitectura religioasămeidievală din Transilvania / Középkori egyházi épitészet Erdélyben / Medieval Ecclesiastical Architecture in Transylvania II, hrsg. von Rusu, Adrian Andrei - SzÓcs, Péter Levente, Satu Mare, 2002. 79-110.

Rostás 2006 - Rostás, Tibor: Eine kleine „Drakologie“. Ornamentik der Tišnover Porta Coeli und Ungarn, Österreichische Zeitschrift für Kunst und Denkmalpflege LX. 2006. 349-366.

Rostás 2010 - Rostás, Tibor: Három Dráván túli emlék a 13. századból [Drei Denkmäler jenseits der Drau aus dem 13. Jahrhundert], in Dél-Magyarország 2010, 213-287.

Rотн 1934 - Rотн, Viktor: Die deutsche Kunst in Siebenbürgen, Berlin, 1934.

Salzburg 1987 - Kovacsovics, Wilfried K. - MoOsLeitner, Fritz: Führer durch die Domgrabungen in Salzburg, Schriftenreihe des Salzburger Museums Carolino Augusteum Nr. 8, Salzburg, 1987.

SARKADI 2010 - SARKADI Márton: „s folytatva magát a régi müvet". Tanulmányok a gyulafehérvári székesegyház és püspöki palota történetérôl [Studien über die Kathedrale und den Bischofspalast in Karlsburg], Budapest, 2010.

SAUER 1902 - SAUER, Joseph: Symbolik des Kirchengebäudes und seiner Ausstattung in der Auffassung des Mittelalters, Freiburg i. B., 1902.

SAUERLÄNDER 1986 - SAUERLÄNDER, Willibald: [Besprechung von Marosi 1984], Cahiers de Civilisation Médiévale XIX. 1986. 289

SCHUBERT 1974 - SCHUBERT, Ernst: Der Magdeburger Dom, Berlin, 1974.

SEEger 1997 - SeEger, Ulrike: Zisterzienser und Gotikrezeption. Die Bautätigkeit des Babenbergers Leopold VI. in Lilienfeld und Klosterneuburg, München-Berlin 1997.

SolymOSi 2006 - Solymosi, László: Írásbeliség és társadalom az Árpád-korban. Diplomatikai és pecséttani tanulmányok [Schriftlichkeit und Gesellschaft in der Árpádenzeit. Studien zu Diplomatik und Siegelkunde], Budapest, 2006.

SRH 1937-1938 - Scriptores Rerum Hungaricarum tempore ducum regumque stirpis Arpadianae gestarum I-II., ed. SzentPÉTERY, Emericus, Budapest, 1937-1938. (Reprint: Budapest, 1999.)

Studien 1976 - Studien zur siebenbürgischen Kunstgeschichte, hrsg. von Gündisch, Gustav - KLEIn, Albert - KRASSER, Harald - Streitfeld, Theobald, Bukarest, 1976.

SuCKALE 2003 - SuCKALE, Robert: Die Rosenfenster der Ebracher Klosterkirche [1985], in Stil und Funktion. Ausgewählte Schriften zur Kunst des Mittelalters, hrsg. von SCHMid, Peter - Wedekind, Gregor, München, 2003. 361-380.

Szék 1942 - A széki református templom [Die reformierte Kirche zu Szék], Technika 1942/7. 250-252.

SzÉLESS 1761/1998 - Az esztergomi székesegyház. Széless György 1761. évi leirása a Szent Adalbert-székesegyház és a Szent István-templom romjairól [Die Kathedrale von Esztergom - Die Beschreibung von György Széless über die Ruinen der St. Adalbertskathedrale und der St. Stefanskirche von 1761], hrsg. von HoRváTH, István - MAROSI, Ernô, Esztergom, 1998.

Szent Adalbert 2000 - Ezer év Szent Adalbert oltalma alatt [Tausend Jahre unter dem Schutz des Heiligen Adalbert], hrsg. von HeGEDƯs, András - BÁRDos, István, Esztergom, 2000. (Strigonium antiquum IV.)

SZENTESI 2012 - SzENTESI, Edit: Az intézményes múemlékvédelem kezdetei Magyarországon [Die Anfänge der institutionellen Denkmalpflege in Ungarn], Múemlékvédelem LVI/1-2. 2012. 2-29.

TAKÁCS 1988 - TAKÁCS, Imre: Esztergomi síremléktöredékek a 13. századból [Grabplattenfragmente in Esztergom aus dem 13. Jh.], Ars Hungarica XVI. 1988. 121-132.

TAKÁCS 1989 - TAKÁCs, Miklós: A bélakúti / péterváradi ciszterci monostor [Das Zisterzienserkloster von Bélakút/ Pétervárad], Újvidék, 1989.

TAKÁCS 1996 - TAKÁCS, Imre: Pannonhalma újjáépítése a 13. században [Die Wiedererrichtung von Pannonhalma im 13. Jahrhundert], in Mons Sacer 1996, I. 170-236.

TAKÁCS 2000 - TAKÁCS, Imre: Egy eltúnt katedrális nyomában. Újabb töredékek a 13. századi kalocsai székesegyházból [Auf der Spur einer verschwundenen Kathedrale. Neuere Fragmente aus der Kathedrale des 13. Jahrhunderts von Kalocsa], in Dél-Alföld 2000, 305-335.

TAKÁCS 2000/2004 - TAKÁCS, Imre: Az 1200 körüli márványmûvesség néhány emléke [Einige Denkmäler der Marmorbearbeitung um 1200], in Ráckeve 2000, 39-52.

TAKÁCS 2017 - TAKÁCS, Imre: Az esztergomi Porta speciosa programjának kérdéseirôl [Über die Fragen des Programms der Porta speciosa in Esztergom], in Metropolis Hungariae 2017, 107-134.

TĂTARU 1983 - TĂTARU, Marius: Kerz und die mitteleuropäische Zisterzienserarchitektur, in MACHAT: Beiträge 1983, 23-33.

Tihany 1976 - K. PALÁgYi, Sylvia - TóTH, Sándor: A római és középkori kôtár katalógusa, Tihanyi múzeum [Museum in Tihany, Katalog des Lapidariums von Römerzeit und Mittelalter], Veszprém, 1976.

То́тн 1964 - То́тн, Sándor: Veszprémi középkori sírkôtöredékek. (A Bakonyi Múzeum kôtárának ismertetése II.) [Mittelalterliche Grabsteinfragmente von Veszprém], A Veszprém megyei múzeumok közleményei II. 1964. $167-187$.

Tо́тн 1967 - Tо́тH, Sándor: XIII. századi építőműhely Veszprémben. (A Bakonyi Múzeum kôtárának ismertetése III.) [Eine Bauhütte des 13. Jahrhunderts in Veszprém], A Veszprém megyei múzeumok közleményei 6. 1967. $163-182$.

Tо́тн 1976 - TóтH, Sándor: Egy gótikus részletmegoldás történetéhez [Zur Geschichte einer gotischen Einzelform], Soproni Szemle XXX/4. 1976. 329-344.

То́тн 2000 - TóтH, Sándor: Esztergom Szent Adalbertszékesegyháza és az Árpád-kori építészet [Die St. Adalbertskathedrale von Esztergom und die Baukunst der Árpádenzeit], in Szent Adalbert 2000, 121-154.

То́тн 2001 - То́тH, Sándor: A 11-12. századi Magyarország Benedek-rendi templomainak maradványai [Denkmäler der Kirchen des Benediktinerordens vom Ungarn des 11.-12. Jahrhunderts], in Paradisum plantavit 2001, 229-266. 
Tо́тн 2010a - Tóтн, Sándor: Dombó és a templomépítés módjai a gótikus Magyarországon [Dombó und die Kirchenbautypen im gotischen Ungarn], in Dél-Magyarország 2010, 717-741.

Tо́тн 2010b - То́тн, Sándor: Román kori köfaragványok a Magyar Nemzeti Galéria Régi magyar gyũjteményében [Romanische Steinskulpturen in der Sammlung der alten ungarischen Kunst der Ungarischen Nationalgalerie], hrsg. von MıKó, Árpád, Budapest, 2010.

Untermann 2001 - Untermann, Matthias: Forma Ordinis. Die mittelalterliche Baukunst der Zisterzienser, MünchenBerlin, 2001.

VÁRADY 1999 - VÁRADY, Zoltán: Romanische und frühgotische Inschriften, Communicationes Academiae Paedagogicae Szekszardiensis, Szekszárd, 1999. 71-84.

VÁRADY 2000 - VÁRADY, Zoltán: Román kori, korai gótikus és gótikus maiuscula feliratok a Dunántúlon [Romanische, frühgotische und gotische Maiuskelinschriften in Transdanubien], Szekszárd, 2000. (IPF-Könyvek 8.)
VARGA 1979 - VARGA, Lívia: Die mittelalterliche Baugeschichte der evangelischen Kirche in Mühlbach, Acta Historiae Artium XXV. 1979. 187-235.

VARGA 1984 - VARGA, Lívia: A szászsebesi evangélikus templom középkori épitéstörténete [Die mittelalterliche Baugeschichte der evangelischen Kirche in Mühlbach], Budapest, 1984. (Múvészettörténeti Füzetek 16.)

VĂTĂŞIANU 1959 - VĂTĂşIANU, Virgil: Istoria artei feudale în ţările Romîne, vol. I, București, 1959

WAGNER-RIEGER 1988 - WAGNER-RIEGER, Renate: Mittelalterliche Architektur in Österreich, St. Pölten-Wien, 1988.

WALICKI 1971 - Sztuka polska przedromańska i romańska do schytku XIII wieku. Dzieje sztuki poskiej, tom pierwszy, hrsg. von WaLICKI, Michał, Warszawa, 1971.

ZOLNAY 1964 - ZOLNAY, László: István ifjabb király számadása 1264-ból [Eine Rechnung des Jungkönigs Stefan von 1264], Budapest Régiségei XXI. 1964. 79-114.

Zsoldos 2011 - Zsoldos, Attila: Magyarország világi archontológiája 1000-1301 [Weltliche Archontologie Ungarns 1000-1301], Budapest, 2011.

\section{ANMERKUNGEN}

\footnotetext{
${ }^{1}$ Magyarországi múvészet 1987, 88 (MArosi, Ernô), 309

(ENTZ, Géza).

2 Magyarországi múvészet 1987, 676.

${ }^{3}$ GerEVICH 1938.

${ }^{4}$ DERCSÉNYI 1943.

${ }^{5}$ Árpád-kori 1978

${ }^{6}$ MAROSI 1984

7 DERCSÉNYI 1943.

${ }^{8}$ Tóth 2010b, 87-91.

${ }^{9}$ Die Abbildungen ohne Quellenangabe stammen aus dem Archiv des Verfassers.

${ }^{10}$ MRT 5. 1979, 101 (8/1m); vgl. ProkOpP 2010, 195; HAVASI 2008, Anm. 57.

${ }^{11}$ MARosi 1984, 13 und Anm. 9.

12 MÁTHes 1827.

${ }^{13}$ MÁthes 1827, 31 ( 860 ).

${ }^{14}$ MÁthes 1827, Taf. V.

${ }^{15} \mathrm{Zu}$ den zeichnerischen Quellen des Baus siehe MAROsI 1984, Anm. 11.

${ }^{16}$ MAROSI 1994.

${ }^{17}$ MAROSI 2000a.

18 Marosi 2001a.

${ }^{19}$ Tóth 2000, 123.

${ }^{20}$ Marosi 2017

${ }^{21}$ MÁtHes 1827, 40 (§ 80).

22 Tóth 2010a, 50-56.

23 BuZÁs 2004, 11.

${ }^{24}$ MÁTHES $1827,39-40$ (§ 79).

25 TAKÁCs 2000/2004; LỐVEI 2000/2004; LÔVEI 2001; LÔVEI 2017.

${ }^{26}$ HEGEDƯs 2015

27 SzÉLESS 1761/1998, 94 (Faksimile), 95 (Übersetzung); zur Deutung: LÓVEI 2000/2004, 56-59; LÓVEI 2017, 96-97.

${ }^{28}$ IsTVÁNFFI, Nicolaus: Regni Hungarici historia, Köln, 1685, L. XV, 172, angeführt von HEGEDÜs 2015, 135.

${ }^{29}$ Hegedứs 2015, 135.

30 Pannonia Regia 1994, 69 (Kat.-Nr. I-7: TóTH, Sándor).

31 Siehe zuletzt То́тн 2010b, 44, mit Literaturangaben.
}

32 Marosi 1984, 16 (Kat.-Nr. 10), 193-194, Abb. 28-29.

${ }_{33}$ Marosi 1984, 16 (Kat.-Nr. 31), 197, Abb. 30; Pannonia Regia 1994, 59, 90 (Kat.-Nr. I-30: TóтH, Sándor); ТóтH 2010b, 17, Abb. 20.

34 Marosi 1984.

35 Pannonia Regia 1994, 90-91 (Kat.-Nr. I-31, I-32: Tо́тН, Sándor); MAROSI 1984, 57 (Kat.-Nr. 41), 199, Abb. 115 Pannonia Regia 1994, 122 (Kat.-Nr. I-62: TóтH, Sándor); Esztergom, Vármúzeum 2004, 149 (Kat.-Nr. 20/4: BuZÁs, Gergely). - Zum Fundstück aus dem Boden des Franziskanerklosters von Esztergom siehe: Árpád-kori 1978, 189-190 (Kat.-Nr. 115: MAROSI, Ernô); MRT 5. 1979, 145 (Nr. 8/3m) Taf. 72/2. - Zum Zahnschnitt vgl. u. а. Tо́тн 2010b, 142143, Abb. 147, 152

${ }^{36}$ Siehe eine kurze Monographie des der Hl. Margarethe geweihten Stifts: TótH 2010b, 63-67.

${ }^{37}$ Das Kapitell mit Widdern und Drachen, das heute als das Einzige mit den Stützen des Langhauses von Dömös gilt, haben wir als Kat.-Nr. 17 noch als ein Stück aus Esztergom veröffentlicht: MAROSI 1984, 195; vgl. Esztergom, Vármúzeum 2004, 109 (Kat.-Nr. 2: BuZÁs, Gergely).

38 BuZÁs 2004, 12-13.

${ }^{39}$ Marosi 1984, 195 (Kat.-Nr. 14), Abb. 40-41; vgl. MAROSI 1984, 195 (Kat.-Nr. 15), Abb. 39 und seine nahe Parallele aus Dömös: MAROsi 1984, Abb. 45; Tótн 2010b, 150 (Kat.-Nr. 15) und 59. Vgl. noch То́тн 2010b, 62-63.

${ }^{40}$ István 2013, 361 (Kat.-Nr. 94: MAROsi, Ernô, allein über die Zeichnung der Porta speciosa).

${ }^{41}$ Kötzsche 1973, 65 (Kat.-Nr. 1), 19-20.

${ }^{42}$ То́тн 2010b, 67-72, Abb. 146.

${ }^{43}$ Martyrius kommt 1158 nicht mehr in Frage. Sein Nachfolger, Lukas (1158-1181), wurde zuerst ohne Nennung seines Sitzes erwähnt; siehe Zsoldos 2011, 80.

${ }^{44}$ Marosi $1984,18-22$

${ }^{45}$ Marosi 1984, 207-209, Taf. XXXV.

${ }^{46}$ Marosi $1984,18-22$.

${ }^{47}$ Marosi 1984, 191 (Kat.-Nr. 1-2), Abb. 75-77. 
${ }^{48}$ Es ergeben sich als untere Durchmesser ca. $74 \mathrm{~cm}$ bzw. $56 \mathrm{~cm}$; siehe MAROSI 1984, 15.

${ }^{49}$ Marosi 1984, 18; vgl. die Tabellen der Maßzusammenhänge: MAROSI 1984, 14-15; Kapitelle: ebd., 191-192, (Kat.-Nr. 3, 4); maßstäblich verwandte Fragmente von Wandvorlagen: Kat.-Nr. 26 und 24: MAROSI 1984, Taf. XXXI, 3, 5 .

50 SRH I. 1937, 492-493.

${ }^{51}$ HAVASI 2008, 193.

${ }^{52} \mathrm{Zu}$ Programm und Stifterdarstellungen der Porta speciosa zusammen mit der kritischen Übersicht der Fachliteratur Siehe: TAKÁCS 2017.

53 RaFFAY 2000, 468-470; RAFFAY 2006, 7-15; RAFFAY 2009; Tóth 2010, 42-43; MAROsi 2017, 77-78.

54 SAUERLÄNDER 1986.

55 Esztergom, Vármúzeum 2004, 108-109 (Kat.-Nr. 1-2: BuZÁs, Gergely).

${ }^{56}$ Esztergom, Vármúzeum 2004, 110-114 (Kat.-Nr. 3-6: BuzÁs, Gergely), 143-153 (Kat.-Nr. 18-20: BuZÁs, Gergely).

${ }^{57}$ Esztergom, Vármúzeum 2004, 127-139 (Kat.-Nr. 1015: BozóKI, Lajos bzw. BuzÁs, Gergely).

${ }^{58}$ MAROSI 1985.

${ }^{59}$ Am radikalsten erscheint die Unterscheidung von RAFFAY 2010, 17 ff. Vgl. TAKÁCS, Imre: „Wie logisch es auch erscheinen könnte, beide Bauten der Tätigkeit einer gemeinsamen Werkstatt zuzuschreiben, kann ihr Wirken auf Grund eines genaueren Vergleichs zwischen ihren Fragmenten eher als parallel bezeichnet werden." (A gótika recepciója a Magyar Királyságban II. András korában [Die Gotikrezeption im Königreich Ungarn in der Zeit Andreas II.], Dissertation für den Doktortitel der Ungarischen Akademie der Wissenschaften, Manuskript, 2009, 85).

${ }^{60}$ Esztergom, Vármúzeum 2004, 114 (Kat.-Nr. 6: BuZÁs, Gergely); ferner, in eine Pfeilerrekonstruktion einbezogen, von den übrigen, zu derselben Gruppe gehörenden Fragmenten auf eine kaum zu erklärende Weise abgesondert: Esztergom, Vármúzeum 2004, 149 (Kat.-Nr. 20/4 - neues Stück: BuZÁs, Gergely; Kat.-Nr. 20/5: BuZÁs, Gergely). - Zur ganzen Gruppe und zu ihrer Stelle vgl. immer noch: MAROSI 1984, 202-204 (Kat.-Nr. 60a-h), Taf. VIII-IX, ferner: 71, zu ihrer Wirkung: 103-104.

${ }^{61}$ Marosi 1984, Kat.-Nr. 62 und Rekonstruktion: Taf. VII.

62 Beispiele einer funktionell bedingten Materialwahl: KôFALVI 1980, 240-248.

63 Über diesen Zusammenhang siehe zuerst Marosi 1971.

${ }^{64}$ Siehe Anm. 24-25.

${ }^{65}$ RAFFAY 2006; RAFFAY 2010.

${ }^{66}$ Vgl. Quintavalle, Arturo Carlo: Benedetto Antelami, Enciclopedia dell'Arte Medievale II, Roma, 1991. 68: die Rekonstruktion der „Persönlichkeit“, mit stilkritischen Argumenten für die Kenntnis der Quellgebiete der Gotik in der Île-de-France; bzw. GANDOLFO, Enrico: Antelami Magistri, ebd. 68-70.

67 SAUERLÄNDER, Willibald: [Besprechung von MAROSI 1984], Cahiers de Civilisation Médiévale XIX. 1986. 289.

${ }_{68}$ MAROSi 2002/2005, 269-298.

${ }^{69}$ Wagner-Rieger 1988, 50-53.

70 FUHRMANN 1960

${ }^{71}$ TAKÁCS 2000, 313, Abb. 23. Zum Dombau des Erzbischofs Konrad III. vgl. Salzburg 1987, 16-21. - Ich danke Imre Takács für seine Hilfe. - Vgl. Geschichte der bildenden
Kunst in Österreich 1998, 239 f., 381-382 (DAHM, Friedrich).

72 Siehe unten: Exkurs.

${ }^{73}$ Messerer 1978, 138-151.

${ }^{74}$ FuHRMAnN 1960.

75 Zur Reihenfolge und Datierung der zu diesem Kreis gehörenden Denkmäler siehe: Messerer 1978, 14-142.

${ }^{76}$ LÓVEI 2000/2004; LÓVEI 2015; LÓVEI 2017.

77 MAROSI 1984, 34

${ }^{78}$ MAROSi 1971, 192 ff.; Árpád-kori 1978, 195-196 (Kat.Nr. 124a: MAROSI, Ernô). - Zur Symbolik des Bischofsthrons als erhobene Warte des Winzers siehe Honorius Augustodunensis: Gemma animae, Pars III, Cap. CLXXXIII: „... episcopus dicitur superintendens, quasi de alto prospiciens mores et vitam subiectorum. Sicut enim custos vineae in alto residens undique prospicit, sic episcopus Christi Vineae, scilicet Ecclesiae custos, quasi in alto residens populum sub se positum prospiciens instruit. Unde et speculator dicitur quia sicut speculator in alta turri ponitur, út hostes adventantes speculetur, et cives ad resistendum adhortetur; sic episcopus, quasi in specula collocatur, út populum contra hostes daemones et haereses armare nitatur." PL tom. 172, col. 600; Derselbe, Sacramentarium, seu de Causis et significatu mystico rituum divini in ecclesia officii liber, Pars III, Cap. XXXIX: „Altior locus positus est episcopis, ut ipsi superintendan, et populum custodiant: et tanquam vinitori altior locus sit ad custodiendam vineam suam, id est civitatem suam, sanctam scilicet Ecclesiam." PL tom. 172, col. 767. Vgl. auch Durandus: Rationale... LII. c.xi, De episcopo 2: „Quia ergo Episcopus speculator est, ideo ex institutione Clementis I. cathedra, sive locus ejus, in Ecclesia altior est, ut superintendat, et populum custodiat, omnesque conspiciat, et illum cuncti, sicut vinitori aliter locus est pro vinea custodienda." DuRANDUS: Rationale divinorum officiorum, Neapoli, 1858, 95; siehe auch SAUER 1902, 135-138.

${ }^{79}$ FuHrmann 1960, Anm. 88, die offensichtlich falsche Lesung ,intertvm“ berichtigend. Siehe daselbst auch die fehlerhaft erhaltene Inschrift am unteren Rand des Bogenfelds: HOC.OPVS .EXTERIUS . NIT... (IDE) . DECORATVM - SIC .DEVS .INTERIVS .COR .ADORNET .PVRIFICATVM. - Der Sinn des nicht ganz lesbaren Texts wurde offensichtlich mit der Parallele zwischen äußerer Pracht und reinem Herz begründet.

${ }^{80}$ Geschichte der bildenden Kunst in Österreich 1998, 239 f., 381-382 (DAHM, Friedrich). - Im reichen Inschriftenmaterial der Salzburger Gruppe von Portalen wurde die Symbolik des Kirchenportals auch thematisiert, was wiederum als eine Parallele zu Esztergom betrachtet werden kann. An St. Peter steht: JANVA.SVM . VITE . SALVANDI . QVIQVE: VENITE. PER. ME. TRANSITE. VIA. NON . EST. ALTERA. VITE. (FuHRMANN 1960, Anm. 91). Die Inschrift in Nonnberg - PORTA.PATET.VITE. CHR(ISTV)S.VIA VERA.VENITE (FuHRMAnN 1960, Anm. 95) - stellt sogar eine Variation der Hauptinschrift der Porta speciosa von Esztergom dar.

${ }^{81}$ TAKÁCS 2004, 43-51; LÔVEI 2004, 56-59.

${ }^{82}$ Havasi 2008, 197-198 und Abb. 8; vgl. LÓVEI 2017, 97-92.

${ }^{83}$ TAKÁCS 2004, 50.

${ }^{84}$ BUZÁs 2004, 20-21.

85 SOlyMOSI 2006, 103-104.

${ }^{86}$ Die Zusammenfassung der Ergebnisse eines in Manuskript vorliegenden Aufsatzes des Verfassers über die Bau- 
geschichte und den Umkreis der Zisterzienserabtei Kerz. Anregung und Beistand verdanke ich Herrn Tibor Kollár.

87 ReIsSEnBerger 1894, 7-8, besonders 8, Anm. 1.

88 HeRvai 1984, 112-119.

${ }^{89}$ GYÖRFFY II, 1987, 448.

90 Zsoldos 2011, 37, 288

${ }^{91}$ CD III/1, 400.

92 RÓMER 1877; die neuere Übersicht der Frage und ihrer Literatur: HUNYADI 2012

93 GYÖRFFY II, 1987, 448; HeRVAI 1984, 112-113, vgl. daselbst 118, eine Kartenskizze von den Gütern der Abtei von Kerz. Zur Hypothese, dass die Erbauer Deutschen waren, siehe noch TĂTARU 1983, 29; GYÖRFFY II, 1987, 448.

${ }^{94}$ KegleVich 2008, 22-23.

${ }^{95}$ KegleVICH 2008, 24.

${ }^{96}$ Die Maßangaben verdanke ich Imre Takács, mit dem ich das Denkmal von Kerz zuletzt 2015 besucht habe.

${ }^{97}$ De vera religione 1.1, S. Aurelii Augustini Opera Omnia, PL tom. 34, 121.

${ }^{98}$ An Parallelen aus dem gleichzeitigen Ungarn sind zu nennen: der sog. IACOB-Stein, die Inschriftenfragmente der Porta speciosa in Esztergom (mit mehr Unzialbuchstaben), der Grabstein des Domherrn Wilhelmus daselbst (TAKÁcs 1988, 123-124) und die Inschrift über die Altargründung von König Emmerich in der Zisterzienserabtei von Zirc; siehe VÁrADY 1999, 72, 73-74; VÁRADY 2000, 6-10, 44-46 (Kat. 3), 53-53 (Kat. 14), 75 (Kat. 45), Abb. 6, 8-10, 11/2, 15.

99 ENTZ 1963a; ENTz 1963b.

100 Roth 1934, 20; MACHAT 1977, 44; TĂTARU 1983.

${ }^{101}$ Zur Kritik dieser Konzeptionen siehe: Marosi 1984, 196.

102 UNTERMANN 2001, 31

103 UNTERMANN 2001, 23-40, 39.

104 KraUtHEIMER 1942/1969.

105 UNTERMANN 2001, 17-21.

106 Marosi 1984, 162.

107 WALICKI 1971, I, $171 \mathrm{ff}$.

108 Über die archäologisch ungenügende Publikation der angeblichen Reste eines „Vorgängerbaus", die im nördlichen Querschiffarm gefunden und als Argumente für die Spätdatierung benutzt wurden, siehe UNTERMANN 2001, 511-512 und Abb. 322

${ }^{109}$ TAKÁCS 1989, 22, ferner Abb. auf S. 87. 1. (2), S. 90. 1. (5), beide: 1688; vgl. HerVAI 1984, 133-140.

110 UNTERMANN 2001, 511-513.

111 ENTZ 1963a, 139.

112 Fraccaro de LONGHI 1958, 261-267; De PaOlis-OberTI 1978; UnTERMANN 2001, 509-510. - Diejenige Aufnahmezeichnung, auf der das Rundfenster in der Achse des westlichen Doppeljochs des Kerzer Langhauses erscheint, ist offensichtlich falsch (Budapest, Planarchiv des ehemaligen Denkmalamtes, Inv.-Nr. K 6540 - N. 17 einer Reihe von Aufnahmezeichnungen aus dem Jahr 1911); vgl. Langschnitt nach Süden, mit der Signatur von Ferenc Tautz, ebd.: Sammlung Lux Nr. 00845; vgl. RosTás 2010, 243 und Anm. 91.

113 Marosi 1984, 205 (Kat.-Nr. 68), Abb. 269.

${ }^{114}$ Marosi 1984, 205 (Kat.-Nr. 67), Abb. 270.

115 Marosi 1984, 206 (Kat.-Nr. 73), Abb. 272; Esztergom, Vármúzeum 2004, 127-139 (Kat.-Nr. 10-15: BOzÓKI, La- jos bzw. BuzÁs, Gergely); vgl. Havasi 2008, 222-231 (Kat. $1-30)$.

116 Entsprechendes Detail an der Aufnahmezeichnung der Ostwand: Budapest, Planarchiv des ehemaligen Denkmalamtes, Inv.-Nr. K 6538 (Nr. 15).

117 Marosi 1984, 204 (Kat.-Nr. 62), Rekonstruktion: Taf. VII, vgl. 35-36; Esztergom, Vármúzeum 2004, 129-132 (Kat.-Nr. 12: BozóKI, Lajos).

118 Marosi 1984, 204-205 (Kat.-Nr. 63), vgl. 36; Havasi 2008, 228-229 (Kat.-Nr. 21), vgl. 208.

119 Marosi 1984, Abb. 223.

120 Marosi 1984, Abb. 259

${ }^{121}$ Reproduziert: Marosi 2013a, Abb. 56.

122 MAROSI 1984, 345, Abb. 343; TAKÁCS 1996, Abb. 69 über seine Beziehungen zu Bamberg und Ebrach: 220, vgl. Abb. 70, Taf. 88, C5.

123 HaVAsi 2007; HaVAsi 2008, 207-209, 212-213.

${ }^{124}$ Morres 1929, 164-165 und Abb. 37. - Der durch eine Apsis abgeschlossene Chor kann - zusammen mit dem südlich anschließenden Nebenraum, der altertümliche Details aufweist - als Denkmal einer früheren Periode des 13. Jahrhunderts betrachtet werden. Von M. Dumitrache werden zwei Bauperioden angenommen (DumitRacHE 1983, 44-47): die erste zwischen 1220-1225, zur Zeit des Deutschen Ritterordens, und die zweite wird zur Tätigkeit der Kerzer Werkstatt gerechnet. Sie hat die Halbsäulen am Triumphbogen, die die fraglichen Kapitelle tragen, auf die zweite Periode datiert. Dieser Trennung widerspricht aber die Profilierung des Gesimses oberhalb der Kapitelle, die auch die Pfeiler gliedert.

125 VARGA 1984, 21-23. - Über unterschiedliche Konzeptionen der Periodisierung des Baus siehe KRASSER 1976.

${ }^{126}$ HeItel 1964, 7-17; zwischen 16-17 wird eine Reihe von Grundrissen in den fünf Phasen der Baugeschichte unterschieden.

127 VARGA 1984, Abb. 2 und 3, die laut Bildunterschrift „auf Grund der Aufnahme der Landeskommission der Kunstdenkmale (also vor 1918) von Alice Mezey gezeichnet wurden" - was bestimmt auf den Grundriss der bestehenden Bauteile hinweist. (Der Gesamtgrundriss in der Reihe der Aufnahmen der Steindl-Schüler: Budapest, Planarchiv des ehemaligen Denkmalamtes, Inv.-Nr. K 3370, signiert: István Simko, István Santho.) Den Details, die allein in den Grundmauern dem Studium zur Verfügung standen und zur Zeit der Forschungen von Lívia Varga allein durch eine unterschiedliche Farbe im Fußboden der Kirche markiert wurden, konnten nur diese Schemazeichnungen als Quellen gedient haben. Die wichtigsten Quellen dieser Rekonstruktionszeichnungen illustrieren die beiden Perioden (12-13. Jahrhundert bzw. dem Stil von Kerz entsprechend), die Albert Klein vermutete: KLEIN 1976, 23-28, 28-34 sowie die zugehörigen Rekonstruktionszeichnungen: ebd., Plan I und II

${ }^{128}$ Heitel 1964, 10-13.

${ }^{129}$ HeItel 1964, 13-17.

130 VARGa 1984, Abb. 3, vgl. 20-26.

131 VARGA 1984, 22-23.

132 VARGA 1984, Abb 29 (unten).

${ }^{133}$ CD IV/3, 550-552.

134 Reissenberger 1894, 8; Keglevich 2008, 37.

135 Herval 1984, 117.

136 ZsOLDOS 2011, 81, 329. 
137 OsZVAld 1957, 237; GYÖRFFy I, 1963/1987, 827. - Über das Kloster der Zisterziensernonnen in Kronstadt siehe HeRVAI 1984, 80-82.

138 ENTZ 1994, 152.

139 ENTZ 1994, 154; GYÖRFFY II, 1987, 87-88.

140 ENTZ 1994, 142; GYÖRFFY I, 1963, 562.

${ }^{141}$ ENTZ 1994, 78; GYÖRFFY I, 1963, 560.

${ }^{142}$ Die Rechnung des Kaufmanns Syr Wylalmus über Ausgaben im Auftrag des Herzogs Stefan: GYÖRFFY I, 1963, 558; vgl. Zolnay 1964, 82, 106 (Nr. 120). - 1268 hat Graf Hench, der spätere (1279) Rektor von Buda, die Hälfte eines Hauses in Roden gekauft: GYÖRFFY I, 1963, 563.

${ }^{143}$ Zur Unterscheidung von „plate-like windows" und „bar tracery“: BRANNER 1965, 16. - Erstere wurden (wohl übertrieben) als wichtigste Indizien eines Ursprungs im Rheingebiet betrachtet: MACHAT 1983 .

${ }^{144}$ RostÁs 2010, 243-244, Abb. 65.

145 Morres 1929, 169-170, Abb. 167.

146 ENTZ-SEBESTYÉN 1947, 6-7

${ }_{147}$ MORRES 1929, 166, Abb. 11lb.

148 Horwath 1929, 116-123, Abb. 102-103, 106, 108, $110-112$

149 HORWATH 1929, Abb. 105.

150 ROSTÁs 2010, 242-245.

151 ROSTÁs 2010, 244.

152 Hahnloser 1972, Taf. 20 und Kommentare: 56-57 und 354 (Unterscheidung zwischen forme und verrière); sowie Taf. 63, vgl. 171 (63h).

${ }^{153}$ Hahnloser 1972, Taf. 30, vgl. 75-76; Taf. 31, vgl. 7677, 358; besonders lehrreich ist Abb. 56.

154 SUCKALE 2003.

155 Branner 1965, 26-28, Fig. 23-25, 30-39, Fig. 26, 36.

156 Kimpel-SuCKale 1985, Abb. 166, vgl. 169-170 und 519

${ }^{157}$ Aufnahmezeichnung des Profils des Westportals unter anderen Details, von István Téglás 1909: Budapest, Planarchiv des ehemaligen Ungarischen Denkmalamtes, Inv.-Nr. K 1364.

158 То́тн 1976.

159 То́тн 1964, 167-168; sowie Tóтн 1967; Tóтн, Sándor in Tihany 1976, Kat.-Nr. 39-40 (Tihany), Kat.-Nr. 59 (Balatonakali).

160 ENTZ 1963a, 135.

161 То́тн, Sándor in Tihany 1976, Kat.-Nr. 46.

162 Gosebruch 1983, 8-10, 72, Abb. 2, 3, 95; vgl. SchuBERT 1974, 19-20.

163 UNTERMANN 2001, 454-455.

164 ENTZ 1963a, 141.

165 ENTZ 1963a, 143.

${ }^{166}$ Eine Übersicht der Denkmäler: Rostás 2000a, 32-33.

167 MAROSI 2011.

168 Vgl. Tóth 1967, 169 (Rekonstruktionszeichnung).

169 Rostás 2000a, 5, Abb. 2; Rostás 2000b, 64-65.

170 KimPEL-SuCKALE 1985, 15-16 und Abb. 7, 11.

${ }^{171}$ Zeichnung von Ferenc Téglás: Budapest, Planarchiv des ehemaligen Ungarischen Denkmalamtes, Inv.-Nr. K 6968, K 6969.

172 VARGA 1984, 23.

173 CSÁNYI-LUX 1943.

174 То́тн 1976, 332.

175 То́тн 1976, 336. - Albert Klein hat seinen Fundort in der Stufe vor dem südlichen Chorportal genau angegeben.
Klein, der von der Sekundärverwendung des Sakristeiportals in der Nordmauer berichtete, hat den Stil Kerzer Ursprungs der anderen Skulptur nicht erkannt und daraus die Schlussfolgerung gezogen, dass sie zu einer Sakristeitür vor 1241 (d. i. in der von ihm angenommenen I. Periode) gehört hatte: KLEIN 1976, 27.

176 Marosi 1984, 16, 15, Taf. XXII: Sponheim und Heiligenkreuz.

177 TAKÁCs 2000, 316, Abb. 23. Zum Dombau des Erzbischofs Konrad III. vgl. Salzburg 1987, 16-21. - Imre Takács bin ich für seine freundliche Hilfe zum besten Dank verpflichtet.

178 Der Zusammenhang wurde bereits registriert von RosTÁs 2000, 30; siehe auch RosTÁs 2002, 96.

179 Gerevich 1938, 165 und Taf. CLX/1 mit Parallelen von Pécs und Székesfehérvár. Vgl. die Erwähnung des Westportals im Kontext der "siebenbürgischen Gruppe des Portaltypus von Esztergom": GEREVICH 1938, 101. D. DERCSÉNYI betrachtet es als Fernwirkung der Werkstatt von Pécs: DeRCSÉNYI 1956, 45. Vgl. ROSTÁs 2002, 97-98.

180 Zur Übersicht des Denkmalbestands und der Chronologie des ornamentalen Typs siehe Marosi 2000b, 118-120; То́тH 2001, 249-255.

181 Rostás 2002, 80-82.

182 HaVASI 2006, 226-230 und Abb. 29-33. - Das Archivoltfragment, das als Parallele der Ornamentik in Holmwegen angeführt werden kann: Havası 2006, 236, Anhang Nr. 9; sowie Havasi 2007, 9-10, Abb. 5: Aufnahme- und Rekonstruktionszeichnung von Dezsó Várnai, 1949. Ich bedanke mich bei Frau Krisztina Havasi für ihren Rat und ihre Hilfe. - Die genauen Parallelen der Schaftringe von Holmwegen findet man auch in Óbuda: Havasi 2006, 37, Abb. 38.

183 TAKÁCS 2000, 316, 329 (Anhang Nr. 11), Abb. 16, Rekonstruktionszeichnung: Abb. 17.

184 EnTz 1966, 36 (Kat.-Nr. 4), Fig. 23; 36 (Kat.-Nr. 5), Fig. 24; 36-37 (Kat.-Nr. 6), Fig. 26; TAKÁCs 2000, 330-331 (Anhang Nr. 17-18), Abb. 32-35.

185 Wie man Bestände aus dem Planarchiv des ehemaligen Ungarischen Denkmalamtes (Budapest) heute nur unter Berufung an die kürzlich aufgehobene Institution anführen kann, zeugt die Grabung von Kalocsa auch von einer Anomalie der ungarischen Denkmalpflege. Man kann nur hoffen, dass die Grabungsfunde von Kalocsa, deren Studium vom Erzbischof verweigert wurde, bald der Forschung zugänglich gemacht werden.

${ }^{186}$ ENTz 1966, 58 (Nr. 8), Fig. 28 und 40-41 (Nr. 13), Fig. 34.

187 Gute Abbildungen: TAKÁcs 2000, Abb. 27, 28.

188 Messerer 1978, 132, Abb. 18. - Die Frage, ob sich bei diesen Steinskulpturen um einen Planwechsel handelt oder sie ohne Berücksichtigung eines Gesamtplans versetzt wurden, wird hier (ebd. 127 ff.) ebenso behandelt, wie im viel diskutierten Fall der säulentragenden Löwen der Porta speciosa in Esztergom.

189 То́тн 1990, 150 (Kat.-Nr. 12, 14, 15), 163; Pannonia Regia 1994, 178 (Kat.-Nr. I-96: TóтH, Sándor); Paradisum plantavit 2001, 452 (Kat.-Nr. V.65: TóтH, Sándor).

190 Eine Grundrissrekonstruktion auf Grund von HORWATH 1929, 149-108, 207, Abb. 205-207: Götz 1968, Abb. 5, 6. ${ }^{191}$ Havasi 2012, 91, Abb. 7; Fốszentély 2012, 53, Abb. $11-12$. 
192 ENTZ-SEBESTYÉN 1947, 19.

193 EntZ-SebestyÉn 1947, 19 (mit einer Ableitung der Profilform von Karlsburg).

194 ENTZ-SEBESTYÉN 1947, 19.

195 ENTZ-SEBESTYÉN 1947, 5-6.

${ }^{196}$ Budapest, Planarchiv des ehemaligen Ungarischen Denkmalamtes, Inv.-Nr. K 6739; Szék 1942, 251.

197 Szék 1942, 250.

198 Vgl. Rostás 1998.

199 CSÁNYI-LuX 1943, 3; vgl. aber Rostás 1998, wo die beiden Bauteile richtig als eine Einheit vorgeführt werden.
${ }^{200}$ Die entsprechenden Bilder: RosTás 1998, 18, 22, 23 bzw. 6,8 .

${ }^{201}$ ROSTÁs 1998, 24 und Abb. 7.

202 ENTZ 1958, 109-110; SARKADI 2010, 81.

203 HAVASI 2013, 113-122.

${ }^{204}$ Vgl. HaVASI 2013, 6, Abb. 11 n.

205 HAVASI 2013, 116.

206 Zum Beispiel Havasi 2013, Abb. 13.

207 Havasi 2013, Abb. 15, 17, 19. 